Strengthening Sustainable Development Diplomacy:

\title{
NEGOTIATION DYNAMICS AND
}

\section{EARLY IMPLEMENTATION}

RELATED TO CLIMATE,

FORESTS, AND CATLEE

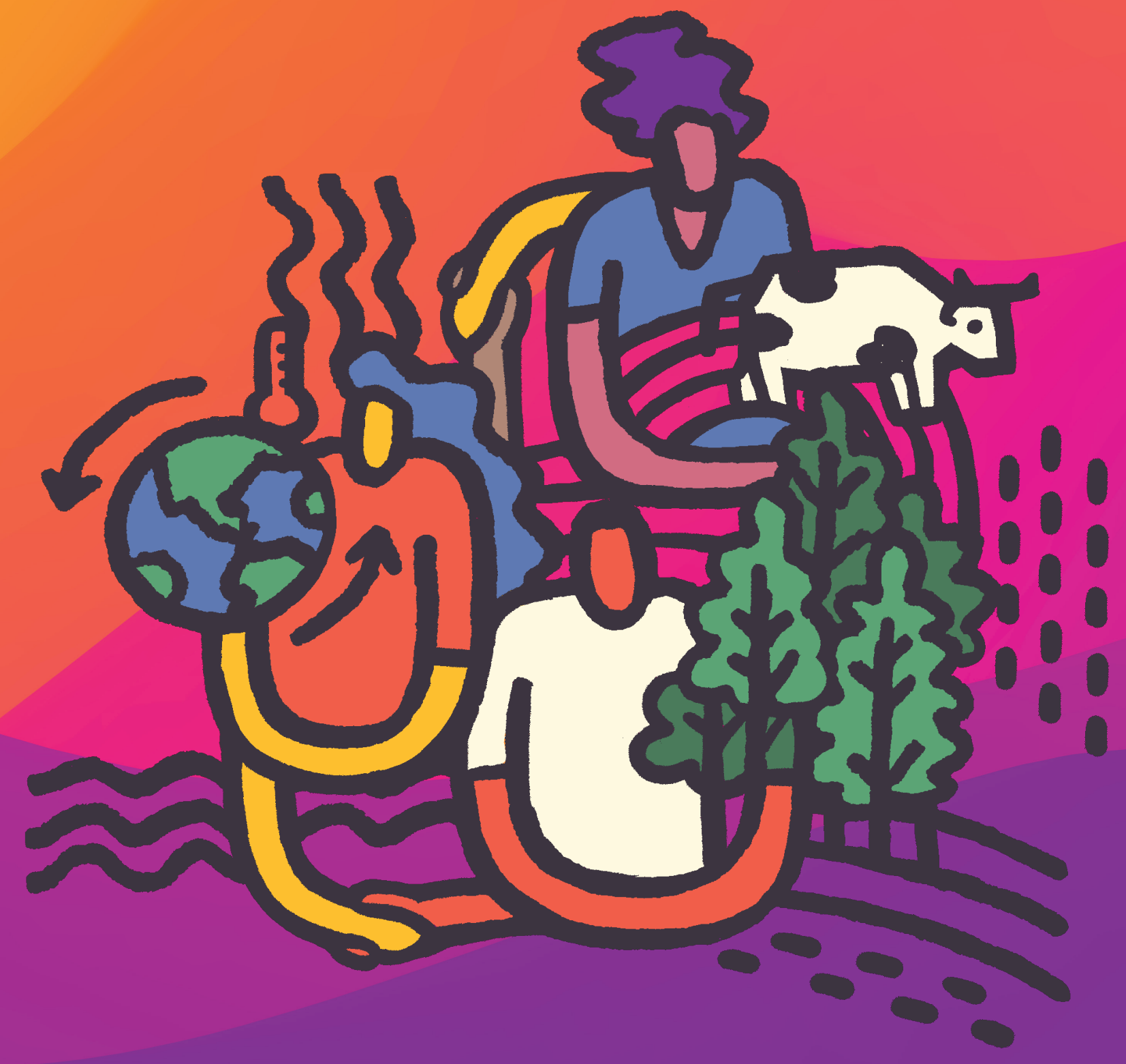

KRISTY J. BUCKLEY 


\section{Propositions}

1. Facilitators of, and chairs in, climate change diplomacy are key agents to strengthen and leverage enabling negotiation dynamics to overcome challenges in Sustainable Development Diplomacy (this thesis).

2. Facilitating successful negotiation and early-implementation outcomes to address complex global sustainability challenges requires alignment across state and non-state stakeholders (this thesis).

3. Multi-stakeholder models practiced in the field of technical internet governance have demonstrated efficacy in managing a global public good.

4. Cross-ministerial coordination beyond the Ministry of Health offers a systemssolution to addressing the complex problem of antimicrobial resistance.

5. While excruciatingly difficult and ill-advised, it is only possible for a working mother to finish a doctoral thesis during a pandemic because earplugs are available.

6. Digitization of human interaction disproportionately engages the brain's left hemisphere emotions of anger and hostility.

7. Conducting remote research should not entail jeopardizing digital privacy via insecure websites including *.ezproxy.library.wur.nl.

Propositions belonging to the thesis, entitled

Strengthening Sustainable Development Diplomacy: Negotiation Dynamics and Early Implementation related to climate, forests, and cattle

Kristy J. Buckley

Wageningen, 16 June 2021 
Strengthening Sustainable Development Diplomacy: Negotiation Dynamics and Early Implementation related to climate, forests, and cattle

Kristy J. Buckley 


\section{Thesis committee}

\section{Promoters}

Prof. Dr B. Arts

Personal chair, Forest and Nature Conservation Policy

Wageningen University \& Research

Prof. Dr Hosny El-Lakany

Adjunct Professor and Director of International Programs in Forestry

University of British Columbia, Vancouver, Canada

\section{Other Members}

Prof. Dr A. Gupta, Wageningen University \& Research

Prof. Dr S. Karlsson-Vinkhuyzen, Wageningen University \& Research

Prof. Dr M.J. Sanz Sánchez, Basque Centre for Climate Change, Leioa, Spain

Prof. Dr P. Verkooijen, University of Groningen and Climate Adaptation Centre

This research was conducted under the auspices of the Wageningen School of Social Science (WASS) 


\title{
Strengthening Sustainable Development Diplomacy: Negotiation Dynamics and Early Implementation related to climate, forests, and cattle
}

\author{
Kristy J. Buckley
}

Thesis

submitted in fulfilment of the requirements for the degree of doctor

at Wageningen University

by the authority of the Rector Magnificus,

Prof. Dr A.P.J. Mol

in the presence of the

Thesis Committee appointed by the Academic Board

to be defended in public

on Wednesday 16 June 2021

at 4 p.m. in the Aula. 
Kristy J. Buckley

Strengthening Sustainable Development Diplomacy: Negotiation Dynamics and Early Implementation related to climate, forests, and cattle

221 pages.

$\mathrm{PhD}$ thesis, Wageningen University, Wageningen, the Netherlands (2021)

With references, with summary in English

ISBN 978-94-6395-812-7

DOI https://doi.org/10.18174/546728 


\section{Acknowledgements}

"Resilience is knowing that you are the only one that has the power and the responsibility to pick yourself up." - Mary Holloway

Over the course of my doctoral research journey, I have learned and re-learned personal resilience many times over. While being a remote doctoral student is a relatively monastic experience, I am exceedingly grateful to many people who shared their energy, wisdom, intellect, kindness, and friendship. Without these people, mustering the energy to "pick myself up" time and again would have been impossible. Knowing I had support from so many incredible people continuously replenished my motivation to finish. Here, I attempt to express my appreciation for as many of those people as possible.

First, I would like to extend my great appreciation to Prof. Dr. Patrick Verkooijen, who saw potential in me that I didn't quite yet see in myself. While at a UNFCCC meeting in Tianjin, China, Patrick riddled me about the need for a "five-year plan" and suggested I pursue a doctorate. I admitted this was a dream of mine, but I didn't see how it was possible given the demands of my professional work and travel. Patrick was very encouraging and made it seem possible to do part-time. Shortly after being admitted to the program, my promoter Prof. Dr. Bas Arts gave me some advice. He said it was possible to work and do a Ph.D., or have kids and do a Ph.D., but it was not possible to do all three: Ph.D., work, and kids. While that was extremely wise advice, I have since proven that it is possible to do all three. Although, it took considerably longer than five years.

For all of the time and patience that it took to complete this thesis, I am incredibly grateful to my co-promoters Prof. Dr. Bas Arts and Prof. Dr. Hosny El-Lakany who kept nudging, encouraging, redirecting, and giving me space when I needed it. Their different perspectives and even locations complemented each other very well. I have learned a great deal from them both and I hope to carry this forward into my future endeavors.

In addition to my promoters, my colleagues Dr. John Ehrmann and Dr. Michael Lesnick provided invaluable advice and mentorship to me. I remain grateful for the many growth opportunities and flexibility that they, and Meridian Institute, provided. After exploring a sea of potential research topics, I found that Dr. Ehrmann's doctoral thesis seemed to reflect what I had observed in the UNFCCC negotiations. Ultimately, Dr. Ehrmann's conceptual 
framework served as the foundation for my own research. As such, I especially appreciated the rare gift of being able to consult with him as the architect of the Policy Dialogue Model. The ability to attend, observe, and learn from UNFCCC negotiations was a great privilege, without which, I would not have been able to bring first-hand experience to my research. For the colleagues, clients, and funders that supported the projects that led to this work, I am grateful for the opportunities these projects provided and for the relationships that were built as a result. To my many dear friends and family from all over, thank you for being there, for sharing a laugh, a rant, a walk, a cry, a drink, a hug. Thank you for listening and inspiring; and for embodying qualities that I continue to cultivate in myself. To my Dad, thanks your support and encouragement in sticking with it so I could (finally) finish this thesis.

Having recently lost my mother, grandmother, and aunt - important family matriarchs - I increasingly look to the many amazing women I am fortunate enough to have in my life. While I cannot acknowledge them all in a meaningful way beyond a list of names, I hope the friends in my life understand the depth of my gratitude. To honor and call out just a few of them, I would like to give thanks to Dr. Roxanne Van de Water, for being the first woman I knew personally to hold a doctorate, and for encouraging me to pursue mine. I would also like to extend a special thanks to Erin Prelypchan, a brilliantly talented friend who volunteered to proofread my draft thesis and provided many helpful insights and clarifications. Many thanks, also, to my mother-in-law, Sylvia Malthouse, who wisely chose not to "do all three" but who has been tremendously supportive to me, my husband, and our two children while I was locked away writing for days on end.

Finally, I wish to thank my husband, Jacob Malthouse, for being an unwavering optimist, for listening to my esoteric ramblings, and for providing creative, sound advice. On the practical side, I am grateful for all the days he looked after our little ones so I could write in relative peace. By enthusiastically celebrating my thesis milestones along the way, he sustained my determination to keep going. The arrival of our two inquisitive children, Baker and Sequoia, required significant pauses in my research, but I remain thankful that I did not lose too much time with them in their early years. In the final push to finish my thesis, they tried hard to understand why I worked so much and why I will not be able to practice medicine as a result of this work. At the same time, they have taught me to multi-task like I never thought possible and to recenter my values around what is most important in my life. They are two of my greatest teachers and I continue to learn from them every day. 
Table of Contents

LIST OF TABLES $\quad$ VI

LIST OF FIGURES $\quad$ VI

LIST OF ABBREVIATIONS AND ACRONYMS VII

CHAPTER 1 | GENERAL INTRODUCTION

1.1 General IntROdUCtion 2

1.2 Problem Definition and Knowledge Gaps 8

1.3 Objectives and Research Questions 16

1.4 Conceptual Frameworks 18

1.5 Methodology: Nested Case Study Approach 23

$\begin{array}{lll}1.6 & \text { Thesis OUtLINE } & 30\end{array}$

CHAPTER 2 | UNDERSTANDING THE CLIMATE CHANGE NEGOTIATIONS: TOWARDS AN INTEGRATED NEGOTIATION DYNAMICS MODEL* 32

2.1 INTRODUCTION 33

2.2 Theoretical Context 34

2.3 Methods 36

$\begin{array}{lll}2.4 & \text { RESULTS } & 40\end{array}$

2.5 DISCUSSION 60

$\begin{array}{lll}2.6 & \text { CONCLUSION } & 73\end{array}$

CHAPTER 3 | ANALYZING THE NEGOTIATION DYNAMICS LEADING TO THE PROMINENCE OF FORESTS IN THE PARIS AGREEMENT OF THE UNITED NATIONS FRAMEWORK CONVENTION ON CLIMATE CHANGE*

3.1 INTRODUCTION

3.2 Objectives, Integrated Negotiation Dynamics Model (INDM), and Rationale 78

$\begin{array}{lll}3.3 & \text { METHODS } & 79\end{array}$

3.4 RESULTS

3.5 DISCUSSION 96

3.6 CONCLUSIONS 100

CHAPTER 4 | PURSUING SUSTAINABILITY THROUGH MULTI ACTOR COLLABORATION:

EARLY IMPLEMENTATION OF THE ROUNDTABLES FOR SUSTAINABLE BEEF AND EFFORTS

TO REDUCE DEFORESTATION 
$\begin{array}{llr}4.1 & \text { INTRODUCTION } & 104\end{array}$

$\begin{array}{llr}4.2 & \text { Methods } & 107\end{array}$

$\begin{array}{llr}4.3 \text { ANALYSIS } & 109\end{array}$

$\begin{array}{llr}4.4 & \text { RESULTS } & 111\end{array}$

$\begin{array}{llr}4.5 & \text { DISCUSSION } & 129\end{array}$

4.6 EXPLORING THE EVOLUTION FROM STATE-DRIVEN TO MULTI-STAKEHOLDER EFFORTS TO REDUCE DEFORESTATION 143

$\begin{array}{llr}4.7 & \text { CONCLUSIONS } & 151\end{array}$

CHAPTER 5 | SYNTHESIS AND CONCLUSIONS 155

$\begin{array}{llr}5.1 & \text { INTRODUCTION } & 156\end{array}$

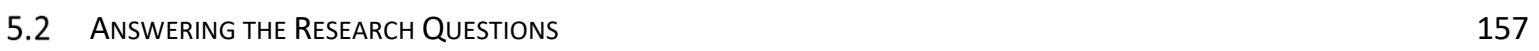

$\begin{array}{llr}5.3 & \text { ReSEARCH AgENDA } & 175\end{array}$

$\begin{array}{lrr}5.4 & \text { Reflections on the Research Approach } & 177\end{array}$

$\begin{array}{llr}5.5 & \text { Reflections on Methods and Frameworks } & 181\end{array}$

$\begin{array}{llr}5.6 & \text { Reflections on Conceptual Frameworks } & 183\end{array}$

$\begin{array}{lll}5.7 & \text { Policy ReCOMmendations } & 186\end{array}$

$\begin{array}{lr}\text { REFERENCES } & 190\end{array}$

$\begin{array}{lr}\text { SUMMARY } & 207\end{array}$

APPENDIX A | INTERVIEW QUESTIONS CHAPTER 2

APPENDIX B | SURVEY AND INTERVIEW QUESTIONS CHAPTER 3

APPENDIX C | INTERVIEW QUESTIONS CHAPTER 4

APPENDIX D | VISITS $\quad 219$

APPENDIX E | SUSTAINABLE DEVELOPMENT GOALS 220 


\section{List of Tables}

Table 1. Interviews and Survey 25

Table 2. Visits $\quad 26$

Table 3. Respondents Geographic and Role Affiliations 39

Table 4. Summary of Negotiation Dynamic Sub-factors 43

Table 5. Respondent Data on Primary-, Secondary- Enabling, and Constraining Negotiation

Dynamics 58

Table 6. Summary of Respondent Affiliations and Geographic Expertise 112

Table 7. List of Key Informants (anonymized) 113

Table 8. Summary of the Roundtables' Progress, Roles, Actions, and Activities 121

Table 9. Summary of Revisions from the Policy Dialogue Model to the Integrated

Negotiation Dynamics Model 159

Table 10. Characteristics of Multi-stakeholder Market Oriented (MSMO) Approaches, as compared to Non-state Market Driven (NSMD) 172

Table 11. Strengthening SD Diplomacy Diagnostics 175

\section{List of Figures}

Figure 1. Policy Dialogue Model* 20

Figure 2. Nested Case Study: multi-actor processes of sustainable development 24

Figure 3: Integrated Negotiation Dynamics Model (INDM) 42

Figure 4. Illustrative Negotiation Dynamic Relationships 70

Figure 5. Constraining Negotiation Dynamics within UNFCCC- Range and Distribution 83

Figure 6. Enabling Negotiation Dynamics within UNFCCC- Range and Distribution 85

Figure 7. Constraining Negotiation Dynamics in REDD+ processes outside the UNFCCC-

$\begin{array}{ll}\text { Range and Distribution } & 88\end{array}$

Figure 8. Enabling Negotiation Dynamics in REDD+ processes outside the UNFCCC - Range $\begin{array}{ll}\text { and Distribution } & 90\end{array}$

Figure 9. Comparison of Negotiation Dynamics' Enabling and Constraining Effects 166 


\section{List of Abbreviations and Acronyms}

ADR alternative dispute resolution

BATNA best alternative to a negotiated agreement

CfRN Coalition for Rainforest Nations

COP

Conference of the Parties to the United Nations Framework Convention on Climate Change (UNFCCC). The COP is the ultimate decision-making body of the Convention. UN Member States that are Parties to the Convention (UNFCCC) have representation within the COP which typically meets annually. Each COP is numbered (e.g., COP-13). See: https://unfccc.int/process/bodies/supremebodies/conference-of-the-parties-cop

COP-13 $13^{\text {th }}$ session of the Conference of the Parties to the UNFCCC

COP-15 $15^{\text {th }}$ session of the Conference of the Parties to the UNFCCC

COP-16 $16^{\text {th }}$ session of the Conference of the Parties to the UNFCCC

COP-21 $21^{\text {st }}$ session of the Conference of the Parties to the UNFCCC

COPs Refers generally to Conferences of the Parties to the UNFCCC rather than to a specific COP

CoRSB Colombia Roundtable for Sustainable Beef

CRSB Canadian Roundtable for Sustainable Beef

EIP/EIPs early implementation platform/s

FAO Food and Agriculture Organization

FCPF Forest Carbon Partnership Facility

G-77 Group of seventy-seven, referring to the original group of developing countries formed in 1964 although its membership has grown to over 100 developing countries. Within the UNFCCC context, the "G-77 plus China" is a group of countries that have formed a negotiating bloc. See: https://uat.g77.org/background/

GDP gross domestic product

GHG greenhouse gas 


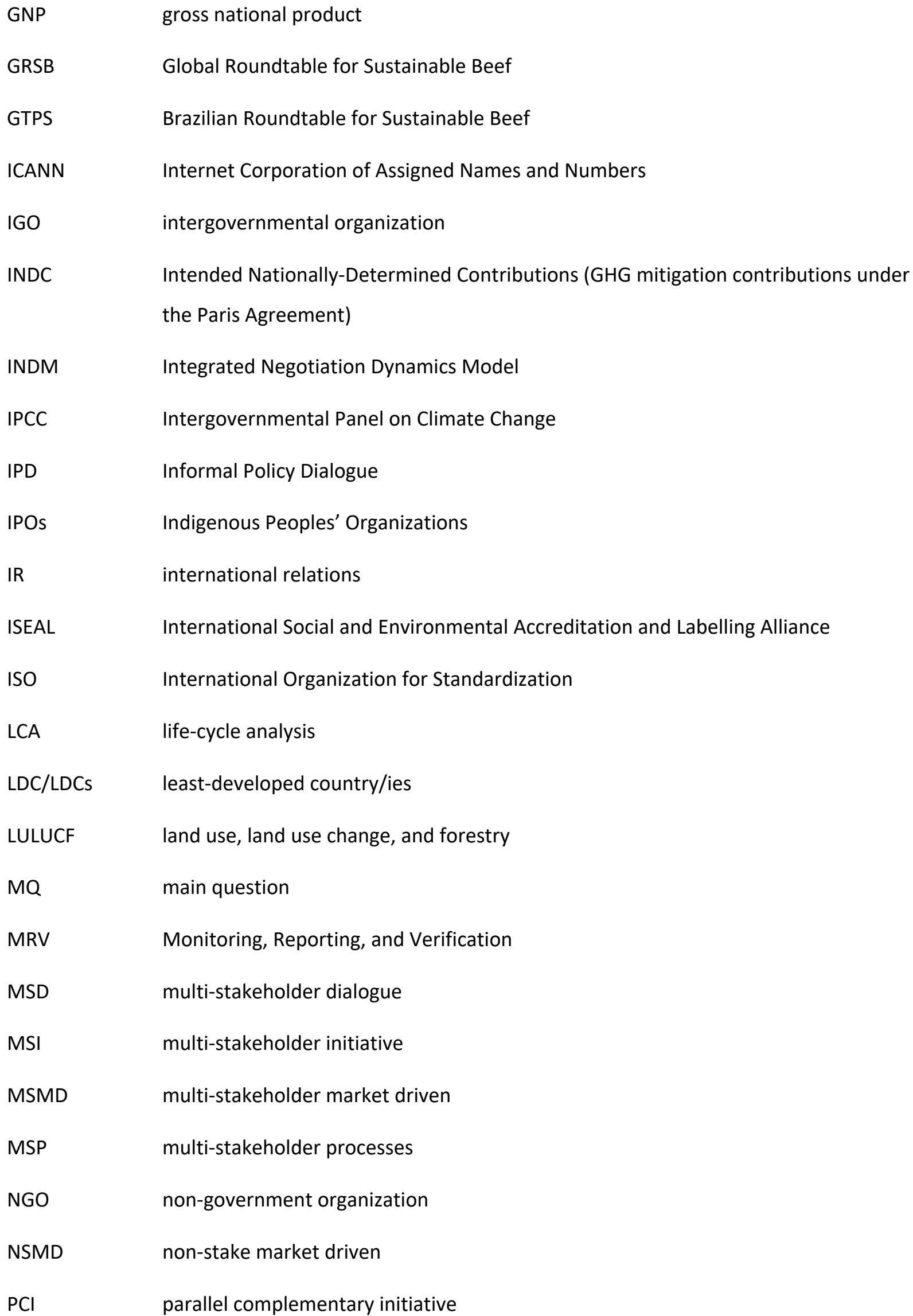


parallel informal negotiations

RA/SAN

Rainforest Alliance/Sustainable Agriculture Network

REDD+

reducing emissions from deforestation and degradation

$\mathrm{RQ}$

research questions of thesis research

RSPO

Roundtable on Sustainable Palm Oil

SAI

Sustainable Agriculture Initiative

SBSTA 38

$38^{\text {th }}$ meeting of the Subsidiary Body for Scientific and Technological Advice, a body of the UNFCCC

$\mathrm{SD}$

sustainable development

SDG

Sustainable Development Goals

UN

United Nations

UNCCD

UN Convention to Combat Desertification

UNFCCC

United Nations Framework Convention on Climate Change

UN-REDD

United Nations program for Reducing Emissions from Deforestation and

Degradation (REDD+)

US

United States

USRSB

United States Roundtable on Sustainable Beef

WD

World Development

WRI

World Resources Institute 
CHAPTER 1 | GENERAL INTRODUCTION 


\subsection{General Introduction}

The 1987 Brundtland report ${ }^{1}$ defined the term sustainable development as " ...development that meets the needs of the present without compromising the ability of future generations to meet their own needs" (World Commission on Environment and Development, 1987). Based upon experience negotiating and observing a suite of intergovernmental treaty negotiations related to sustainable development pursuits, Bo Kjellén (2008) - a former career diplomatsaw the need for coherent systems to support global cooperation if sustainable development was ever to be achieved. He posited the need for a "new diplomacy for sustainable development" suited to reflect the degree of cooperation necessary to respond to major global change and to pursue sustainable development (Kjellén, 2008). According to Kjellén, sustainable development is about protecting future generations, not nation states (Kjellén, 2008, p. 43). It is through a new diplomacy on sustainable development that the Brundtland definition can be realized. This new diplomacy—sustainable development diplomacy (SD diplomacy $^{2}$ ) — is defined as the "process of negotiating and implementing the [Sustainable Development Goals] at all scales" (Moomaw et al., 2017, p. 73). This thesis will employ this definition of SD diplomacy throughout.

Since the conception of SD diplomacy, the United Nations Summit adopted 'Transforming our world: The 2030 Agenda for Sustainable Development' in September 2015 with the overarching goal to eradicate poverty and achieve sustainable development (United Nations General Assembly, 2015). The 2030 agenda later came to be commonly known as the

\footnotetext{
${ }^{1}$ Also known as the report of the World Commission on Environment and Development, "Our Common Future" which later became better known as the Brundtland report, named after the Chairman of the Commission, Gro Harlem Brundtland.

${ }^{2}$ The relevant literature sometimes refers to sustainable development diplomacy in short form as "SDD." To avoid confusion with a similar acronym used in this thesis, SDG (for sustainable development goal), this thesis uses the term "SD diplomacy" throughout.
} 
Sustainable Development Goals (SDGs). ${ }^{3}$ The UN and its member states adopted the SDGs as a multilateral agenda that included 17 SDGs and 169 related targets that were agreed to be “integrated and indivisible" (United Nations General Assembly, 2015, p. 6), thereby reiterating the need for more interconnected approaches posited by SD diplomacy scholars. The SDGs encompass a broad agenda (from zero hunger, gender equality, to climate action) that is inclusive of both environmental and developmental goals, thereby linking these two pursuits in the policy world. Yet, the continued realization of SDGs occurs in siloed negotiations and institutions across a diverse landscape of venues and actors, from intergovernmental conventions to multi-stakeholder collaborations. Scholars of SD diplomacy assert that "meeting the SDGs will require multiple agreements regarding implementation policies, strategies and actions at all scales from international to local, and across sectors of society and the economy" (Moomaw et al., 2017). As Moomaw et al. (2017) recognize, the diversity, complexity, and scales of sustainable development necessarily expand beyond national governments and includes other 'non-state' sectors, actors, and processes (Hoogeveen \& Verkooijen, 2010; Moomaw et al., 2017).

In an effort to operationalize SD diplomacy, Moomaw et al. (2017) offer seven diagnostics for negotiating and implementing the SDGs:

1. "reframe issues into a sustainable development context instead of framing them as environmental, social or economic problems" (75);

2. "utilize mutual gains negotiation techniques to benefit as many state and non-state parties as possible while effectively addressing the issue of concern" (76);

3. “engage multiple state and non-state stakeholders" (76);

4. "assemble the relevant scientific, economic, and political information to identify the underlying causes of a problem or issue" (77);

\footnotetext{
${ }^{3}$ The Sustainable Development Goals were preceded by the Millennium Development Goals (MGDs). The MGDs were a result of the Millennium Project, launched in 2002 by the United Nations Secretary-General as a means to address global "poverty, hunger and disease" by 2015. The SDGs were negotiated as a global agenda to 2030. See: https://www.un.org/millenniumgoals/bkgd.shtml and
} https://sustainabledevelopment.un.org/topics/sustainabledevelopmentgoals 
5. "create a portfolio of actions that can address the stated goals at a level of complexity that is compatible with the complexity of the problem" (p. 77);

6. "identify the levels of political and societal organization where intervention is most acceptable and governance will be most effective and accountable" (p. 78); and

7. ensuring "instruments are living and flexible and able to respond effectively to new information and the evolving context as actions are taken" (Moomaw et al., 2017; 7879).

At its essence, SD diplomacy emphasizes the multi-faceted nature of sustainable development, with greater focus on negotiations (as five out of seven of the diagnostics indicate) (Moomaw et al., 2017). This multi-faceted nature, the definition, and above diagnostics of SD diplomacy suggest linkages and relevance to at least three broader literatures: international relations (IR), multi-party negotiation, and conflict (or dispute) resolution. ${ }^{4}$ Yet, the emergent discipline of SD diplomacy draws little from these robust disciplines nor does it contribute to them. Drawing upon related literatures can strengthen SD diplomacy's relevance and provide an integrated understanding of the diverse array of processes SD diplomacy scholars call for to support sustainable development.

With regards to the first body of literature, international relations (IR), the term 'diplomacy' is grounded in and defined by this field (Plischke, 1973), although some argue diplomacy is not central enough to the theory or practice of IR (Plischke, 1973; Sharp, 1999). Definitions of diplomacy vary - from use of the term without any definition (Plischke, 1973, p. 337), to more precise definitions. For example, diplomacy has been defined as a "discrete human practice constituted by the explicit construction, representation, negotiation, and manipulation of necessarily ambiguous identities" (Sharp, 1999, p. 33) and as encompassing both art and science in the "making (negotiating) and implementing of foreign policy, at all levels, centrally and in the field" (Plischke, 1973, p. 333). The latter definition closely reflects the one of SD diplomacy with the exception that it is limited to foreign policy. SD diplomacy argues that corresponding local and national policies and actions are needed to

\footnotetext{
${ }^{4}$ SD diplomacy also has linkages to diplomacy, governance, and systems literatures, but for the purposes of this thesis, the focus is on international relations, multi-party negotiation, and conflict (or dispute) resolution. In addition, it is noted that 'diplomacy' is grounded within the field of international relations.
} 
achieve sustainable development at all scales (Moomaw et al. 207). While calling for an institutional reform in a "new era of international cooperation," Kjellén (2008) recognizes the realities facing interstate relations, that "boundaries of traditional diplomacy-concentrated on national security and economic and commercial matters - are being extended to a much broader concern for global sustainability," and that "power politics continue to rule the world" (Kjellén, 2008, p. xvi). This argument reflects a rationalist view of international relations theory in that areas where states typically cooperate and compete such as security can also be extended to addressing sustainability issues even though states remain principally focused on "power and interest" (Stein, 2008, p. 203). While SD diplomacy is not limited to the field of international relations, its terminology, definition, and raison d'être are derived from, and relevant to, that field.

The second body of literature, multi-party negotiation, offers insight into the analysis of complex negotiations involving many sides. Literature on multi-party negotiation is embedded within the fields of international negotiation, multilateral negotiation, and negotiation theory. Recognizing that even with the "integrated and indivisible" SDGs (UN General Assembly, 2015, p.6), the pursuit of these goals is taking place across a myriad of multi-party negotiation processes. For instance, the UN Framework Convention on Climate Change (UNFCCC) treaty was adopted in 1992, well before the SDGs, and negotiations continue under that framework to address climate change - climate action being one of the SDGs (SDG 13). Multi-party negotiation theorists such as Zartman (2002) and Crump (2015) offer frameworks of analysis for understanding key variables in these complex negotiations. These analysis frameworks are relevant for understanding ongoing negotiations related to sustainable development, considering that these negotiations are multi-party in nature. Yet these frameworks do not fully reflect the policy contexts within and between states, ${ }^{5}$ the roles

\footnotetext{
${ }^{5}$ Zartman (2002) does not address the context of the negotiation whereas Crump (2015) does include understanding of the context as part of the analytical framework.
} 
of supporting institutions and parallel processes, ${ }^{6}$ nor the continuous nature ${ }^{7}$ of sustainable development negotiations.

The third literature, conflict resolution, a subset of alternative dispute resolution (ADR) (Emerson et al., 2017) is applicable to SD diplomacy for several reasons. Firstly, SD diplomacy is not limited to foreign policy (which would put it squarely in the field of IR) since it posits that negotiation and implementation need to happen across diverse stakeholders and sectors spanning local to global scales (Moomaw et al., 2017). Secondly, the definition of SD diplomacy, concepts proposed by SD diplomacy scholars, and the coherence called for by the UN 2030 Agenda suggest the need for collaboration within and across intergovernmental, multi-party, and multi-stakeholder ${ }^{8}$ negotiation processes. Since the 1990s, participatory, multi-stakeholder collaboration has been used to resolve environmental conflict and inform environmental policy (Ehrmann, 1997; Emerson et al., 2017). A central tenet of collaboration is the interdependence of parties or stakeholders: they need each other in order to solve the problem (Ehrmann, 1997; Gray, 1989), echoing Kjellén's assertion that we need a new diplomacy that reflects this interdependence. Thirdly, intergovernmental sustainable development negotiations have long been supported by informal dialogue via "track-two diplomacy" which emerged from the field of conflict resolution (Jones, 2015, p. 9). Conflict resolution offers insight into the myriad of informal dialogues, parallel processes, and multi-stakeholder collaborations related to environmental policy (Ehrmann, 1997; Jones,

\footnotetext{
${ }^{6}$ Both Zartman (2002) and Crump (2015) focus on analysis of negotiations between parties and do not consider the institutional structure under which parties may be negotiating. While other negotiation scholars offer insight into parallel informal negotiation (Susskind, et al. 1996), these are not addressed in multi-party negotiation analytical frameworks.

${ }^{7}$ While intergovernmental treaties do reach decisions, the ongoing nature of negotiations do not necessarily reflect a clear beginning, middle, and end. For example, the UNFCCC Conference of the Parties (COPs) have produced dozens of decisions on an annual basis since 1996. See:

https://unfccc.int/decisions?f $\% 5 \mathrm{~B} 0 \% 5 \mathrm{D}=$ body $\% 3 \mathrm{~A} 1343$

${ }^{8}$ In this thesis, multi-stakeholder refers to negotiation processes that involve a diverse range of participantscivil society, scientists, Indigenous Peoples organizations, international organizations, private sector, government representatives - that have an interest in the process and/or outcome. Some of these participants may be decision-makers on the issue at hand and the multi-stakeholder process plays a supporting role for primary negotiating parties in a decision-making policy process (Crump and Glendon, 2003, p.201-202).
} 
2015) as well as sustainable development negotiations (Daniels et al., 2012; Mearns \& Norton, 2010; Sprinz \& Vaahtoranta, 1994). Like SD diplomacy (specifically diagnostic 2, (Moomaw et al. 2017)), conflict resolution scholars and practitioners emphasize interestbased negotiation to reach agreement (Marcus et al., 2012; Sprinz \& Vaahtoranta, 1994) to produce a "win/win outcome with mutual benefits" (Moore, 2014, p. 147). SD diplomacy also calls for stakeholder collaboration in implementing negotiated outcomes (Moomaw et al. 2017; Kjellén 2008), again echoing the collaborative practices employed in the field of conflict resolution (Emerson et al., 2017; Savage et al., 2010).

For clarity of terminology for the purposes of this thesis, the term 'intergovernmental negotiation' will refer to the international arena of state-to-state negotiations, and the term 'multi-party' will refer to negotiations involving many sides (state and/or non-state) (Crump, 2003). For the purposes of this thesis, 'party' refers to those with decision-making ability or 'problem-opportunity ownership' (Crump \& Glendon, 2003, p. 199). The term multistakeholder collaboration refers to many sides (state and/or non-state) involved in implementation. The term 'stakeholder' is defined as

key individuals, groups, and organizations that have an interest in the issue at hand. They may be responsible for seeing a problem resolved or a decision made, they may be affected by a problem or decision, or they may have the power to thwart a solution or decision (C. Carlson, 1999, p. 171).

When referring collectively to intergovernmental, multi-party negotiations and multistakeholder collaborations on implementation, this thesis will employ the meta-term 'multi-actor processes' to encompass the diversity of actors engaged across negotiation and implementation processes contributing to the sustainable development objective examined.

A consistent characteristic of IR, multi-party negotiation, and conflict resolution literature is power (Ehrmann, 1997; Sharp, 1999; Susskind et al., 2003; Zartman, 1994; Zartman \& Rubin, 2002). The literature has defined 'power' in a myriad of ways, from "an action intended to produce movement" (Zartman, 2002, p. 6) to the size of a country's economy (Weiler, 2012). While scholars may argue over precise definitions, they invariably emphasize

\footnotetext{
${ }^{9}$ This definition of 'stakeholder' differs from corporate or organizational stakeholder where individuals or groups may have a financial or legal obligation.
} 
the role of power as a - and sometimes the - fundamental factor in multi-actor negotiations. For example, one study demonstrated a positive correlation between the size of a country's economy the likelihood they will achieve their desired negotiated outcome (Weiler, 2012). However, SD diplomacy diagnostics, briefly acknowledge that "fundamental issues of power may still remain" (Moomaw et al., 2017) but do not address it otherwise-a significant gap in understanding from the perspective of international relations, multi-party negotiation, and conflict resolution literatures.

In examining the above literatures as they relate to multi-actor sustainable development negotiations (Bäckstrand, 2006; Crump \& Glendon, 2003; Daniels et al., 2012; Susskind et

al., 1996, 2003; Zartman, 1994), three primary themes emerge: 1) a need to better understand how key negotiation factors (variables) relate to each other and to reaching agreement; 2) understanding the primacy of negotiation factors in constraining or enabling multi-actor agreement; and 3) a shortage of literature and debate about multi-stakeholder processes in terms of influence and effectiveness in contributing to sustainable development.

\subsection{Problem Definition and Knowledge Gaps}

According to SD diplomacy scholars, a new diplomacy is needed to continue negotiating and implementing sustainable development objectives. As states, sectors, and actors work across scales to negotiate and implement the SDGs, they are forming and participating in a myriad of multi-actor processes. These are indicative of the 'new diplomacy' for sustainable development which Kjellén envisioned in 2008. SD diplomacy offers a different framing of sustainable development: as an opportunity instead of a burden. Its diagnostics offer practical actions for negotiation and implementation across sectors and scales. Yet, for SD diplomacy to gain traction within broader disciplines that inform and influence actors working in sustainable development, it needs to be rooted in, and contributing to, the highly relevant fields of international relations, multi-party negotiation, and conflict resolution. However new the SD diplomacy approach may be, many of its components echo long-standing perspectives, analysis, and knowledge from the bodies of literature. With an overall aim of strengthening SD diplomacy, this thesis will focus on multi-actor negotiations related to the SDGs with a primary focus on climate change (SDG 13) - which deforestation and cattle production exacerbate. As such, this thesis includes examination of climate-related SDG 
efforts to reduce deforestation and degradation (related to SDG 13 on climate change ${ }^{10}$ and SDG 15 life on land), and to enhance the sustainability of cattle production (SDG 12) - a key driver of deforestation, greenhouse gas emissions, and loss of biodiversity (Mekonnen \& Hoekstra, 2012; Nijdam et al., 2012; Ripple et al., 2014). It is worth noting that work on these sustainable development issues, and the concept of SD diplomacy itself, precedes the negotiation and agreement of SDGs (in some cases, by decades). Yet the SDGs provide a global framework for understanding the aims of these sustainability issues and for monitoring progress over time. For these reasons and with the overall objective of strengthening SD diplomacy, these SDGs are employed to help frame the thesis. To articulate the problem and to identify knowledge gaps, key themes across the bodies of literature are explored in turn. First, a key theme in understanding factors involved in multi-party negotiation and the relationships between them is based upon the underlying current of managing complexity (Zartman, 1994). Scholars have referred to complexity as a 'dominant characteristic' (Crump, 2003 , p. 205) and emphasize the need to better understand and manage complexity in multiparty negotiations (Crump, 2003, 2015; Druckman, 2001; Zartman, 1994, 2002). Efforts to understand complexity offer several entry points and scales. The architecture and sequence of negotiations provide a structural analysis which is broken down into analysis on coalitions, leadership, and procedures (Zartman, 1994). Others aim to understand the outcomes of a negotiation through analysis of 'turning points' (Druckman, 2001) or through power relationships across parties, institutions, coalitions (Dimitrov, 2010; Zartman, 1992) and even individuals (Dimitrov, 2003). Negotiation scholars also strive to better understand the most critical factors playing a role in the negotiation (also referred to in the literature as variables, elements, building blocks, dynamics, diagnostics).

A second theme in the literature is to understand which factors in a negotiation are most critical in relation to reaching agreement. There is convergence in the literature on key factors in a multi-party negotiation and how to use them to analyze negotiations (Zartman, 2002; Crump, 2015; Daniels et al. 2012). Zartman summarized this convergence based upon negotiation literature in 2002 but additional multi-party (Crump, 2015) and participatory

\footnotetext{
${ }^{10}$ Deforestation is a significant contributor to global greenhouse gas emissions (IPCC, 2019).
} 
frameworks (Daniels, et al. 2012) have since emerged that further our understanding. Key factors in multi-party negotiations can be summarized as:

1) Context - the situation in which the negotiation takes place (Crump, 2015) including cultural background (Daniels et al. 2012);

2) Behavior - "the characteristics of the actors and their interaction" (Zartman, 2002, p. 11), party relations and "communication patterns" (Crump, 2015);

3) Power-intrinsic or influential power (Zartman, 2002) to protect interests and achieve goals (Daniels, et al. 2012) or in terms of power relationships (Crump, 2015);

4) Process - the "exchange of concessions and compensations" that occur to support a final agreement (Zartman, 2002) including the phases and "critical moments" of the negotiation (Crump, 2015) and the institutional mechanisms that "regulate interactions" (Daniels et al. 2012);

5) Strategy — the set of options available to a party to yield a desired outcome vis-à-vis other parties' available options (Zartman, 2002), including incentives related to potential loss or gain (Daniels et al. 2012); and

6) Outcome - the final agreement or result (Zartman, 2002) and the procedural rules governing the process for decision-making (Crump, 2015).

Despite the degrees of convergence in the above-mentioned frameworks, there is little understanding of which factors most enable or constrain agreement (Zartman, 1998; 2002; Crump 2003, 2015). At the same time, existing multi-party negotiation (Crump 2003, 2015) and international negotiation (Zartman, 2002) frameworks do not fully consider the sustainable development context of negotiations which happens across sectors, scales, and actors (Moomaw et al., 2017). Existing multi-party negotiation frameworks also do not offer diagnostics for how these factors should optimally function in multi-party negotiation settings. Moomaw et al. (2017) do offer insight into how to optimize multi-party negotiations in the context of SD diplomacy yet do not link their approach to the above-mentioned frameworks. Linking existing multi-party frameworks with SD diplomacy literature can help tailor those frameworks to a sustainable development context while further grounding SD diplomacy approaches in related multi-party negotiation literature. 
A third theme in the literature is the debate about non-state actor processes for sustainable development; specifically, the legitimacy and effectiveness of non-state-led collaborations and the roles of non-state actors in primarily intergovernmental settings (Arts, 2000; Bäckstrand, 2006; Hampson \& Hart, 1995). Even prior to the adoption of the SDGs, there have been a plethora of negotiation and implementation processes in support of sustainable development (Kjellén, 2008). Some of these are intergovernmental policy negotiations (e.g., UN Framework Convention on Climate Change; Convention on Biological Diversity). Others are multi-stakeholder collaboration processes comprised of government representatives, civil society, private sector, multilateral funders, and/or scientific experts that also focus on implementation, not solely negotiation (e.g., Forest Carbon Partnership Facility; Commodity Roundtables). As noted above and to reiterate here, to refer collectively to both types of processes (intergovernmental negotiation and multi-stakeholder collaboration process) this thesis uses the term 'multi-actor processes.' The literature documents the emergence of different types of multi-actor negotiations, typically divided into either multi-stakeholder or multi-party processes (Dentoni H. C., 2011; Fortin, 2013; Fowler \& Biekart, 2017) which form a mix of policy agreements, voluntary agreements (Bailey \& Rupp, 2005), partnerships (Bäckstrand, 2006), and negotiations around the mechanisms of implementing sustainable development practices (Bäckstrand, 2006; Dooley et al., 2011; Fowler \& Biekart, 2017; Vieira et al., 2016). Literature on multi-stakeholder processes for sustainable development note their rise in popularity and focus on questions of legitimacy (Bernstein, 2011; Mena \& Palazzo, 2012), accountability (Fowler \& Biekart, 2017), efficacy (Cattau et al., 2016), and relationship to democratic values (Mena \& Palazzo, 2012). Considering SD diplomacy scholars call for many scales, sectors, and actors to engage in sustainable development (Kjellén, 2008; Moomaw et al., 2017), the rise of these multi-stakeholder collaboration processes is a reflection of SD diplomacy in action. While some SDGs are linked to international policy frameworks - for instance, SDG 13 on Climate Action and the UN Framework Convention on Climate Change - this type of framework is not available for all goals. For instance, for sustainable production and consumption (SDG 12), the goal has already been negotiated via the SDG process and there is no corresponding international policy treaty for ongoing negotiation. Instead, there is a proliferation of multi-stakeholder processes emerging (Ingram et al., 2018; Schouten \& Glasbergen, 2012), many of which are focused on implementation of sustainable practices (Bernstein, 2011). As such, these multistakeholder collaboration processes represent a different aspect of the policy chain: that of 
implementation, not negotiation. Yet, the literature on these processes is sparse and tends to perpetuate debate on whether non-state actor ('private') efforts serve as a viable alternative to government policy intervention (Brassett et al., 2012; Turcotte \& Pasquero, 2001) -leaving their evolution and potential contributions minimally understood.

Based upon the landscape outlined above, an understanding of how key variables - context, behavior, power, process, strategy, and outcome - relate to each other in the complex multiactor negotiations of sustainable development is lacking. Perhaps the most visibly urgent sustainable development objective - addressing climate change - has spurred many to wonder why and how the negotiations under the UN Framework Convention on Climate Change (UNFCCC) have yielded little in mitigation action. There is also little understanding of which factors in SD negotiations are most critical to reaching agreement. Looking to the relative success of the negotiations on reducing emissions from deforestation and degradation $(\mathrm{REDD}+)^{11}$ (e.g., the historic Paris Agreement) can provide insight on what factors most constrained or enabled their agreements. Finally, there is a lack of literature and understanding of multi-stakeholder negotiation processes contributing to SDGs. Exploring the linkages between intergovernmental and multi-stakeholder REDD+ negotiations as well as the multi-stakeholder sustainable beef commodity roundtables - the leading effort on sustainability in beef, cattle, and dairy production — can provide evidence-based understanding. These insights will advance SD diplomacy's applicability across disciplines, venues, and actors that are critical to sustainable development.

\subsubsection{Relationships Between Factors in SD Negotiations}

The fields of international relations, multi-party negotiation, and conflict resolution offer different perspectives on the factors involved in multi-actor negotiations. The word 'diplomacy' refers to relationships between states - something that is well covered in IR literature. Yet we know from the definition of SD diplomacy that this type of diplomacy goes well beyond state-to-state relationships. SD diplomacy also encompasses negotiationsanother topic with robust literatures including negotiation theory, international negotiation,

\footnotetext{
${ }^{11}$ Reducing emissions from deforestation and forest degradation and the role of conservation, sustainable management of forests and enhancement of forest carbon stocks in developing countries. See: https://unfccc.int/topics/land-use/workstreams/reddplus
} 
and multi-party negotiation. The discipline of conflict resolution is also relevant as parties seek to resolve differences and collectively pursue sustainable development. Drawing upon these diverse literatures provides an integrative understanding of how SD diplomacy negotiations have evolved to reach the 2030 Agenda for Sustainable Development and can evolve to support realization of SDGs.

First, IR focuses on factors involved in state-to-state negotiations (e.g., UN Framework Climate Change Convention, the UN Convention on Biological Diversity). There are many competing IR theories surrounding state cooperation or lack thereof, especially around SDG 13 on climate action. Some scholars argue that states' domestic political context focuses on traditional threats to power and security (Lacy, 2012; Mearsheimer, 2001), which diminishes motivation to address slow-moving threats (e.g., climate change) (Grieco, 1988; Mearsheimer, 2001). Others argue that international institutions and regimes facilitate cooperation and redistribute power (Haas, 1964; Keohane, 2018). Yet cooperation can be undermined if those institutions cannot handle challenges (Haas, 2008) or by states' temptation to prioritize short-term economic gain (Stavins, 2011) and defect on commitments (Keohane, 2018; Victor, 2006; Vogler, 2009). Others maintain that a lack of hegemonic leadership at a global level thwarts progress on sustainable development (Gupta, 2012, p. 636).

Second, the field of multi-party negotiation has developed approaches for analyzing the process and the key factors that play a role in negotiations with multiple parties. The factors involved are variously labeled in the literatures - as variables, elements, diagnostics, and dynamics - but all point to a collective set of factors that play roles in multi-actor sustainable development negotiations. These are well documented, even if with slightly different terminology and definitions. However, the tendency is to identify and define these factors theoretically. As Crump identified, there is a lack of understanding around the relationships between negotiation factors (Crump, 2003, 2015). Similarly, Crump asserts that the foundational descriptive analytical framework provides the basis for future complex negotiation analysis "which could include establishing a relationship between key negotiation variables" (Crump, 2015, p. 133). SD diplomacy does not offer insights into whether or how the diagnostics relate to each other (Moomaw et al., 2017) which presents an opportunity to contribute to improved understanding. 
Third, the field of conflict resolution also offers tools for analysis and understanding of multiactor negotiations on sustainable development. Daniels et al. (2012) present a "Unifying Negotiation Framework" which views SD negotiations as a 'discourse process' that is “designing a participatory decision model” (Daniels et al., 2012, p. 11). Within that design, Daniels et al. argue, it important to encompass all 'factors' and 'levels' of participatory policy negotiations (Daniels et al., 2012) which they argue are: culture ("shared learned behaviors and meanings") (2012, p.11); agency ("ability to protect interests and achieve goals" and includes "power and capacity"); cognition ("information processing and decisionmaking”); and parties' orientation ('psychological concepts' related to parties' interest in engaging) (Daniels et al. 2012, p.14).

Taking an integrative approach across these literatures can provide a more holistic, interdisciplinary perspective on the key factors involved in multi-actor sustainable development negotiations. Combined with empirical evidence aimed at understanding the relationships between these factors and how they relate to reaching agreement can strengthen SD diplomacy and enable it to contribute to the three related disciplines.

\subsubsection{Factors Enabling or Constraining Agreement(s)}

The disciplines of international relations, multi-party negotiations, and conflict resolution each have something to offer in understanding the SD diplomacy multiparty negotiation processes, including the factors that play a role in those negotiations and in reaching agreement. Few offer empirically grounded frameworks for understanding how these factors may enable or constrain agreement. While SD diplomacy diagnostics (Moomaw et al., 2017) emphasize optimization of five (out of seven) factors (these are also mentioned in section 1.4) in the negotiation, they do not offer a sense of priority on which factors are most important to reaching agreement, resulting in the conclusion that they are equally important. In addition, a factor broadly articulated in IR, negotiation, and conflict resolution literatures as seminal in multi-actor negotiations, is critically missing from SD diplomacy diagnostics. The relative influence of factors such as power (variably defined and articulated) in multi-actor negotiations is debated in IR literature and explored deeply in negotiation theory.

Within IR literature, scholars emphasize different types of power: geopolitical (Terhalle \& Depledge, 2013), economic (Weiler, 2012, p. 553); coalition (Zartman in Rubin, 1994, p. 215); and individual (Dimitrov, 2003, p. 144). Different scholars argue about the types of power and the degree to which it is influential in states cooperating and/or reaching 
agreement (Dimitrov, 2003; Mearsheimer, 2001; Powell, 1991). Within the field of negotiation, scholars also recognize different types and effects of power. Kim et al., for instance, outline four elements of power: "potential power; perceived power; power tactics; and realized power." (Kim et al., 2005, p. 799). Others posit that a similar distribution of power among actors yields mutual gains (one of the SD diplomacy diagnostics) while an unequal distribution enhances the agreement's efficacy (Zartman \& Rubin, 2002, p. 5).

Based upon these literatures, power is too pivotal a factor for SD diplomacy diagnostics to exclude. However, it is also important to explore the relative importance of key factors in multi-actor SD negotiations, previously synthesized from existing multi-party negotiation literature. These were context, behavior, power, process, strategy, and outcome. The outcome, however, is also a result of interaction between the other factors, as opposed to an independent factor itself. This thesis will explore how those factors support the outcomespecifically, reaching agreement in multi-actor SD negotiations.

\subsubsection{Evolution of Multi-stakeholder Collaboration Processes in Contributing to Sustainable Development (SD) Diplomacy}

As noted earlier, SD diplomacy emphasizes the need to engage diverse sectors, actors, and scales (Kjellén, 2008) yet it is unclear how the plethora of processes, even on the same SDG, collectively contribute or relate to one another. For example, how the multi-stakeholder process within the Forest Carbon Partnership Facility, among other initiatives, contributed to the REDD+ negotiations under the UNFCCC. Among international relations scholars, there is much debate on the roles of non-state actors (Arts, 2000, 2006) in what many scholars see as state-centric policy negotiations on multilateral legal agreements (Donnelly, 2000; Krasner, 1982; Stein, 2008). Yet as articulated by SD diplomacy scholars, negotiation and implementation of sustainable development necessitates broader multi-stakeholder approaches (Hoogeveen \& Verkooijen, 2010; Kjellén, 2008; Moomaw et al., 2017). The literature offers many examples of multi-stakeholder processes (Hemmati, 2002) which are referred to as multi-stakeholder initiatives (MSIs) (Fowler \& Biekart, 2017; Gilbert \& Rasche, 2008) or multi-stakeholder dialogues (MSDs) (Susskind et al., 2003). As Fowler and Biekart describe,

"with various labels, MSIs have gained popularity as mechanisms to address complex societal problems whose causes span diverse institutions and whose resolution requires the alignment and application of different competencies and locations of authority and 
power...sometimes distinguished between intermittent dialogues and practical long-term collaborations" (Fowler \& Biekart, 2017, p. 82).

Negotiation scholars tend to focus on MSI's supporting role to corresponding decisionmaking policy negotiations (Crump \& Glendon, 2003), yet in the case of the roundtables for sustainable beef, there is no parallel global policy process. In the case of reducing deforestation, efforts catalyzed and/or implemented by multi-stakeholder collaboration processes have contributed to a portfolio approach solution called for by SD diplomacy scholars (Hoogeveen \& Verkooijen, 2010; Moomaw et al., 2017). When combined with policy interventions, multi-stakeholder efforts such as zero-deforestation supply chain commitments (What Is the New York Declaration on Forests?, n.d.), have also contributed to reduced deforestation outcomes (Nepstad et al., 2013, 2014). While multi-stakeholder collaborations on their own may be insufficient to address the complexity of the deforestation problem (Gibbs, Munger, et al., 2015; Lambin et al., 2018) it is important to understand how these efforts evolve in a manner that allows them to effectively contribute. Studies have variably examined, for example: the competencies of multi-stakeholder initiatives in operationalizing the SDGs (Fowler \& Biekart, 2017); the evolution from informal to formal governance in a multi-stakeholder supply chain network (Alvarez et al., 2010); and the phases that private sector multi-stakeholder supply chain efforts move through towards achieving widespread participation and authority ("political legitimacy") (Bernstein \& Cashore, 2007). The latter is a focus of analysis in Chapter 4. If multi-stakeholder approaches are critical to the new diplomacy of sustainable development, it is equally imperative to understand their workings and how they evolve to a point of making sustainability contributions.

\subsection{Objectives and Research Questions}

The overarching objective of this thesis is to strengthen the theory and practice of sustainable development diplomacy (SD diplomacy) as an approach for understanding progress on the Sustainable Development Goals related to climate, deforestation, and cattle production. Specifically, this thesis examines, in the context of SD diplomacy, three interrelated processes: the intergovernmental negotiations under the UNFCCC; intergovernmental negotiation and multi-stakeholder processes for REDD+; and the multi-stakeholder approach to the roundtables for sustainable beef (RSBs). Based upon empirical evidence from these three fields and by drawing upon the relevant literatures of international relations, multi-party 
negotiation, and conflict resolution, this study aims to explore: 1) how key factors in the negotiations of the UNFCCC relate to each other and to reaching agreement; and 2) the degree to which those factors enabled or constrained agreement in the UNFCCC and REDD+ negotiation contexts. It will also explore the evolutionary characteristics and phases of multistakeholder implementation processes on cattle production and reducing deforestation that underpin their potential for contributions to sustainable development. Recognizing this latter topic is another step in the policy chain (post-negotiated agreement and into implementation), it will need a different conceptual framework than the one used to examine negotiation factors. Both frameworks are outlined below.

Addressing this research objective requires an interdisciplinary lens that draws from international relations, multi-party negotiation theory, and conflict resolution. In pursuit of these objectives, the research questions are:

Question 1 (RQ1): What are the negotiation factors involved ${ }^{12}$ in the UNFCCC negotiations; how do those factors relate to each other and to reaching agreement?

This question is addressed in Chapter 2 which introduces a conceptual framework with five dimensions (also referred to as factors, elements, or variables in the broader literature) as a starting point and presents empirical evidence to ground the resulting revised model in an intergovernmental negotiation forum (related to advancing the climate aspects of sustainable development), the UNFCCC.

Question 2 (RQ2): How did negotiation factors enable or constrain multi-actor agreements in REDD+ negotiations and supporting multi-stakeholder REDD+ processes?

The third chapter also examines relationships between negotiation dynamics in terms of the degree to which negotiation factors enabled or constrained agreement on REDD+. ${ }^{13}$

\footnotetext{
${ }^{12}$ As noted earlier in this chapter, multi-party negotiation literature converges around a set of key variables, or factors in the negotiation. Recognizing that multi-party negotiations are by definition complex and likely have hundreds of variables, this thesis will focus on the main ones as a priority for the research.

${ }^{13}$ Reducing emissions from deforestation and forest degradation and the role of conservation, sustainable management of forests and enhancement of forest carbon stocks in developing countries. See: https://unfccc.int/topics/land-use/workstreams/reddplus
} 
Question 3 (RQ3): What are the evolutionary characteristics and phases of multistakeholder collaborations on cattle and deforestation that underpin their potential for sustainability impact?

The fourth chapter examines governance and accountability characteristics in two multistakeholder contexts: 1) the roundtables for sustainable beef (RSBs); and 2) early implementation efforts to reduce deforestation (via REDD+ and zero-deforestation commitments). Since these efforts are focused on implementation instead of negotiation, a different conceptual framework was needed.

To answer the three RQs, the thesis applies two conceptual frameworks across three chapters that are connected through the research questions (RQs). In answering these RQs, this thesis aims to strengthen the SD diplomacy approach and practice in two ways: 1) by drawing upon relevant international relations, multi-party negotiation, and conflict resolution literatures and 2) by presenting empirical evidence from sustainable development negotiations related to climate action (SDG 13), life on land (SDG 15), and sustainable consumption and production (SDG 12).

\subsection{Conceptual Frameworks}

Considering that the three cases - UNFCCC, REDD+, and RSBs - presented different stages of the policy process from negotiation to implementation, two conceptual frameworks were necessary to study them and to answer the research question.

For research questions (RQ) 1 and 2, this thesis focused on the UNFCCC and REDD+ cases, employing an iterative, grounded theory method. Based upon the researcher's years of observing negotiations in the UNFCCC, REDD+, and land use contexts, a set of common factors in the negotiation started to emerge. These factors reflected a conflict resolution model familiar to the author as a professional mediator (referred to here as the Policy Dialogue Model, see below). As outlined previously, common factors, or variables, in multiactor negotiations were also reflected in the literatures yet had not been applied empirically in the sustainable development context. Recognizing the conflict resolution model was developed in a different context and may not be entirely suited for understanding intergovernmental negotiations, the study used the grounded theory (Glaser \& Strauss, 1967) approach with the initial hypothesis that the model was a useful starting point for further 
understanding specific sustainable development negotiation contexts of the UNFCCC and REDD+.

For research question 3, this thesis examined the multi-stakeholder collaborations of the roundtables for sustainable beef (RSBs) and implementation efforts to reduce deforestation. These cases represented a different part of the policy spectrum beyond the policy negotiation stage and into the policy implementation stage. As such, a different conceptual framework was needed to answer RQ3 in order to explore the evolution and underpinnings of multistakeholder collaboration as it relates to their potential for sustainable development contributions. This framework is referred to here as the non-state market driven (NSMD) model and is outlined towards the end of this section.

The thesis begins with a descriptive conceptual framework - the Policy Dialogue Modelwhich was developed as "a new approach to formulating environmental policy" (Ehrmann, 1997). It is comprised of five dynamics: three main dynamics and two cross-cutting, underlying dynamics (Figure 1) (Ehrmann 1997). The three main dynamics are: 1) Political Context: "refers to the political environment within which a policy dialogue takes place." (Ehrmann, 1997: 65.); 2) Negotiation Dynamics: encompasses the substance of what is being negotiated and the communication and understanding of those issues in the contexts of interests and positions, including participants' negotiation skills and experience (Ehrmann, 1997); 3) Group Process: refers to small group dynamics; decision-making theory; the creation and dynamics of temporary systems; human relationships; and personal styles (Ehrmann, 1997).

The two cross-cutting dynamics that underpin and interact with, and between, all three of the main dynamics are: 4) Power: an underlying process within the model and is described as playing two roles: a) as differentiated degrees of power held by relevant societal interests; and b) via interpersonal power dynamics (Ehrmann, 1997, 135).; 5) Data, Information, and Communication: informs the scientific or technical aspects of the policy dialogue; the way data and information is developed and communicated by experts; how data and information relates to, supports and/or refutes different policy positions; and how data and information and the communication of it is perceived by participants (Ehrmann, 1997). 


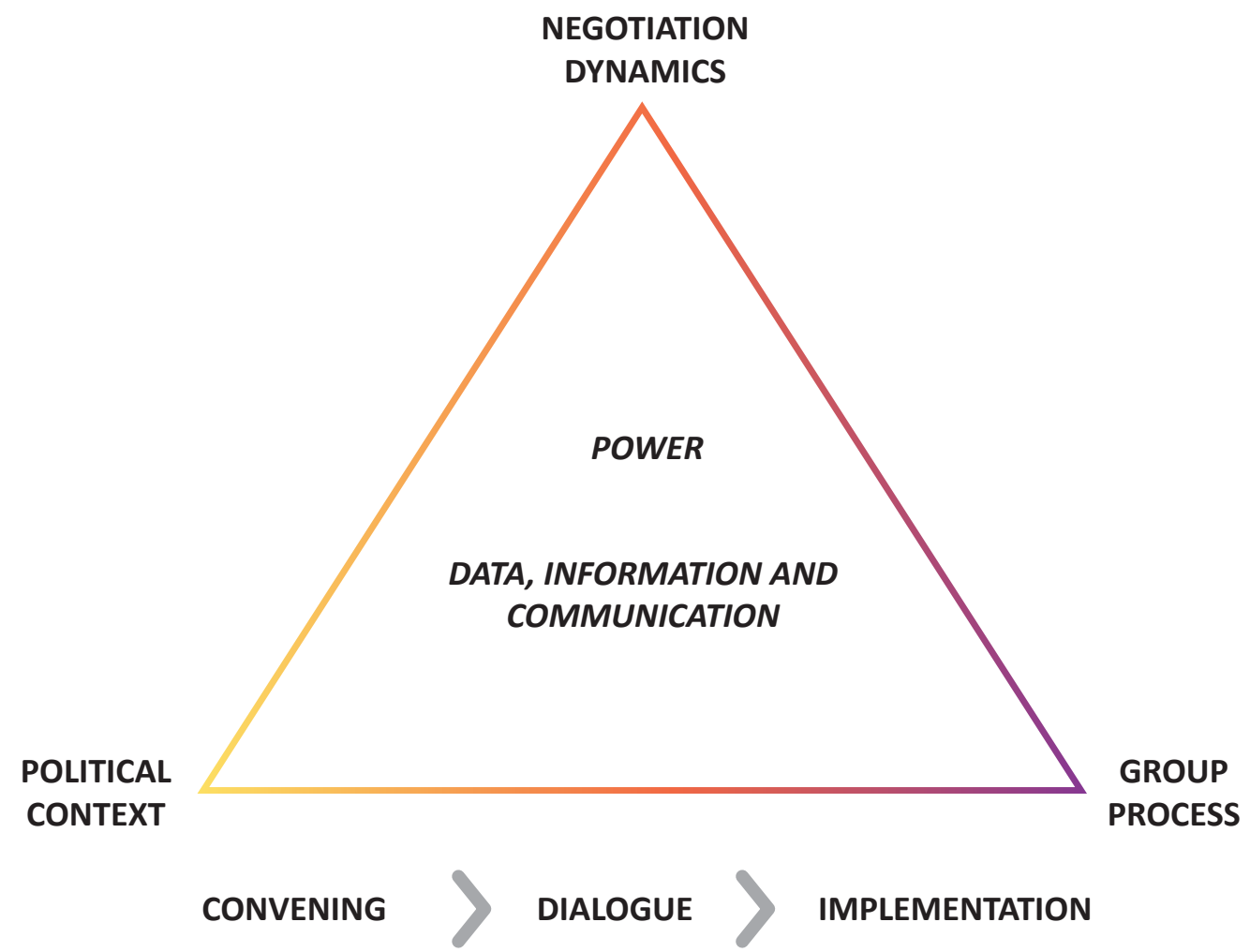

*(Ehrmann, 1997) Reproduced with permission from the author.

The Policy Dialogue Model includes key factors that are prevalent in international relations (e.g., politics, power) (Keohane \& Nye, 2011; Mearsheimer, 2001) 1); and multi-party negotiations and conflict resolution literature (e.g., power, process, and communication) (Zartman, 2002; Susskind, 2003; Crump, 2015; Daniels et al. 2012; Gray, 1989). Applied in sustainable development negotiation contexts, this thesis begins with the initial hypothesis (see Methodology section 1.5) that the Policy Dialogue Model can provide a synthesized, multi-disciplinary perspective understanding to answering the research questions. By applying empirical evidence to ground the Policy Dialogue Model in intergovernmental negotiations, the revised model can be used to analyze the relationships among negotiation factors, including their relative influence as constraining or enabling agreement. In contrast to most international relations theories that focus on one or two key variables such as power and politics (Keohane and Nye, 2011; Mearsheimer, 2001), and SD diplomacy which excludes power (Moomaw et al. 2017), the Policy Dialogue Model reflects the collective negotiation factors identified in multi-party negotiation and conflict resolution literatures. Whereas SD 
diplomacy scholars offer a set of diagnostics for optimizing the negotiation and implementation of sustainable development, (e.g., mutual gains approach and negotiating in good faith) (Moomaw et al. 2017), the Policy Dialogue Model does not prescribe the ways in which key factors need to operate. Instead, it offers insights into the key factors in a negotiation.

In Chapter 2, the Policy Dialogue Model was empirically grounded through in-depth interviews with key informants ${ }^{14}$ (Babbie, 2016) in the UNFCCC negotiations combined with drawing from multiple disciplines of related literature: international relations, negotiation theory, and conflict resolution. The results of this study informed a revised framework as a reflection of the empirical research: the Integrated Negotiation Dynamics Model (INDM) (the full set of revisions are outlined in Chapter 2). The resulting conceptual framework was then used in Chapter 3. To briefly outline the model's evolution here: all of the factors are dynamics in the negotiation, defined as: "forces or processes that produce change inside a group or system” ('Dynamics'). The Policy Dialogue Model's 'Negotiation Dynamics' dimension was renamed 'Negotiation Process' to reflect both the interview data and multiparty negotiation literature. A sixth dynamic, 'Communication' was identified as a distinct negotiation dynamic based upon the interview data which showed relationships between communication and all other negotiation dynamics, not only Data and Information.

The second conceptual framework employed for research question 3 (RQ3) and utilized in Chapter 4 was the non-state market driven (NSMD) framework (Bernstein \& Cashore, 2007). The NSMD framework outlines five characteristics and three phases of an "ideal-type NSMD system;” ideal meaning attaining 'political legitimacy' (Bernstein \& Cashore, 2007, p. 349). The five NSMD characteristics are: 1) they do not "derive governing authority from states nor are they accountable to them" (p. 349); 2) they comprise diverse stakeholders collectively developing and working towards goals; 3 ) they gain "authority" via their supply chain members, each which maintain sovereignty over the choice to certify products or services (pp. 349-350); 4) they aim to improve sustainability of the industry, thereby "reconfiguring" the current markets (p. 350); and 5) they develop mechanisms for addressing compliance (Buckley et al. 2019 citing Bernstein and Cashore 2007 pp. 349-350). The three

\footnotetext{
${ }^{14}$ This is further explained in the Methods section but to briefly define it here, the term informants refers to a "member of the group who [could] talk directly about the group..." (Babbie, 2016, p. 189).
} 
phases that NSMD systems evolve through are initiation (I), building support (II), and political legitimacy (III). The focus on political legitimacy is to understand "what an acceptable or appropriate institution should look like and the bounds of what it can and should do" (Bernstein \& Cashore, 2007, p. 351). Multi-stakeholder processes implementing sustainable practices do not have the same governing authority of states or intergovernmental institutions. Nevertheless, they are contributing to and in some cases leading multistakeholder, private sector, and supply chain (i.e., market-oriented) efforts for implementing sustainable development practices. This thesis employs the NSMD framework as a means to understand the evolutionary characteristics and phases of implementation-focused multistakeholder processes and how they underpin their potential for sustainability contributions. Specifically, Chapter 4 employs the NSMD framework to explore the roundtables for sustainable beef, REDD+ multi-stakeholder early implementation processes, and multistakeholder zero-deforestation commitments.

In the case of sustainable cattle ${ }^{15}$ production in Chapter 4 of this thesis, the roundtables are a collection of global and national multi-stakeholder initiatives for improving the sustainability of cattle production. In the absence of governmental policy for sustainable cattle production, these non-state processes represent the forefront of implementation activities on sustainable commodity production related to SDG 12, sustainable consumption and production. In the case of REDD + , it has been argued that the original vision was rooted in a market or performance-based approach, "integral to a global cap-and-trade carbon market" (which did not materialize) (Angelsen et al., 2017). Recognizing that addressing the problem of deforestation would require involvement of agricultural commodity supply chains, the solution expanded to include multi-stakeholder voluntary supply chain zero-deforestation commitments. While none of these contexts are purely non-state or market-driven, they nonetheless reflect NSMD characteristics and phases of evolution. Understanding these may provide insights into the pre-conditions for their success (defined as lasting and significant sustainability contributions).

\footnotetext{
15 The term 'cattle' is used here instead of 'beef' to acknowledge that some of the national roundtables for sustainable beef include dairy and leather production, not only beef.
} 


\subsection{Methodology: Nested Case Study Approach}

This thesis investigates how SD diplomacy can be strengthened by applying empirical evidence from sustainable development negotiation contexts and through relating to the literatures of international relations, multi-party negotiation, and conflict resolution. The research draws primarily upon qualitative methods for social sciences. This thesis explores sustainable development negotiation contexts - all of which involve people, social interaction, and social systems - with the aim of better understanding aspects of the social phenomenon contributing to actors reaching agreement. Specifically, the research explains how SD diplomacy can be strengthened by theoretically and empirically grounding it in: 1) the key factors of sustainable development negotiation and how those factors inter-relate; 2) how factors in the negotiation enable or constrain agreement; and 3) how multi-stakeholder processes contribute to Sustainable Development Goals related to climate change, deforestation, and cattle production.

These substantive topics were chosen as the focus of the thesis due to their linkages to climate change and their multi-faceted relationships across several SDGs. The methods design is based upon a nested case study approach to examine multiple related cases that offer insights on the overall object of study (Thomas, 2011). In this thesis, there are two streams of nesting within the case studies chosen. First, the substantive sustainability topics of study are related in that climate change (SDG 13 on Climate Action) is exacerbated by deforestation and land degradation (SDG 15) (United Nations, 2015; Van Der Werf et al., 2009); and that deforestation and land degradation are driven, in part, through the production of cattle (SDG 12) (Nijdam et al., 2012). While not a focus of this thesis, it is worth noting that land productivity and cattle production are also linked to food security (SDG 2), nutrition (SDG 3), and economic growth (SDG 8), among other SDGs. Taken together, the contexts of cattle production, deforestation, and land degradation are all contributing to climate change and relate to many of the Sustainable Development Goals. Second, these cases are nested in the sense of process types examined. The three cases provided insights within and across diverse contexts of multi-actor processes: intergovernmental negotiations (UNFCCC and REDD+), multi-stakeholder negotiations (REDD+), and multi-stakeholder implementation processes (REDD + and roundtables for sustainable beef-RSBs). Ultimately, all of these process types aim to contribute to sustainable development, whether they were still in the 
negotiation stages or in the implementation stages. Figure 2 provides a graphic representation of the nested case study approach employed in this study.

Figure 2. Nested Case Study: multi-actor processes of sustainable development

Nested Case Study Approach

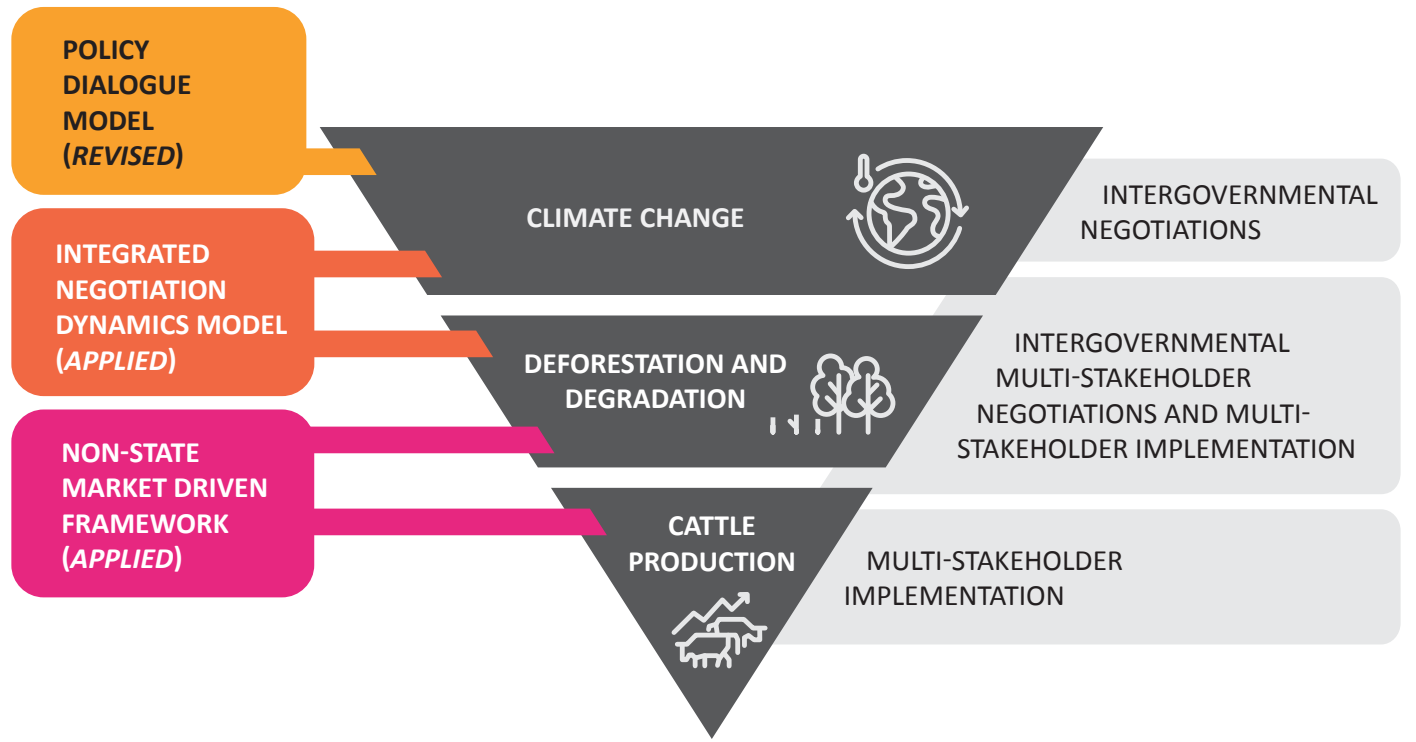

\subsubsection{Data Collection}

The study began with a grounded theory approach (Babbie, 2016; Glaser \& Strauss, 1967) based upon the author's professional experience observing negotiations in the UNFCCC, REDD+, and agriculture contexts and in facilitating negotiator and multi-stakeholder interactions on the margins of those contexts. The emergent patterns seemed to reflect a conflict resolution model on multi-stakeholder policy dialogues (Ehrmann, 1997) that was known to the researcher as a practitioner in that field (this informed the conceptual framework described below). This thesis employed an iterative approach starting with practitioner observations of patterns emerging, using the conflict resolution model as an initial hypothesis, then applying empirical data to inform evolutions to the Policy Dialogue Model that reflected the complex, interdisciplinary nature of intergovernmental and multistakeholder negotiations on issues of sustainable development. Interview respondents were systematically asked, in an open-ended manner, to share their experience and observations for each of the key factors in the 'Policy Dialogue Model' so they could ascribe their own meaning to the terms based upon their experience (Galletta, 2013). They were also asked 
about key factors in the negotiation beyond those already discussed and their observations about the relationships between factors.

With the conflict resolution model as an initial conceptual framework, this thesis is based upon primary and secondary qualitative data. Primary data were collected using interviews, an online survey, and field research. Interview data were collected in three different periods: May-June 2013 (Chapter 2); May 2016 (Chapter 3); and May-August 2016 (Chapter 4). Survey data for Chapter 3 were collected between April and May 2016. In-person visits were conducted between June 2010 and May 2016. Table 1 shows a summary of the interviews and survey. Table 2 shows a summary of in-person practitioner observations (more details are available in Appendix D).

Table 1. Interviews and Survey

\begin{tabular}{|c|c|c|c|c|c|}
\hline Type of Respondent & $\begin{array}{l}\text { UNFCCC } \\
\text { Interviews }\end{array}$ & $\begin{array}{c}\text { REDD+ } \\
\text { Interviews }\end{array}$ & $\begin{array}{l}\text { REDD+ } \\
\text { Survey }\end{array}$ & $\begin{array}{c}\text { RSB } \\
\text { Interviews }\end{array}$ & $\begin{array}{c}\text { Total } \\
\text { Affiliations }\end{array}$ \\
\hline Civil Society: NGO/IGO & 0 & 0 & $7^{*}$ & 9 & 15 \\
\hline Funders & 0 & 0 & 0 & 2 & 2 \\
\hline Scientists and Experts & 3 & 1 & $2^{*}$ & 4 & 8 \\
\hline Indigenous Peoples Organizations & 0 & 1 & 0 & 0 & 0 \\
\hline $\begin{array}{l}\text { Industry: } \\
\text { Producer/Retailer/Processor/ } \\
\text { Multinational }\end{array}$ & 0 & 0 & 0 & 7 & 7 \\
\hline REDD+ Donor Country & 0 & 1 & $3^{*}$ & 0 & 3 \\
\hline REDD+ Partner Country & 0 & 0 & $4^{*}$ & 0 & 4 \\
\hline Country Negotiator & $17^{*}$ & 0 & 5 & 0 & 22 \\
\hline Secretariat Staff & 3 & 1 & $1^{*}$ & 2 & 6 \\
\hline Chairs/Facilitators & $5^{*}$ & 0 & $2^{*}$ & 0 & 7 \\
\hline Total Respondents & $21 *$ & 3 & $12^{*}$ & $20 *$ & 56 \\
\hline
\end{tabular}

Acronym Key: IGO = Intergovernmental Organization; NGO = Non-governmental Organization; REDD+ = Reducing Emissions from Deforestation and Degradation; RSB = Roundtable for Sustainable Beef, UNFCCC = UN Framework Convention on Climate Change

*Some respondents had more than one affiliation at the time of the interview, so the total number of respondents on the last line in the table does not necessarily reflect the sum of the affiliations. However, the total respondents number accurately reflects the total respondents for that method of data collection. 
Table 2. Visits

(also see Appendix D)

\begin{tabular}{lccc} 
Type & Observation & Side Event & Total \\
UNFCCC COP & 2 & 2 & 4 \\
UNFCCC Intersessional & 6 & 2 & 8 \\
REDD+ Processes & 4 & 0 & 4 \\
Total Visits & 12 & 4 & 16 \\
\hline
\end{tabular}

Acronym Key: $\mathrm{COP}=$ Conference of the Parties; REDD+ = Reducing Emissions from Deforestation and Degradation; UNFCCC = UN Framework Convention on Climate Change.

In advance of all interviews, participants were informed about the research objectives and how their responses would be used. Basic demographic information was collected and reported, but the identity of respondents and attribution was anonymized. Interviews were conducted through one-on-one telephone calls between the researcher and respondent. All interviews were in-depth qualitative interviews (Babbie, 2016, pp. 310-313) that were semistructured in nature in order to reflect aspects of the research questions while also allowing respondents to share their experiences, observations, and their significance (Galletta, 2013, pp. 1-2). Those invited for an interview were highly engaged expert informants and/or experts in the topic under investigation that were willing to share their knowledgeotherwise known as informants (Babbie, 2016, p. 189-190). While the author recognizes the differences in how scholars define 'respondents,' 'participants,' and 'informants' (Babbie, 2016, pp. 189-190; Morse, 1991), this thesis uses the terms interchangeably with the upfront explanation that all interview participants and survey respondents were expert informants. Meaning, they represented a "member of the group who [could] talk directly about the group..." (Babbie, 2016, p. 189). In the case of this thesis, expert informants included individuals intimately involved in the fields under study: UNFCCC negotiations; REDD+ negotiations and supporting REDD+ processes; and founding members and leaders from the roundtables for sustainable beef.

Recognizing the author's role as both a practitioner and researcher, efforts were made to engage respondents that were familiar with the author and those that were not. Respondents were steeped in each of the three research contexts, respectively: UNFCCC negotiations (all sectors); REDD+ negotiations; and roundtables for sustainable beef. Initial invitations were 
developed based upon the researchers' knowledge and by reviewing participant lists from the above contexts. Additional suggested informants were added using the snowballing method (Babbie, 2016, p. 188).

An online qualitative survey $(\mathrm{N}=12)$ among highly knowledgeable REDD+ experts was used to generate data for use in Chapter 3. The survey was comprised of open-ended questions and included a 5-point Likert scale (Likert, 1932) to gather information about the degree to which a negotiation factor in the REDD+ context enabled or constrained agreement. Qualitative questions were designed to gather respondents' experience and observation of new or additional factors in the negotiation that were not included in the survey questions. Survey invitations were sent to individuals engaged in REDD+ negotiations under the UNFCCC and in related REDD+ negotiation processes including the REDD+ Partnership ${ }^{16}$, the Forest Carbon Partnership Facility (FCPF) ${ }^{17}$, and UN-REDD Programme. ${ }^{18}$

A portion of the interview and survey questions for Chapters 2 and 3 were designed based upon the five key factors, or variables, in the Policy Dialogue Model (Political Context; Negotiation Dynamics; Group Process; Power; and Data, Information, and Communication). Based upon practitioner observations in the UNFCCC and REDD+ negotiation contexts, these variables offered an initial conceptual framework through which to explore these

\footnotetext{
${ }^{16}$ The REDD+ Partnership was a state-led initiative starting in 2010 and ending in 2014. Its aim was to "scale up REDD+ actions and finance...to take immediate action, including improving the effectiveness efficiency, transparency and coordination of REDD+ initiatives and financial instruments, to facilitate among other things knowledge transfer, capacity enhancement, mitigation actions and technology development and transfer." See: http://www.climateinitiativesplatform.org/index.php/REDD\%2B Partnership
}

17 “The Forest Carbon Partnership Facility (FCPF) is a global partnership of governments, businesses, civil society, and Indigenous Peoples focused on reducing emissions from deforestation and forest degradation, forest carbon stock conservation, the sustainable management of forests, and the enhancement of forest carbon stocks in developing countries, activities commonly referred to as REDD+." See:

https://www.forestcarbonpartnership.org/

18 “The UN-REDD Programme, and other multilaterals including the Forest Carbon Partnership Facility (FCPF) and Forest Investment Program (FIP), facilitated by the World Bank, support developing countries with financial and technical assistance to build the capacities to design and implement REDD+ strategies." See: https://www.unredd.net/about/what-is-redd-plus.html 
sustainable development negotiation contexts. Field research included both non-participatory and participatory observation (Babbie, 2016 pp. 291-296); drawing upon 17 in-person, nonparticipatory visits to the UN Framework Convention on Climate Change negotiations and five visits to REDD+ processes including the REDD+ Partnership meetings. It also included participatory observations from facilitating three side events on consensus-building in the UNFCCC as practitioner or a 'participant observer' (Babbie, 2016. pp. 291-292).

Secondary data was collected through analyzing relevant literature, organizational and multistakeholder negotiation documents, international treaties, multilateral negotiated accords and agreements. Outside of the academic literature, secondary data was selected based upon over 12 years of the researcher's professional experience and background as a mediator working within and on the margins of the UNFCCC, REDD+, agriculture, and land use. The author also relied upon interviews for secondary data such as documents and reports that respondents suggested as resources.

Primary data was collected via interviews, an online survey, and through observational field visits. The names, affiliations, and identifying information of all respondents are confidential and were used solely for this research, with the exception of data from Chapter 2 which was collected with the prior, informed consent from participants to be used in a public-facing professional project, "Consensus-building in the UNFCCC", funded by the Climate and Development Knowledge Network. ${ }^{19}$ While the synthesized results from those interviews were shared with all participants, attribution was strictly confidential. The primary data are stored on the Wageningen University Database ("FNP archive drive") according to the longterm protocol for storing data under the Data Management Plan.

\subsubsection{Data Analysis}

All interviews were conducted in English and data were transcribed verbatim in real-time. ${ }^{20}$ For one interview used in Chapter 2, the call was also recorded, with permission, to ensure accurate transcription due to the respondent's fast speech and strong accent. In the author's

\footnotetext{
${ }^{19}$ See the Climate and Development Knowledge Network (CDKN): $\underline{\text { https://cdkn.org/ }}$

${ }^{20}$ For the avoidance of doubt, this means that interview notes were, in fact, a transcript of the interview rather than summary points. Therefore, the interview data could be immediately analyzed and coded in Microsoft OneNote without needing to first transcribe the interview recording.
} 
experience as a mediator conducting hundreds of sensitive and sometimes confidential interviews, individuals being interviewed are less comfortable and candid when being recorded. Based upon conversations with national diplomats and negotiators, this seems to stem from the notion that text or a quote that might relate back to the respondent is easier to deny or distance from than an audio or video recording. In some instances, respondents insisted that discussions take place over a landline rather than a mobile phone or Voice over Internet Protocol (VoIP) such as Skype. There is also some evidence in healthcare literature of respondents' discomfort and increased formality when interviews are recorded (AlYateem, 2012). As observed in development research methods, "all research is political and has the power to change people's lives" (Harrison, 2011). Although studying negotiations is not development research, it is an examination into political worlds where actors are highly guarded.

Data analysis of interview question responses in Chapter 2 and open-ended survey questions for Chapter 3 entailed a three-step process. First, data was coded thematically based upon the five factors, or variables, in the Policy Dialogue Model which served as an initial hypothesis (Glaser and Strauss, 1967). Second, open and axial coding was applied to data that fell outside the five factors and/or their original definitions (Babbie, 2016, pp. 387-390). The third round of analysis entailed reading the open and axial coded data, referring back to the original Policy Dialogue Model definitions, and to the negotiation factors identified in the literatures. This enabled the identification of factors beyond the original five and expanded meanings or definitions ascribed by respondents.

Chapter 3 also included a qualitative survey and analysis of the responses. The survey included a Likert scale to inform analysis beyond descriptions of the negotiation dynamics. While not statistically significant, the scale offered a means to understand negotiation dynamics' relative enabling or constraining effects on reaching agreement. The Likert scale ratings were weighted and first analyzed through calculating the mean and standard deviation. Second, the results were plotted on box and whisker graphs to illustrate the degree to which a factor enabled or constrained agreement, including the degree to which respondents converged or diverged. The grounded theory approach and multi-round data analysis for Chapters 2 and 3 provided a cumulative, empirically based approach to informing and refining the Integrated Negotiation Dynamics Model (INDM). 
For Chapter 4, the first round of interview data analysis used targeted coding to organize data based upon the main topic which typically followed the interview question topic. Interview responses were also coded for geography to ensure comments about a specific roundtable were attributed accordingly. Second, data within the main categories was open-coded to identify new patterns and concepts (Babbie, 2016).

\subsection{Thesis Outline}

This thesis is comprised of five Chapters. Chapter 1 provides the theoretical context and an overview of the objectives and research. Chapter 2 begins with a conceptual model drawn from the field of conflict resolution and applies empirical data from interviews with UNFCCC negotiators, chairs, facilitators, and Secretariat staff, along with practitioner observations to inform the development of a revised, empirically grounded conceptual framework: the Integrated Negotiation Dynamics Model (INDM). Relating the results to the broader literatures, the INDM provides a synthesis between key factors identified in IR, multi-party negotiation, and conflict resolution literatures.

Chapter 3 applies the empirically grounded INDM to both the intergovernmental negotiations and multi-stakeholder REDD+ processes. Applying the INDM to REDD+ provides insights into its relative success compared to other sectoral negotiations under the climate regime. The chapter also demonstrates the relationships between these negotiation dynamics-a recognized gap in multiparty negotiation literature. In addition, it examines the degree to which negotiation dynamics played an enabling and/or constraining role in reaching agreement.

Chapter 4 applies the non-state market driven (NSMD) framework (Bernstein \& Cashore, 2007) to global and national roundtables for sustainable beef (RSBs). This chapter provides some of the first scientific insights into the structure, governance, and perceived potential for the sustainability impact of RSBs. Chapter 4 also applies the NSMD framework to explore the evolutionary characteristics and phases of multi-stakeholder collaboration efforts to reduce deforestation, specifically examining early implementation efforts on REDD + and private sector supply chain efforts.

Finally, Chapter 5 provides a synthesis of the preceding chapters and the conclusions of the research based upon the nested case studies. First, Chapter 5 articulates the negotiation factors involved in the UNFCCC and REDD+ negotiations, the relationships between those 
factors, and their role in reaching agreement. Second, Chapter 5 identifies how particular negotiation factors enabled and/or constrained parties' ability to reach agreement in the context of UNFCCC and REDD+ negotiations. Third, Chapter 5 discusses the characteristics of REDD+ and beef roundtables' multi-stakeholder implementation processes that support their potential for sustainability impact. The synthesis then offers a suggested research agenda followed by reflections on the research approach and methods. Finally, based upon the overall thesis, the chapter offers a set of policy recommendations. 


\section{ChaPTER 2 | Understanding the Climate Change NEGOTIATIONS: TOWARDS AN INTEGRATED NEGOTIATION DYNAMICS MODEL*}

*An abbreviated version of this chapter has been prepared for submission to a peer-reviewed journal. 


\subsection{Introduction}

The stewardship of our climate — which is a global public good — and the regime established to enable the management of that public good - the United Nations Convention on Climate Change (UNFCCC) - require international cooperation. ${ }^{21}$ As evidenced by the start of the global climate change regime in 1992 and the conclusion of a comprehensive global agreement in Paris in 2015, cooperation also requires significant intergovernmental negotiation. Within the UNFCCC, achieving agreement on measures to mitigate and adapt to climate change requires consensus, which in practice means that no party objects to the decision. $^{22}$

Within the field of international relations, debates abound as to whether international cooperation beyond self-interest is feasible (J. M. Grieco, 1988; Mearsheimer, 1994) and the extent to which such cooperative results will manifest as a result of, or despite, an international regime such as the UNFCCC (J. M. Grieco, 1988; Keohane \& Oppenheimer, 2016; Krasner, 1982; Mearsheimer, 1994). As the Conference of the Parties (COP21 23) Paris Agreement demonstrated, international cooperation and agreement is possible. SD diplomacy scholars argue that negotiation and implementation across all scales and stakeholders is necessary to achieve the Sustainable Development Goals (SDGs) (Kjellén, 2008; Hoogeveen and Verkooijen, 2011; Moomaw et al. 2017)—of which climate is one.

\footnotetext{
${ }^{21}$ Due to their transboundary nature, reducing atmospheric greenhouse gas emissions requires some type of coordinated and/or cooperative action among a majority of states. While some nations will fare better than others in a changing climate, unilateral and bilateral action to mitigate greenhouse gases will not curb the effects of climate change enough to support life on earth as we know it. The upward limit of carbon dioxide (a greenhouse gas) concentrations in the atmosphere is generally considered by the scientific community and, increasingly, by the public, to be 350 parts per million (ppm). See: Hansen et al., 2008.

${ }^{22}$ Note that the rules of procedure for the UNFCCC, drafted in 1996, have still not been adopted. They remain as bracketed draft text under Rule 42 of the Convention. However, UNFCCC decisions have been made, de facto, by consensus among the parties. Although, there have been instances, notably at COP-16 in Cancún and COP-18 in Doha where a party has objected to a COP decision and has been 'gaveled over' by the COP chair.

${ }^{23}$ Refers to the $21^{\text {st }}$ Conference of the Parties to the UNFCCC.
} 
The objective of the research reflected in this chapter is not to determine why or why not climate cooperation occurred, but rather to provide insights and enhanced understanding of the main negotiation factors within the intergovernmental negotiation setting of the UNFCCC. Specifically, this chapter explores how negotiation factors relate to each other and to reaching agreement. This chapter uses Ehrmann's Policy Dialogue Model (Figure 1) as its basis. Applying empirical data from interviews with UNFCCC negotiators, chairs, facilitators, Secretariat staff, and practitioner observations informed a revised, empirically grounded framework that is applicable to the intergovernmental negotiations of the UNFCCC. The resulting Integrated Negotiation Dynamics Model (INDM) provides a synthesis of key negotiation factors identified in the fields of international relations, multiparty negotiation, and conflict resolution.

By applying a descriptive conflict resolution model to examine the UNFCCC negotiations, this research aims to go beyond the classic state-actor or negotiations-focused approach to understanding the UNFCCC negotiations. Drawing upon UNFCCC negotiator and facilitator experiences, the chapter explores the key factors involved in the negotiations and how they contribute to reaching agreement. This enhanced understanding is intended to be useful both retrospectively and in real-time to identify key factors in the negotiation and to help diagnose challenges to parties reaching agreement.

\subsection{Theoretical Context}

There are competing and overlapping international relations (IR) and international negotiation theories as to why a comprehensive global climate change agreement remained elusive for so long. Within the diverse field of international relations, scholars identify a host of challenges facing an intergovernmental negotiation such as the UNFCCC and parties' ability to reach agreement (Dimitrov, 2010; J. Grieco, 1990; Weiler, 2012). The neorealism, or structural realism, school of thought argues that states' domestic political context focuses on traditional threats to - and desired acquisition of - power and security (Gilpin, 1996; Keohane, 1986a; Mearsheimer, 2001), which saps states' political will to collectively and preventatively address a non-traditional, slow-moving threat such as climate change (Lacy, 2012 citing Mearsheimer, 2001).

Neoliberal and liberal institutionalist scholars argue that international institutions and regimes (such as the UNFCCC) facilitate cooperation (Keohane \& Nye, 2011; Krasner, 1982). However, neoliberalism also points to game theory models that can undermine cooperation 
by demonstrating states' ability to defect from their commitments (e.g., the 'free-rider' problem and the prisoner's dilemma) (Keohane, 1986a; Wood, 2011) (Keohane, 1986; Wood, 2011) under international legal commitments which rarely have enforcement mechanisms. The main argument for state defection is that states are incented to prioritize short-term economic gain (e.g., rational actor model) (Stavins, 2011). Other reasons cited for lack of action on climate change is that significant progress requires clear hegemonic leadership (Gupta, 2012: 636) and that climate change has not been taken seriously because it seemingly does not pose a security or economic threat (Lacy, 2012, p. 31; Michaelowa \& Michaelowa, 2012).

International negotiation and multi-party negotiation scholars have developed many variations on how to best understand multi-party negotiations (Crump, 2015; Druckman, 1997; Gupta, 2012; Hernández, 2014; Raiffa, 1982; Zartman, 1988, 2002). Some of these methods are analytical - they aim to understand the negotiation process that led to a certain outcome (Crump \& Glendon, 2003; Zartman, 1988). Others aim to describe the complexity of the multi-party negotiation process (Daniels et al. 2012). Overall, these efforts aim to provide "concepts and methods to reduce or to manage complexity" (Crump and Glendon, 2003) - a dominant characteristic of international, multilateral negotiations (Zartman, 1994; Crump and Glendon, 2003, citing Winham, 1997 and Hampson and Hart, 1995). Other scholars have pointed to the need for more systematic and in-depth research on multilateral negotiations (Crump \& Glendon, 2003; Gupta, 2012; Tomlinson, 2015; Zartman, 1988, 2002).

Scholars have cited common elements to analyzing negotiations across multiple theories and approaches to analyzing negotiations in general (Zartman, 1988; 2002; Crump, 2015). Other scholars have combined elements of international relations (IR), negotiation theory, problem structuring, and international law to the UNFCCC specifically (Gupta, 2012). SD diplomacy scholars argue that the UNFCCC negotiations must be restructured to transform the notions of responsibility and 'burden-sharing' into opportunities for sustainable development, from which all countries can gain (Moomaw and Papa, 2012). Negotiation scholars underscore the need to restructure the environmental treaty systems and procedures in order to enable effective governance over global public goods (Susskind \& Ali, 2014).

There are high degrees of commonality within and across the key negotiation 'factors' identified in the literature (Zartman, 1988, 2002; Crump, 2015; Daniels et al. 2012). For 
simplicity, this chapter uses the term 'factors,' although the literature differs in terminology (e.g., variables, elements, dimensions), precise definitions, and organization. The common factors in the literature range from context, behavior, and structure, to process, power, and politics, yet no frameworks capture these factors in an integrated way. Nor do existing frameworks provide an integrated approach to understanding how negotiation factors relate to each other (Crump, 2015) or to parties reaching agreement.

Considering the objectives of the chapter-greater multi-disciplinary understanding of UNFCCC context negotiation factors, how they relate to each other and to reaching agreement, Ehrmann's Policy Dialogue Model (Figure 1) offers a useful starting point for examination. By applying empirical evidence to the model, the intent is to evolve the Policy Dialogue Model into an applicable descriptive and diagnostic model for better understanding the UNFCCC negotiations.

\subsection{Methods}

The research that contributed to this chapter began with an inductive approach of grounded theory (Glaser \& Strauss, 1967) based upon initial data and observations as a practitioner working in the UNFCCC context. For several years, the author served as a designer, convener, and facilitator of UNFCCC negotiator dialogues - including conducting dozens of interviews with UNFCCC negotiators. This work also entailed observing multiple tracks of UNFCCC negotiations over several years. This experience provided initial data and observation opportunities. The patterns emerging from initial data seemed to reflect a set of key factors in the negotiations. Those emerging key factors echoed a conceptual framework from the field of conflict resolution: the Policy Dialogue Model (Ehrmann, 1997). The starting hypothesis was that the Policy Dialogue Model would be applicable outside its original context and if applied to the UNFCCC context, it would offer insights into key factors involved in otherwise complex UNFCCC negotiations. Upon further exploration into existing literatures of the key factors in multi-party negotiations-drawing from international negotiations, international relations, conflict resolution, and sustainable development diplomacy - the Policy Dialogue Model encompassed all these factors in a comprehensive whole. Recognizing that some of the Policy Dialogue Model factors may not be applicable to the UNFCCC context or may need refinements, it was clear that further data collection would "refine understanding and, in turn, shape the focus of data collection itself" (Babbie, 2016, 
p.302). This helped shape the selection of resulting case studies in the thesis. The Policy Dialogue Model therefore served as an appropriate starting point for exploring the intergovernmental negotiations of the UNFCCC.

The research reflected in this chapter utilized an iterative, grounded theory method (Babbie, 2016; Glaser \& Strauss, 1967) starting with practitioner observations, employing the Policy Dialogue Model as an initial hypothesis of the patterns emerging. The research then applied empirical data from negotiator and facilitator interviews to the Policy Dialogue Model and extracted insights on the UNFCCC negotiations from application of the Policy Dialogue Model. Insights from the interview data were then used to evolve the Policy Dialogue Model. Finally, the researcher held a group discussion of the results with UNFCCC negotiator and facilitators at an official UNFCCC side event.

This iterative approach intended to yield two sets of insights: 1) the Policy Dialogue Model offered a lens through which to examine key factors in intergovernmental negotiations based upon first-hand experiences of negotiators and facilitators; and 2) the empirical data gathered from applying the Policy Dialogue Model to the new context refined the model to better reflect the key factors UNFCCC negotiation context.

Practitioner observations were collected between 2009 and 2014. Practitioner observations were gathered by attending (as an observer) eight UNFCCC COP and subsidiary body negotiations; observing four REDD+ processes on the margins of UNFCCC sessions; participating in scores of conversations with UNFCCC country negotiators, chairs, facilitators, and UNFCCC Secretariat staff; and hosting four UNFCCC side events. In addition, practitioner insights are offered based upon designing and facilitating six, two- to three-day informal policy dialogues among UNFCCC negotiators. ${ }^{24}$ Originally, practitioner insights suggested that the Policy Dialogue Model seemed to have potential application and

\footnotetext{
${ }^{24}$ Informal policy dialogues mainly focused on issues of land use and agriculture in the UNFCCC. Many of the dialogue participants had responsibility and technical background in land use issues, although a portion of participants were from other ministries such as foreign affairs, economic development, trade, or tourism. Experience from facilitating these dialogues is drawn upon in the thesis, although due to the confidential nature of these dialogues, no specific observations are provided.
} 
utility for enhancing understanding of the key factors of reaching agreement and the negotiation dynamics involved in an intergovernmental setting such as the UNFCCC process. For the interview data, 54 individuals were invited to participate in an in-depth 60-to-120minute telephone interview. Of those, 21 individuals including UNFCCC negotiators, chairs, facilitators, and Secretariat staff participated. ${ }^{25}$ Interviews were conducted individually from May 2013 to February 2014 in a semi-structured format consisting of 13 sequential questions developed in advance. Five questions were structured, open-ended questions that asked the respondent to describe their observations of each factor in the Policy Dialogue Model (political context; group process; negotiation dynamics; power; data, information and communication $)^{26}$ based on their experience in the UNFCCC negotiations. The structure of the interview questions followed the key factors in the model without pre-defining them. This allowed respondents to assign their own meanings to the factor based upon their UNFCCC negotiation experience. Respondents were asked whether, and how, each factor influenced the negotiations, including how factor(s) related to reaching agreement. To gather insights on the UNFCCC negotiation factors that may fall outside of the original factors in the Policy Dialogue Model, respondents were asked an additional six open-ended questions. These aimed to gather experience or observations that could provide additional insights on the UNFCCC negotiations and to inform refinements to the model in the UNFCCC context. For example, those interviewed were asked for their observations of any key dynamics not already covered by the original five dimensions. Respondents were also asked whether all of the factors identified (both the original five and others from their own experience) "are equally important in reaching agreement and if not, which factor(s) are the most important in your experience?"

\footnotetext{
${ }^{25}$ This $<50 \%$ response rate was likely a result of the demand of these individuals' time. They are only part-time negotiators and facilitators in the UNFCCC context. Within their respective ministries, they also have roles and responsibilities that are not UNFCCC-related. Therefore, spending additional time on an interview regarding UNFCCC negotiations may not have been a priority for most people invited to participate.

26 The original Policy Dialogue Model (Figure 1), also included a temporal dimension, starting with design and ending with implementation. Since the focus of this research was on the UNFCCC negotiations rather than the design or the implementation of those negotiations, the temporal elements of the PDM were not explicitly part of the interview questions.
} 
Among those interviewed, there was geographic and role diversity (see Table 3).

Respondents were also asked about the number of years' experience they had in the UNFCCC negotiations. The average was nine years of experience across respondents.

Respondents were also asked about previous roles as chairs, facilitators, or working with the Secretariat. Over one third of respondents had performed in multiple roles, although only their current roles at the time of the interview are reflected in Table 3.

Table 3. Respondents Geographic and Role Affiliations

\begin{tabular}{|lcc|c|c|c|c|} 
& $\begin{array}{c}\text { North } \\
\text { America }\end{array}$ & $\begin{array}{c}\text { Latin } \\
\text { America }\end{array}$ & Europe & Africa & $\begin{array}{c}\text { Asia/ } \\
\text { Oceania }\end{array}$ & Total \\
\hline Negotiator & 3 & 2 & $4^{*}$ & 3 & 4 & $19^{*}$ \\
\hline Chair/Facilitator & $1^{*}$ & $1^{*}$ & $1^{*}$ & $1^{*}$ & $2^{*}$ & $6^{*}$ \\
\hline Secretariat & 1 & 3 & & & 3 \\
\hline Observer & 4 & 2 & 8 & 3 & 4 & 21 \\
\hline Total & 4 & $\mathbf{2}$ & 2 & & 3 \\
\hline
\end{tabular}

*Some respondents had more than one affiliation at the time of the interview, so the total number of respondents on the last line in the table does not necessarily reflect the sum of the affiliations. However, the total respondents number accurately reflects the total respondents from that region and the total respondents overall.

Data was analyzed qualitatively starting with the categories from the Policy Dialogue Model (Political Context; Negotiation Dynamics; Group Process; Power; and Data, Information and Communications) and open and axial coding (Babbie, 2016) to categorize concepts beyond the five factors in the Policy Dialogue Model. Responses with the same codes were grouped into categories and analyzed in aggregate (Babbie, 2016). Open coding was especially useful for data responses to open-ended interview questions which asked respondents to identify and discuss any other factors they saw as important to the negotiations and to reaching agreement. Interview respondents were also asked if there was one factor, in particular, that was most important to reaching agreement in the UNFCCC. The responses to this question were analyzed collectively and are characterized in qualitative terms representing most, a majority, some, or few.

In addition to the interviews, the research draws upon a discussion held at an official side event at the $38^{\text {th }}$ meeting of the Subsidiary Body for Scientific and Technological Advice (SBSTA 38) meeting in June 2013. The interview findings and a revised iteration of the 
Policy Dialogue Model were presented and discussed among 60+ participants including UNFCCC negotiators, chairs, facilitators, and Secretariat staff. Consistent with qualitative research methods, the discussion data was collected, analyzed in the same manner as the interviews, and used to inform the development of a final revised model — the Integrated Negotiation Dynamics Model—which is empirically grounded in the intergovernmental negotiation context of the UNFCCC and applicable for understanding negotiation factors therein (Strauss and Corbin, 1990).

This chapter addresses RQ1: What are the negotiation factors involved ${ }^{27}$ in the UNFCCC negotiations; how do those factors relate to each other and to reaching agreement?

\subsection{Results}

The results encompassed two sets of findings: 1) revisions made to the model based upon applying empirical data from the UNFCCC context; and 2) insights gained on the UNFCCC negotiations for each of the factors in the model. Unless otherwise noted, the results reflect findings from the interview and event observation data.

\subsubsection{Integrated Negotiation Dynamics Model (INDM)}

Based upon the results of the study, this chapter proposes a revised model, the Integrated Negotiation Dynamics Model (INDM). Before describing the findings for each factor, it is worth outlining the overarching findings and rationale for the INDM. First, the name 'Policy Dialogue Model' was not fitting for the UNFCCC context of intergovernmental negotiations. However, based upon practitioner observation and the literature, the Policy Dialogue Model was a relevant starting point for identifying and understanding key factors in the UNFCCC context. After reflecting on the literature and empirical data, the author introduced a new term for the model: 'Integrated Negotiation Dynamics Model' (INDM). There were several reasons for introducing modified terminology.

First, the model was applied more broadly to intergovernmental negotiations, not only to multi-stakeholder dialogues about policy. Second, interview data and practitioner

\footnotetext{
${ }^{27}$ As noted in Chapter 1, multi-party negotiation literature converges around a set of key variables, or factors in the negotiation. Recognizing that multi-party negotiations are by definition complex and likely have hundreds of variables, this thesis will focus on the main ones as a priority for the research.
} 
observations suggested that each of the model's factors are negotiation dynamics not one, as was defined in the Policy Dialogue Model (Interviews, Practitioner Observations). The definition of 'dynamics' - "forces or processes that produce change inside a group or system" ("Dynamics") seems to support respondents' interpretation that negotiation dynamics refers to all key factors in the UNFCCC negotiations. Therefore, the original factor in the Policy Dialogue Model called 'Negotiation Dynamics'—positioned in only one of the corners of the triangle - was changed to 'Negotiation Process' to better reflect the contents of that factor. The term 'Negotiation Dynamics' then applies to the entire model as opposed to one aspect. In addition, the linear process outlined below the Policy Dialogue Model triangle - convening, dialogue, implementation — was described by respondents as part of the Negotiation Process dynamic and as a cyclical — not linear-phenomenon. In the UNFCCC context, negotiations begin with agenda-setting, followed by substantive negotiations. Assuming those negotiations yield agreement, Parties ${ }^{28}$ move to implementation. Their experience with implementation then informs any future negotiation agendas and the process begins anew.

Third, the new name reflects the integrated nature of the model's dynamics as a collective framework through which to understand the UNFCCC negotiations. The process of grounding the Policy Dialogue Model in the UNFCCC context and related literatures provided an interdisciplinary, integrated understanding of negotiation dynamics in the UNFCCC context.

In addition to the overall evolution of the Policy Dialogue Model, the interview data reflected Communication as its own distinct negotiation dynamic, not only linked to Data and Information as it was in the Policy Dialogue Model, but also to the communication of Political Context, of interests and positions, of Power. In the INDM, Communication is its own dynamic to capture its relationships with other dynamics beyond data and information. The revised, Integrated Negotiation Dynamics Model (INDM) is depicted as a hexagon (Figure 3 below), rather than a triangle, to reflect parity among negotiation dynamics and to emphasize relationships between all dynamics, based upon the results. The INDM shown in

\footnotetext{
28 The term 'Parties' here refers to signatories of the UN Framework Convention on Climate Change (UNFCCC). Since this reference is not generically referring to parties in a negotiation but rather specifically to Parties in the UNFCCC, it is capitalized as it is in the UNFCCC context.
} 
Figure 3 lists the negotiation dynamics in the order that they were presented in the thesis and is not intended to confer a particular ordering of dynamics.

Figure 3: Integrated Negotiation Dynamics Model (INDM)

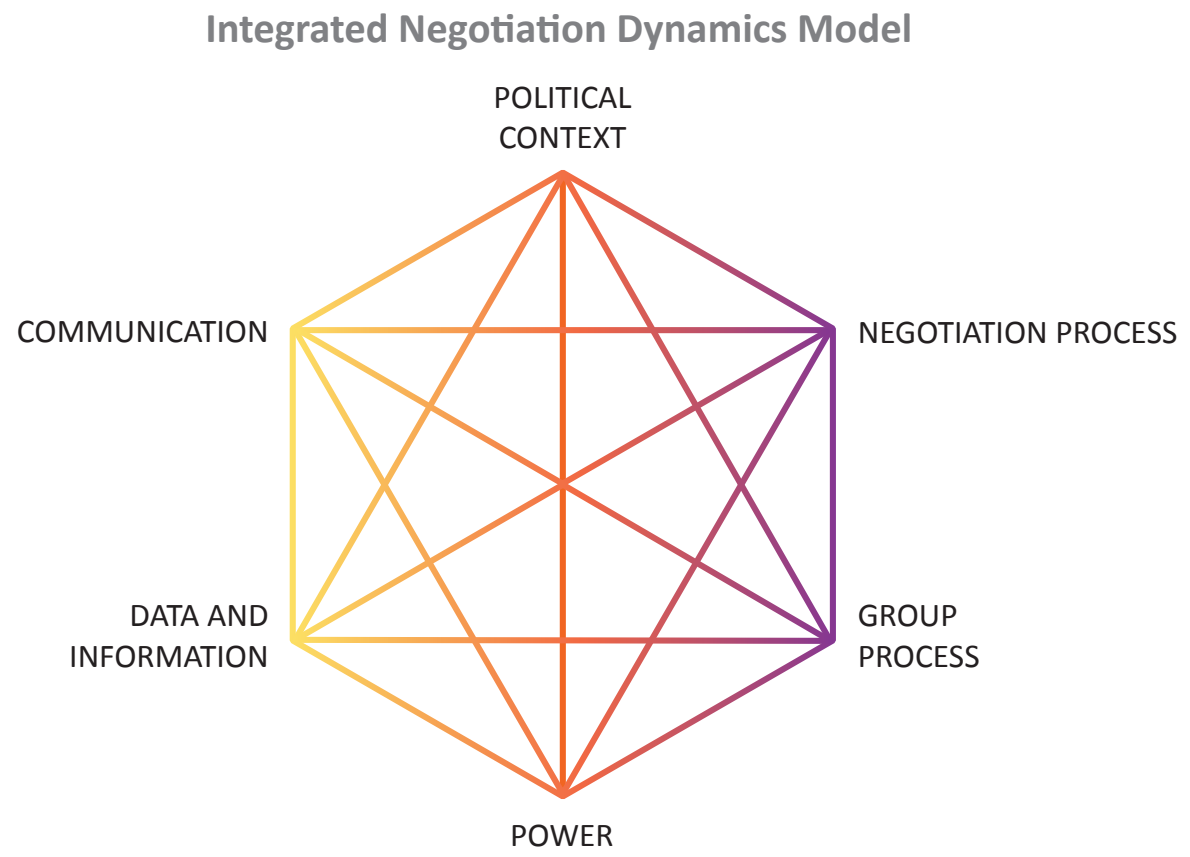

The following sections offer empirical insights on each of the negotiation dynamics within the UNFCCC context. Overall, all respondents indicated that all negotiation dynamics were indeed relevant in the UNFCCC context. Negotiation dynamics' definitions and sub-factors are elaborated below based upon the interview data. A summary of these definitions and subfactors is presented in Table 4. 
Table 4. Summary of Negotiation Dynamic Sub-factors

\begin{tabular}{|c|c|}
\hline Negotiation Dynamic & Sub-factors \\
\hline \multirow{4}{*}{ Political Context } & Domestic \\
\hline & Inter-state \\
\hline & Global \\
\hline & Regime \\
\hline \multirow{3}{*}{ Negotiation Process } & $\begin{array}{l}\text { Substantive issues; how substance is communicated through } \\
\text { negotiation styles; negotiator skills (Policy Dialogue Model) }\end{array}$ \\
\hline & Negotiation Design \\
\hline & Stages of Negotiation \\
\hline \multirow{3}{*}{ Group Process } & Human (individual, not party) relationships \\
\hline & Relationship-building \\
\hline & Trust among individuals \\
\hline \multirow{4}{*}{ Power } & Political (state) \\
\hline & Interpersonal (individual) \\
\hline & Knowledge-based \\
\hline & Procedural \\
\hline \multirow{3}{*}{ Data and Information } & Scientific and Technical \\
\hline & Political \\
\hline & Regime \\
\hline \multirow{3}{*}{ Communication } & Clarity \\
\hline & Listening \\
\hline & Understanding \\
\hline
\end{tabular}


Prominent patterns across the interview data showed that the most enabling negotiation dynamics for reaching agreement in the UNFCCC were Group Process and Communication. The most constraining, or challenging, negotiation dynamics were Political Context and Power. Where the data offered insights on relationships between the negotiation dynamics, this is also described.

\subsubsection{Political Context}

The Policy Dialogue Model's definition of Political Context was also reflected in the data from the UNFCCC context although more nuanced descriptions of different scales of Political Context emerged from the Interview data. These were: 1) domestic; 2) inter-state; 3) global; and 4) regime; all of which are described in turn. The domestic scale Political Context refers to domestic policies and politics on climate change (including constituent sentiments on the subject), which varies widely among the 195 Parties to the UNFCCC. For example, a small island state facing imminent sea level rise has a vastly different political orientation towards addressing climate change than a wealthy oil-producing state with strong economic incentives to continue production and demand for fossil fuels. In the words of one respondent,

Power to determine a COP outcome is different than the base case of geopolitical power, a small island state can be much more powerful and get some countries who have been isolated as more powerful to be less powerful in reaching agreement (Interviews).

Respondents underscored the importance of keeping the domestic Political Context in mind when negotiating in the UNFCCC, specifically when trying to understand another Party's interests. This understanding encompassed relationships between Political Context and three other dynamics. A negotiator's skills to engage with other negotiators reflects the Negotiation Process; building relationships and trust reflects the Group Process dynamic; and leveraging drawing upon available Data and Information.

The inter-state scale of Political Context refers to existing bilateral relationships and alliances. This included non-climate or environment-related alliances such as trade, development, or foreign aid relationships. These existing state-to-state diplomatic relationships are sometimes utilized by countries before and during the UNFCCC negotiation to develop a common position, share intelligence about other countries' positions, and to develop joint negotiating strategies. Even where broader bilateral relationships do not exist, some Parties may find like-minded countries and ways to cooperate towards the same goal in 
the UNFCCC process. While most of the data linked inter-state Political Context to cooperation, there was some evidence that inter-state Political Context is also leveraged to wield power over other parties (e.g., threatening consequences to trade or foreign aid), demonstrating a relationship with the Power dynamic. As observed by respondents,

We also see emerging economies using their positions within the third world and particularly their close relations to see how they can influence the Africa positionsthrough trade and economic relations. Sometimes before COP meetings the developed countries send requests of support through their respective embassies to support their positions in the negotiations (Interviews).

... a [developed country] delegate went to bully a representative from [a developing country] and he wanted to recall to her how much money [the developed country] government gave in foreign aid in reaction to an extreme position by [the developing country] on an issue related to intellectual property (Interviews). ${ }^{29}$

These findings point to relationships between the inter-state Political Context and the skills, tactics, and strategies used in the Negotiation Process dynamic to leverage Power.

The global scale of Political Context encompassed current geopolitics and socio-economic trends such as political instability or economic strife. Major events such as a global economic downturn have had significant influence over the level of interest and ambition in addressing the challenge of climate change. Some respondents indicated that even where other negotiation dynamics seem favorable to supporting agreement, that challenges within the global scale of Political Context would undermine the potential within other negotiation dynamics (Interview Data). As one respondent observed,

...global politics, relationships with trade between developed and developing countries make it difficult to agree on technical issues that we would otherwise be able to reach consensus on if it weren't for international politics (Interviews).

Lastly, the regime Political Context refers to politics of regional groups or negotiating blocs within the UNFCCC process. For example, the regime Political Context within the African

${ }^{29}$ The country names are omitted and replaced with developed and developing country labels in response to a request by the interview respondent that the country names not be used. 
Group $^{30}$ or the between G-77 and China ${ }^{31}$ and the Umbrella Group ${ }^{32}$. These relationships often reflect the domestic and inter-state contexts but also take on their own nuanced, regime Political Context within and between the group settings. In one respondent's observation, Smaller country groups AOSIS ${ }^{33}$ and $L D C S^{34}$ are many and they have an influence. They can probably never force consensus by themselves if China, US, India doesn't [sic] want

30 "The African Group of Negotiators (African Group) was established at COP1 in Berlin, Germany in 1995 as an alliance of African member states that represents the interests of the region in the international climate change negotiations, with a common and unified voice. The Group comprises 54 Parties. The African Group is active in and supportive to all aspects of the climate change negotiating process, for instance regarding vulnerability, mitigation and adaptation to climate change." See: https://unfccc.int/process-and-meetings/partiesnon-party-stakeholders/parties/party-groupings

31 "Developing country Parties generally work through the Group of 77 to establish common negotiating positions. The G-77 was founded in 1964 in the context of the UN Conference on Trade and Development (UNCTAD) and now functions throughout the UN system. As at May 2014, there are 133 members in the Group. The Party holding the Chair of the G-77 in New York (which rotates every year) often speaks for the G77 and China as a whole. However, because the G-77 and China is a diverse group with differing interests on climate change issues, individual developing country Parties also intervene in debates, as do groups within the G-77, such as the African Group, the Small Island Developing States and the group of Least Developed Countries." Ibid.

32 "The Umbrella Group is a coalition of Parties which formed following the adoption of the Kyoto Protocol. The Group is made up of Australia, Belarus, Canada, Iceland, Israel, Japan, New Zealand, Kazakhstan, Norway, the Russian Federation, Ukraine and the United States." Ibid.

${ }^{33}$ AOSIS stands for the Alliance of Small Island States. "AOSIS is a coalition of 44 small island and low-lying coastal developing states, including five observers" and helps to advocate on behalf of small island developing countries (SIDS). See: https://www.aosis.org/about/ The terms AOSIS and SIDS are often used interchangeably by negotiators in the UNFCCC context, although SIDS is the official name of UNFCC Party groupings and is described as, " is a coalition of some 40 low-lying islands, most of which are members of the G-77 that are particularly vulnerable to sea-level rise. SIDS Parties are united by the threat that climate change poses to their survival and frequently adopt a common stance in negotiations." See: https://unfccc.int/process-andmeetings/parties-non-party-stakeholders/parties/party-groupings

${ }^{34}$ The term LDCs refers to "the 48 Parties defined as Least Developed Countries by the UN regularly work together in the wider UN system. They have become increasingly active in the climate change process, often working together to defend their particular interests, for example with regard to vulnerability and adaptation to climate change. Previously there were 49 Parties in the LDCs Group. However, in 2014 Samoa graduated from the LDCs." Ibid. 
it, but they can stop consensus-that's their power. They can say they won't move forward unless some of their issues are dealt with (Interviews).

This illustrates the relationship between regime Political Context and the Group Process dynamic. Findings show that regime Political Context is often, but not always, influenced by outside "real world" politics but that different political alliances and relationships can emerge that do not otherwise exist outside of the UNFCCC context. Historic COP decisions have also illustrated how UNFCCC Political Context differs,

Some people think we did this in Bali-[the] US held objections to outcome until the last minute and then conceded. That demonstrated the most powerful country in the room was isolated by the unique dynamics of the UNFCCC (Interviews).

As evidenced by the findings, there are many different types of 'political contexts' at different scales interacting with each other in the UNFCCC negotiations. The combination of different scales and the interaction between these scales was captured by one negotiator:

[The UNFCCC] is a political process and domestic issues affect the negotiations. It is best if those factors are well understood and open for people to understand, whether it's a trading bloc or a national security issue (Interviews).

\subsubsection{Negotiation Process}

Applying the Policy Dialogue Model to the UNFCCC context informed a name change for this factor from 'Negotiation Dynamics' to 'Negotiation Process'. Ehrmann's definition of Negotiation Dynamics in the Policy Dialogue Model focused on 1) the substantive issues, 2) how the substance is communicated through negotiation styles, and 3) the skills of negotiators. Building upon this, respondents in this study also ascribed the negotiation design and stages of negotiation to the Negotiation Process dynamic. Each dimension of the Negotiation Process from the UNFCCC is described in turn, based upon the interview data. First, respondents emphasized that the substantive issues of the negotiation are diverse in the UNFCCC. Negotiators draw upon different substantive expertise to effectively participate in UNFCCC across different negotiating tracks - for example, energy, transport, deforestation, agriculture, and accounting rules. Having specialized knowledge for each of these within a Party's delegation is resource-intensive and therefore most common among developed nations. Some respondents observed significant imbalances in the level of substantive knowledge negotiators have on the topic at hand.

If you wish to be an active participant, you need to be deeply informed about the subject matter otherwise you don't know what you're agreeing or not agreeing to. If you don't 
want to be an active participant in the meeting, you should listen a lot and support positions that make sense. Don't try to dominate the whole time [with] limited substantive knowledge--it can be disruptive to the process. This happens a lot-when countries have defensive positions it's because they don't know the implications of what's being discussed so they just block (Interviews).

This can lead to inefficient negotiations and lack of movement towards an agreed outcome as some Parties catch up on the substance and/or stall negotiations because they cannot make an informed decision on the topic vis-à-vis their national interests. Specialized knowledge can also wield a lot of influence in the negotiations. In the words of one respondent,

...people with strong tech skills and capacity have had considerable influence in technical negotiations. Other negotiators with less technical skills and knowledge rely a bit on individuals that are technically proficient to build understanding and lead the way. There are sometimes technically competent people who are viewed as honest, objective and credible--not taking political positions. These people are very influential in the long term because they gain the trust of people in the room and can lead the way to find technically sound solutions that will work for everyone in the room (Interviews).

Second, Parties' negotiation style (e.g., interest-based bargaining or positional bargaining ${ }^{35}$ ) was indicated by a majority of interview respondents as most important to reaching agreement. Most respondents stressed the importance of Parties clearly articulating their position on an issue so that others could understand it and work towards compromise. However, several respondents made a clear distinction between a clear articulation of one's position and using a hard-bargaining, positional negotiation style - the latter seen as ineffective in the UNFCCC context due to the consensus-based nature of reaching agreement which depends upon Parties sharing their interests and finding convergence. In the words of one negotiator,

If a party is very firm in its position from the beginning to end, it influences the outcome and dynamics of the negotiations because it means that at some point, each and every party has to give in some of its position to a group in order to reach an outcome. It's always good to hear a lot of parties with clear positions-but then they need to share interests in order to come to consensus (Interviews).

\footnotetext{
${ }^{35}$ Fisher and Ury (2011) distinguish between interest-based and positional-bargaining in the following way: "Your position is something you have decided upon. Your interests are what caused you to so decide." (Fisher and Ury, 2011, pp. 26-27). In other words, a Party's position is often the end outcome they are seeking whereas both/all Parties have underlying interests that inform that position. Uncovering those interests provides more options for identifying common ground across negotiating parties.
} 
Most respondents attributed negotiation style with the negotiating individual, not the country, and some observed that a hard-bargaining style could indicate the negotiator does not adequately understand the substance of the discussion nor realize that taking a hard-lined position could ultimately marginalize that Party in the negotiation (Interviews).

Third, and related to negotiation style, respondents observed that parties' negotiating skills and experience varied widely in the UNFCCC context. Some observed that if a negotiator does not fully know or understand their country's interests on an issue, they may not have a consistent position and/or can be more easily swayed by inter-state or regime Political Context or Power dynamics. Respondents observed this happening most frequently within less-developed country delegations. In addition, the interview data revealed different "types" of negotiator depending on whether their orientation and training is substantively- or diplomatically- oriented. As one respondent described,

There are three types of negotiators--the most successful is the hybrid, you can't be a bull in a china shop and be oblivious to politics. You need to be diplomatic and make your points in a way that can be understood by other diplomats. You can't always be technical otherwise you won't build understanding. In the long run, of the three types of negotiators [diplomat, technical, and hybrid], those who are purely diplomatic may have less influence on the outcomes than you'd think. Some of the solid technical information takes a long time to build understanding and crystallize into policy language people can move forward with but it determines the shape and outcome of the agreements (Interviews).

Fourth, many respondents underscored the importance of negotiation design - a new aspect of the Negotiation Process dynamic. This included: the quality of the venue; the ease of wayfinding in the venue; transportation to/from the negotiations; availability of appropriate food and drink (e.g., taking into account cultural dietary restrictions and preferences); and the important roles of the COP-Presidents, Chairs, Facilitators, and the UNFCCC Secretariat. On the roles of the COP Presidencies, as well as the Chairs, Facilitators, and the UNFCCC Secretariat, many respondents indicated that having capable chairs and facilitators to guide negotiations was a critical element towards reaching agreement. Additionally, the importance of informal discussions at various levels (between individuals, bilaterally, or in "informalinformal" 36 groups) was seen to be a particularly helpful process design element that

\footnotetext{
36 "Informal-informals (also referred to as drafting groups or spin off groups) have been used to troubleshoot a specific problematic issue or advance negotiations on contentious issues, e.g., to draft a specific section of text
} 
facilitated progress by allowing parties to more openly discuss and share their interests on an issue.

Finally, some respondents described a cycle of negotiation as part of the Negotiation Process dynamic (in contrast to the linear process outside of the dynamics, as it was in the Policy Dialogue Model with Convening, Dialogue, Implementation). The cycle begins with parties negotiating to set the agenda, determining boundaries for discussion and how to proceed. Assuming agreement on this, negotiations evolved into in-depth technical discussions that require substantive expertise on the issue at hand. Without agreement, negotiations over the agenda could be prolonged and prevent substantive negotiations on the topic at hand. Some negotiators with experience in implementation (e.g., from developing the phases of a mechanism for reducing emissions from deforestation and degradation [REDD+] or from those involved with negotiating land use accounting rules) described that Parties' implementation experience often informed the next round of negotiations in terms of agenda and substance. As one respondent shared, "...countries may not play a role in shaping the agenda for research but may have rich background from activities on the ground and can use that experience in the negotiations" (Interviews). This experience-driven agenda shaping reflects the ongoing nature of UNFCCC negotiations (in contrast to more limited, time-bound policy dialogues in the Policy Dialogue Model) and reveals a cycle instead of a linear process.

\subsubsection{Group Process}

With the exception of seasoned facilitators and UNFCCC Secretariat staff, few respondents described Group Process as the Policy Dialogue Model did (e.g., small group dynamics, decision-making theory, creation of temporary systems). Instead, respondents underscored the human relations aspect of Group Process. Trust was described as something built across individual relationships and personalities. These relationships allowed negotiators from different backgrounds, cultures, languages, to better understand each other by creating a common 'language' (defined as mutual understanding of terms to avoid using the same terms

or resolve a specific problem. These informal informals are established with the agreement of the group or under presiding officers' own responsibility. The presiding officer may request a delegate to facilitate such meetings, which may be open ended or limited to only those delegates invited to participate." Guide for Presiding

Officers. UNFCCC. 2011. P. 17 
but meaning different things), sharing their respective interests, and fostering trust that they "understand each other's interests and can predict with some confidence the way in which they will behave" (Interview Data). It is worth underscoring that trust was ascribed to individuals not states/parties. Several respondents described trusted relationships emerging between negotiators despite tensions or mistrust between their nation-states (Interviews). One respondent observed there is no trust between countries saying, "the only thing you can trust a country to do is to act in their own national interests, but you can have trust between individuals" (Interviews). Despite this distinction, trusted relationships were described as a means to better understanding Parties' interests, concerns, and motivations - much of which cannot be readily discerned from stated policy positions (Interviews). Several respondents emphasized that a fundamental aspect of trust among individuals was to ensure all Parties negotiate in good faith. Meaning, a party has a genuine interest in reaching agreement and they are not there simply to thwart progress. In one respondent's own words: "Trust is very important because we have to trust in order to reach agreement. If you don't trust, then you won't be negotiating in good faith." (Interviews)

In the Policy Dialogue Model, human relationships comprised one of four aspects of Group Process, but trust did not feature prominently, in contrast to the UNFCCC context. Ehrmann mentions the role of trust between parties and the sometimes-asymmetrical levels of trust built between parties within the dialogue compared to their constituents outside (Ehrmann, 1997 pp. 126-127). Within the UNFCCC context, many respondents emphasized the importance of building relationships and trust in order to make progress in the negotiations and ultimately reach agreement. The roles that relationships and trust have are captured in the following respondent quotes:

A lot of lack of agreement comes from misunderstanding. One side interprets another side's position in a way that's not correct [sic]. Relationships allow a lot of the misunderstanding to be removed - they [negotiators] can ask each other why they are saying $X$, and better understand where they're coming from and respond more effectively (Interviews).

Trust means that national interests and preferences are expressed in such a way that they are open for searching for mutual ground with other countries who present similar views, so the mood is not searching for differences, but rather searching for things that are common and shared among negotiators, as consensus will be located in the space that is common to all the interest (Interviews).

Having trust of colleagues and personal relationships are extremely important [sic]. If you have trust and confidence of colleagues that you will hear their concerns and handle 
information discreetly then you have a full picture of concerns from all groups. Without trust you don't have the full picture (Interviews).

It is also worth noting that only those respondents with an outside vantage point - facilitators, chairs, and UNFCCC Secretariat staff_reflected on the three other aspects of Group Process as defined in the Policy Dialogue Model (small group dynamics, decision-making theory, and creation of temporary systems) which reflects the group as a whole. In contrast, negotiators and observers (non-chair/facilitator) respondents emphasized the role of individuals as UNFCCC chairs and facilitators - citing that many UNFCCC agreements have been shepherded by these individuals. In the UNFCCC context, negotiating tracks are officially chaired by countries, often those that have a moderate amount of power (e.g., Philippines or Argentina) instead of those with a significant amount of power (e.g., US or China). Yet the ability to foster agreement in the UNFCCC was attributed to the efficacy of the individual chair, not the country they represent. For example, as one respondent described, “...UNFCCC history [is] full of agreements facilitated by individuals...much of Kyoto Protocol was Argentina-yet it was individuals, not because Argentina as a country is more effective" (Interview Data).

\subsubsection{Power}

Similar to the original Policy Dialogue Model, most interview respondents described the role of Power in the UNFCCC as an underlying dynamic with multiple facets and layers. Interview data revealed four types of Power in the UNFCCC context: 1) political (state); 2) interpersonal (individual); 3) knowledge-based; and 4) procedural. First, the political power aspect of this dynamic was not purely aligned with existing geopolitical power. Interviewees pointed to variations of political power that are leveraged in the UNFCCC context that are not or cannot be leveraged in other intergovernmental fora. As one interviewee observed, "some countries have been more important in the [UNFCCC] negotiations than their geopolitical position suggests." For example, a small island state that typically does not yield much in the way of traditional geopolitical power can gather significant attention in the UNFCCC context through a charismatic, impassioned individual negotiator that emphasizes their state's unique vulnerabilities to climate change and issues like sea level rise. This increased attention - catalyzed by leveraging individual power - can create a temporary bully pulpit from which a small state can exercise much greater power than it has outside of the UNFCCC context. Another aspect of political power identified from the interview data was 
the ability of some states to leverage state relationships, alliances or power-balances outside of the UNFCCC context in order to influence the way a state or group of states behaved within the UNFCCC. For example, a state with significant foreign direct investment or development assistance within other state could leverage that power differential to influence another state's decision to agree to something in the UNFCCC context. This power is sometimes leveraged outside of the UNFCCC negotiation process. For example, as one leastdeveloped country (LDC) respondent described,

We also see emerging economies using their positions within the third world and particularly their close relations to see how they can influence the Africa positionsthrough trade and economic relations. Sometimes before COP meetings the developed countries send requests of support through their respective embassies to support their positions in the negotiations (Interviews).

This aspect of Power illustrates its relationships with inter-state Political Context and Negotiation Process dynamics.

Second, interview data showed a linkage between political and interpersonal Power. That the creation of political Power can emanate from individual leadership and personality. As one seasoned negotiator described, "I've seen lead negotiators from a country be really effective and then they're replaced and the country gets marginalized because it comes down to an individual capacity, regardless of what a country's position is" (Interviews). Interpersonal power, built on trusted relationships with others, is another aspect of how Power is wielded in the UNFCCC context. As described by one interviewee,

Major economies-China, US, Brazil, EU, India-will always have a lot of influence, but individual countries can also have power with the right individual with the right combination of diplomatic and technical skills who can be unbelievably influential and make things happen (Interviews).

Examples of this type of Power included trusted, well-liked chairs and facilitators that could maintain agreement within a fractioned negotiating bloc or keep negotiators at the table through challenging discussions. These examples demonstrate how interpersonal power links to trust within the Group Process and Negotiation Process dynamics.

Third, many developed country respondents described knowledge-based Power-meaning that some Parties (usually developed countries) have access to Data and Information that others do not; and that some Parties have the resources and capacity to effectively translate information into knowledge among negotiators on their delegation. Some interviewees also 
indicated that knowledge-based Power had the ability to extend far beyond the reaches of that state's delegation and influence the broader UNFCCC community. For example, if a study funded by a particular Party was made public via a report and/or a side event, its findings could be used to inform other states, non-governmental or civil society organizations, and the private sector. How respondents described this 'ripple effect' of knowledge-based Power depended largely on their perceptions of objectivity about where the knowledge originated from and the motivations in making it public. This finding demonstrates a strong relationship between knowledge-based Power and Data and Information dynamics.

Lastly, interview data also revealed procedural Power as another aspect of the Power dynamic. Procedural Power most often plays a role in the agenda-setting (sometimes referred to as pre-negotiations) and decision-making stages. Parties may prevent movement from the agenda-setting stage into the negotiation stage by blocking agreement on an agenda. In the decision-making stage, several seasoned chairs and negotiators pointed out that the UNFCCC rules of procedure on decision-making are still in draft form but described that the de facto way in which decisions are reached is by consensus - defined, in practice, as no Party objecting. The UNFCCC system is structured to provide equal weight to every country; if consensus is de facto practiced as no Party objecting, this translates to all Parties having veto power. Because of this, a small, geopolitically weak state can disproportionately affect the entire outcome of a UNFCCC negotiation session by refusing to agree or abstaining unless their demands are sufficiently met.

The four types of Power identified by respondents - political, interpersonal, knowledgebased, and procedural — relate to other Negotiation Dynamics. Interpersonal Power and knowledge-based Power are leveraged to "produce an intended effect on another" (Rubin and Zartman, 1995, p. 350). By building relationships and trust (part of the Group Process dynamic), individuals are leveraging interpersonal Power. As trust is built, there is greater sharing of information and individuals and increasingly individuals - and the parties they represent - are leveraging knowledge-based Power (related to Data and Information dynamic) to inform their approach to the negotiation. Examples described by respondents indicate political Power and procedural Power are often leveraged by Parties, typically in the final stages of finding common ground and devising an agreement. In addition, political Power often expresses itself as power asymmetries among Parties (e.g., a wealthy developed country Party threatening its development assistance to a poor developing country if they do 
not support the proposal). Whereas procedural Power expresses structural symmetry in that under the UNFCCC, all Parties effectively have veto power to block final agreement. These last two types of power seem to be leveraged against one another in the final throes of Parties trying to reach agreement.

\subsubsection{Data and Information}

All interview respondents strongly emphasized the importance of Data and Information in the UNFCCC negotiation context. In the words of one respondent, Data and Information are significant and equal access among UNFCCC Parties has changed over time,

[Data and Information play] a big role; it's more equal in terms of information because everyone has wi-fi now. It's important but not as important as it used to be. Those who had access to information previously had an advantage but now everyone has access to that info and it's immediately available (Interviews).

However, several respondents cautioned about the veracity of data and information and/or the challenges with varying interpretations or even misinterpretation. As observed by one respondent,

[Data and information play a] ...very powerful role, for better and for worse. If it's factual and not interpreted or miscommunicated, it's extremely important that people are informed. Sometimes data or information is misinterpreted or miscommunicated which is very destructive. It supports a particular position of a Party or group that want to influence in a certain way, and it can be difficult to deal with (Interviews).

Interview analysis revealed three main types of Data and Information: 1) scientific and technical; 2) political; and 3) regime. First, scientific and technical information on climate change informs the substance of the negotiations in the UNFCCC. The Intergovernmental Panel on Climate Change (IPCC) plays a particularly important role in providing trusted, globally derived scientific information on climate. However, there are many other scientific and technical reports on topics within negotiation tracks. Developing country respondents reported experiencing several challenges in interpreting and incorporating this information: determining the degree to which data and information is objective and credible; mistrust of a third party's interpretation of scientific data; and a delegation's and/or negotiator's capacity (or relative lack thereof) to absorb overwhelming amounts of information. Most respondents indicated that parties' capacity to translate information into knowledge was critical to determining what is in their best interest, making informed decisions, and leveraging all of the above to effectively negotiate. In the words of one negotiator, "Science helps enhance our 
common scientific understanding, which gets reflected in our politics. As our understanding of an issue expands...we then start [to] agree on how to resolve that issue" (Interviews). At the same time, scientific and technical information can be apolitical—something that is threatening, as observed by one respondent,

I can see a lot of negotiators, individually, or even countries, feeling very threatened by forums that push ideas on technical grounds that are difficult for them to fight back. It's easier to say, 'I'd rather keep it political'. If it's based on technical then I'm forced to accept them because they're technically correct (Interviews).

Second, political Data and Information emerged from the interviews as a particular type of data, but one that is intimately connected to Political Context and Negotiation Process. Specifically, gathering Data and Information about other Parties' positions, the interests behind those positions, and their domestic Political Contexts was seen as critical to informing the negotiation and beginning to uncover potential common ground. Respondents correlated the gathering of political Data and Information with a negotiator's skills (Negotiation Process) in building relationships and trust with other negotiators (Group Process) from key states (defined as potential allies in the climate negotiations and/or critical for informing their own negotiating strategy). Negotiators' understanding about other Parties' domestic Political Context helped them understand and anticipate underlying interests.

Third, regime Data and Information refers to the UNFCCC processes and procedures (i.e., information and understanding of the UNFCCC as an institution and a process). This type of Data and Information is also connected to negotiators' skills and experience, discussed above in the Negotiation Process dynamic. Based on the interviews, regime Data and Information included understanding: the rules of procedure; how to follow various negotiating tracks and know which issues are being addressed within each of those tracks; and where and how to access draft text, daily agendas, and announcements. Tracking all of this information is incredibly difficult for Parties and their negotiators. In the words of one, developed country respondent:

There are too many meetings, you don't have the time in between meetings, talk to colleagues, stakeholders and have discussions to try to work out how the next meeting will play out. The positions don't have time to change and reflect and absorb and make adjustments. Even if you manage to find time to reflect on your own position and modify your approach you don't have time to let other colleagues know (Interviews).

Seasoned negotiator respondents mentioned the need for all negotiators to understand historical UNFCCC information (e.g., the Articles of the Convention or the process by which 
those Articles were agreed) since these are often referred to in current negotiations. Therefore, understanding them provides valuable context for the discussions at hand (Interviews). It is worth noting that some respondents highlighted the disadvantage newer negotiators have in relation to political and regime Data and Information — citing that some Parties (more often developed country negotiators, according to a respondent) seem to frequently rotate negotiators on or off their delegations. This observation and its potential implications are further explored in the Discussion.

\subsubsection{Communication}

In the Policy Dialogue Model (Policy Dialogue Model), Communication was combined with Data and Information and defined within that context as how data and information is communicated and perceived by negotiation participants. Based on the interview data and the author's own observations of the UNFCCC context, Communication emerged as its own dynamic. Most respondents underscored the importance of communication-defined as clearly communicating, listening, and understanding each other-for helping to find common ground. The latter two (listening and understanding) were most emphasized by seasoned negotiators, chairs/facilitators, and Secretariat staff. As two seasoned UNFCCC negotiators shared,

Communication is very important. First people need to know each other and understand each other's language. This is a result of building relations. If I talk to someone, I understand him more and more, even the way in which he/she formulates opinions, something like psychological features. Without this [individual relationships], negotiations are difficult because of this lack of trust (Interviews).

The communications, relationship building leads to trust. Without communication, there's no relationship, with no relationships, there's no trust. All build on each other (Interviews).

Communication was also frequently linked to other dynamics. For instance, respondents indicated that Communication helped negotiators to: 1) build individual relationships and trust (Group Process), 2) convey their domestic Political Contexts (Political Context), and 3) better understand the interests behind their counterparts' policy positions (Negotiation Process). These linkages indicate that Communication was a cross-cutting dynamic similar to Power, and Data and Information. The majority of those interviewed associated Communication with interpersonal style - elements of the Group Process dynamic. However, respondents also cited Communication linkages with respect to how domestic and global Political Context was communicated, or with how Parties and their negotiators 
communicated and, more importantly, understood others' interests or positions (Negotiation Process dynamic). Even the way in which an individual negotiator communicated could invoke interpersonal Power beyond that of his or her nation-state. A couple of respondents also shared the same example of the importance of communication style - citing a case where there was enough alignment between Parties' positions to find convergence, but the way in which an individual negotiator communicated in the discussion led to significant rifts, thereby stalling agreement (Interviews).

\subsubsection{Negotiation Dynamics and Reaching Agreement}

Respondent data indicated the degree to which a negotiation dynamic was seen as supporting or enabling parties to reach agreement. This yielded identification of both a primary and secondary enabling negotiation dynamic (with all 21 respondents indicating a primary enabling dynamic and 20 identifying a secondary enabling dynamic). In addition, 20 out of 21 respondents also responded to the question by sharing their views on the most constraining dynamic to reaching agreement. See Table 5 for a summary of results across the negotiation dynamics.

Table 5. Respondent Data on Primary-, Secondary- Enabling, and Constraining Negotiation Dynamics

\begin{tabular}{|lcc|c|c|} 
& $\begin{array}{l}\text { Primary } \\
\text { Enabling } \\
\text { Dynamic }\end{array}$ & $\begin{array}{l}\text { Secondary } \\
\text { Enabling } \\
\text { Dynamic }\end{array}$ & $\begin{array}{l}\text { Total Count } \\
\text { for Enabling }\end{array}$ & $\begin{array}{l}\text { Total Count } \\
\text { for Constraining } \\
\text { Dynamic }\end{array}$ \\
\hline Political Context & 3 & 2 & 5 & 10 \\
\hline Negotiation Process & 4 & 6 & 10 & 2 \\
\hline Group Process & 10 & 3 & 13 & 0 \\
\hline Power & 1 & 3 & 4 & 5 \\
\hline Data and Information & 1 & 2 & 3 & 1 \\
\hline Communication & 1 & 6 & 7 & 0 \\
\hline All Dynamics & 2 & 0 & 2 & 2 \\
\hline $\begin{array}{l}\text { Power and Political Context } \\
\text { together }\end{array}$ & 0 & 0 & 0 & 0 \\
\hline \hline
\end{tabular}


Two respondents indicated that all negotiation dynamics were equally important to supporting agreement in the UNFCCC, while two respondents indicated that both Power and Political Context, together, were most constraining to reaching agreement. This relationship between Power and Political Context was also reflected more broadly in the interview data (beyond the duo being constraining) and is explored further in the Discussion section.

While some negotiation dynamics were seen as more important for supporting agreement and some were seen as more challenging to Parties reaching agreement, the interview data indicates that all negotiation dynamics were relevant and played a role in the UNFCCC context. Table 5 shows which negotiation dynamics were cited more frequently in terms of being enabling or constraining. Group Process, Negotiation Process, Communications, and Data and Information were more enabling than constraining to reaching agreement. In particular, Group Process was seen as the primary enabling dynamic to reaching agreement followed by Negotiation Process. On the other hand, Political Context was most constraining followed by Power, and the combination of the two together. Qualitative analysis of the data revealed more nuanced results: 1) how certain aspects of negotiation dynamics play a role in enabling or constraining agreement; and 2) that constraining or enabling effects of some dynamics can change depending on the stage of the negotiation.

First, respondents that identified Group Process as most important emphasized specific aspects of that dynamic — individual relationships and trust — as particularly critical to supporting parties reaching agreement. Respondents that identified Negotiation Process emphasized the need to understand others' interests and in creating a shared understanding of all interests. Axial coding also revealed a set of relationships between negotiation dynamics (and components therein) that indicate a more sequential process of how these dynamics enable agreement. Relationships and trust-building (part of the Group Process dynamic) fostered more open communication and greater sharing of information, especially about parties' interests and domestic Political Context. This provided a foundation for supporting a collective understanding of interests upon which to find common ground for potential agreement.

Second, the enabling and constraining effects of some negotiation dynamics shifted over the course of the negotiation. The prominence of Group Process and Negotiation Process 
dynamics were most attributed to the UNFCCC inter-sessionals, informal processes ${ }^{37}$, and pre-COP negotiations. In these contexts, respondents described the structure of the UNFCCC as more egalitarian among parties. Political Context and Power were seen as the most challenging dynamics in terms of moving forward in the negotiations, finding common ground, and building agreement. In these negotiation settings, when global Political Context and Power dynamics were leveraged by more powerful states, less powerful states resisted because they held the notion that "under this umbrella [of] UNFCCC, I'm just as powerful as you" (Interview Data). In contrast, Political Context and Power were described as becoming at once incredibly challenging but also integral to striking a final deal. Despite the UNFCCC concept of 'one country, one vote, ${ }^{38}$ respondents widely acknowledged that alignment of geopolitically powerful countries' interests was a prerequisite to reaching a final COP agreement. These results reveal two limitations of the enabling effects of Group Process and Negotiation Process dynamics: 1) their role in supporting forward movement in the negotiations is most prominent in non-COP negotiation contexts; and 2) if the global and/or domestic Political Context among major geopolitical powers is not aligned by the time of a COP negotiation and decision, then no amount of prior relationship, trust-building, and favorable Negotiation Process can overcome that.

\subsection{Discussion}

\subsubsection{Constraints of the Policy Dialogue Model}

Based upon the responses provided by interview respondents and the results of the study, Ehrmann's Policy Dialogue Model (1997) proved to be an applicable lens through which to explore the UNFCCC negotiations. The findings provided insights into how negotiation dynamics play out in the UNFCCC including how the model's factors can be refined and defined to reflect that particular context. The resulting Integrated Negotiation Dynamics Model (INDM) still has limitations and areas where additional research may be helpful.

\footnotetext{
${ }^{37}$ Informal processes are those where "the formal Rules of Procedure do not apply and they are not recorded or in any other way treated as part of the formal conference.” pp. 47-48, Manual for UN Delegates: Conference Process, Procedure and Negotiation. https://dx.doi.org/10.18356/385699ed-en

${ }^{38}$ Respondents frequently used the phrase 'one country, one vote' to reflect the nature of UNFCCC decisions which requires consensus, meaning that all parties have to agree even though parties do not actually vote.
} 
These are presented and discussed followed by how key findings relate to the broader literatures.

The results of this study illuminated several constraints of the model, the first of which corresponds to one of the study's most significant findings. First, some of the relationships between dynamics, or aspects therein, that this study uncovered are not readily evident in the visual representation of the model. For example, the finding that trust — an element of the Group Process dynamic - was the most important factor for reaching agreement in the UNFCCC but "trust" is not included in the visual depiction of the INDM, only described as part of Group Process. This seems to reflect the other literatures of international relations, multi-party negotiation, and even SD diplomacy_where trust does not typically play a central theoretical role. This finding's significance is further explored below, following discussion of the model's limitations.

Second, respondents attributed some dynamics or aspects therein (e.g., relationships, trust, interpersonal power) to individual negotiators, not to Parties to the UNFCCC ${ }^{39}$. This finding contrasts many international relations scholars' assumptions about state-to-state negotiations which emphasizes states as bloc entities exercising their geopolitical power (Keohane, 1986) and pursuing national self-interest (Gilpin, 1996) as key factors in whether states reach agreement to cooperate. Respondents' collective definition of trust was imprecise but reflected Kydd's (2005) definition of "a belief about the likely behavior of the other side" (Kydd, 2005, p. 11). Respondents linked the establishment of trust to changes in behavior within other negotiation dynamics: trusted relationships yielded more information sharing between negotiators about their underlying interests, positions, and domestic political contexts (Interviews). In addition, the role of Power in the UNFCCC was sometimes ascribed to the individual (via personality and influence) instead of to the geopolitical power of the state they represented. This result adds another layer of complexity to understanding the

\footnotetext{
39 The term 'Parties' capitalized refers to signatories to the UNFCCC which is different from 'parties' lower case which generically refers to parties or actors that are part of a negotiation.
} 
power dynamics in the UNFCCC, which the existing literature constrains to parties (Zartman, 2002) and "great powers" 40 at the state level (Dimitrov, 2010; Terhalle \& Depledge, 2013).

Third, the research into UNFCCC negotiations revealed more nuanced, human-scale dynamics as critical to reaching agreement among Parties, suggesting that some dynamics are more applicable to individuals than to Parties in the negotiation - again, not something that is visually evident in the INDM depiction. This finding suggests that it is difficult to hold variables constant - negotiators change all the time - which presents challenges for both reaching agreement and studying the UNFCCC negotiations. Further research is needed to determine the degree to which dynamics apply to different scales within the negotiation (e.g., individuals vs. the Parties they represent).

Fourth, respondents often cited the important roles of chairs and facilitators as critical to fostering agreement; however, this is neither explicitly reflected nor explored in the INDM dynamics. Ehrmann's Policy Dialogue Model discussed the roles of third parties (chairs, facilitators) as individuals that can help Parties to better understand each other's positions by clarifying misunderstandings and facilitating the exchange of perspectives (including the context from which that Party is coming from) (Ehrmann, 1997, pp 230-236). In short, third parties can facilitate evolution within and between the dynamics, but the negotiation "system exists independently of the intervenor" (Ehrmann, 1997 p. 231 citing Argyris, 1979 p. 15).

Finally, relationships uncovered between dynamics are evidence-based in the UNFCCC context but may not translate universally, as they may depend upon the negotiation context. Related to this, more research is needed to determine broader theoretical application beyond the UNFCCC to other Sustainable Development Goals' negotiation contexts in light of the notion that all SDGs are "integrated and indivisible" (United Nations General Assembly, 2015).

\subsubsection{Discussion of Main Findings}

Overall, the results showed that: 1) all the factors within the Policy Dialogue Model were relevant and applicable for understanding the UNFCCC negotiations; 2) there are nuanced aspects within each negotiation dynamic - some of which reveal different ways in which that

\footnotetext{
${ }^{40}$ Within the UNFCCC context, Dimitrov (2010) defines these as the United States, China, India, and Brazil whereas Terhalle and Depledge (2013) describe "great-power politics" as between the US and China.
} 
dynamic plays a role in the negotiations (e.g., knowledge-based vs. process Power); and 3) the relationships between dimensions of the Policy Dialogue Model were applicable and several more relationships were identified in the UNFCCC context. Three main findings are discussed here in greater detail. First, the discussion will explore the emphasis that respondents placed on relationships and trust which contrasts with the emphasis that IR and negotiation theorists place on power and politics. Second, discussion on the findings that Power and Political Context were seen as overall constraining to negotiations and to reaching agreement. And last, a discussion on relationships between the negotiation dynamics illuminated by the results.

That respondent data indicated relevance of all factors in the UNFCCC negotiations contrasts with international relations (IR) literature, which focuses on particular aspects of negotiation dynamics (e.g., Power) but discounts the role and importance of other dynamics and aspects therein. Neorealists emphasize inter-state and global aspects of Political Context as well as political Power but neglect the roles of domestic and regime Political Context (Gilpin, 1996; Mearsheimer, 2001). Neoliberals emphasize interdependency between states via economic, corporate, and organizational ties which show degrees of complexity beyond a unified state (Keohane \& Nye, 2011) but lacks understanding of how complex those state-to-state relations can become at individual (negotiator) levels.

Multi-party negotiation theorists provide different approaches to analyzing the complexity that multiparty negotiation contexts present (Zartman, 2002; Crump 2015). As noted in Chapter 1, there is a high degree of commonality among those approaches but based upon the empirical findings of the research reflected in this chapter, existing multiparty analysis frameworks either omit key dynamics or aggregate them in such a way as to lose the distinction and understanding of how that dynamic and aspects therein contribute to the negotiation and resulting outcome(s). Zartman (2002), for example, emphasizes distribution of power, party strategies, behavior (defined as "characteristics of the actors and their interaction in the negotiation process" Zartman, 2002, p. 11), outcomes, and process. This analytical approach does not include analysis of the negotiation context, data and information, communications, or the relationships between individuals as negotiators, only their behavior as negotiators. Crump, on the other hand, does include context, power relationships, and communication patterns in his analytical framework (2015). Yet, relationship analysis is limited to power relations and communication patterns (Crump, 
2015), and fails to recognize that power is not only a function of relationships and that relationships are not only a function of power.

The results of this study have shown a much more nuanced understanding of how relationships and power function in the UNFCCC, separately, and together. In addition, communications were shown to be critically linked to the transmission of (Political) context, data and information, parties' interests and positions, and also include understanding of what is being communicated, beyond the patterns of party communication. In addition, Crump (2015) notes that more research is needed to "establish relationships among key negotiation variables" (Crump, 2015, p. 150).

\subsubsection{Relationships and Trust}

The results showed that nearly half of respondents emphasized individual relationships and trust, part of the Group Process dynamic (Ehrmann, 1997, p. 126), as most important for reaching agreement in the UNFCCC context. Respondents indicated that trust is based upon interpersonal relationships and individual personalities - reiterating the way in which this aspect of Group Process was described in the Policy Dialogue Model (Ehrmann, 1997). In the development of Ehrmann's original Policy Dialogue Model, the Group Process dimension was indicated as the least understood by those involved in a policy dialogue. In this study, many respondents emphasized certain aspects of group process such as interpersonal relationships, trust and interpersonal communication style. Aside from Chairs, Facilitators, and Secretariat staff, negotiators placed little emphasis on Group Process elements Ehrmann defined in the Policy Dialogue Model such as 'small group dynamics and decision-making theory, [and] the creation and dynamics of temporary systems...' (Ehrmann, 1997: 103). It is important to note that the relationship-building and trust aspects of Group Process do not account for the fact that the individuals involved in the UNFCCC negotiation (e.g., negotiators, Chairs, Facilitators, and UNFCCC Secretariat staff) change over time. Relationships, trust, and interpersonal communication can be rebuilt anew, but they may differ significantly from previous relationships.

From the vantage points of international relations (IR) and multi-party negotiation disciplines, the significant role trust played in reaching agreement would seem unexpected, or at least typically discounted. Trust is infrequently mentioned in the literatures of international relations (Hoffman, 2002; Kydd, 2005) and multi-party negotiation (Zartman, 1989) especially where these literatures focus on climate change (Vogler, 2009). While 
relationships and trust are emphasized in broader diplomacy literature ${ }^{41}$, this relationshiptrust dynamic is not included in the SD diplomacy literature (Kjellén, 2008; Moomaw et al. 2017). Trust does play a more central role in conflict resolution literature (Ehrmann, 1997) especially in relation to sustainable development negotiations (H. Saunders, 2009; Schultz et al., 2018) which is discussed further in section 2.5.4. As a main finding of the study, the relationships and trust aspect of the Group Process dynamic are explored across each of the literatures, in turn.

International relations (IR) literature on climate change focuses on trust in relation to compliance (technical and legal) to the negotiated agreement (Vogler, 2009) as opposed to the role trust plays in reaching agreement. Compliance-related mistrust emerges over the 'free rider' problem (Keohane, 2014; Stavins, 2011; Vogler, 2009)—meaning that states benefit from the implemented outcome but do not contribute to achieving that outcome (Stavins, 2011; Keohane, 2014). More broadly in IR theory, trust has been scarcely explored outside a few scholars which focus on the nation-state (Kydd, 2005; Hoffman, 2002; ) or on "leaders enacting policies that delegate control over their states' interests based upon the belief that those interests will not be harmed" (Hoffman, 2002, p. 377). Prisoner's dilemmatype models popular with IR realists (Grieco, 1988) are typically employed to assess trust yet "fail to provide an adequate framework for understanding trust" (Kydd 2005, p. 9). There are many examples of parties opting for "mutual cooperation" instead of "exploiting the other side's cooperation" (Kydd, 2005, p. 10). This cooperation, Kydd argues, hinges upon "a belief about the likely behavior of the other side" $(2005$, p. 11). Yet this this conception of trust also implies a third component of behavior: Hardin posits "...that trust is never unconditional, that it always implies a three-party relation, as in "A trusts B to do x..." (Hardin, 1998, p. 12). This is especially true where parties have a continuous (rather than one-time) relationship: choosing exploitative behavior over cooperation breeds fear of future retaliation (Kydd, 2005, p. 10). Put another way, parties have an interest in the future of the

\footnotetext{
${ }^{41}$ Broader diplomacy literature does include individual relationships and trust; however, the emphasis is on the individual role rather than the dynamics of the negotiation itself. The emphasis of this study was on the negotiation dynamics rather than the role of negotiators/diplomats in them. Therefore, it drew from international relations (IR), multi-party negotiation, and conflict resolution literatures. However, some of the results underscored the importance of individuals. This finding reinforces diplomacy literature, incidentally, but is a contribution to IR and multi-party negotiation literatures, in particular.
} 
relationship. Aside from these few scholars, IR literature neglects relationships and trust cultivated between individual negotiators (not states or political leaders) — one of the reasons this study's finding was unexpected. Yet this finding reinforces the argument that a more integrated, multi-disciplinary model for understanding the UNFCCC negotiations is needed. Within the multi-party negotiations literature, few scholars (Chasek \& Wagner, 2016; Crump, 2015; Zartman, 1989) emphasize the role of trust in reaching agreement, but they describe more human-scale dimensions of it than international relations literature. Crump (2015) only briefly touches on trust, noting that relationships between parties are more complex than simple power dynamics; they include communication and the degree of "trust [in leaders of a negotiation which] can be highly significant to negotiation dynamics" (Crump, 2015; p. 140). Zartman argues that trust appears most prominently in the pre-negotiation stage which is described as a "...period of transition that enables parties to move from conflicting perceptions and behaviors (unilateral attempts at solutions) to co-operative perceptions and behaviors" (Zartman, 1989, p. 243). In contrast, Wagner and Chasek (2016) focus on the important role that trust played in negotiating the Sustainable Development Goals (SDGs), saying that from the start of those negotiations, there was a deficit of trust. "Long-standing inequality" bred inherent mistrust between North and South countries (Wagner and Chasek, 2016, p. 405). Overcoming this required trusted, skilled Chairs to provide leadership combined with "stocktaking" of scientific evidence to ensure trusted, credible data and information were the basis of negotiations (Wagner and Chasek, 2016 p. 406). In conflict resolution, this practice is often referred to as "joint fact-finding" (Ehrmann and Stinson, 1999 pp. 376-377). Echoing Hoffman's (2002) argument that trust between parties requires a third-party, the absence of trust in negotiating the SDGs (SDG 13 being Climate Action) required trust to be built externally, starting with the leadership of third-party Chairs and by developing scientifically credible third-party evidence. In the UNFCCC context, respondents described trust as emerging from relationships between individual negotiators and among groups of negotiators. In contrast to the SDG negotiations, UNFCCC Chairs and facilitators helped navigate Parties through negotiations and towards agreement—but trust in their leadership was not a substitute for negotiators' trust in each other (to behave in a cooperative way).

Conflict resolution literature describes trust as resulting from relationship-building. Conflict resolution scholars describe the symbiotic nature of relationship-building and 
sharing/learning information about where the other side is coming from (Ehrmann, 1997; Schultz et al. 2018). The conflict resolution dialogue setting contrasts with that of intergovernmental negotiations. In a conflict resolution setting, relationship-building and sharing information is associated with the dialogue process itself through fostering exchange and promoting 'transformative social learning' about parties' interests (Schultz et al. 2018). In contrast, conflict resolution scholars argue that a negotiation setting promotes positional approaches and over-emphasizes outcomes, perpetuating political power dynamics and neglecting the transformative influence of relationship-building and collective learning that can occur in a conflict resolution dialogue setting (Saunders 2009 p.377).

In developing the Policy Dialogue Model, Ehrmann describes "the role of trust or lack thereof between individuals...can be significant." (1997, p. 126). Yet the formation of relationships and trust between individuals may be distinct from the degree to which they agree with each other (Ehrmann, 1997 p. 126-127). Trust can create pathways to explore a substantive issue or idea "because they trust their counterpoint in the process" which may contrast with the negotiator's broader constituent sentiments since their constituents do not share that relationship or trust (Ehrmann, 1997 p. 126-127). These observations from the Policy Dialogue Model context were also echoed in this study's results focused on the UNFCCC: relationships and trust may evolve among individuals even when the Parties they represent lack such relationships and trust.

\subsubsection{Political Context and Power}

In terms of the most constraining dynamics, roughly half of respondents saw Political Context as most constraining followed by Power; two respondents felt that Political Context and Power were equally constraining dynamics. Each of the dynamic's results is discussed separately in turn, then together to explore the relationship between them in the UNFCCC context.

Considering the level of attention that geopolitics and power receive in the literatures of international relations (Gilpin, 1996; Mearsheimer, 2001), it was expected that negotiators, Chairs, Facilitators, and Secretariat Staff of the UNFCCC would have indicated these dynamics as prevalent throughout the negotiations and emphasized their role in terms of reaching agreement. This is perhaps due to the differentiated nature of the non-COP negotiations where respondents described more informal individual interaction focused on understanding the issues and each other's interests; whereas COP negotiations are more 
formal state-to-state interactions focused on countries' positions, especially leading to the point where ministers are involved. In order to build relationships, gain each other's trust, and understand parties' interests in the inter-sessionals, negotiators are less inclined to leverage their country's political standing and power. Yet in the context of high-stakes, final dealmaking negotiations, these dynamics are utilized to reach agreement. Although, as the data has shown, this is not always reflective of the broader geopolitical context of power distribution. Powerful individual personalities from small, geopolitically weak states can wield significant power in the final throes of reaching a COP agreement.

It was unexpected (although understandable) that the constraining effects of Political Context and Power were mainly ascribed to UNFCCC $\mathrm{COP}^{42}$ negotiations as opposed to all UNFCCC negotiations (or 'non-COP negotiations'). COP negotiations are the final negotiation for that year and are attended by ministers (and sometimes even heads of state ${ }^{43}$ ).

Power, especially in the context of a negotiation such as the UNFCCC, is an incredibly complex dynamic that most likely cannot be fully described or encapsulated beyond the macro-level aspects of how it plays out in relation to other negotiation dynamics. There are many definitions and theories of power from both international relations and multi-party negotiation disciplines. The model and the empirical research did not attempt to develop a clear-cut definition of Power in the UNFCCC context. It aimed to explore what Power meant to those involved in the negotiations; and whether and how the Power negotiation dynamic relates to other dynamics. These relationships are further explored in the next section (2.5.3).

\subsubsection{Relationships Between Dynamics}

The data showed that building relationships and trust among negotiators leads to greater sharing of data and information about a Party's interests, position, and domestic political context, and thus increased the significance of the Data and Information dynamic. This

\footnotetext{
${ }^{42}$ UNFCCC Conference of the Parties (COP) negotiations happen once annually. Leading up to the annual COP negotiations are a series of supporting 'intersessional negotiations' which are termed here 'non-COP negotiations'.

${ }^{43}$ For instance, COP-15 in Copenhagen was attended by heads of state. The final negotiated outcome, The Copenhagen Accord (FCCC/CP/2009/11/Add.1 30 March 2010), was also negotiated by a subset of heads of state (Dimitrov, 2010).
} 
sharing of data and information and subsequent relationship- and trust-building enables a clearer understanding of potential common ground among Parties - key factors in reaching agreement. While these results illustrate a chain of reaction starting with relationships and trust among individuals, neither the respondents nor this author are under the illusion that relationships and trust alone can lead to agreement in future UNFCCC negotiations or unlock all negotiation challenges. Indeed, even if individual relationships and trust led to sharing of interests and positions at the UNFCCC Party level, there is still no guarantee that there would be common ground upon which to build agreement. If individual negotiators were able to build relationships and trust, this may be indicative of an enabling Political Context dynamic, otherwise governments would instruct their negotiators to avoid productive negotiations, thereby blocking progress. The relationships between the dynamics uncovered in this study closely correlate to the social constructivist theory of international relations: that states' interests are informed, created, and transformed through the process of interacting with other states in the negotiation process (Wendt, 1992). While social constructivism is still statecentric, it emphasizes social interaction - again something that occurs at the human-scale amongst individuals which may be an overlooked aspect of social constructivist theory. This result demonstrates a chain of relationships between those dynamics (and parts therein), that help Parties to reach agreement. Figure 4 provides a basic illustration of these relationships between dynamics articulated in the results although the author notes that Negotiation Dynamic relationships are not linear. 
Figure 4. Illustrative Negotiation Dynamic Relationships

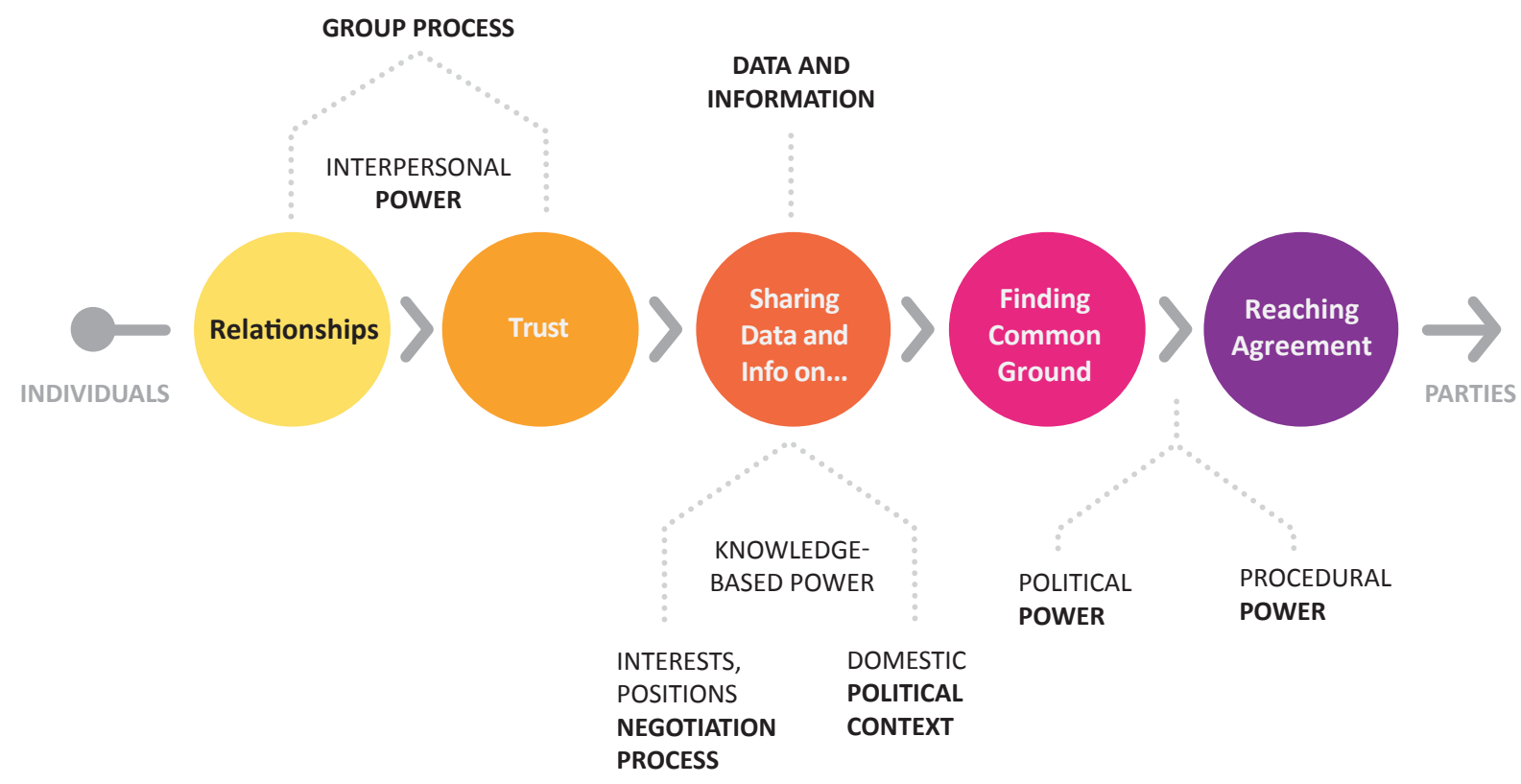

Figure 4 provides a simplistic illustration of negotiation dynamic relationships that help enable agreement, recognizing that these are not typically unidirectional or linear in negotiations. In addition to this chain of relationships, results demonstrated Power as a central, crosscutting dynamic and revealed several different types and uses of power in the UNFCCC context while simultaneously highlighting important relationships and linkages between power and all other dimensions of the INDM. Thereby, validating both the existence of those other dynamics and providing insights on the relationships between power and other negotiation dynamic variables. However, more research is needed to develop a comprehensive definition of the Power dynamic and aspects therein to determine whether and how that definition changes depending on the multilateral negotiation context. For example, a state with significant foreign direct investment or development assistance within other state could leverage that power differential to influence another state's decision to agree to something in the UNFCCC context.

The process of party interaction to establish shared understanding of a problem, a common and trusted set of data and information, and the influence this interaction has on parties' interests and identities has been well documented by social constructivists (Checkel, 1998; Pettenger, 2013; Wendt, 1992, 1994; Young, 2001). While this dimension of the model and 
this study's evidenced-based definition seems to point to those social interactions and constructions, that aspect of the model could be further explored through subsequent research. Similar to the constraints of the group process dynamic, it is important to recall that within an intergovernmental context like the UNFCCC, negotiators, chairs, and facilitators are constantly changing. Experienced negotiators, chairs, and facilitators leave, and new ones take their place. New replacements often lack fundamental resources available to their predecessor: trusted relationships with other Parties, knowledge of available data and information, where to access that information, what information to trust, and regime information about how the UNFCCC negotiation process works. Therefore, it is important to recognize the fluidity of these negotiation dynamics when applying the model descriptively or diagnostically to a multilateral negotiation.

\subsubsection{Contributions to Sustainable Development (SD) Diplomacy}

The concept of SD diplomacy is aimed at positively redefining the problem (e.g., climate change) as a Sustainable Development Goal (Moomaw et al. 2017). Moomaw and Papa (2012) argue that for climate change, the UNFCCC is "negotiating the wrong treaty" because it is problem-centric on air pollution rather than solution-centric around sustainable development opportunities. The present author fully subscribes to this argument and idea. However, there is a reality of existing institutions and negotiation processes to contend with. This paper focused on exploring and understanding the key variables of the UNFCCC negotiations in an effort to draw upon those insights to strengthen SD diplomacy, especially in contexts where mutual gains may be more challenging to achieve.

In contributing to SD diplomacy, the results illuminate the role of relationships and trust as a critical aspect to consider in developing new approaches to sustainable development (SD diplomacy). While SD diplomacy scholars do not focus on trust and relationships explicitly, their reframing of sustainable development as a beneficial opportunity (win-win) for countries instead of a zero-sum or win-lose prospect helps foster trust and collaboration within sustainable development negotiations. This was evidenced by the Paris Agreement (United Nations, 2015). Parties to the UNFCCC spent over 20 years negotiating to reach a comprehensive agreement (History of the Convention $\mid$ UNFCCC, n.d.) (comprehensive 
defined as covering all Parties ${ }^{44}$; the Kyoto Protocol covered developed countries but omitted the United States). In the lead-up to the Paris Agreement, the concept of Intended NationallyDetermined Contributions (INDCs) was agreed (United Nations, 2015) — this reframed Parties' emissions reductions as voluntary, self-determined, and inclusive of all member states (United Nations, 2015). Instead of continuing positional negotiations on which countries should contribute, how much, and whether contributions would be legally binding or not, Parties reframed the problem of climate change as a goal to spur collective climate action. This structural shift in the negotiations reflects a more SD diplomacy-like approach (Moomaw et al. 2017), by putting the responsibility on Parties to deliver their own results rather than to seek concessions from each other for an outcome. It also set the expectation that all Parties would contribute, thereby preventing the distrust that arises from positional negotiations about which Parties should contribute what.

In contrast with SD diplomacy's mutual gains approach, the Climate Change Convention (UNFCCC) was negotiated under the auspices of the United Nations - a forum that includes 197 countries (Parties $\mid$ UNFCCC, 2018). Ongoing negotiations about specific parts of the Climate Convention (e.g., sectoral approaches, legal status, accounting rules) occur in an environment where Parties are already at the table. Parties are negotiating because it is in their national interest to do so as UN member states (History of the Convention | UNFCCC, n.d.), not because they volunteered for a mutually beneficial solution on climate change in cooperation with other Parties. Many Parties and scholars have long viewed the solution to the problem of climate change as a threat to their country's economic development and prosperity (Keohane \& Oppenheimer, 2016; Stavins, 2011; Wood, 2011). The transition from pre-negotiation to negotiation that Zartman (1989) describes does not fully apply to the UNFCCC context. Parties have self-interest in participating in the UN process but have not necessarily agreed to do so in good faith towards a solution to the problem, if they have calculated that climate change is a better outcome than the costs of addressing it (Keohane \& Oppenheimer, 2016; Wood, 2011). SD diplomacy diagnostics overlook this predicamentlong cited in IR literature-when they call for a mutual gains approach to negotiations-

\footnotetext{
${ }^{44}$ It is important to note that the Paris Agreement covered all UNFCCC Parties up until November 2019, when the US. Trump Administration began the process of withdrawal. Since the 2020 US election, the Biden Administration has recommitted to the Paris Climate Accord.
} 
making an assumption that this is always possible to implement or that Parties are negotiating in good faith. At the same time, assignment of trust to the pre-negotiation phase and the ongoing testing and "reaffirmation" of that transition (Zartman, 1989, p. 243) seems to echo this study's finding that negotiations in the UNFCCC context are cyclical, not purely linear.

\subsection{Conclusion}

The aim in applying this model to the UNFCCC context was to offer an improved understanding of the key dynamics of that negotiation. Employing the Policy Dialogue Model to the UNFCCC negotiations provided a new perspective on multiple aspects of how dynamics in the negotiation relate to one another and to reaching agreement. As this chapter has shown, and forthcoming case studies will further explore, the Integrated Negotiation Dynamics Model (INDM) provides both descriptive and diagnostic capabilities for improving understanding of the dynamics in a negotiation and how those variables interact to support agreement.

Recognizing that IR theory is more about state-to-state relations than particular treaty negotiations, and that multi-party negotiation literature is specifically focused on negotiation variables, this chapter demonstrates the importance of taking an integrative approach to understanding intergovernmental negotiations such as those under the UNFCCC. It is not that either of those schools is incorrect in how they interpret intergovernmental negotiations, it is that they are incomplete.

The INDM introduced in this chapter provides a means to examine the nuances of Political Context, Negotiation Process, the process by which groups operate (Group Process) and communicate (Communication), as well as the underlying influences of Power and the role of Data and Information. In this way, the integrated model, originating from the field of conflict resolution, aims to offer a synthesis of key dynamics within two mainstream perspectives: IR and multi-party negotiation theory. In doing so, it provides new perspectives for understanding how the UNFCCC negotiation process works.

The result is a revised conceptual framework: the Integrated Negotiation Dynamics Model (INDM), which is grounded in empirical evidence and applicable to intergovernmental negotiations such as the UNFCCC. The study also yielded several lessons for describing the negotiation dynamics and for diagnosing challenges in the UNFCCC. For example, the INDM provides a way of interpreting complex negotiations through improved understanding 
of key dynamics and how they relate to one another. This could help UNFCCC chairs, facilitators, and negotiators better diagnose and interpret what is happening in the negotiation and to adjust their interventions accordingly.

While there are naturally dominant forces such as Power and Political Context, in intergovernmental negotiations such as the UNFCCC, greater understanding and utilization of other negotiation dynamics can help to overcome some of the challenges presented by Political Context and Power dynamics. This will be explored in greater detail through specific case studies. Moreover, drawing upon other negotiation dynamics such as Group Process, Communication, and Data and Information can shift the overall process from that of a distributive negotiation to an integrative negotiation by identifying more options and exploring ways for parties to mutually gain from the negotiated outcome. This improved understanding of dynamics and nuances therein contributes to the evolution of SD diplomacy approaches by highlighting areas of importance that need to be considered.

The end result, an Integrated Negotiation Dynamics Model (INDM), is still a work in progress and would benefit from broader empirical applications and development. It is intended to be both a descriptive and a diagnostic model for examining and better understanding the key dynamics of the UNFCCC negotiations. In this research, the model is only applied to the context of the UNFCCC. However, it has been designed, at least theoretically, to be applicable in other intergovernmental negotiation processes.

\subsubsection{Areas for Further Research}

Individual leadership including chairing and facilitation of negotiation sessions, permanent bodies and negotiating blocs was seen as crucial to enabling progress in the negotiations and the ability for parties to reach agreement. There are many different scales within which the INDM could be applied and how those different scale applications interact with each other, which has the greatest influence in the ability for the UNFCCC negotiation process - and comparable processes - to make progress or reach consensus decisions is still unclear. Further empirical research would be useful for understanding how the INDM applies within and across different scales in the UNFCCC process such as permanent bodies or specific negotiating tracks. 


\section{ChAPTER 3 | ANALYZING THE NEGOTIATION DyNAMICS LEADING TO THE PROMINENCE OF FORESTS IN THE PARIS AGREEMENT OF THE UNITED NATIONS FRAMEWORK CONVENTION ON CLIMATE CHANGE*}

This chapter is based upon the below cited paper which was modified from the original publication for the purposes of this thesis in the following ways: 1) the result section was elaborated since there were no word count constraints; 2 ) some wording was edited for clarification to the reader and to integrate it as a thesis chapter rather than an independent study; and 3) repetition between chapters was minimized, for instance, removing the overview of the Policy Dialogue Model across multiple chapters.

Buckley, K., El-Lakany, H., and Arts, B. (2018). Analyzing the Negotiation Dynamics Leading to the Prominence of Forests in the Paris Agreement of the UN Framework Convention on Climate Change. Journal Of Arbitration And Mediation, 7(1), pp. 95127. 


\subsection{Introduction}

Forests, covering nearly one-third of the earth's terrestrial surface, have always been regarded as an essential natural heritage, important for sustaining the livelihoods of billions of people, and vital for stabilizing the global environment. They account for almost half the terrestrial carbon pool and thus play a significant role in regulating the earth's climate. Tropical forests are particularly important in the global carbon budget because they contain as much carbon in their vegetation and soils as temperate and boreal forests combined. Forest disturbances - mostly through deforestation-therefore have serious economic, environmental and social consequences, including accounting for a significant portion of annual global greenhouse gas (GHG) emissions (IPCC, 2019).

Over the last three decades, a variety of international actors attempted to implement, monitor, and enforce forest-related agreements aiming at better forest protection and sustainable use of forest resources around the globe, but the lack of coordination capacity and mechanisms has resulted in a suboptimal system of global forest governance. Hoogeveen and Verkooijen (2010) concluded that foremost of the challenges for global forest governance are: 1) complexity of issues, inter-linkages, fragmentation and proliferations of arenas; 2) complexity of actors, lack of cooperation and coordination; and 3) complexity of instruments and lack of implementation. Nevertheless, the debate continued unabated around three interrelated focal areas encompassing the system of global forest governance: issues, actors, and institutions.

The last decade of the $20^{\text {th }}$ century witnessed growing interests in curbing deforestation as a cost-effective mitigation option for climate change. Curbing deforestation also emerged as a potential development opportunity, since it would provide additional financial resources for national governments and local communities to invest in health, education, and sustainable development (Eliasch, 2008; Lubowski, 2008; Stern, 2007). Ultimately, a framework for 
reducing emissions from deforestation and degradation (REDD +$)^{45}$ was adopted in the Paris Agreement (United Nations, 2015) under the United Nations Convention on Climate Change (UNFCCC) which, among other things, is arguably one of the most advanced international forestry-related agreements. ${ }^{46}$

In comparison to other greenhouse gas emitting sectors such as energy, transportation, and agriculture, forests and REDD+ featured most prominently in the Paris Agreement. This was a result of over eight years of intergovernmental REDD+ negotiations under the UNFCCC and a host of supporting REDD+ forums and processes (Roelfsema et al., 2015), which are termed in this study as parallel complementary initiatives (PCIs). As the results will show, PCIs can be further categorized into early implementation platforms (EIPs) (e.g., the Forest Carbon Partnership Facility, UN-REDD Programme, among others) and informal policy dialogues (IPDs) (e.g., REDD+ Options Assessment Report consultations). ${ }^{47}$

To demonstrate the geo-political, socio-economic, technical, and financial complexities of reaching an agreement on REDD+, it is worth noting some of the major topics of negotiation. These included (Hufty \& Haakenstad, 2011): 1) baseline, or the level of emissions that would occur in the absence of a forest carbon policy and that is used as a reference case for

\footnotetext{
45 The internationally agreed definition of REDD+ is "Reducing emissions from deforestation and forest degradation in developing countries; and the role of conservation, sustainable management of forests and enhancement of forest carbon stocks in developing countries". For a short history of the framework see: Den Besten, J.W.; Arts, B.J.M. and Verkooijen, P. (2014). The evolution of REDD+: An analysis of discursiveinstitutional dynamics. Environmental Science and Policy 35 (1). - p. 40-48.
}

\footnotetext{
${ }^{46}$ Article 5 of the Paris Agreement states that "Parties should take action to conserve and enhance as appropriate, sinks and reservoirs of GHGs as referred to in Convention Article 4.1(d) including forests;" and, "Parties are encouraged to take action to implement and support, including through results-based payments, the existing framework as set out in related guidance and decisions already agreed under the Convention for policy approaches and positive incentives for activities relating to REDD+, and alternative policy approaches, such as joint mitigation and adaptation approaches for the integral and sustainable management of forests, while reaffirming the importance of incentivizing, as appropriate, non-carbon benefits associated with such approaches".

${ }^{47}$ Between 2009-2017, the author's organization of employment, Meridian Institute, conducted 20 consultations to inform a set of Options Assessment Reports on REDD+ and other land use related policy topics under the
} UNFCCC. See: https://merid.org/case-study/redd-options-assessments/ 
quantifying mitigation performance; 2) monitoring, reporting, and verification (MRV), verifying how much carbon is sequestered and the effective reduction of deforestation); and 3) scale, the REDD+ mechanism would mainly follow a national or country-driven approach but projects would nevertheless be "sub-national".

Other topics of negotiation were: 1) Leakage, a situation in which deforestation avoided in one area results in deforestation in another, whether within or between countries; 2) Additionality, reduction in deforestation should be greater than what would have occurred otherwise, without REDD+ in place; 3) Permanence, the maintenance of forests and their carbon sequestration capacities over time; 4) Governance, the design of the mechanism at all levels, norms-setting procedures, related legal and informal institutional arrangements, and interactions between involved state and non-state actors; and 5) Safeguards, or social aspects such as conflict over local and community land tenure, Indigenous peoples' rights, restricted access to forest resources, and unfair distribution of carbon revenues. Finally, Funding proved to be one of the most contentious issues throughout REDD+ negotiations as the annual costs for halving emissions from forests could be in the range of US\$7 to \$33 billion, which tropical forested developing countries would receive for their efforts to reduce deforestation (Eliasch, 2008).

\subsection{Objectives, Integrated Negotiation Dynamics Model (INDM), and}

\section{Rationale}

Considering the complexity of addressing the multifaceted nature of reducing emissions from deforestation and degradation in light of its prominence in the Paris Agreement, this chapter aims to better understand the REDD+ negotiations and supporting REDD+ processes in an integrated manner by applying the multidisciplinary INDM introduced in Chapter 2. The chapter aims to identify the relative degree to which negotiation dynamics (or variables) constrain and enable collective agreements on forests and the REDD+ mechanism. This includes identifying relationships between those dynamics (i.e., which variables were more constraining or enabling than others, and how certain variables were leveraged to overcome challenges in others). The chapter also explores the relationships between intergovernmental negotiations on REDD+ under the UNFCCC and PCIs that served to inform and support the UNFCCC negotiations. In doing so, it addresses RQ2: How did negotiation factors enable or 
constrain multi-actor agreements in REDD+ negotiations and supporting multi-stakeholder REDD+ processes?

The chapter uses a multi-modal method, drawing from: survey data; interview data; practitioner observations based on the authors' collective professional and scientific experience with UNFCCC processes; relevant UNFCCC negotiation and decision texts as well as stakeholders' views on the negotiations; and from documentation of multi-stakeholder processes on REDD+. The chapter again employed the Integrated Negotiation Dynamics Model (INDM) comprised of six dynamics: Political Context, Power, Negotiation Process, Group Process, Data and Information, and Communication (see Figure 3).

The INDM provides a systematic and integrated way of understanding main negotiation dynamics and the relationships between them, as shown in Chapter 2. The model was previously applied in intergovernmental negotiations under the UNFCCC. Therefore, the INDM seemed an appropriate model for analyzing the negotiation dynamics involved in the process of informing, supporting, and negotiating an agreement on REDD+.

Since the INDM includes factors that are also prevalent in international relations (e.g., politics, power) and international negotiations (e.g., Negotiation Process and Group Process) literature, it can provide a synthesized, multidisciplinary perspective to understanding the primary dynamics involved in a negotiation context such as that of REDD+. Moreover, the model can be used to analyze the relationships between negotiation dynamics, including their relative influence as constraining or enabling on the ability to reach agreement. The model can also provide insights on whether and how some dynamics can be drawn upon to overcome challenges in others. In contrast to leading international relations theories such as neoliberalism or neorealism that focus on one or two key variables of state-to-state interaction (e.g., balance of power, self-interest), the INDM examines a more diverse range of factors. The model was applied to the REDD+ negotiation context to understand those dynamics' relative significance in relation to reaching a negotiated agreement.

\subsection{Methods}

The research employs a multi-modal method, drawing from: an online survey; interview data; practitioner observations; relevant UNFCCC negotiation and decision texts on REDD+; and documentation of multi-stakeholder REDD+ processes. This chapter represents a second case 
study in the nested case study approach employed in the thesis overall, as described in Chapter 1.

For the survey, 51 individuals from diverse backgrounds, geographies, roles, and areas of expertise were invited to respond to an online survey. These individuals were also intimately involved with REDD+ negotiations, parallel complementary initiatives (PCIs), or both. The survey was comprised of nine questions, which were a mix of multiple choice, using a 5point Likert scale, and open-ended formats. The 5-point Likert scale questions asked respondents to rank each dynamic from 1 to 5 in terms of which dynamics were the most challenging (1) to reaching agreement; and which dynamics most contributed (1) to reaching agreement for reaching agreement on establishing a REDD+ mechanism (COP-16 Cancún) and reaching consensus on forests and REDD+ in the Paris Agreement (COP-21). The Likert scale survey questions imposed a forced ranking; participants could not indicate that all or some negotiation dynamics were equally constraining or enabling. However, each question included a comment box and respondents were encouraged to share their perspective and experience.

Respondents were asked to rank the dynamics in both the UNFCCC REDD+ negotiation context and in REDD+ processes external to the UNFCCC negotiation context (parallel complementary initiatives, or PCIs). While PCIs do not represent negotiations, per se, the INDM evolved from a model intended to describe informal policy dialogues, not intergovernmental negotiations, and is therefore also applicable to the PCI context.

Respondents were asked: to indicate their affiliation(s) with the REDD+ informal processes ${ }^{48}$ and formal negotiations over the last five years; to provide their views on which negotiation dynamics presented the greatest challenge for parties' ability to reach agreement within intergovernmental and multi-stakeholder negotiations; which negotiation dynamics most contributed to parties ${ }^{\prime 49}$ ability to reach agreement within intergovernmental and multi-

\footnotetext{
${ }^{48}$ Informal processes referring to multi-stakeholder processes such as FCPF, UN-REDD Programme, and informal policy dialogues. The terms 'formal' and 'informal' were later clarified as 'intergovernmental' and multi-stakeholder' since 'informal-informal' meetings can also happen within intergovernmental negotiation settings.

${ }^{49}$ Here, the term 'parties' in lower case refers to both Parties to the UNFCCC negotiating REDD+ and parties to non-UNFCCC negotiations and processes on REDD+.
} 
stakeholder negotiations to describe the relationships between the dynamics they viewed as most dominant; and to indicate the level of import and influence that REDD+ processes had on parties' ability to reach agreement on REDD+ within the formal UNFCCC negotiations. The 5-point Likert scale ratings were each assigned a weight (a rank of $1=5$ points for most constraining to reaching agreement; and a rank of $5=1$ point for most enabling to reaching agreement). There was also a 'not applicable' choice, which was not counted in graphical presentation of the results to avoid skewing the box plots and because the answer choice was between 1-5 and did not include a ' 0 '. However, responses of 'not applicable' were qualitatively analyzed in conjunction with the respondent's comments. Responses to the Likert scale questions were entered into Excel; weighted accordingly, and plotted on a box and whisker graph for the purposes of graphically presenting them (Potter, 2006) since this only requires an $\mathrm{N}=5$ (Krzywinski \& Altman, 2014). Open-ended responses and comments were analyzed individually, within the context of the respondent's other answers, with the aim of collecting additional insights as to their ranking of the negotiation dynamics, whether they disagreed with any of the given dynamics or definitions, and to determine any additional dynamics the respondent may have identified.

In addition to the surveys, 60-90-minute semi-structured interviews were conducted with three of the most involved people over the course of the eight years of REDD+ negotiations. Interviews were conducted via Skype and notes were recorded into Microsoft OneNote. Interview respondents each played multiple roles - from UNFCCC Secretariat staff, REDD+ negotiation facilitators, PCI participants, and UNFCCC observers, to REDD+ Indigenous Peoples representatives. In addition, practitioner observations draw from the author's professional and scientific experiences attending UNFCCC meetings and from observing UNFCCC negotiations, REDD+ Partnership meetings, REDD+ side events, and from convening and facilitating informal policy dialogues among UNFCCC negotiators (including those involved in REDD+), experts, civil society, and multilateral institutions. Practitioner observations are identified as such in the results section in order to distinguish them from the survey and interview data. 


\subsection{Results}

Of the 51 people invited to participate in the online survey, 12 responded. Although the response rate was $l o w^{50}$, all respondents volunteered their identity in their survey response, which enabled the authors to determine that the 11 respondents were some of the most involved in the evolution of REDD+ since its inception. A majority of respondents played significant leadership roles within the UNFCCC REDD+ negotiations as negotiators, facilitators, or as UNFCCC Secretariat supporting the REDD+ negotiations. All respondents were also actively engaged in one or more of the parallel complementary initiatives (PCIs). As a result, this group of respondents includes some of the most knowledgeable experts on the topic of REDD+ within both the UNFCCC negotiation and PCI contexts. Therefore, while this study's findings are based on a small sample, respondents represent a select group of highly experienced climate change negotiators and observers, which is itself more valuable than an extensive sample of people who have limited experience, knowledge, and insight about the REDD+ negotiations and supporting processes. Additionally, the results draw upon the practitioner experiences and observations of the researcher and her collaborator(s) - as observers and researchers of the evolution of REDD+ policy and practice, and as professionals that contributed to a number of PCIs.

\subsubsection{Within the UNFCCC REDD+ Negotiation Context}

The results showed that political context, negotiation process, group process, and power have been more constraining than other factors such as data and information, and communication (see Figure 5 below). While the mean scores across those four dynamics are similar, it is worth noting that the majority of respondents indicated that Political Context, in particular, ranked as $\geq 3$ out of 5 , making its overall ranking the most constraining dynamic within the UNFCCC REDD+ negotiation context. Similarly, the majority of respondents converged around negotiation process as the second most constraining dynamic. Whereas there is

\footnotetext{
${ }^{50}$ Although it is impossible to know for sure why the response rate was low, it seems likely that a significant reason was that this group of individuals involved in REDD+ are in high demand, many of them playing multiple roles in their ministries and organizations and doing frequent international travel. Those that responded were most integrally involved in the REDD+ negotiations and supporting processes and despite their busy schedules, perhaps they saw merit in contributing to research about the REDD+ negotiation process.
} 
greater distribution within the group process dynamic, indicating there was less agreement among respondents as to how constraining that variable was. In contrast, there was more agreement among respondents on data and information being one of the least constraining negotiation dynamics within the UNFCCC REDD+ negotiation context. Respondents also indicated Communication was less constraining, but with more divergence on its relative placement. Overall, it is possible to see a distinction between the top four ranked dynamics, and the bottom two, in terms of how constraining each were in this context.

Figure 5. Constraining Negotiation Dynamics within UNFCCC- Range and Distribution Constraining Negotiation Dynamics within UNFCCC—Range and Distribution

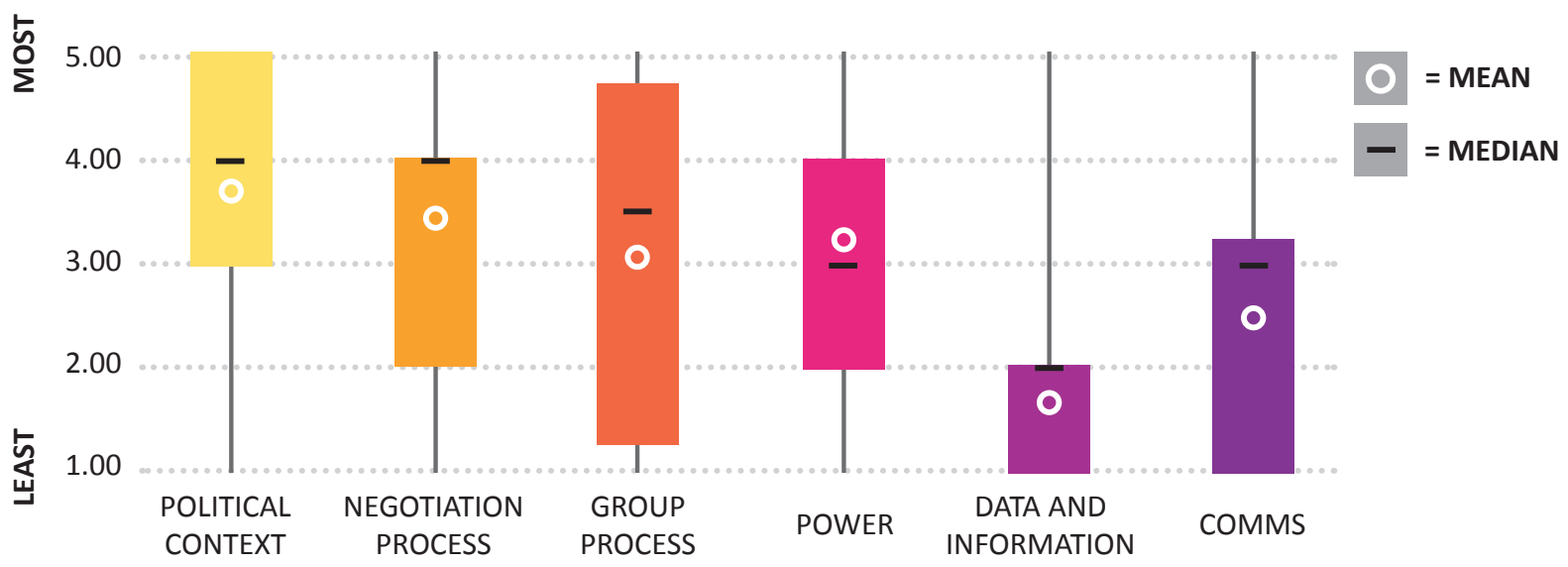

In addition to the Likert scale questions, respondents were able to elaborate on their rankings and provide additional insights on the negotiation dynamics within the UNFCCC REDD+ context. One respondent observed that in the lead up to the Paris COP-21 negotiation,

the biggest issue...was how prominently REDD+ should be in the Paris Agreement. Some countries thought implicit references were sufficient while others wanted explicit mentions of REDD+/land use/forests...some Parties (donor countries mainly) [indicated] that REDD+ was finished and the focus should be on other other issues. Others (REDD+ countries) felt that [REDD] was not yet finished and they needed $R E D D+$ to be part of the Paris Agreement for political reasons, as a way to justify to their domestic constituencies [emphasis added] (Survey Results).

Other respondents explained that the Political Context around REDD+ was often weighed down by various domestic expectations and perceptions around REDD+ financing both among donor countries and REDD+ countries (Interview Data). Another respondent that identified as scientific expert spoke to the relationship between Political Context and Data and Information, saying, "[Political Context] not surprisingly was the most challenging, but 
that is always the case. As someone who works on trying to make data and information easily accessible and transparent, it is disappointing how little data and information is used to actually make political deals" (Survey Results).

In relation to both Negotiation Process and Power, several respondents and interviewees mentioned the role of the Coalition for Rainforest Nations (CfRN, an intergovernmental organization established by tropic forest countries) as being a significant constraint within the REDD+ UNFCCC negotiations (and within the PCI context, discussed below). In particular, respondents cited CfRN's power, its ability to control the REDD+ agenda, and its role in setting REDD+ countries' domestic political orientation to the issues (Survey and Interview Data). One interview respondent reflected that the symmetrical power structure within the UNFCCC (typically referred to as "one-country, one-vote" 51 ) catalyzed coalition building with the aim of creating a more asymmetrical power balance. A "one-country, one-vote power struggle led in many ways to the construction of coalitions such as CfRN as a way to exercise greater power as a coalition than any one country could exercise alone" (Interview Data). This result demonstrates how a shift in the negotiation process including party groupings or coalitions and their respective negotiating tactics can influence the overall negotiation and in particular, the power dynamics.

While there was greater divergence among respondents about Group Process' relative rank as a constraining factor, respondents elaborated on some of those Group Process constraints. For instance, one respondent cited personality clashes and gaming negotiation tactics that "destroyed significant trust..." and "inserted ill-will into the process." (Survey Results). Another explained that the group of REDD+ negotiators had worked together for over a decade and therefore knew each other well. Over the course of that decade, some negotiators had destroyed their relationships and trustworthiness with the group and as a result, many of their interventions, even if a "good proposal or compromise," were viewed suspiciously and often dismissed (Survey Results).

Figure 6 below illustrates that Group Process and Political Context were the most enabling factors. There was a greater range of opinions about how enabling the negotiation process

\footnotetext{
${ }^{51}$ While Parties to the UNFCCC do not 'vote' on decisions, under the United Nations framework, the power structure was referred to as symmetrical in comparison with 'real world' power outside of the UNFCCC.
} 
dynamic was, but the mean followed closely behind Group Process and Political Context. It is also worth noting that in Figure 6, there was significant divergence on the relative importance of 5 out of 6 factors, with a high degree of convergence on the placement of power in relation to the other negotiation dynamics.

\section{Figure 6. Enabling Negotiation Dynamics within UNFCCC- Range and Distribution}

\section{Enabling Negotiation Dynamics within UNFCCC- Range and Distribution}

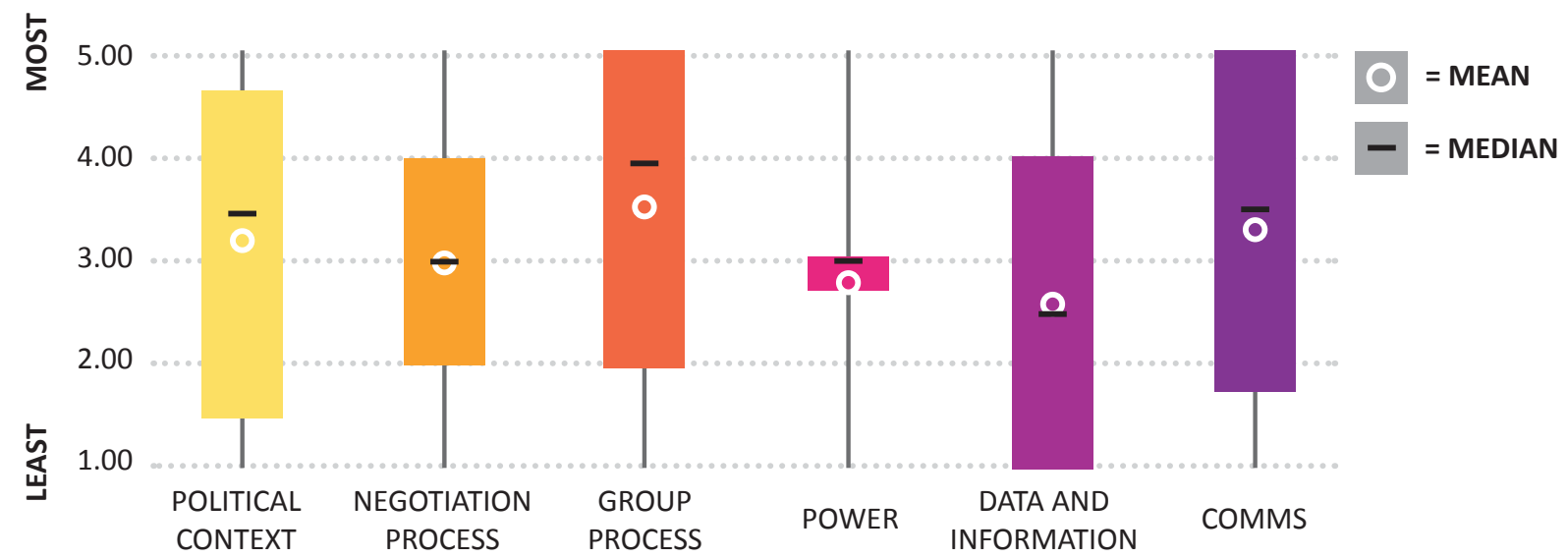

Respondents also elaborated on some of the enabling elements of certain negotiation dynamics. Many survey and interview respondents underscored the Group Process elements of the role of the REDD+ chairs and facilitators to guide, push, and pull parties to reach consensus (Interview and Survey Results). Others reflected that despite a few challenging individual personalities, the stable base of negotiators kept REDD+ on track over the years, due to the relationships built over time- "one of the main benefits of good interpersonal relations and trust was that it allowed the process to move more quickly" (Survey Results). This also contributed to REDD+ negotiators' familiarity with other aspects of the negotiation such as the various domestic Political Contexts and also their understanding of relevant REDD + policy and technical Data and Information (Survey Results). As a partial explanation for the Data and Information negotiation dynamic's ascent as enabling within the PCI context, several interviewees observed that the availability and credibility of data and information on REDD+ from various PCI and IPD forums led respondents to rank it as less constraining and more enabling vis-à-vis the other negotiation dynamics. One survey respondent observed,

By the time the negotiations were closer to Paris, the data and information available to make an informed decision about REDD was already there for negotiators to have a 
clearer idea of what they wanted to achieve. A sign of that is the large number of countries including forests within their INDCs [Intended Nationally Determined Contributions $]^{52}$ (Survey Results).

Several other respondents elaborated on the complexity of the Political Context dimension and provided observations that elements of Political Context served as a strong motivating factor for reaching agreement. For example, "the high level political profiling of REDD + at several COPs served as a strong incentive for the negotiators to succeed in reaching an agreement" combined with "a significant desire to see the negotiations advance with all parties making commitments, which contributed to REDD+ being seen as a key part of that equation" (Survey Results).

The ability for REDD+ to create its own unique negotiation dyanmics compared to most other negotiation tracks in the UNFCCC was both an anomaly and a critical aspect of parties' ability to reach agreement on it. In the words of one respondent, "it was in a way remarkable that REDD + made the amount of progress it did even during COP-15 when talk about mitigation in developing countries [Political Context] was a no-go in almost all other negotiation rooms" (Survey Results). As another respondent observed, this was in part because REDD+ was negotiated "by a group of negotiators that focused on a specific topic which seemed to separate from the bigger picture negotiations" (Survey Results). Even though the Political Context for REDD+ was constraining for reaching an agreement, there were other enabling negotiation dynamics that allowed the REDD+ Political Context to diverge from that of the broader UNFCCC negotiations.

Comparing negotiation dynamics between Figures 5 and 6, Group Process was more enabling than constraining. Overall compared to other negotiation dynamics, Group Process was most enabling factor to parties' ability to reach agreement. Negotiation Process and Political Context were slightly more constraining than enabling, and respondents converged more on

\footnotetext{
${ }^{52}$ Intended Nationally Determined Contributions (INDCs) were part of the UNFCCC COP 20 Decision and refer to "common but differentiated responsibilities and respective capabilities, in light of different national circumstances" and that INDCs represent additional national efforts to meet the objective of the Convention as outlined in Article 2 (See: FCCC/CP/2014/10/Add.1). Also see UNFCCC Article 2: "The ultimate objective of this Convention and any related legal instruments...is to achieve...stabilization of greenhouse gas concentrations in the atmosphere at a level that would prevent dangerous anthropogenic interference with the climate system.” UNFCCC, Article 2, p. 4).
} 
the constraining than on the enabling side of both factors. The mean scores for Power were equally constraining and enabling, whereas Data and Information were more enabling than constraining for reaching agreement. Communication was both least constraining and least enabling as a negotiation dynamic within the UNFCCC REDD+ context. As a partial explanation for this result, one interviewee reflected that "negotiators had a lot of communication vehicles... [including] opportunities to mingle, have bilaterals, and group discussions. [Communication]...was so pervasive...that it was taken for granted" (Interview Data).

\subsubsection{Processes Outside of the UNFCCC REDD+ Negotiation Context}

This section describes the most constraining and enabling negotiation dynamics in REDD+ related processes outside of the UNFCCC REDD+ context (e.g., UN-REDD Programme, Forest Carbon Partnership Facility, among others). Recall that while REDD+ processes outside of the UNFCCC context were not reaching international negotiated legal text, they were still discussing and negotiating around early implementation of REDD+ pilots, projects, accounting and reporting requirements, safeguards, and financing - all of which served to advance REDD+ implementation in-country and to inform the REDD+ international policy negotiations.

Figure 7 shows that overall, there were higher degrees of convergence among respondents, with the exception of negotiation process. Political context, indicated by all respondents as $\geq 3$, was the most constraining dynamic, followed by power. In contrast, there were similar mean scores for negotiation process, group process, data and information, and communication. 
Figure 7. Constraining Negotiation Dynamics in REDD+ processes outside the UNFCCC- Range and Distribution

\section{Constraining Negotiation Dynamics in REDD+ processes outside the UNFCCC- Range and Distribution}

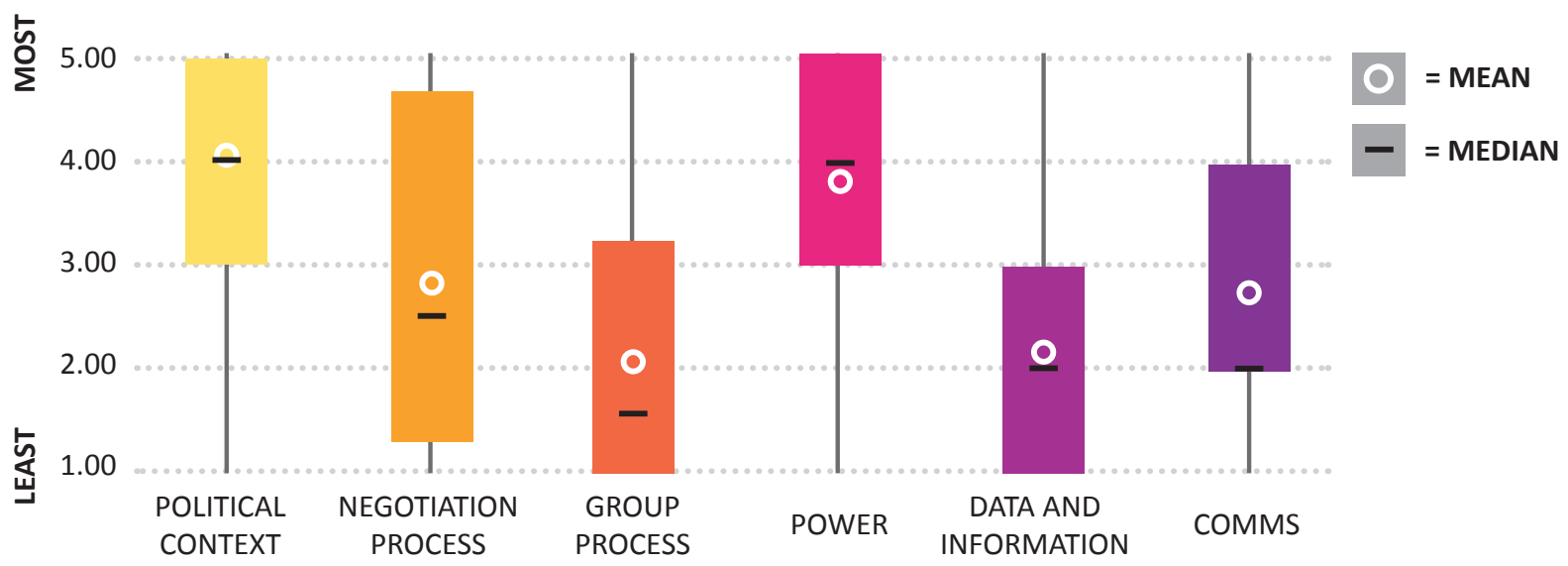

The survey comments provided additional insights into the ranking results. In relation to Political Context, one REDD+ country respondent explained that the biggest constraint was national contexts, specifically their lack of capacity to follow REDD+ in various forums and changes in REDD+ country governments and within their national REDD+ teams (Survey Results). In relation to the constraining nature of the Power dynamic, one respondent reflected that in PCI processes, "the traditional donor-recipient dynamic and power imbalance was more common" than in the UNFCCC (Survey Results).

On the constraining nature of Political Context and Power, one respondent observed, "negotiators representing donor countries... were under political pressure from NGOs to increase demands [for reducing deforestation]. In some cases, donors and international NGOs could use [the Political Context in PCIs] to press for things that were impossible to achieve in the UNFCCC process" (Survey Results). Another interview respondent reflected that donor countries had a lot of money and power and utilized PCIs as opportunities to articulate their expectations of REDD+ countries without fully understanding their domestic political contexts and challenges playing out among "actors on the ground" (Interview Data). Several survey respondents observed that CfRN translated the same negotiating tactics they used in the UNFCCC REDD+ context into PCI forums, which caused constraints within several negotiation dynamics. As one respondent described, "CfRN used their power and disruptive negotiating tactics to try to direct resources to coalition members" which "only created 
distrust, frustration, and delayed decision-making within [the] UN-REDD Programme and REDD+ Partnership" (Survey Results).

A couple interviewees distinguished between constraining dynamics in different PCIs. One person observed the same participants attending different PCI meetings in succession would approach them with completely different negotiation tactics. In FCPF, one respondent observed, participants would be more collaborative and interest-based. In other forums such as UN-REDD Programme, the same participants would switch to more positional negotiating tactics, which dramatically changed the Political Context and Power balance by focusing discussion on contentious issues such as finance. Participants also shifted the balance of power from leading REDD+ countries (in the FCPF) to all potential REDD+ countries by reflecting the views of the political coalitions that existed under the UNFCCC (Interview Data).

As shown in Figure 8, it is evident that Group Process was the most enabling negotiation dynamic in REDD+ processes outside of the UNFCCC, with most respondents selecting it as $\geq 3$. Data and Information ranked second and, compared to its relative insignificance within the UNFCCC REDD+ negotiation context, one can conclude that Data and Information was much more important as an enabling dynamic in REDD+ processes outside the UNFCCC negotiation context than inside the REDD+ UNFCCC negotiations.

Negotiation Process was the least enabling for reaching agreement within those REDD+ processes (the majority choosing values $\leq 2$ ), with some respondents indicating in their comments that the negotiation process dynamic was less relevant in processes outside of the intergovernmental REDD+ negotiations, which were, by nature, more technical discussions than political negotiations. Compared with Figure 4, Political Context and Power were more constraining than enabling in REDD+ processes outside the UNFCCC. 
Figure 8. Enabling Negotiation Dynamics in REDD+ processes outside the UNFCCC Range and Distribution

Enabling Negotiation Dynamics in REDD+ processes outside the UNFCCC - Range and Distribution

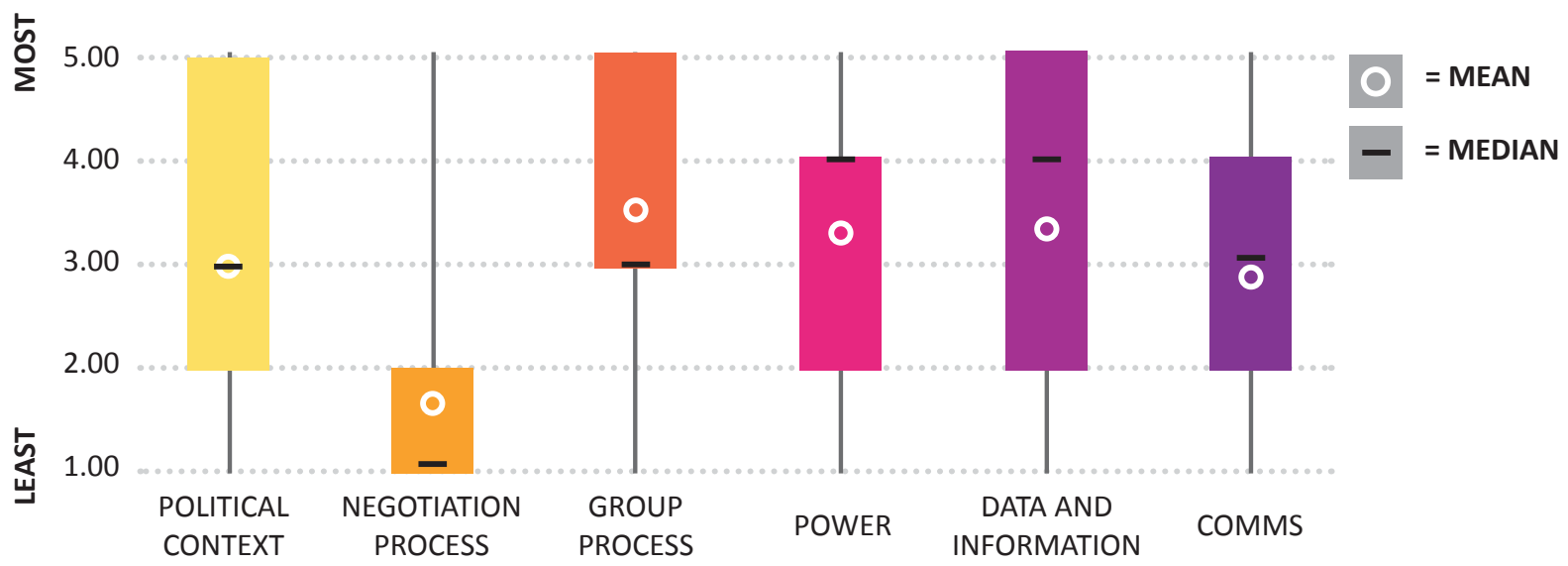

In addition to the rankings, many respondents provided supplementary comments describing the dynamics outside of the UNFCCC REDD+ context and on the roles of external REDD+ processes (PCIs and IPDs). As a partial explanation for why Group Process was considered most enabling within the PCI context, a couple of respondents indicated that "overall, personal relationships amongst the players built during non-negotiation events and activities [PCIs] contributed to overcoming challenges" (Survey Results) and that the PCIs "had a virtue of mingling and mixing of the factions that allowed countries to engage in different ways and in mini-coalitions" (Interview Data). In relation to Data and Information, a couple respondents also indicated that PCIs provided information about early implementation of REDD+ (Interview Data) and "gave the REDD+ countries first-hand experience in what they were signing up [for] and how difficult it could be" (Survey Results).

Several survey respondents and interviewees also referred to PCIs as creating "communities of practice" (further explored in the section on roles of PCIs) for REDD+ which contributed in particular to relationship- and trust-building (Group Process) and the exchange and exploration of data and information (Survey Results and Interview Data).

\subsubsection{Degree to which Parallel Complementary Initiatives were Important and Influential for the REDD+ Negotiations under the UNFCCC}

Survey respondents were also asked to indicate the degree to which PCIs were important and influential to parties' ability to reach agreement on REDD+ within the UNFCCC 
negotiations. Half of respondents indicated PCIs were very important and influential, and the other half thought PCIs were somewhat important and influential. No respondent indicated that PCIs were not important nor influential, meaning that all of the respondents indicated PCIs were either very or somewhat important and influential to parties' ability to reach agreement within the UNFCCC negotiations (Survey Results).

Overall, on the role of PCIs in relation to the formal REDD+ negotiations, one respondent stated, "REDD+ was not growing out of a single forum. It was negotiated in a multiplicity of forums" (Interview Data). Others highlighted that PCIs "facilitate[d] communication and access to credible information/data" (Survey Results). Several other respondents went further to reference and describe these initiatives as creating "communities of practice" (Survey Results), noting that those that participated in PCIs - the REDD+ country focal points, were often also the REDD+ UNFCCC negotiator. "As such they were also involved in other processes (FCPF, UN-REDD, REDD+ Partnership) and had therefore developed a community of practice that enabled them to trust each other and have a common language" (Survey Results). Another respondent described several negotiation dynamics within the PCI context and how those PCI dynamics contributed to the UNFCCC REDD+ negotiation context, as follows:

While support provided by the multilateral initiatives [PCIs] can be criticized... [Political Context] would have been even worse if everything came directly from the donor countries... [PCIs] provided a ...coherent framework and a platform for discussion among countries, which to a large degree were represented in participant committee/policy boards by their REDD + negotiators.... this also helped form [a more] united group of REDD+ negotiators [Group Process]-something that other UNFCCC negotiating tracks lack. The ability to have so much dialogue [Communication] was very helpful. [Participants] still had different views but at least there was good understanding of those different views [Negotiation Process] and this meant negotiators did not come unprepared to negotiations, but already had... a picture of a possible solution (Interview Data).

Comments in the survey and interview results also provided a greater articulation of the nuance within the broad spectrum of PCIs. The first sub-category was referred to by several respondents as "early implementation platforms (EIPs) of an international agreement" (Interview Data). EIPs include the Forest Carbon Partnership Facility, UN-REDD 
Programme, and the Forest Investment Program (FIP) ${ }^{53}$ (Interview Data). EIPs were "not informal negotiations but de facto, they were informal negotiation spaces" (Interview Data) and they challenged participants to translate the high-level discussions on REDD + in the UNFCCC into something that was operational in order to "reality test" those ideas in practice (Interview Data). Another interview respondent who played many different roles throughout the evolution of REDD+ observed that one of the most unique aspects of the relationship between EIPs and the formal REDD+ negotiations was that EIPs provided early and ongoing in-country pilot demonstrations which, in turn, helped to inform multlateral regulations and create a global "umbrella" in order for pilots to have global impact (Interview Data). This observation helps to explain why Data and Information ranked the highest as an enabling dynamic within the PCI context.

The second sub-category of PCI respondents identified in the qualitative survey responses and interviews was informal policy dialogues (IPDs; in some cases called multi-stakeholder dialogues or processes) (Susskind et al., 2003). This was already known by the authors as a process-type, but the interviews served to further define it vis-à-vis other REDD+ processes. IPDs differed from early implementation platforms (EIPs) and multi-stakeholder dialogues in that they provided a space for REDD+ negotiators to meet informally in their personal, unofficial capacities. The IPD context was reported to enhance the relationship and trust elements of the Group Process dynamic; IPDs also enabled more open communication about a party's interests (reflecting the Communication and Negotiation Process dynamics). Since in the REDD+ context, IPDs did not often involve "a range of interest group representatives" (Susskind et al., 2003) they are considered distinct from multi-stakeholder dialogues (MSDs). The study revealed several important distinctions between EIPs and IPDs. First, IPDs were not an institutionalized or long-term process (Practitioner Observations). They were temporary processes aimed at exploring a specific topic or set of questions that were

\footnotetext{
53 The Forest Investment Program (FIP) “supports developing countries' efforts to reduce deforestation and forest degradation (REDD) and promotes sustainable forest management that leads to emission reductions and the protection of carbon reservoirs. It achieves this by providing scaled-up financing to developing countries for readiness reforms and public and private investments, identified through national REDD readiness or equivalent strategies". See: https://climatefundsupdate.org/the-funds/forest-investment-program/
} 
particularly salient and timely in relation to the REDD+ negotiations under the UNFCCC (Practitioner Observations). Second, IPDs focused on:

conceputal clarity and robustness by facilitating "thorough, open discussion...on the nuance of issues, which was more profound than any of the discussions within [the EIPS]. The...consideration of those options was critical for the negotiations to at least understand the caveats of what they [parties] were opting for (Interview Data).

Third, participants engaged in their personal, individual capacities, not in their official government or negotiator roles, which lessened the constraining effects of Political Context and Power dynamics seen in EIPs and the UNFCCC negotiation setting. Further, dialogues were conducted under the Chatham House rule: "participants are free to use the information received, but neither the identity nor the affiliation of the speaker(s), nor that of any other participant, may be revealed" (Chatham House, n.d.).

On PCIs' importance and influence in relation to the UNFCCC REDD+ negotiations, several respondents made the distinction that the PCIs themselves were not influential to the negotiations per se. REDD+ negotiators were often the REDD+ focal point for their country that participated in EIPs and IPDs, and these processes served to convene, support, and inform the parties that were negotiating (Survey and Interview Data). PCIs provided opportunities for formal parties (i.e., countries via their negotiators) to better understand different views which, in turn, helped negotiators better prepare for the negotiations and in some cases begin to think about potential compromise solutions that would help parties reach consensus $^{54}$ (Survey and Interview Data). In addition, the fact that many of the same individuals were involved in the REDD+ negotiations as in the PCIs created a community of practice which fostered relationship- and trust- building, the development of a "common language" (Survey Data), and south-south collaboration among countries (Interview Data).

One interview respondent, an Indigenous Peoples' organization representative, described PCIs as providing opportunities

...to approach [REDD+] negotiators and facilitators outside of the negotiations and to share our ideas and proposals and, in contrast to more formal forums like the UNFCCC

\footnotetext{
${ }^{54}$ Note that the rules of procedure for the UNFCCC, drafted in 1996, have not been adopted. They remain as bracketed draft text under Rule 42 of the Convention. However, UNFCCC decisions have been made, de facto, by consensus among the parties.
} 
negotiations where countries did not want to listen to Indigenous Peoples, PCIs provided a forum for all participants to "learn how to communicate, to listen to each other, and respect each other, even when we were in disagreement with each other (Interview Data).

In the same vein, another respondent underscored that "interpersonal relations built on shared experiences from other fora and a common dedication to forest issues did help overcome the overall atmosphere of mistrust and frustration that could be found in the UNFCCC negotiations" (Survey Data). Both of these observations about the value of PCIs in providing opportunities and the enabling conditions for participants to build relations and trust reinforces the ranking results that Group Process was the most enabling dynamic in REDD+ processes outside the UNFCCC. While it is clear from the rankings results that the negotiation dynamics differed between the UNFCCC REDD+ negotiation context and the PCIs, the qualitative data also indicates that they influenced each other.

Despite the ranking result that Political Context was most contraining in the PCI context, several respondents cited the value of PCIs keeping REDD+ high on the international political agenda by demonstrating commitment to action even while the UNFCCC negotiations were ongoing.

\subsubsection{Relationships between Negotiation Dynamics}

In addition to the Likert scale questions, respondents were asked to share their observations about the relationships between the negotiation dynamics, and in particular, whether they observed some negotiation dyanmics being leveraged to help overcome challenges in other dyamics. Some of the observed negotiation dynamic relationships are articulated in this quote:

...the relative degree of challenge for each of these variables varied over the course of the negotiations, depending on the particular issue(s) being addressed within the REDD negotiations and the quality and contentiousness of the negotiations on 'big ticket items'. (e.g., in one session, it may be a combination of country positions and group power dynamics that were most difficult to overcome, in another session it was a breakdown in trust [Group Process] that hindered progress or prevented consensus. On some occasions, it was the physical environment (wrong size of room) [Negotiation Process] that was the challenge (Survey Results).

In another example, one respondent observed that among the negotiators, their trust and willingness to work together as a group (Group Process) allowed them to manage a constant challenge of "limited negotiating time...” (Negotiation Process) which “...was often 
overcome by negotiators' willingness to work outside of the scheduled UNFCCC hours" and motivated by negotiators' expectation that agreement could be found (Survey Results).

Several respondents cited elements within the Negotiation Process dynamic as being leveraged to overcome challenges. In particular, several respondents underscored as a key factor the importance of how the negotiation process was designed, managed, and facilitated. Others cited the relationship between the design and facilitation (Negotiation Process) and the trust and relationship aspects (Group Process) — noting that "the role of the REDD+ negotiation facilitators and the trust they had earned, was often leveraged to overcome challenges, as were the relationships between facilitators and the negotiators and the UNFCCC Secretariat" (Survey Results). Others described the relationships and trustworthiness of a chair or facilitator as providing them power to manage the negotiations and negotiators in a way that drove parties towards agreement (Survey Results).

Another respondent highlighted the relationship between Political Context and Data and Information. According to the respondent, REDD+ negotiators were "well informed by experiences of REDD+ on the ground," (Survey Data) which also points to the relationship between the UNFCCC REDD+ negotiation context and that of parallel complementary initiatives (PCIs). The respondent noted that REDD+ negotiators' awareness of experiences of REDD+ on the ground provided opportunities for REDD+ to be piloted in key countries, thereby affecting those countries' experience and perceptions of REDD+ (Political Context). Negotiators' experience with REDD+ on the ground also provided valuable information about REDD+ implementation that could be used to inform further policy development. This observation points to both a relationship between dynamics (Data and Information and Political Context) but also to the relationship between the UNFCCC REDD+ negotiation and PCIs.

The results of the study confirm the complexity of intergovernmental and multi-party negotiations and processes; however, they also provide valuable insights into how a specific set of negotiation dynamics factored into the REDD+ negotiations and supporting REDD+ processes. The survey and interview data also illustrated the relationships between those dynamics - not only in terms of their relative constraining/enabling nature, but also in terms of evidence (albeit anectdotal) from REDD+ negotiators and facilitators that certain negotiation dynamics could be drawn upon to overcome challenges in others. The results also 
document the nuanced nature by which a host of supporting parallel initiatives (PCIs) informed and contributed to the formal REDD+ negotiations under the UNFCCC.

\subsection{Discussion}

\subsubsection{Most Constraining and Enabling Negotiation Dynamics}

The most constraining factor in both negotiation contexts (inside and outside the UNFCCC) was Political Context and the most enabling one was Group Process. This is interesting to note, because the much of the international relations literature (neorealists and neoliberals, in particular) would generally suggest that the intergovernmental negotiation context is highly politicized, and thus dependent on domestic politics, concerns about self-help, absolute and relative gains, and global geopolitical circumstances (Giddens, 2009; Powell et al., 1994; Terhalle \& Depledge, 2013; Waltz, 1979). Whereas the present finding that Group Process was enabling seems to align with social constructivist arguments that their interests are constructed through interaction (Pettenger, 2013; Wendt, 1992).

Yet, both dynamics were found to be equally applicable to both contexts: Group Process can as much enable intergovernmental negotiations as Political Context can constrain parallel complementary initiatives (PCIs). Yet, both contexts also show differences. Comparing both, one can conclude that 'inside REDD+ UNFCCC' negotiations were constrained by Negotiation Process, which was less the case for parallel complementary initiatives. PCIs were positively influenced by the availability of data and information, which was not a crucial factor for the UNFCCC REDD+ negotiations.

The finding that Political Context ranked highly as a constraining negotiation dynamic seems to align with the neorealist assertion that the political context of climate change is influenced by 'great-power politics' (Terhalle \& Depledge, 2013) and concerns around relative-gains playing out at both domestic and global levels, particularly as it relates to climate finance (Purdon, 2014).

While financing for REDD+ was identified by many respondents as one of the most challenging topics under negotiation overall, and often the most contentious topic from a political context standpoint, one could also argue that the REDD+ mechanism has mobilized 
significant financing in comparison to financial support for mitigation in other sectors. ${ }^{55}$ Perhaps equally important for balancing the real and potential challenges of great-power politics and relative-gains concerns was parties' ability to self-determine their mitigation contributions through REDD+, if applicable, but more broadly through their Intended Nationally-Determined Contributions (INDCs). ${ }^{56}$

As far as the formal REDD+ negotiations are concerned, the results also show a distinctionwithin the Integrated Negotiation Dynamics Model (INDM) - between the three main dynamics which were ranked high by respondents (namely, Political Context, Negotiation Process and Group Process) and the three cross-cutting, underlying dynamics which were ranked relatively lower (namely Power, Data and Information, and Communications). This reinforces the model's overall structure and the notion that, in contrast to many leading international relations theories, no one or two dynamics (e.g., anarchy; power; absolute or relative gains; discourse) dominated the REDD+ negotiation process and outcome.

The findings also empirically reinforce some leading international negotiation theoretical paradigms that outline similar sets of variables common to negotiations. For example, Zartman (1988) outlined that there is a general sense, across a range of disciplines, about the types of variables in a negotiation: process, timing, power, personality, negotiation tactics. Similarly, Crump combined aspects of both negotiation and international negotiation theory to deliver a five-part analytical framework as a descriptive lens for interpreting the key variables of negotiation analysis which includes: application to multiparty negotiations; negotiation context; structural and relational analysis (relationships, especially related to

\footnotetext{
${ }^{55}$ A report by the Informal Working Group on Interim Finance for Reducing Emissions from Deforestation and Forest Degradation (IWG-IFR) estimated a 25\% reduction in deforestation could be achieved with a financial commitment of 15-20 billion Euros (US\$22-29 billion) by 2015 .

${ }^{56}$ Intended Nationally Determined Contributions (INDCs) were part of the UNFCCC COP 20 Decision and refer to "common but differentiated responsibilities and respective capabilities, in light of different national circumstances" and that INDCs represent additional national efforts to meet the objective of the Convention as outlined in Article 2. See FCCC/CP/2014/10/Add.1. Also see UNFCCC Article 2: "The ultimate objective of this Convention and any related legal instruments...is to achieve...stabilization of greenhouse gas concentrations in the atmosphere at a level that would prevent dangerous anthropogenic interference with the climate system." (UNFCCC, Article 2, p. 4).
} 
power); communication patterns; relationships, rapport, and trust between parties (Crump, 2015).

The INDM reflects variables similar (if differently organized) to those identified by Zartman (1988) and Crump (2015), but as this study shows, survey and interview data also provided insights on the relationships between those negotiation dynamics - something identified as a significant gap in understanding (Crump, 2015). These insights demonstrated how enabling dynamics were drawn upon to overcome constraints in other dynamics. These results go beyond descriptions of the negotiation dynamics to provide diagnostic information about how to overcome challenges to reaching agreement in multi-actor negotiations.

Within the parallel complementary initiatives (PCIs), though, one crosscutting dynamic was put at the forefront by a majority of respondents, as most enabling: Data and Information. This confirms the idea often expressed in the literature that parallel negotiations outside the intergovernmental context are more about technical deliberations and less about political decision-making (Susskind et al., 1996, 2003).

\subsubsection{Roles and Subcategories of PCIs}

It was clear from both the survey results and interviews that PCIs played important roles - in particular, the early implementation platforms (EIPs) provided technical guidance and early financing for piloting and implementing REDD+ on the ground; served as forums for REDD+ negotiators, experts, and stakeholders to engage, communicate, and build relationships and trust; thereby catalyzing REDD+ communities of practice. While some EIPrelated literature (Dooley et al., 2011; Griffiths \& Martone, 2009) critiques these initiatives and their institutions, the diverse respondents and informants for this case study generally described EIPs as adding significant value to informing the technical and policy aspects of REDD+, but also for facilitating multi-stakeholder communication.

Informal policy dialogues (IPDs) emerged as a distinct sub-category process under parallel complementary initiatives (PCIs). IPDs most closely relate to other well-documented processes in the literature such as parallel informal negotiations (PINs) (L. Susskind, Chayes, and Martinez 1996) and multi-stakeholder dialogues (MSDs) (Susskind et al., 2003). The results of this study show that the objectives for IPDs were to generate off-the-record discussion and assessments of technical or policy options and to explore topics and questions that were timely and salient to the ongoing REDD+ negotiations. IPDs also yielded the 
secondary benefit of allowing individuals (who were often also REDD+ negotiators under the UNFCCC) to build relationships, trust, and to share information such as interests behind their negotiation positions or aspects of their domestic Political Context.

In addition, the results showed that EIPs and IPDs did not influence (nor aim to influence) the REDD+ UNFCCC negotiations directly. However, through the process of engaging REDD+ negotiators and focal points and by providing opportunities for those negotiators to become more informed about technical or policy issues, options, and implications, they indirectly influenced the formal REDD+ negotiation process. In some cases, this catalyzed or contributed to "building consensus" (Susskind et al., 2003) in the formal REDD+ negotiations, although that was not the objective of EIPs or IPDs.

EIPs and IPDs (two types of parallel complementary initiatives [PCIs]) also served to support and inform those involved in the REDD+ negotiations. As this paper has demonstrated, these PCIs supported and informed actors and processes, and thereby had influence, albeit indirectly, on the UNFCCC REDD+ negotiations. PCIs were initiated with substantial bilateral and multilateral funding and implemented concurrently with the formal negotiation processes over eight years, well before an international agreement on REDD+ was reached.

\subsubsection{Power}

While Power ${ }^{57}$ was only one negotiation dynamic, the study's results seem to warrant additional exploration in relation to (some of) the international relations and international negotiation literature, since power is a main focal point for both disciplines. As Zartman and Rubin point out, there are two interpretations about Power's role in enabling parties to reach agreement: 1) that power symmetry among parties leads to mutually beneficial negotiated outcomes; and 2) that power asymmetry among parties enables a more efficient and effective agreement (Zartman and Rubin 2000: p.5). Within the field of international relations, neorealist scholars (Mearsheimer, 2001; Waltz, 1979) argue that states are chiefly concerned with the pursuit of their national security and interests in an intergovernmental negotiation context (i.e., not with achieving a mutually beneficial outcome) and that the exercise of geopolitical power is an effective way of doing this (Mearsheimer, 2001).

\footnotetext{
57 The term "Power" capitalized refers to the negotiation dynamic from the model whereas the lowercase "power" refers generically to the term as it is discussed in the literature.
} 
Based upon power's prominence across the dominant literature, it was somewhat unexpected to see the results show that Power was not as significant of a dynamic within the UNFCCC REDD+ negotiation context as one might expect. Survey and interview respondents saw Power as more constraining in the PCI context. The finding that some individuals participating in both the REDD+ UNFCCC negotiations and PCI contexts dramatically switched negotiating tactics to change the balance of Power within the PCI context must have eroded individuals' ability to trust each other in both contexts.

Within the UNFCCC REDD+ context, it is worth noting that the survey data showed a high degree of agreement among respondents that Power ranked right in the middle of the Likert scale in terms of being both constraining and enabling to parties' ability to reach agreement. This finding seems to indicate that Power is, at least in some cases such as in the REDD+ context, not as significant a dynamic as neorealists would claim.

As the results demonstrated, there were different perceptions of Power within the UNFCCC REDD+ negotiation context where it was one country, one "vote" which helped to "level the playing field" (Zartman and Rubin 2000: p.22) and within PCI contexts where more traditional geopolitical Power asymmetries arose. Within the UNFCCC REDD+ context, some respondents also cited examples of countries forming coalitions (e.g., the Coalition for Rainforest Nations, or CfRN). This had the effect of shifting the Power balance from individual party Power to collective coalition Power. Yet, surveys of and interviews with the foremost REDD+ negotiators, facilitators, and experts as part of this chapter found that Power was neither the most constraining nor enabling dynamic in relation to parties' ability to reach agreement to accord REDD+ such a prominent position in the Paris Agreement. As an enabling factor to reaching agreement, there was significant agreement among respondents that Power ranked behind Group Process, Political Context, and Negotiation Process. This would seem to contradict a prevalent theme in international- negotiation and relations literature that Power - symmetrical or otherwise - is the most important factor in reaching an international agreement.

\subsection{Conclusions}

The findings of this chapter show that the international negotiation dynamics for REDD+, both within and outside the UNFCCC context, were multi-faceted. The UNFCCC REDD+ negotiations and parallel complementary initiatives on REDD+ were shaped by a multitude 
of factors that cannot be reduced to single overarching ones such as power (as neoconservatives would suggest), rules (institutionalists) or communicative interaction (constructivists). As such, the theory behind the INDM model - that all of these negotiation dynamics play significant roles in both the international negotiation context of REDD + as well as the parallel complementary initiatives (PCIs) of REDD + - has been reinforced by the data collected. This echoes the factors described in negotiation literature but stands in contrast with much of the international relations literature.

Particularly crucial for both REDD+ contexts (inside and outside the UNFCCC) were Political Context (more constraining than enabling), Group Process (more enabling than constraining) and — to a lesser extent—Power (more constraining than enabling). The results also showed that the various negotiation dynamics are interrelated, and a blockage in one could be accommodated by an opening in another. Elements of Group Process, in particular, were cited by a number of respondents as helpful for overcoming challenges within the Negotiation Process, Political Context, and Power dynamics, which may be a helpful consideration for addressing challenges in other intergovernmental negotiation contexts.

All respondents considered the PCIs important and influential for reaching agreement on REDD+ within the UNFCC climate negotiations. In particular, Data and Information was considered an enabling factor within the PCI context. Without these parallel processes to "reality test" REDD+ policy concepts on the ground, there would not have been so much experience to inform the ongoing REDD+ policy negotiations. In addition, the fact that REDD+ negotiators and country focal points participated in various PCI forums provided numerous opportunities to: 1) communicate with other negotiators and experts; 2) build relationships and trust over time; 3 ) understand the pros and cons of different technical and policy options; and 4) improve understanding of countries' interests and negotiating positions. All of these opportunities available through PCIs served to inform those individuals as they represented their countries' interests in the formal REDD+ UNFCCC negotiations. Without these opportunities, an agreement on REDD+ may not have occurred. This finding can help inform SD diplomacy in that it underscores the importance of understanding how parallel processes working towards the same sustainable development objective can be mutually reinforcing, as was the case between REDD+ and REDD+ EIPs. As the surveys, interviews, and practitioner observations show, a number of factors combined to lead to an agreement on a REDD+ mechanism and to the prominence of forests and 
REDD + in the Paris Agreement. Firstly, significant finance and impetus came from donor countries, particularly Norway, as the "champion" of forests. Results-based finance significantly altered the global political context and tropical forested countries' domestic political contexts in relation to forest protection. While the Political Context for REDD+ was considered most constraining to reaching agreement, without significant financing committed, global and domestic political contexts would not have been likely to align enough to make REDD+ possible. Secondly, finance from donor countries also catalyzed and supported the proliferation of REDD+ PCIs. As the results showed, PCIs created communities of practice and continuous opportunities for interaction both among REDD+ negotiators but also between those negotiators and other stakeholders such as Indigenous Peoples Organizations and NGO representatives. These interactions served to facilitate the flow of data and information as well as for participants to build relationships and trust and to understand better their respective negotiation positions which aligns with the study results that Group Process and Data and Information were most enabling in the PCI context. Thirdly, the relatively stable base of REDD+ negotiators over the years also helped maintain continuity and build stronger relationships over time. Continuity among the pool of REDD+ negotiators was a resource drawn upon both in the REDD+ negotiations and the PCI contexts when other aspects became challenging (long hours, difficulty with certain coalitions; poor negotiation process conditions).

No other sectoral negotiations under the UNFCCC have had the support of any of the main factors outlined above. While REDD+ may indeed be an anomaly even within the UNFCCC context, this study shows there were a host of contributing factors - including the range of negotiation dynamics and the roles of the PCIs - that led to forests' unique position and atmosphere both within and outside the UNFCCC negotiations. The interaction of these factors over the course of the evolution of REDD+ ultimately enabled parties to reach agreements on a REDD+ mechanism and also led to both forests and REDD+ being featured prominently in the Paris Agreement. 


\section{CHAPTER 4 | PURSUING SUSTAINABILITY THROUGH MULTI ACTOR COLLABORATION: EARLY IMPLEMENTATION OF THE ROUNDTABLES FOR SUSTAINABLE BEEF AND EFFORTS TO REDUCE DEFORESTATION}

* This chapter is based upon the below cited paper which was modified from the original publication for the purposes of this thesis in the following ways: 1) the results section was elaborated upon since there were no word count constraints; 2) some wording was edited for clarification to the reader and to integrate it as a thesis chapter rather than an independent study; and 3) using the same conceptual model, the original paper was expanded to explore evolutionary characteristics and phases multi-stakeholder efforts to reduce deforestation.

Buckley, K., Newton, P., Gibbs, H., McConnel, I., and Ehrmann, J. (2019). Pursuing sustainability through multi-stakeholder collaboration: a description of the governance, actions, and perceived sustainability impacts of the Roundtables for Sustainable Beef. World Development Journal. Volume 121. pp. 203-217. https://doi.org/10.1016/j.worlddev.2018.07.019 


\subsection{Introduction}

Cattle production is anticipated to increase globally in coming decades in response to the demands of a growing population with increasingly meat-heavy diets (Tilman \& Clark, 2014). Cattle represent important economic, socio-cultural, livelihood, and food security values in many parts of the world (Herrero et al., 2009). Cattle also present major challenges to sustainability, including being associated with high levels of global greenhouse gas (GHG) emissions, extensive land use change, freshwater consumption, and biodiversity loss (Mekonnen \& Hoekstra, 2012; Nijdam et al., 2012; Ripple et al., 2014). In the context of increasing beef demand, there is thus an imperative to balance environmental, economic, and social sustainability dimensions across the entire beef supply chain: from production and processing to consumption and food waste management (Herrero et al., 2015).

Formal, state-led regulation to improve sustainability of the beef sector is unlikely due to the trade disputes this would likely trigger (Bernstein \& Cashore, 2007, p.354). In the absence of policy regulation, collective efforts by governments, civil society, and the private sector to enhance the sustainability of cattle production (particularly reducing deforestation) while meeting growing demand have taken many forms (Garnett, 2009; Gibbs, Munger, et al., 2015; Lambin et al., 2018; D. C. Nepstad et al., 2014). In particular, non-state market-driven (NSMD) governance systems have gained traction in many places (Cashore, 2002). NSMD systems are defined as, "deliberative and adaptive governance institutions designed to embed social and environmental norms in the global marketplace that derive authority directly from interested audiences, including those they seek to regulate, not from sovereign states" (Bernstein \& Cashore, 2007, p. 348). One example in Brazil was an agreement by the four biggest slaughterhouses to eliminate illegal Amazonian deforestation from their supply chains resulted in significant changes in the purchasing behavior of those slaughterhouses (Gibbs et al., 2015), though may not yet have had a significant impact on deforestation rates (Alix-Garcia et al., 2019; Klingler et al., 2018). Also, in Brazil, a series of NGO-led pilot programs aim to intensify pasture-based beef production: producing more beef on less land to reduce deforestation pressure and greenhouse gas (GHG) emissions (Bogaerts et al., 2017; Latawiec et al., 2014). The Sustainable Agriculture Network has also developed a third-party 
certification program. This program enables cattle ranchers that demonstrate compliance with a voluntary set of standards to use the Rainforest Alliance seal on their products, with certified farms in Brazil, Colombia, and Costa Rica (Newton et al., 2015).

Commodity roundtables are a form of NSMD governance system that have gained significant traction in some sectors over the last decade (Brassett et al., 2010). Roundtables are multistakeholder institutions - usually involving representatives of industry and non-governmental organizations (NGOs). Roundtables are organized around specific commodities and create a forum for collaboration, exchange, and supply chain governance separate from state institutions. The multi-stakeholder approach of roundtables enables a diverse range of constituencies to be involved in determining what sustainability means for that sector and how it might be achieved. This approach fosters greater credibility, accountability, stakeholder support, and legitimacy for the NSMD governance system and its activities (Bernstein \& Cashore, 2007).

As described in Chapter 3, the REDD+ mechanism to reduce tropical deforestation was negotiated and agreed to by member states only, under the UNFCCC. However, supporting REDD+ processes (early implementation platforms (EIPs)) included more diverse (non-state) stakeholder perspectives that informed what REDD+ meant and how it could be implemented. Since REDD+ was adopted, additional multi-stakeholder efforts have collectively committed to reduce deforestation, especially within private sector supply chains. Both of these efforts-REDD+ EIPs and private sector supply chain commitments- have fostered greater credibility, accountability, stakeholder support, and legitimacy as described in the NSMD governance system (Bernstein \& Cashore, 2007). This is further explored in section 4.6.

As a governance mechanism, commodity roundtables have emerged over the last 10-15 years; the roundtables for sustainable palm oil and soy were established in 2004 and 2006, respectively. Several roundtables, including the Roundtable on Sustainable Palm Oil (RSPO), Round Table on Responsible Soy, and the Roundtable on Sustainable Biomaterials have created third-party certification programs as a central part of their activities. There is mixed evidence about the effectiveness of these roundtable-generated certification programs in enhancing sustainability. For example, the RSPO certification program certified approximately 19\% (11.62 million tonnes) of palm oil traded globally in 2017 ("Impacts: 
RSPO in Numbers," 2018), and a recent study showed a decline in deforestation but little impact on fire or clearing of peatland among certified growers (K. M. Carlson et al., 2018). In contrast, forest conservation is an unlikely outcome of the soy certification program because of very low adoption rates (Garrett et al., 2016).

Roundtables for the beef industry have evolved more recently: the first, the Brazilian Roundtable on Sustainable Livestock (better known by its Portuguese acronym GTPS), was established in 2009, in large part to coordinate an industry response to international criticism of the cattle sector's association with Amazonian deforestation. Roundtables for sustainable beef (henceforth referred to as RSBs) are active at the global level, and at the national-level in Brazil, Canada, and the United States. A sustainable beef roundtable was established in Australia but was later dissolved. ${ }^{58} \mathrm{RSBs}$ are in the process of being initiated in Argentina, Colombia, Mexico, and Paraguay (GRSB Sustainability Report, 2018). Other countries have national or regional organizations working on similar beef sustainability issues, in the absence of a formally developed roundtable (Interview Data).

RSBs embody a sector-wide approach to enhancing beef sustainability. Their membership currently represents a small proportion of the sector globally, which comprised 995.2 million heads of cattle in 2017 (USDA Foreign Agricultural Service, 2017). However, it is possible for a relatively small number of well-organized influential actors to have an outsized impact compared to their share of the sector. It is therefore important to understand the scope of RSBs and the potential for them to affect sustainability within the cattle sector. To date, little has been written in the peer-reviewed literature to addresses these aims.

This chapter aims to describe and characterize the state of understanding about RSBs, and to fill knowledge gaps about their role and potential impact. The chapter will explore the

\footnotetext{
${ }^{58}$ According to the practitioner experience of one of the study's co-authors, the Australian roundtable for sustainable beef was dissolved due to the inability to build trust between non-governmental civil society organizations and industry. The reputational risk for those involved in the roundtable was too high due to mounting pressure from groups outside of the roundtable. This caused the roundtable to dissolve. As an alternative to the multi-stakeholder roundtable approach, the Australian Beef Sustainability Framework was created by the industry, in collaboration with other stakeholders. See:

https://www.sustainableaustralianbeef.com.au/
} 
historic and possible future trajectories of the RSBs at the country- and global-levels, by responding to RQ3: What are the evolutionary characteristics and phases of multi-stakeholder collaborations on cattle and deforestation that underpin their potential for sustainability impact? ${ }^{59}$

It is anticipated that this analysis (Pursuing Sustainability through Multi-stakeholder Collaboration) will be of interest both to scholars of non-state market driven (NSMD) governance system and to practitioners involved in developing and implementing policies and programs to promote enhanced sustainability within the beef sector and other supply chains. This chapter does not aim to: present a normative review of the RSBs; enter the debate about whether sustainable beef is an oxymoron; compare the RSBs to an alternative definition of, or approach to, sustainability; or measure impact of the RSBs, except through the reported perceptions of respondents. This chapter aims to provide a description of the RSBs - including what they are, where they are, what they aim to do, and what people involved in them think might happen as a result. ${ }^{60}$

\subsection{Methods}

\subsubsection{Interviews}

The approach involved semi-structured interviews with 20 key informants. The interviews aimed to understand the RSBs' governance structure, actions taken, and potential for sustainability contributions, as defined within the RSB approach. Respondents were individual experts and leaders who were all knowledgeable about the inception, progress, and continued evolution of at least one RSB, and who represented a diverse range of perspectives on all of the RSBs. Interview respondents were either: 1) leaders and/or members in existing RSBs (i.e., global, Brazil, Canada, and U.S.) and emerging RSBs (i.e., Colombia and Mexico); and/or 2) experts in beef and livestock sustainability who were involved in complementary initiatives such as the Global Agenda for Sustainable Livestock (housed at

\footnotetext{
59 The original article this chapter is based upon had more specific research sub-questions.

${ }^{60}$ Publication of the paper upon which this chapter is based represented the first time the RSBs had been written about in peer-reviewed literature.
} 
Food and Agriculture Organization of the U.N. (FAO)), and the Sustainable Agriculture Initiative (SAI) Platform. This second set of respondents were thus informed about, but not directly involved or invested in, the RSBs.

The RSBs publish their member organizations but not names of specific individuals that represent that entity unless they hold a key leadership role. Therefore, the study employed a snowballing sampling method to identify potential key informant respondents (Bryman, 2016). The initial list of 10 potential respondents was developed by the author team, drawing upon their professional networks as scientists and practitioners, with an eye towards identifying geographically diverse RSB leadership and engaged civil society representatives. These initial interviews led to additional suggestions for invited respondents. All respondents were asked to recommend additional potential respondents.

In total, 43 individuals involved in, or informed about, the RSBs were invited to participate in a semi-structured interview. Of those, 20 interviewees accepted. The 23 that did not respond were a mix of national RSB members (producers, civil society, processors) and were not significantly different from the respondent pool in any critical dimension. Despite the small sample size, the respondents comprised a representative mix of affiliations, geographic representation, and expertise. Approximately $70 \%$ of respondents had been, or currently were part of, the RSBs' leadership and governance. The remaining 30\% provided an informed external perspective of the RSBs. The sample thus represented a diverse cross-section of RSB constituencies and outside observers. Respondents included industry members (e.g., producers, producer associations, processors, and consumer-facing companies), civil society members and observers, sustainability standard-setting representatives, funders, and sustainability experts. The researcher, together with collaborators, concluded that the sample had reached data saturation (B. Saunders et al., 2017) when most additional potential respondents recommended were those already interviewed, and when the responses to interview questions provided little new or additional information beyond what had already been collected.

A common set of interview questions (Appendix C) was used for each respondent. These questions focused on the three framework categories - governance; actions; and sustainability impacts. Interviews were conducted by telephone or Skype and lasted approximately one hour each. 
The method for analyzing multi-stakeholder efforts to reduce deforestation conducted in section 4.6 of this chapter was to apply the NSMD framework to: 1) results from Chapter 3 on REDD+ early implementation platforms (EIPs); 2) practitioner experience based on the author's professional work with REDD+ and multi-stakeholder efforts to reduce deforestation; and 3) publicly available information on REDD+ (EIPs) (e.g., UN-REDD Programme and Forest Carbon Partnership Facility), voluntary private sector commitments, and zero-deforestation commitments (e.g., New York Declaration on Forests). Section 4.6 applied the NSMD framework to these contexts as a means to better understand their evolution towards accountability, stakeholder support, and political legitimacyunderpinnings of their potential for future sustainability impact. The results of this analysis were then examined through the lens of SD diplomacy, specifically the SD diplomacy diagnostics. Embedded in these diagnostics are calls for involvement of diverse state and non-state actors across different scales as well as a portfolio of solutions to address complex problems (Moomaw et al., 2017) — tenets that are salient to the contexts under study.

\section{$4.3 \quad$ Analysis}

Responses were recorded in Microsoft OneNote. The first round of analysis employed targeted coding to categorize data based upon the main topic, which often corresponded with the interview question (i.e., governance, actions, sustainability impacts). Interview analysis also included sub-codes to attribute the response data to the appropriate geographic beef roundtable context(s) as well as to the appropriate topic (Miles \& Huberman, 1994). After identifying main topics and geographies, the author employed open coding to identify additional patterns and categories within the data. Responses with the same codes were grouped into categories and analyzed in aggregate (Babbie, 2016). In this way, comments were not attributed to - and are not traceable to - a particular individual ${ }^{61}$, but to the

\footnotetext{
${ }^{61}$ This approach to the analysis was important to explain to respondents upfront, many of which had questions about whether and how their responses would be attributed to them or easily traced back to them by identification of their role or geography. Respondents' caution seemed to stem from mainly civil society organizations (CSOs) or private sector members. These respondents seemed to fear retribution for being critical or open about the challenges of the RSBs. For CSOs, they were concerned their funders (who fund and require
} 
appropriate context (e.g., observations about governance within the Brazil roundtable context; observations about limitations to sustainability impact globally).

Based upon the research questions, the researcher and collaborators developed three categories to help organize the results: 1) governance, including transparency, identification and engagement of interested parties or stakeholders, accountability, decision-making, and scientific-grounding, which relates to several NSMD governance system features (Bernstein and Cashore 2007 p. 349-350).; 2) actions, including monitoring, verification, and compliance, which reflect NSMD governance system features; and 3) sustainability impacts, including current and potential impact pathways, as well as limitations of the RSBs, which also relates to NSMD governance system features (Bernstein and Cashore 2007 p. 350). The results provide a holistic synthesis of the RSBs' governance and actions to date, potential future opportunities, and limitations to their ability to have an impact on sustainability. In order to provide a big picture understanding of the RSBs, the results section is organized by the interview categories and data coding (governance; actions; and sustainability impact). Within those categories, the results summarize main findings relevant to the beef roundtable context and, where possible, provide examples to indicate observations relevant to a specific roundtable context.

In order to relate the RSBs to the broader context of voluntary private governance efforts, the discussion draws upon Bernstein and Cashore's (2007) five features (characteristics) of nonstate market driven (NSMD) governance systems and the phases through which NSMD governance systems gain legitimacy as a venue for problem-solving. Features of NSMD governance systems are that: 1) they do not "derive governing authority from states nor are they accountable to them" (p.349); 2) they comprise diverse stakeholders collectively learning, developing, and working towards goals (p.349); 3) they gain "authority" via their supply chain members, each which maintain sovereignty over the choice to certify products or services (pp.349-350); 4) they aim to improve sustainability of the industry, thereby "reconfiguring" the current markets (p.350); and 5) they develop mechanisms for addressing

CSO participation in the RSBs) would be upset with RSB criticism stemming from those grant recipients. For private sector respondents, they were concerned that remarks they shared about the RSBs would be used against them by (non-RSB member) CSOs as evidence that the RSB approach will not improve sustainability. 
compliance (Bernstein \& Cashore, 2007 pp. 349-350). The three phases that NSMD systems move through are: initiation which represents early support and initial participation from private sector entities that view it as a competitive edge (Phase I); building broader support and participation in the system which involves "the emergence of shared norms and learning" (p. 358) which, in turn, "redefines" the self-interested, "strategic behavior" of participating firms and civil society groups (Phase II); and reaching political legitimacy meaning that there is widespread stakeholder participation and a shift from debating the validity system itself to debating policy within the system (Phase III)(Bernstein \& Cashore, 2007).

\subsection{Results}

Our respondents had a diverse set of experience and expertise in relation to the roundtables for sustainable beef and cattle sustainability (shown below in Table 6). Many respondents had been involved with more than one RSB and several had played more than one role (e.g., industry and civil society) over the course of their careers. This section reports interview results as they pertain to the three research questions. Unless otherwise stated, all reported information is derived from the interviews. 
Table 6. Summary of Respondent Affiliations and Geographic Expertise

\begin{tabular}{l|l}
\hline Respondent affiliation(s) / experience & Number of respondents \\
\hline Geographic expertise & 6 \\
\hline Global Roundtable & 7 \\
Brazil Roundtable & 2 \\
Canada Roundtable & 2 \\
Colombia Roundtable & 1 \\
\hline Mexico Roundtable & 2 \\
US Roundtable & 3 \\
\hline Non-roundtable: Sustainable Beef/Livestock Initiatives & 3 \\
\hline Organizational expertise & 2 \\
\hline Industry (ranchers, producers, processors, retail) & 7 \\
\hline Civil Society/Non-/Inter-governmental Organization & 9 \\
\hline Funders & 2 \\
\hline Veterinarians/Animal Health Experts & 4 \\
\hline
\end{tabular}

As shown above in Table 6, out of 20 respondents, some had affiliations and/or geographic expertise in more than one organization or region. As noted under Methods, $70 \%$ of respondents had been or currently were part of the RSBs' founding leadership and ongoing governance. The remaining 30\% provided an informed external perspective of the RSBs. Table 7 below provides information about key informants' primary role in relation to the RSBs. As described in the Methods, this information was anonymized to respect the confidentiality of respondents' identities, as agreed to in the interviews. 


\section{Table 7. List of Key Informants (anonymized)}

1. Civil Society Representative, GTPS

2. Senior staff, GRSB

3. Civil Society Representative, Soy Roundtable and GRSB

4. Senior staff, global beef corporation; member of GRSB, US roundtable, Canadian roundtable

5. Senior scientist, Food and Agriculture Organization

6. Senior staff, Canadian Roundtable

7. Expert Consultant, livestock and deforestation in Amazon region

8. Industry member, GTPS

9. Producer and member, Canadian roundtable and GRSB

10. Consultant, Sustainable Agriculture Initiative (SAI)

11. Executive, cattle cooperative; member of US Roundtable; member of GRSB

12. Civil society representative, member of GTPS; member of GRSB; advisor for all national-level roundtables

13. Civil society representative, advisor to Colombian roundtable, participant in GRSB

14. Civil society representative; former philanthropic foundation representative, member of GTPS and GRSB

15. Senior staff, International Social and Environmental Accreditation and Labelling Alliance (ISEAL)

16. Civil society representative, member of US roundtable and GRSB; advisor to Mexico and Colombia roundtables

17. Senior staff, global beef corporation; member of GTPS and GRSB

18. Civil society representative, GTPS

19. Senior staff, global corporate retailer; member of GRSB, GTPS, Canadian and US roundtables, and Sustainable Agriculture Initiative (SAI)

\subsubsection{Evolution of the Roundtables for Sustainable Beef (RSBs)}

Several respondents who served as the original architects of the RSBs shared highlights of how the RSBs evolved, and why the RSBs chose to organize themselves differently than other commodity roundtables such as soy and palm oil. A brief overview of the history and rationale is provided below.

Convening of the Brazilian Roundtable on Sustainable Livestock (better known by its Portuguese acronym GTPS) was partly motivated by increased international attention on the 
issue of deforestation and linkages to beef production in Amazonia (Greenpeace, 2009). Its original intent was to define criteria for a 'sustainable product' - following the model of other commodity roundtables, such as palm oil. However, after much debate, the group agreed that developing a set of standards for beef was not appropriate, for two main reasons: 1) a thirdparty sustainability certification program, developed by the Rainforest Alliance/Sustainable Agriculture Network, already existed and therefore it would not be helpful to create another standard that might compete with that; and 2) a majority of cattle ranchers would not be able to comply with the standard, since many are not compliant with fundamental environmental legislation including Brazil's Forest Code. Therefore, early architects of the GTPS chose a model based on continuous improvement and the dissemination of good practices, instead of setting formal standards. Early on, the GTPS caught the attention of the world beef industry, including many companies that were expanding internationally: eventually, this led to the creation of the Global Roundtable for Sustainable Beef (GRSB).

Those involved with the early iterations of what later became the GRSB observed mistrust between producers and processors, as well as between processors and retailers. However, as groups continued to convene, common ground eventually emerged. This common ground began with a shared understanding that: 1) beef ${ }^{62}$ production systems are more variable than soy or palm oil, as beef can be produced in many different agro-ecological zones and, within that, there is a tremendous diversity of production systems; and 2) despite early mistrust, various actors shared a concern about heavy criticism of the whole industry and a lack of coordinated response. As a result of the shared understanding that emerged through early multi-stakeholder discussions and the collective desire to address criticism of the sector, the GRSB was formerly launched in 2012 (Global Roundtable for Sustainable Beef, 2016) followed by other national roundtables in Australia (2012), Canada (CRSB, 2014), and the United States (USRSB, 2015) (Canadian Roundtable for Sustainable Beef, n.d.; U.S. Roundtable for Sustainable Beef, 2015). RSB efforts have also begun in Colombia, Mexico, and Paraguay.

\footnotetext{
${ }^{62}$ The roundtables for sustainable beef refer to their work as focused on 'beef production', however, it is worth noting that some of the national beef roundtables look more broadly to cattle production which includes dairy and leather.
} 
In addition to catalyzing activities at the national level, the GRSB has worked collaboratively with other sustainable beef and livestock initiatives such as the Sustainable Agriculture Initiative (SAI) Platform and the Global Agenda on Sustainable Livestock. The SAI Platform is a member of the GRSB and works to co-develop tools and guidance to support global and local sustainable sourcing and agriculture practices for beef producers, associations, and retailers. The GRSB is a partner of the Global Agenda on Sustainable Livestock, which convenes global stakeholders including government representatives and recently explored how livestock can play important roles in realizing the Sustainable Development Goals (SDGs). According to respondents, while it is possible the SAI Platform may evolve into a European roundtable for sustainable beef, one of the GRSB's objectives is to recognize and elevate other sustainable beef and livestock initiatives in order to promote complementarity, as opposed to spawning similar and competing national or regional RSBs.

\subsubsection{Governance of the Roundtables for Sustainable Beef (RSBs)}

Commodity roundtables are all structured around a system of multi-stakeholder governance, and most respondents observed that this multi-stakeholder nature was a fundamental characteristic of the roundtables. "The roundtables take their name from the fact that a variety of stakeholders comprise their membership, and, nominally at least, there is equal status between them in agenda-setting and decision-making" (Brassett et al., 2012). Respondents reported a range of perceived benefits and challenges of this multi-stakeholder approach. On the one hand, simply convening a diverse set of stakeholders and reaching some agreement on important issues was seen by many respondents as a main role and a significant achievement of the RSBs. On the other hand, many respondents viewed the multi-stakeholder process as being inefficient due to diverse interests and expectations and saw this as an impediment to streamlining tangible progress on enhancing sustainability.

The nature of the multi-stakeholder process differs between sectors and geographies. For example, the Global Roundtable for Sustainable Beef (GRSB) and the Canadian Roundtable for Sustainable Beef (CRSB) are the only two RSBs to include transparency measures such as public consultation and comment periods. As a second example, the Brazilian Roundtable for Sustainable Beef (GTPS) and the Colombia Roundtable for Sustainable Beef (CoRSB) are the only two RSBs to include public-sector participation, with technical and government representatives from the Ministries of Agriculture and Environment. 
Each RSB has its own decision-making process. The GRSB, for example, aims for consensus (no objection). When consensus is not possible, decisions are put to a weighted vote across its five constituencies: producers, commerce and processing, civil society, national roundtables, and retailers, plus observers (governments or international organizations). Each member has one vote that it casts within its constituency group which are tiered according to scale (e.g., small, medium, and large producers). This helps ensure that small producers have the same weight as medium and large producers. Each tier's net vote is calculated (e.g., 4 in favor, 3 against yields a +1 vote in favor). The net votes across constituency tiers are tallied for an overall decision and sustained objections are noted.

A common challenge for all RSBs has been how best to engage small- and medium-size producers. Barriers for smallholders include unfamiliarity with the roundtable proceedings or with industry- and sustainability- terminology being used at the meetings. A second challenge for roundtable governance is geographic representativeness. Most of the national roundtables are in the Americas. And while the GRSB aspires to be global, its membership is North- and South- America-centric. There are not many European members of the GRSB, in part because most potential members belong instead to the Sustainable Agriculture Initiative (SAI) platform, and there is little representation from producers, processors, or retailers from Asia and Africa. Many respondents therefore believed that for RSBs to achieve global impact, the GRSB would need to achieve more global representation, and/or national or regional roundtables would need to be established in geographies that are currently underrepresented.

\subsubsection{Roundtable for Sustainable Beef (RSB) Actions}

Respondents reported a range of specific and more general actions that the RSBs have taken to date. This section first reports on the common approach of 'continuous improvement' adopted by all of the RSBs. Second, this section reports on the specific actions of each RSB in turn.

\subsubsection{The Continuous Improvement Model}

Many roundtables in other sectors have created formal third-party certification programs, which are characterized by a set of voluntary standards that codify the practice of sustainable production, and usually also include an assurance system (e.g., third-party audits to verify 
compliance with the standards), as well as an associated label to differentiate certified from non-certified products. For example, the Roundtable for Sustainable Palm Oil, Roundtable for Sustainable Soy, and Roundtable for Sustainable Biofuels have all developed and implemented certification programs. In contrast, none of the RSBs have stated an intention to create a sustainability certification program, and all of the RSBs have instead adopted an approach that aims to support a continuous improvement model for beef value chains. This model fosters gradual progress across the entire supply chain by providing principles and indicators that its members can choose to implement and track progress against. Individual RSB members may choose to conduct self-assessments or have their improvements verified by an independent third party. The RSB does not verify, certify, or provide a certification label for its members to comply with. Instead, they provide a framework of principles and indicators to guide continuous improvement across the sector.

Many respondents expressed strong support for the RSB's approach of continuous improvement as an alternative to a certification standard. Foremost, they cited the rationale that this approach is more likely to be inclusive of, and to improve sustainability performance among, a much larger proportion of producers within beef supply chains. This, they argue, contrasts with a certification program with stringent standards, which may appeal to - and be achieved by — only a small number of top performers who have the capacity and resources to meet those standards (as compared to a sector-wide approach).

However, other actions that monitor, report, and verify progress are being implemented to various degrees across the different RSBs. These actions include self-assessments, the establishment of baselines, and other monitoring and reporting mechanisms such as thirdparty verification against national criteria and indicators. Several respondents expressed an opinion that further efforts to demonstrate sustainability impact would be useful, for several key reasons: 1) it would document the continuous improvements being made; 2) it would filter out members that were not making serious commitments or that did not intend to fulfill them; and 3) it would respond to consumer and retailer demands for greater sustainability in the beef sector and provide assurances for sustainability claims.

Despite the RSBs' resistance to developing a certification standard, many respondents indicated that they were open to considering how the roundtables could support progress towards verified sustainability impacts and verified sustainable products, and perhaps 
eventually some type of endorsement by the roundtable for achieving a certain level of sustainability. Respondents' perceptions about the primary benefit of verification vs. certification was that the former fostered an inclusive, sector-wide, bottom-up approach to incremental sustainability improvements over time. Top performers could verify adherence to principles and indicators without excluding other roundtable members from adopting sustainability practices by setting a requisite threshold of performance as is the case with certification standards.

Several respondents pointed to national- and project-level examples where third-party verification against roundtable indicators is already underway and described this trend as creating de facto standards. For example, McDonald's has pilot projects in both Canada and in Brazil, using the roundtable indicators to demonstrate and verify the sustainability of their beef supply chains (McDonald's Canada, 2016). While some respondents saw verification as an eventual end-goal or outcome, others saw the need for roundtables to provide clear incentives (e.g., a logo) for farmers and ranchers to engage in the process and to help inform what needs to be verified on-farm. Beyond verifying project, national, and regional efforts, respondents reported that it may be increasingly important for the roundtables to show improvements on a global level, which will require some level of comparability or complementarity of locally relevant indicators and for those indicators to be housed under the same umbrella.

\subsubsection{Global Roundtable for Sustainable Beef (GRSB)}

The GRSB has developed a summary definition of sustainable beef as being "a socially responsible, environmentally sound and economically viable product that prioritizes Planet... People... Animals... and Progress", and which reflects a set of global principles and supporting criteria (GRSB, 2016). It developed this definition and these principles and criteria through a multi-stakeholder process that was intended to align with the International Social and Environmental Accreditation and Labelling Alliance (ISEAL) Standard-Setting Code of Good Practice (Beef, 2014). In 2014, the GRSB agreed to five principles: 1) produce beef in a manner that identifies and manages natural resources responsibly and maintains or enhances the health of ecosystems; 2) protect and respect human rights; 3 ) respect and manage animals to ensure their health and welfare; 4) ensure the safety and quality of beef products and utilize information-sharing systems that promote beef sustainability; 5) 
encourage innovation, optimize production, reduce waste and add to economic viability (Global Roundtable for Sustainable Beef Principles \& Criteria, 2014). Together with 32 criteria, these are intended to be broadly applicable to all national or regional contexts, and aspire to "provide the baseline understanding of sustainable beef" by defining globally what is meant by sustainable beef- "not as a labeled product but the system of sustainable beef" [emphasis added] (Global Roundtable for Sustainable Beef, 2016). The principles and criteria are intended to help inform the development of national-level sustainability indicators that can provide additional guidance on implementation, as well as metrics for assessing progress in more specific contexts (Global Roundtable for Sustainable Beef, 2016).

A main role for the GRSB is to be a credible international body for developing a global framework comprised of a clear, strong definition of sustainability principles and criteria that can be applied and measured worldwide. The GRSB additionally plays a second, more bottom-up, role by coordinating the activities of national roundtables to facilitate the aggregation and sharing of their experiences as they progress. This also entails compiling and analyzing the extent of national-level implementation in order to assess global impact. A third role of the GRSB is to incubate the emergence of national or regional roundtables. For example, the GRSB helps roundtables develop operational documents and infrastructure, and makes connections between emerging and existing national beef sustainability efforts to facilitate exchange. In all three of these roles, there is a strong level of interaction between the GRSB and the national roundtables.

\subsubsection{National Roundtables for Sustainable Beef}

National efforts generally aspire to achieve similar aims to each other, including improving stakeholders' understanding of sustainability, initiating pilot project demonstrations, and providing indicators and metrics for member assessment of improvements over time. The different RSBs have engaged in several lines of action to date. Firstly, they aimed to bring together a diverse range of important stakeholders across beef value chains. Secondly, they aimed to serve as a platform for fostering multi-stakeholder dialogue, exchange, collaboration, and agreement. Thirdly, they aimed to develop and adopt a common definition of sustainability, and then to use these global-level principles and criteria to develop nationallevel indicators. Fourthly, they aimed to monitor continuous improvement related to sustainability criteria, indicators, and metrics. Finally, they aimed to share information, best 
practices, and lessons learned among stakeholders, with an aim to building value chain — and particularly producer - capacity and understanding of what sustainability means for beef supply chains, and how to achieve it. Each national roundtable has variously engaged in different subsets of these actions.

Examples from two of the national-level RSBs serve to illustrate the diversity in activities that they have engaged in to date. First, the GTPS in Brazil has created a rating scale of national indicators intended to serve as a platform for farmers and ranchers to conduct selfassessments. The three major commitments are zero deforestation, labor rights, and sanitation. The GTPS intends to develop a capacity-building program, including a database of good examples, based on the indicators and best practices to help inform a set of pilot projects and expand the potential for sustainability impact. Second, the Canadian (CRSB) Verified Sustainable Beef Pilot Project was the first program to make the GRSB principles and criteria actionable across an entire beef value chain. Between 2014 and 2016, McDonald's Canada engaged stakeholders to form a Project Management Team which gathered input from Canadian ranchers, feedlot operators, processors, retailers, academic, civil society, government and industry groups to inform the development of "segmentspecific, locally-relevant, outcome-based indicators" (McDonald's, 2016)(McDonald's Canada, 2016). This pilot project tracked 8,967 cows on a total of 182 third-party verified sustainable ranches, feedlots, processors, and plants (McDonald's, 2016). 
Table 8. Summary of the Roundtables' Progress, Roles, Actions, and Activities

(as of November 2016)

\begin{tabular}{|c|c|c|c|c|}
\hline $\begin{array}{l}\text { Round- } \\
\text { table }\end{array}$ & Launch & Mission/ Principles & Progress/Activity & $\begin{array}{l}\text { No. of Members/ } \\
\text { Sectors }\end{array}$ \\
\hline GTPS & 2009 & $\begin{array}{l}\text { Mission: promote the sustainable } \\
\text { development of livestock through chain } \\
\text { linkage, continuous improvement and } \\
\text { dissemination of information. } \\
\text { Principles: continuous improvement; } \\
\text { transparency and ethics; good } \\
\text { agricultural practices; and legal } \\
\text { compliance }\end{array}$ & $\begin{array}{l}\text { Priority commitments: zero- } \\
\text { deforestation; labor rights; and } \\
\text { sanitation. } \\
\text { Established national indicators } \\
\text { and metrics including a 1-5 rating } \\
\text { system for self-assessment or } \\
\text { third-party verification }\end{array}$ & $\begin{array}{l}76 \text { members / } 7 \\
\text { sectors (producers, } \\
\text { industry, inputs and } \\
\text { services, retail and } \\
\text { restaurant, financial } \\
\text { institutions, civil } \\
\text { society and } \\
\text { research, } \\
\text { government). }\end{array}$ \\
\hline GRSB & 2012 & $\begin{array}{l}\text { Mission: to advance continuous } \\
\text { improvement in sustainability of the } \\
\text { global beef value chain through } \\
\text { leadership, science and multi-stakeholder } \\
\text { engagement and collaboration. } \\
\text { Principles: Natural Resources, People and } \\
\text { the Community; Animal Health and Well- } \\
\text { being; Food; Efficiency and Innovation. }\end{array}$ & $\begin{array}{l}\text { Adopted the 'Principles and } \\
\text { Criteria for defining global } \\
\text { sustainable beef' } \\
\text { 2016-2021 Strategic Plan goals } \\
\text { include: expanding global reach; } \\
\text { demonstrating results by } \\
\text { aggregating and tracking national } \\
\text { data }\end{array}$ & $\begin{array}{l}75 \text { members / } 5 \\
\text { sectors (producers, } \\
\text { commerce and } \\
\text { processing, retail, } \\
\text { civil society, } \\
\text { roundtable } \\
\text { constituency, } \\
\text { observers) }\end{array}$ \\
\hline CRSB & 2014 & $\begin{array}{l}\text { Mission: To facilitate the framework for } \\
\text { the Canadian beef industry to be a global } \\
\text { leader in the continuous improvement } \\
\text { and sustainability of the beef value chain } \\
\text { through science, multi-stakeholder } \\
\text { engagement, communication and } \\
\text { collaboration. } \\
\text { Principles: adopted GRSB principles to } \\
\text { guide national level indicators. }\end{array}$ & $\begin{array}{l}\text { Completed National Beef } \\
\text { Sustainability Assessment in 2016, } \\
\text { which benchmarked sustainability } \\
\text { performance and identified } 10 \\
\text { national goals. Concluded a } \\
\text { Verified Sustainable Beef Pilot by } \\
\text { McDonald's Canada in } 2016 \text {; } \\
\text { resulting indicators and } \\
\text { verification protocols underwent } \\
\text { public consultation in late } 2017 .\end{array}$ & $\begin{array}{l}54 \text { members / } 6 \\
\text { sectors (food and ag } \\
\text { business, non- } \\
\text { governmental } \\
\text { organizations, } \\
\text { processors, } \\
\text { producers, food and } \\
\text { retail service, } \\
\text { observers) }\end{array}$ \\
\hline Colombia & 2014 & $\begin{array}{l}\text { Mission: A focus on cattle ranching (beef } \\
\text { and dairy) with emphasis on markets, } \\
\text { institutions, and technical information }\end{array}$ & $\begin{array}{l}\text { Developed working definition of } \\
\text { sustainable cattle ranching; } \\
\text { established a technical secretariat; }\end{array}$ & $\begin{array}{l}\text { 45 members / } \\
\text { sectors } \\
\text { (government, civil }\end{array}$ \\
\hline
\end{tabular}




\begin{tabular}{|c|c|c|c|c|}
\hline $\begin{array}{l}\text { Round- } \\
\text { table }\end{array}$ & Launch & Mission/ Principles & Progress/Activity & $\begin{array}{l}\text { No. of Members/ } \\
\text { Sectors }\end{array}$ \\
\hline & & $\begin{array}{l}\text { Principles: adopted GRSB principles with } \\
\text { a broader focus on cattle ranching (both } \\
\text { beef and dairy) }\end{array}$ & $\begin{array}{l}\text { convened workshops; working on } \\
2017 \text { action plans }\end{array}$ & $\begin{array}{l}\text { society, research } \\
\text { institutions, dairy } \\
\text { and beef producers, } \\
\text { processors }\end{array}$ \\
\hline USRSB & 2015 & $\begin{array}{l}\text { Mission: To advance, support and } \\
\text { communicate continuous improvement } \\
\text { in the sustainability of U.S. beef } \\
\text { production by educating and engaging } \\
\text { the beef value-chain through a } \\
\text { collaborative multi-stakeholder effort. } \\
\text { Principles: aligned with GRSB principles }\end{array}$ & $\begin{array}{l}\text { Developed a sustainability } \\
\text { assurance framework. Established } \\
\text { working groups to shepherd } \\
\text { development of national } \\
\text { indicators and metrics 2015-2017. }\end{array}$ & $\begin{array}{l}101 \text { members / } 5 \\
\text { sectors (producers; } \\
\text { allied industry; } \\
\text { packers/processors; } \\
\text { retail, civil society). }\end{array}$ \\
\hline Mexico & $\begin{array}{l}\text { Steering } \\
\text { cmte. } \\
\text { Est. } \\
2014\end{array}$ & $\begin{array}{l}\text { Principles: adopted GRSB principles with } \\
\text { a broader focus on cattle ranching (both } \\
\text { beef and dairy) }\end{array}$ & $\begin{array}{l}\text { Agreed mission, vision, and } \\
\text { objectives; working on strategic } \\
\text { plan }\end{array}$ & $\begin{array}{l}\text { 15 members / } 5 \\
\text { sectors (producers, } \\
\text { processors, civil } \\
\text { society, input } \\
\text { industry, retailers) }\end{array}$ \\
\hline $\begin{array}{l}\text { Paraguay } \\
\text { and } \\
\text { Argentina }\end{array}$ & $\begin{array}{l}\text { Concept } \\
\text { stage } \\
\text { (2016) }\end{array}$ & $\mathrm{n} / \mathrm{a}$ & $\mathrm{n} / \mathrm{a}$ & $\mathrm{n} / \mathrm{a}$ \\
\hline
\end{tabular}

While each roundtable is at a different stage of development, respondents widely held an expectation that examples and pilots such as these will be replicable and implemented in other roundtable countries and contexts. The following section provides brief descriptions of each national roundtable.

\subsubsection{Brazilian Roundtable on Sustainable Livestock (GTPS)}

The GTPS has initiated a portfolio of projects that they support - meaning they provide a venue for visibility and credibility through GTPS endorsement, since membership involves major actors across the supply chain with which these projects would not otherwise have a chance to form partnerships. The GTPS has also developed sustainability indicators for all stages of the supply chain, not just for producers. Over the next two years, GTPS members 
intend to apply the indicators through self-assessment to diagnose challenges and to demonstrate sustainability efforts to the rest of the supply chain.

The GTPS provides an example of how national-level roundtable activities can evolve towards verified sustainability impacts. For example, McDonald's agreed to purchase beef for the Rio Olympics in 2016 from a sustainability initiative, Novo Campo, in Brazilian Amazonia (McDonald's, 2016). This represents the first time McDonald's has agreed to buy beef from the Amazon region since their self-imposed 2015 commitment not to source from that biome (McDonald's, 2016; Moutinho et al., 2016). The beef in the Novo Campo project is verified against GTPS indicators rather than being certified with an existing certification standard (i.e., the Sustainable Agriculture Network/Rainforest Alliance program) (MaguireRajpaul et al., 2016). According to respondents, verification allows for a less expensive and onerous transition process for producers.

\subsubsection{North American RSBs: Canadian Roundtable for Sustainable Beef (CRSB) and United States Roundtable for Sustainable Beef (USRSB)}

First, the CRSB developed a sustainability benchmarking assessment across social, environmental, and economic metrics, coupled with a strategy for addressing high-priority areas. The assessments were released in late 2017 following a review by an objective, thirdparty committee (Canfax Research Services, 2016; Deloitte, 2016). Second, the CRSB is also developing a verification framework comprised of indicators and verification protocols designed to allow producers and processers to demonstrate sustainability, to provide retailers with verified sources for sustainable beef, and to articulate clear and accurate consumer messaging. Based upon the sustainability benchmarking and verification framework, CRSB anticipates launching pilot and demonstration projects (Canfax Research Services, 2016; Deloitte, 2016).

The United States Roundtable for Sustainable Beef's (USRSB's) work has largely been a result of an earlier lifecycle assessment on beef (Thoma et al., 2017) after which a group of interested parties formed and established the roundtable. Since then, the USRSB has established three working groups on indicators and goals, verification, and sustainable solutions. It also developed a three-year strategic plan in 2016 which included updated scopes for its working groups, membership surveys, and communications messages for targeted audiences (U.S. Roundtable for Sustainable Beef, 2016). 


\subsubsection{Emerging Roundtables: Mexico and Colombia}

Among all the roundtables in the cattle sector, Mexico's and Colombia's roundtable efforts are the most nascent. Additionally, they have already differentiated their focus and direction from that of the other national roundtables. First, the Mexico roundtable encompasses the dairy sector in addition to the beef sector. Second, it has an explicit focus on public policy and will involve a policymaker constituency. Specifically, the Mexico roundtable aims to create policy incentives for sustainable beef and dairy practices instead of following the voluntary approach of other national RSBs.

Colombia's emerging roundtable also focuses on sustainable cattle ranching, not only beef, to create a venue for discussing a broader set of topics that includes dairy. Colombia's roundtable is focused on three priorities: 1) leveraging market opportunities in a country with $78 \%$ smallholder ranchers and 98\% domestic consumption of beef and dairy; 2) building supporting policies and institutions; and 3) gathering technical information on sustainable cattle ranching and key actors involved in both the beef and dairy supply chains.

\subsubsection{Potential and Limitations of the Roundtables for Sustainable Beef (RSBs)}

The RSBs have defined what sustainable beef production means in their contexts and have identified the kinds of issues that need to be addressed to demonstrate sustainability and improvements around the world. These are the primary ways in which the RSBs can be said to have changed the sustainability landscape of the beef sector thus far. However, this impact does not necessarily translate into changes in sustainability outcomes on the ground and has not yet done so. Indeed, respondents universally reported that it is still too early to assess the impacts of the RSBs on sustainability outcomes. The roundtables were only recently initiated, and many are still in the development stage. Consequently, there has been little opportunity to measure or quantify impacts, and no published research has attempted to do so.

At the same time, many respondents felt that RSBs represent genuine intention and momentum and hold potential to affect sustainability outcomes in a detectable and measurable way in the future. Therefore, our respondents spoke primarily about potential impact pathways; mechanisms by which they expected the RSBs to influence sustainability outcomes in coming years. These included: centralized coordination; geographic expansion; 
demonstrating impact; moving towards verification; and minimum membership criteria. Each of these is discussed in turn.

\subsubsection{Centralized Coordination}

Respondents reported an expectation that the GRSB would eventually play a more centralized coordination role in information-gathering and in evaluation. For example, respondents anticipated that the GRSB could serve as a repository of information, best practices, and resources and make those publicly available for use by current and prospective roundtable members, as well as civil society, researchers, and the general public. Activities are underway to assess the state of beef sustainability globally, by gathering data from GRSB members on existing sustainability commitments. By incorporating other sustainable beef and livestock initiatives, this could provide a global sense of efforts underway and, eventually, their impacts. Another example of coordination that respondents anticipated was that RSB efforts could or would expand to include benchmarking: enabling comparison of information and reporting from national and regional roundtable efforts, as well as enabling market verification. These efforts could evolve into more formal, verified reporting against nationaland regional- indicators and metrics, tracking improvements over time.

\subsubsection{Geographic Expansion}

Respondents broadly agreed that to have a global impact, the GRSB needs to catalyze engagement and activities in more diverse regions that represent significant opportunities for impact. There is a need for RSB efforts to broaden their scope beyond Western companies and NGOs and to include members and companies from African countries, India, and China. However, respondents reported that the GRSB's current four-year strategy is to work within countries and regions that already have indicated an enthusiasm for sustainable beef rather than to attempt to cultivate momentum for additional national roundtable efforts.

At the national level, respondents anticipated that the roundtables would, in the future, need to: conduct pilot projects that demonstrate viability of more sustainable practices; effect change by influencing national and local public policy; and demonstrate, document, and disseminate information about positive impacts, with a clear articulation of what they have achieved. 


\subsubsection{Moving Towards Verification}

Many respondents pointed to the need for the RSBs to eventually develop a mechanism for establishing indicators and metrics that RSBs can verify. For the most part, members are currently using the RSB's indicators and metrics to conduct self-assessments to measure and report continuous improvement over time, rather than to prove their compliance against those indicators and metrics. Few producers are currently verified as demonstrating compliance with a formal set of sustainability standards as part of the Rainforest Alliance/Sustainable Agriculture Network (RA/SAN) certification program. However, third-party verification pilot projects in Brazil and Canada have compared production standards against the national roundtable indicators. Such an approach could be adopted elsewhere (McDonald's 2016), expanding the number of producers who are verified as achieving particular standards, even if outside of the remit of a formal certification program. Certification standards can be complex to develop and challenging to scale, as respondents familiar with such standards highlighted. As a result, many actors are seeking alternative solutions to foster credibility that involve less onerous practices that are easier to scale but that can be verified.

While acknowledging an anticipated trend towards third-party verification against national roundtable indicators, most respondents expected that verification would remain voluntary and retailer-driven, rather than evolve into an RSB role. RSBs have limited resources, and the number of members a national roundtable would have to audit (e.g., 800,000 producers in the U.S.) is high. Therefore, respondents expected that RSBs would provide the metrics and tools underlying any emergent third-party certification standard, but that verification would be funded by retailers interested in sourcing their products more sustainably.

\subsubsection{Minimum Membership Criteria}

Some respondents proposed a need for the global and national roundtables to begin with some minimum thresholds or membership criteria. These criteria would acknowledge that some practices (e.g., forced labor) are simply unacceptable, no matter the extent of commitment to continuous improvement. While not currently in place, respondents indicated that the GRSB may consider requiring its members to make commitments upon entry to the roundtable that would include a minimum benchmark against certain practices. 


\subsubsection{Limitations Sustainability Contributions}

The RSBs face some limits to offering significant sustainability contributions. First, cattle production in many countries is characterized by large numbers of small- and medium-sized producers. Communicating and engaging with large numbers of producers is challenging. Smaller producers are often less able to adopt new practices; for example, they often have less financial capital to pay for new infrastructure. It can therefore be extremely difficult to incentivize smaller producers to change practices, and to measure continuous improvement over time on large number of small properties.

Second, some of the national RSBs have had trouble engaging sustainability leaders. Some see their company's practices as providing a proprietary competitive advantage over their peers in the sector. The RSBs offer a forum for pre-competitive information exchange and dialogue, with the notion that "rising tides lift all boats." However, market competition within the beef sector presents a challenge to this cooperation, and some actors therefore see little incentive to share best practices. Others expressed concern that some roundtable members (as in the McDonald's example highlighted above) were using the roundtable indicators to verify and market their sourcing of 'sustainable beef', which is a controversial approach. This is because some view roundtable efforts as the sector's social license to operate $^{63}$ and as therefore inappropriate to use as leverage for marketing and competitive purposes. Still others argue that the claim of achieving 'sustainable beef' is an overstatement and could jeopardize the credibility of a continuous improvement approach to sustainability.

Third, the competitive nature of the industry also presents a question regarding whether RSB efforts will be incentivized through tools such as guaranteed purchase agreements or price premiums. Many respondents, including those from the retail side of the value chain, indicated a need for incentives and perhaps premium payments for a verified sustainable product. However, few were optimistic that buyers and retailers would provide such incentives. This can present a challenge in incentivizing producers and processors to change

\footnotetext{
63 'Social 'Social license to Operate' can be defined as a set of concepts, values, tools and practices that represent a way of viewing reality for industry and stakeholders. Its purpose is to create a forum for negotiation whereby the parties involved are heard, understood and respected. SLO is a means to earn accountability, credibility, flexibility and capacity for both stakeholders and industry.” (Nelson, J. 2009, p. 161)
} 
practices, which may require additional investment, capacity-building, or adoption of new technologies.

Fourth, a lack of funding and resources was cited as a challenge to achieving sustainability impacts. Additional resources could support more ambitious data gathering, assessment, comparison, and reporting across national levels, as well as aggregation of data and impactassessment at the global level—which requires some degree of comparability across nationallevel data. Many respondents indicated there is tremendous potential, but that a great deal of effort and resources are needed to build the infrastructure of robust information cataloguing and analysis.

Finally, several respondents pointed out that corporate membership in the roundtables represents the 'bare minimum' of what companies can do, and that the participation of sustainability officers does not necessarily translate into changes in sourcing or supply chains. Relatedly, there were different perceptions about the motivations of RSB members. Some members view RSBs as a multi-stakeholder approach to grappling with sustainability challenges and fostering continuous improvement, whereas others view them as an industry association designed to promote marketing and growth. A minority of respondents were critical of the RSBs, claiming they were "greenwashing platforms" 64 for companies and/or that the theories of change for improving sustainable production were unclear, and that dialogue seems to be their main role. Within civil society, some observed that NGOs are obliged by their funders to participate in RSBs, even though they may not see the benefit in doing so or have much faith in the RSBs' credibility. In aggregate, these motivations and perceptions could present challenges to RSB long-term credibility and opportunity for impact.

In addition, two topical areas emerged as clear current limitations in the roundtables' scope: consumption and food waste. Most respondents indicated there is little potential for the RSBs to address consumption, whereas food waste was seen as a more promising area for future roundtable work. For example, the US Life Cycle Analysis (LCA) highlighted food waste as

\footnotetext{
${ }^{64}$ This term refers to an initiative or effort that primarily "make[s] people believe that your company is doing more to protect the environment than it really is" ("greenwash." 2020. In Cambridge Dictionary. Retrieved 15 November 2020, from https://dictionary.cambridge.org/dictionary/english/greenwash).
} 
a tremendous opportunity for improving sustainability across the entire beef value chain (Asem-Hiablie et al., 2019). RSBs may be currently limited in addressing food waste issues yet could serve as a catalytic forum for developing relevant projects outside of roundtable activities.

\subsection{Discussion}

\subsubsection{Roundtables for Sustainable Beef (RSBs) as Non-State Market Driven (NSMD) Initiatives}

This chapter aimed to understand the current and potential governance structures, actions, and perceived sustainability impacts and limitations of the roundtables for sustainable beef. Employing Bernstein and Cashore's NSMD framework helped to systematically explore the extent to which RSBs possess and/or differ from the five defining characteristics of NSMD governance systems and the three phases they move through towards achieving "political legitimacy" (termed "Phase III") (Bernstein \& Cashore, 2007). It is important to note that Bernstein and Cashore (2007) distinguish "political legitimacy" from the broader concept of legitimacy which signifies that “... actions of an entity [are] 'desirable, proper, or appropriate..."” (Bernstein \& Cashore, 2007 quoting Suchman, 1995, p. 574). In contrast, "political legitimacy...concerns the acceptance of a governance relationship, where commands ought to be obeyed" (Bernstein \& Cashore, 2007, p. 351). The NSMD framework focuses on the process of community interaction, shared learning, and norm-formation as the basis for community members to "grant authority" to the emergent governance system (Bernstein \& Cashore, 2007, p. 351). The evolutionary process that emergent non-state governance systems go through to achieve political legitimacy is important to understand because it indicates the system has become mainstream as opposed to niche. It indicates the NSMD system has achieved participatory saturation across stakeholders within the sector and is recognized as the appropriate forum to debate, resolve, and advance sector-specific policy issues (Bernstein \& Cashore, 2007). This section explores the RSBs through the NSMD characteristics to assess where RSBs are on the evolutionary spectrum. The NSMD framework is later applied in Section 4.6 to REDD+ and zero-deforestation commitments to similarly understand the evolution of those efforts towards 'political legitimacy' for the reasons described above. 
In examining the characteristics of RSBs through the NSMD rubric, some national RSBsMexico and Colombia, in particular-diverge slightly from the NSMD governance system definition and the first characteristic. Mexico and Colombia RSBs involve participation and support of national policy makers as part of their stakeholder community. Therefore, it could be argued that state participation imparts some degree of policy-making ability and/or authority (Bernstein \& Cashore, 2007). Of the five NSMD characteristics, all RSBs most closely embody NSMD governance systems' second characteristic of generating "collective goals and values...in which adaptation, inclusion, and learning occur over time and across a wide range of stakeholders" (Bernstein and Cashore 2007, p. 349). While this paper does not seek to compare RSBs to other commodity roundtables, RSBs are unusual in that they embrace an inclusive, sector-wide approach focused on continuous improvement rather than a fixed certification standard that only a subset of the sector can attain. In this way, RSBs also lack the full expression of the third NSMD governance system characteristic of "[certification] for compliance to an NSMD system" (Bernstein and Cashore 2007, p.350). RSB leadership respondents indicated they did not intend to pursue a certification standard or label and instead were in favor of a continuous improvement model exemplary of the second NSMD governance system characteristic. This type of sector-wide continuous improvement approach, it was argued by some respondents, embodies a more mainstream approach as compared to a standards-based certification system which is seen as more niche. Both of these systems have their challenges when it comes to achieving Phase III of 'political legitimacy'(Bernstein \& Cashore, 2007). According to some respondents, a bottom-up continuous improvement approach is not seen as stringent enough to demonstrate significant early impact which some respondents indicated was a pre-requisite to earn their participation and support. A standards-based certification approach risks being inaccessible (e.g., too expensive, too difficult) (Fransen, 2011) for the majority of the sector and risks being inefficient and niche in terms of widespread adoption (Bitzer et al., 2008).

The NSMD governance system's fourth characteristic regarding reconfiguration of markets and an "attempt to ameliorate global problems" (Bernstein and Cashore 2007, p. 350) has yet to be fully realized since sustainability efforts are still underway. Some argue that the notion of sustainable cattle production is not possible to attain, or at least not in comparison to plantbased proteins (Poore \& Nemecek, 2018). However, the RSBs' objective of engaging the entire sector rather than a high-performing subset of actors fits the essence of market 
reconfiguration as defined in a NSMD governance system (Bernstein \& Cashore, 2007). None of the RSBs yet feature the fifth NSMD governance system characteristic of developing mechanisms for addressing compliance (Bernstein and Cashore 2007, pp. 349-350).

One of the concerns that often arises in relation to NSMD governance systems is whether the fiduciary responsibility of participating companies undermines their ability to act in accordance with other non-financial, voluntary priorities such as sustainability goals. As Bernstein and Cashore point out, "this conundrum...is frequently cited...to argue that NSMD governance systems will never be effective" (p. 354). They posit that learning how political legitimacy develops - through a series of three phases — helps to "[address] the paradox of why profit-maximizing firms would ever agree to abide by a non-state political authority that increases burdens and shapes their behavior" (p. 354).

The first phase of 'initiation' encompasses nascent interest in an NSMD governance system followed by cost-benefit analyses by potential civil society and industry stakeholders (Bernstein \& Cashore, 2007, pp. 355-357). Bernstein and Cashore (2007) describe this group of early adopters as a “"political community'... all of whom benefit from addressing global problems" which leads them to identify shared interests and build relationships to collectively address those problems. To do so on any sort of significant scale requires enlisting broader interests (Bernstein \& Cashore, 2007, p. 357).

The second phase of 'building widespread support' is influenced by a number of 'countervailing dynamics' associated with different types of NSMD governance system constituencies (e.g., private sector, civil society) and factions within those constituencies, and their behavior. Whether or not to build widespread support and under what conditions depends upon different constituents' perceptions of the relative benefits, perceived costs, and impacts. For example — and central to the potential sector-wise impacts that RSBs could have-Bernstein and Cashore point out that a subset of participating firms weigh their desire for building support against the financial premiums and competitive advantage they get from producing a distinct 'niche' product (2007, p. 358). Another subset of firms sees building widespread support as proliferating "appropriate business practices" and therefore are in favor. These behaviors were also reflected in our results. Some respondents indicated they see RSB membership as a way of distinguishing their products from the rest of the market, 
whereas others called for roundtables to be less competitive and more focused on sharing best practices and lessons learned to improve sector-wide impact.

This second phase is particularly challenging from an impact-at-scale perspective. Creating a high-bar, and often expensive certification process excludes a portion, if not a majority, of the sector that the system is seeking to change. The stated rationale among RSB leadership for not creating the more common commodity roundtable standard and certification program is precisely to move away from a 'boutique' approach to sustainability. The RSBs claim to "start where producers are" and provide resources and support to incrementally improve their sustainability over time. Presumably, this approach could help to build widespread support among private sector constituents but may have detrimental effects for building support among civil society groups that prefer to set a standard and increase the number of producers that meet that standard over time (Bernstein and Cashore, p. 358-359). The present results reflected similar differentiation of civil society interests ranging from those that were highly supportive of and engaged in RSBs, and others that were more critical of voluntary, nonstandard-setting approaches. However, even in the context of standard-setting certification roundtables, the evidence of significant sustainability impacts remains mixed (K. M. Carlson et al., 2018; Newton et al., 2015; Van Der Ven et al., 2018).

Finally, phase three is achieving 'political legitimacy' which Bernstein and Cashore, (2007) define as "the acceptance of shared rule by a community as appropriate and justified" (p. 348). Hallmarks of this phase include the diverse community of relevant stakeholders recognizing the legitimacy of the NSMD governance system as a forum to "advance interests" and to "mediate disputes and address policy problems" (p. 361). In this phase, the questions are no longer whether the NSMD governance system should exist or whether it can be effective at solving problems, but rather how diverse stakeholders can work collaboratively within the NSMD governance system to ensure its effectiveness. Citing Sasser (2002), Bernstein and Cashore point out that some civil society groups will not grant legitimacy "until the on-the-ground effects are shown to improve environmental and social integrity" (p. 359). This could create a paradox in that members of an NSMD governance system cannot consistently or uniformly achieve social and environmental improvements without NSMD governance system stakeholders, including civil society, fully engaging in the problem-solving that seems to be a characteristic of the political legitimacy phase. While 
these phases may represent the observed norms of NSMD governance, interventions to foster political legitimacy early on may enable NSMD governance approaches to have an impact sooner.

Using this three-phase system as a benchmark, it seems that the longest-established roundtables (i.e., GTPS, GRSB, CRSB, USRSB) are in Phase II of continuing to build widespread support and through that, continuing to develop their collective aims. Colombia and Mexico, by contrast, are still in the initiation phase. Although, Mexico's roundtable involves policymakers as stakeholders with an eye towards informing complementary policy measures to the voluntary continuous improvement program. Involving state actors in its process may confer a greater degree of validity from the start, making it that much easier for the Mexico roundtable to evolve towards the third phase of political legitimacy.

As some interview respondents indicated, the process of building widespread support at a truly global level for the sector would entail roundtable proliferation in major beef- and cattle-producing countries like China and India. Therefore, while it may be possible for RSBs to achieve political legitimacy at national levels, doing so at the global market or sectoral level could present a much greater challenge.

\subsubsection{Governance and Actions}

All RSBs are currently structured as multi-stakeholder initiatives, although with different processes for engagement. While there was broad agreement that a multi-stakeholder process, is important to inform a sector-wide approach and to foster credibility, many respondents expressed frustration with the inefficiencies of a diverse and collaborative approach to pursuing sustainability in the sector. The impetus for a multi-stakeholder initiative (beyond some RSBs subscribing to the ISEAL Standards-Setting Code) can be a result of companies responding to global and often "competing demands...driven by political, legal, economic or social pressures" (Vieira et al., 2016, pp. 5-6). Interviews provided additional insights into this motivation: specifically, that the RSBs were formed to address two primary concerns. First, to provide a platform and sustainability approaches that reflect the complex nature of the beef and cattle industries rather than replicating existing commodity roundtable certification approaches. Second, to respond to criticism and growing consumer concern around beef and dairy sustainability. 
The national RSBs are at different stages of implementation. Some have developed criteria and indicators which industry members can use to advance their individual actions and measure progress. Other roundtables are still forming and have not yet agreed on criteria and indicators. Brassett et al. (2012) observed that other sustainable commodity roundtables, "by maintaining de jure autonomy from governments have been able to project themselves as commercially neutral and move further and faster in agreeing the standards against which producers will be certified" (Brassett et al., 2012). This observation holds for all of the RSBs, except for Colombia's roundtable, which is government-led. This autonomy may enable greater efficiency, although at some future point it may be useful to compare Colombia's government-led roundtable with other autonomous RSBs to assess efficiency and effectiveness of different approaches.

Many respondents expressed frustration with the inefficiencies of a multi-stakeholder consensus-driven process, although judgements about efficiency are presumably in comparison to a different model, each of which would have its pros and cons. While the RSBs differ in approach from other commodity roundtables, the continued proliferation of a multi-stakeholder approach to enhancing commodity sustainability seems to indicate this is an attractive model. As the interview and survey results show, an industry association model may lack legitimacy and credibility. To enhance the quality of dialogue and decision-making, and to make clear the rationale for a multi-stakeholder approach to roundtable members, RSB leadership may benefit from drawing upon the research on multi-stakeholder dialogue, collaboration, and consensus-building. Drawing upon relevant literature on multi-party negotiations and consensus-based decision-making may help RSB leadership communicate the rationale for such an approach to their current and prospective members, as well as to stakeholders in countries that are considering whether to establish a national roundtable. According to Zartman, negotiation is a "positive-sum" process in which parties' interests converge into a single outcome (Zartman, 1977). Each party in a consensus-based process can effectively veto or choose an alternative to reaching a consensus agreement (Fisher \& Ury, 2011). Therefore, while often criticized as challenging and inefficient, it is safe to assume the consensus-based outcome was preferable to all parties than any other individual or collective outcome they could have chosen (Zartman, 1977). Of course, different stakeholders could work independently on the issue of sustainability in the beef and cattle industry, but they do not do so presumably because that would produce less-desirable 
outcomes than a multi-stakeholder consensus process. The process of convening initial multistakeholder dialogue, building diverse participation, and using the forum for collective problem-solving reflects the three phases NSMD governance systems go through to achieve political legitimacy (Bernstein \& Cashore, 2007).

It may be helpful for RSB leadership to understand and communicate the effects of multistakeholder consensus processes, as summarized by Innes (2004) in response to various critiques of this processes:

...it can produce joint learning, intellectual, social, and political capital (Gruber, 1994), feasible actions, innovative problem solving, shared understanding of issues and other players, capacity to work together, skills in dialogue, shared heuristics for action (Booher and Innes, 2002; Connick and Innes, 2003; Unknown, 2003; Innes et al., 1994; Innes and Booher, 1999a, 2003; Ostrom, 1990). It can include new ways for players to understand and reframe their identities in relation to a larger picture (Connick and Innes, 2003; Innes and Connick, 1999) and in a way contingent on others' identities (Innes, 2004, p. 8).

Other scholars emphasize the need for diverse participatory approaches to sustainable development, recognizing that developing and implementing appropriate solutions to the complexity of global sustainability challenges we face requires collaboration and cooperation because no one sector (including via inter-governmental cooperation) can resolve these challenges alone (Hemmati, 2002; Kjellén, 2008; Moomaw et al., 2017).

These effects were confirmed in our results in that all respondents pointed to the roundtables' current primary role as providing a forum for shared learning and information exchange which helps build a collective understanding of the issues. The multi-stakeholder consensusbased process by which they do this will likely continue to yield the above-mentioned effects (and political legitimacy) over time which, in turn, will enhance their ability to work collaboratively to solve problems and have an impact (Bernstein \& Cashore, 2007).

To the multi-stakeholder nature of commodity roundtables, Brassett et al. (2012) outline additional functions of diversified participation including: 1) sharing local knowledge about sustainable practices and challenges; 2) avoiding overlapping sets of sustainability standards; and 3) fostering legitimacy and accountability through civil society participation (Brassett et al., 2012). As RSBs continue to expand and evolve in other countries and regions, it will be important to consider potential trade-offs between perceptions of efficiency vs. legitimacy and credibility. 
More broadly, interviews revealed governance and representation challenges, with a lack of RSB participation in Africa and Asia, as well as limited engagement from small- and medium-sized producers. The challenge of Western-led sustainable commodity roundtable efforts is not unique to the beef sector. Other commodity roundtables are perceived as 'Western' initiatives but labeled as 'global' initiatives (Brassett et al., 2012). Aside from being a representation challenge, lack of engagement from diverse geographic regions is also a challenge to having global sustainability impacts. India, in particular, is a top exporter of beef and cattle (buffalo) (Khan et al., 2016; USDA Foreign Agricultural Service, 2017, 2021) but is currently not involved in an RSB-type initiative, which presents a major gap for global sustainability impact. While this bottom-up approach to proliferating the work of RSBs may help generate local and national buy-in, it may also undermine claims or perceptions that RSBs are having global sustainability impact.

To manage the challenge of engaging small- and medium-sized holders, "capacity-building, education, and awareness-raising programs could facilitate the adoption of better practices by producers, lessen their negative impacts, and increase the sustainability of production" (Newton et al., 2013). Emerging lessons from smallholder engagement in value chains underscores the need for: pilot projects; collaboration on objectives and governance structures; "neutral conveners" to catalyze partnerships and projects; and facilitating investment in smallholder production efforts (Clinton Global Initiative, 2016).

\subsubsection{Potential for Sustainability Impacts}

From an environmental perspective, beef supply chains are in many cases associated with multiple environmental externalities that, in aggregate, generate a significant sustainability footprint (de Vries \& de Boer, 2010; Steinfield et al., 2006). Although beef production systems vary enormously, many are strongly linked with high levels of greenhouse gas emissions, biodiversity loss, land use, and water consumption (Poore \& Nemecek, 2018). The greenhouse gas emissions per unit weight associated with beef are higher than any other animal or plant protein; these emissions are even higher when associated land use change, including tropical deforestation, are incorporated into the equation (Ripple et al., 2014). From a direct-emissions perspective, efforts to better understand and reduce methane emissions from ruminants are underway. The Livestock Research Group project conducted a global rumen census to survey samples in 34 countries across a diverse set of production systems. 
The main finding was that similar methane-producing microbes were consistently found in animals globally (Henderson et al., 2015), meaning interventions and technologies aimed at reducing methane emissions could have global applicability. The study also found that these microbes could be influenced through diet (Henderson et al., 2015) which could present opportunities for RSBs to promote production practices that significantly reduce methane emissions.

Indirect emissions and environmental impacts are particularly relevant to tropical forested countries such as Brazil, Colombia, and Paraguay. In Brazil, for example, sustainable supply chain activities (including, but not limited to, the RSBs) have promoted sectoral and corporate change (Vieira et al., 2016) that has contributed to Brazil's recent ability to simultaneously reduce deforestation (De Oliveira Silva et al., 2016; D. Nepstad et al., 2014) while becoming the world's top beef exporter (USDA Foreign Agricultural Service, 2017). Zero-deforestation cattle agreements have had limited additionality to supply-chain impacts to date (Lambin et al., 2018). Similarly, in the palm oil sector, there have been limited documented impacts of certification reducing peatland fires in Indonesia (K. M. Carlson et al., 2018). As Bernstein and Cashore point out, NSMD governance systems often offer governance opportunities where efforts by national and intergovernmental entities might ignite a dispute (2007, p. 354). To be effective and comprehensive, there needs to be greater attention on a combination of public and private policy efforts to reduce deforestation (Lambin et al., 2018). In this regard, there may be significant future opportunities to learn from beef/cattle roundtable efforts in Mexico and Colombia, where policymakers are playing an active role. Perhaps future governance mechanisms will represent a hybrid between NSMD governance systems and public-private partnerships, which would provide a venue for fostering greater coherence, complementarity, and sustainability impacts.

At the global level, promoting continuous improvement has included developing and agreeing to principles and criteria to serve as a "guiding framework for establishing regional or country specific indicators and metrics" (Global Roundtable for Sustainable Beef, 2016). At the national level, this has included: providing forums or platforms for sharing best practices and lessons learned as well as developing indicators and metrics that can be applied for self-assessment or verified against in second- or third-party audits. 
It is too early to fully assess whether RSB efforts are indeed enhancing the sustainability of beef supply chains, but many respondents agreed that establishing and agreeing upon global principles and criteria as well as national-level indicators and metrics is a first step in that direction. Additional measures for improvement were outlined in a recent study authored by several RSB members and leaders. These included: 1) the need for scientifically grounded frameworks for assessing impacts, 2) more significant engagement of supply chain stakeholders, and 3) enhancing stakeholder communication and consumer information sharing (Maia de Souza et al., 2017). The results of this study and the stakeholder engagement processes outlined in the Maia de Souza et al. (2017) paper point to an iterative process by which different stakeholder interests are negotiated to reach incremental agreements over time.

International relations social constructivist scholars would argue that the process by which states interact "change(s) identities and interests..." (Bisht, 2008, p. 138; Wendt, 1992) which has also been documented within multi-stakeholder interactions (Dewulf, 2007; Schultz et al., 2018). The three phases of a NSMD governance system-from initiation to political legitimacy - also point to transformation in stakeholder perceptions and interests over time (Bernstein \& Cashore, 2007). Market pressures and the level of transparency from both external and participating civil society groups can also be expected to change over time and exert more pressure on RSBs to demonstrate impact. The Cargill and McDonald's ${ }^{65}$ verified sustainable beef pilot projects in Canada and Brazil indicate some members are already using the RSB principles and indicators to demonstrate implementation and impact more clearly. Yet there is not yet scientific literature on these verification efforts, only media articles announcing the first-ever project to implement the GRSB principles and criteria in Canada (McDonald's Canada, 2016; Radke, 2016).

Relative to environmental dimensions, the social aspects of sustainability are not seen as highly prioritized in the RSBs. This is where setting a minimum criteria threshold (e.g., excluding producers that use forced labor) (Nepstad et al., 2006) and finding ways to engage

\footnotetext{
${ }^{65}$ See: https://news.mcdonalds.ca/stories/first-ever-pilot-verify-sustainable-beef-canada-concludes
} 
small- and medium- producers whose livelihoods depend on livestock could be useful for enhancing the roundtables' multi-dimensional sustainability impacts.

To further demonstrate credibility and impacts, RSBs may consider adopting ISEAL's Impacts Code which calls for subscribers to: 1) be explicit about intended impacts and outcomes; 2) articulate strategies for how these will be achieved; and 3) gather evidence to evaluate impact and identify improvements over time (ISEAL Alliance, 2014). If one considers RSBs as cross-sector partnerships, van Tulder et al. (2016) contend that,

...there is an urgent need for cross-sector partnership research to pay greater attention to the monitoring, reporting, and evaluation of the outcomes and impacts on social problems of partnerships. This is necessary to inform and support the legitimacy and credibility of partnerships as an effective and efficient approach to solving complex social and environmental issues, as well as in determining their necessary limits (van Tulder et al., 2016, p. 2).

As RSB activities continue to unfold, improved monitoring and evaluation of their activities and impacts can help inform their ongoing evolution and growth, and tools such as the Impacts Code may be a useful step in that direction.

\subsubsection{Finding Middle Ground in the Continuum from Continuous Improvement to Certification}

Many respondents underscored the need for RSBs to embrace the notion that they are establishing a sustainability standard and that eventually they will need to promote or facilitate third-party verification against that standard. For example, the GTPS could serve as a "stepping stone" that bridges between single-dimension (e.g., zero-deforestation) initiatives and more holistic sustainability standards (e.g., Rainforest Alliance/Sustainable Agriculture Network (RA/SAN) certification) - perhaps acting as a platform for scaling up adoption of the RA/SAN standard.

Respondents shared multiple reasons for not pursuing a certification standard. First, there was a desire to engage the full sector and avoid "considerable time and cost... [without] the benefits in terms of price premiums or market access..." (Walker et al., 2013). Second, other commodity roundtable and certification approaches have come under increasing scrutiny by scientists and NGOs (e.g., (Laurance et al., 2010); Scientists' Statement on RSPO's Revised Principles and Criteria; Greenpeace's “Certifying Destruction”). Third, multiple respondents indicated that one of the reasons for adopting a continuous improvement approach rather than 
certification was their observation that the scientific literature indicated that certification in other sectors (e.g., soy, palm) had only had mixed success, with varying degrees of sectoral adoption and measurable impact (Cattau et al., 2016; Garrett et al., 2016; Tayleur et al., 2017), and with total certified crop area estimated at 1.1 percent of global croplands (Tayleur et al., 2017). While these may present valid concerns about pursuing a certification approach, in comparison to palm, timber, pulp, and soy, the cattle industry's corporate commitments lag far behind (Donofrio et al., 2017) while their annual tropical forest loss may be more than five times that of the above-mentioned commodities (Henders et al., 2015). Despite respondents' concerns about certification, both the results of this research and the examples of verification pilot projects seem to point to a de facto standard, with resulting sustainability claims being made by some RSB members. Without carefully considering how to best manage this evolution, the RSBs' future credibility may be at stake. To have impact and build credibility, RSBs may need to find middle ground along the continuum between self-assessed voluntary continuous improvement and certification.

As RSBs consider options for providing assurance, it may be useful to draw upon existing verification initiatives and guidance. For example, Unilever's Sustainable Agriculture Code provides a comprehensive self-assessment tool for farmers to determine the sustainability of raw materials (King et al., 2010) which could prove useful for fostering sector-wide verification consistency. The International Organization for Standardization (ISO) also provides guidance on environmental self-declared claims and lifecycle declarations. For selfdeclared claims of "sustainability" ISO indicates, "whichever definition of 'sustainability' is used, we are still some way off having internationally agreed benchmarks for the minimum economic, social and environmental performance that would indicate a product had been manufactured in a truly 'sustainable' manner"; and ISO 26000:2010 requires "that selfdeclared claims of achieving sustainability shall not be made" (Dee et al., 2012, p. 11). ISO's guidance on lifecycle declarations may be applicable as they are intended to be used for "independently verified life-cycle" data or impact assessments based on "predetermined parameters" and overseen by an entity such as an "industrial sector or trade association" (Environmental Labels and Declarations: How ISO Standards Help., 2012, p. 22).

RSBs have aimed to create a low barrier to entry, especially for small and medium producers - which has also been a challenge for palm and soy roundtables (Garrett et al., 
2016) and by encouraging and facilitating sustainability improvements across the entire sector. As a model for sector-wide sustainability, it is still too soon to analyze the RSB model's effectiveness in comparison to certification or to other models such as the territorial performance approach ${ }^{66}$ (Nepstad et al., 2014) or Zero Deforestation Zones ${ }^{67}$ (Meyer and Miller, 2015) which would entail much greater integration of supply chain, as well as regulatory and financial institutions. These models may be useful to consider as RSBs proliferate and evolve to include additional actors and sectors. The Mexico and Colombia roundtables, which include public sector engagement, could prove to be useful models for existing and new RSBs. In the interim, diverse stakeholders collectively raising attention and awareness on sustainability issues related to beef and cattle across the sector may foster incremental sustainability impacts over time, as existing RSB members advance national implementation and recruit more members.

\subsubsection{Limitations}

Respondents referenced two major limitations of the RSBs: consumption and food waste, both of which have significant sustainability implications. According to World Resources Institute (WRI), "demand for animal-based food is expected to rise by 80 percent between 2006 and 2050, with beef specifically increasing by 95 percent. Some of this growth in demand will support health and welfare gains, but much of it will be driven by overconsumption of food" (Ranganathan et al., 2016, pp. 2-3). At the same time, consumer concern about the sustainability of the beef and dairy industries is growing in many places, accompanied by a growing body of evidence that reducing consumption of these products is one of the more immediate and effective ways for consumers to reduce their personal carbon

\footnotetext{
${ }^{66}$ Nepstad et al. (2014) define territorial performance approach to deforestation is where "the geographical unit of intervention [is] the county instead of the individual farm" as a way to "stimulate collective action to reduce deforestation" (Nepstad et al. 2014, p. 1119).

${ }^{67}$ Meyer and Miller (2015) define Zero Deforestation Zones (ZDZ) as a "solution...that leverages existing private commitments and certifications, strong governance and REDD+ and incorporates all relevant actors, crops, policies, and infrastructure that drive deforestation. Companies would preferentially source commodities adhering to their zero deforestation requirements from jurisdictions that have established REDD+ programs and are on a downward trajectory toward zero emissions from deforestation by 2020.” (pp. 560-561).
} 
footprints (Wynes \& Nicholas, 2017). More broadly, a growing body of evidence points to the need to decrease consumption (and therefore production) of beef in order to effectively tackle climate change and land use challenges. These projections represent both an economic opportunity and a sustainability challenge for the beef industry.

The self-interest and fiduciary responsibilities of industry members are unlikely to provide any motivation to address the consumption side of sustainable beef, other than by countering trends of reduced beef consumption with sustainability claims, and-for non-producer supply-chain actors - perhaps by diversifying into the "clean meat" ${ }^{\prime 68}$ market. As with any multi-stakeholder process, there are different motivations and interests for participating. As Bernstein and Cashore point out, there are different motivations within industry-some see alignment with their own business values, others see participation as a competitive advantage, and still others are fearful of participating at all (2007, p. 358). These different interests were also reflected in our results, and most industry respondents reflected a combination of these motivations.

Within civil society, there are some individuals that believe in the potential for RSBs (or NSMD governance systems more broadly) to have social or environmental impact. Others participate to more strongly advocate their agencies' position or to have influence in "raising the bar" over time (Bernstein \& Cashore, 2007, p. 358-359). As indicated in our results, still other NGOs participate simply because their funders expect them to do so. These mixed motivations for participating will ultimately affect the ability of RSBs to achieve political legitimacy which, in turn, affects their ability to be effective in having significant social and environmental impact (Bernstein \& Cashore, 2007, p. 359).

Food waste, on the other hand, occurs across the value chain (production, post-harvest handling and storage, processing, and distribution) and is not limited to retail or consumer loss (Gustavsson, Cederberg, Sonesson, Van Otterdijk, and Meybeck, 2011). Although meat product "waste at the consumption level makes up approximately half of total meat losses and waste" (Gustavsson et al., 2001, p. 8) there is still opportunity for RSB members to

\footnotetext{
${ }^{68}$ The term "clean meat" refers to animal meat that is lab-grown rather than produced from livestock animals. Other terms include "cultured meat" or "lab-grown meat." See Paul Shapiro, Clean Meat: How Growing Meat Without Animals Will Revolutionize Dinner and the World (New York: Gallery Books, 2018).
} 
reduce food waste earlier in the value chain. Our interviews indicated that RSBs have not yet tackled food waste, but that it could be a future area of activity and impact. Indeed, addressing food waste is a criterion under the GRSB: "Food waste is reduced throughout the value chain, reusing and recycling wherever practicable" (GRSB, 2014). So, while food waste was perceived by respondents as a limitation, the criteria provide an explicit opportunity for RSBs and their members to address the issue and further their ability to have greater sustainability impacts.

\subsection{Exploring the evolution from state-driven to multi-stakeholder efforts to reduce deforestation}

As described above in section 4.5.1, the ultimate expression (or Phase III) of non-state market driven (NSMD) systems is for them to reach a critical mass with regard to stakeholder participation from the sector at hand. This entails that stakeholders recognize the NSMD system as the appropriate venue for sector-specific policy development and debate- what Bernstein and Cashore call "political legitimacy" (2007). In short, the system becomes mainstream as opposed to niche. Assuming that mainstream participation and widespread recognition of authority are the ultimate expression of NSMDs, then the characteristics they possess and phases they move through to become so are fundamental to their potential for impact. The emphasis is on their potential, since evidence to date shows little to no effects from NSMDs in significantly reducing deforestation in a lasting manner (Lambin et al., 2018; Van Der Ven et al., 2018) unless they are part of a comprehensive portfolio approach to addressing deforestation which includes policy measures (Gibbs et al., 2015.; D. Nepstad et al., 2013, 2014). Although, NSMDs' future potential may hinge on more widespread uptake (Van Der Ven et al., 2018) — emphasizing the importance of understanding how they evolve from niche to mainstream.

This section (4.6) applies the NSMD framework's characteristics and phases as a way of exploring the evolution of multi-actor efforts to reduce deforestation: from a state-driven approach of reducing emissions from degradation and deforestation (REDD + ) to more recent voluntary private sector efforts. This includes commodity roundtables such as the RSBs and zero-deforestation commitments (ZDCs) — both of which represent multi-stakeholder collaborative processes. The resulting insights are then used to strengthen aspects of SD diplomacy. 
The results of Chapter 3 show two types of REDD+ parallel complementary initiatives (PCIs): 1) early implementation platforms (EIPs) which were multi-stakeholder in nature, and provided technical guidance, early financing, and fostered engagement between diverse stakeholders and individuals that served as REDD+ negotiators (under the UNFCCC); and 2) informal policy dialogues (IPDs) involved primarily REDD+ negotiators, in their unofficial or personal capacities, for off-the-record discussion of technical or policy options and to explore topics and questions that were timely and salient to the ongoing REDD+ negotiations. For decades, international relations scholars deliberated over the role of nonstate actors in global governance (Arts, 2006; Keohane \& Nye, 2011), debating the importance and influence of what they termed 'non-state actors' (Arts, 2000, 2006; Held \& McGrew, 2002; Stengel \& Baumann, 2017) in shaping international agreements and policy. More recently, there is greater acknowledgement that non-state actors, and related processes they engage in, play diverse roles in informing and shaping international norms, negotiations, agreements, implementation, and outcomes (Arts, 2000, 2006; Held \& McGrew, 2002; Kirk et al., 2004; Stengel \& Baumann, 2017).

REDD+ EIPs, while multi-stakeholder in nature, were created in service to a state-centric approach to reducing tropical deforestation negotiated by member states under the UNFCCC. The resulting REDD+ mechanism was an intergovernmental agreement between participating REDD + countries (those undertaking measures to reduce domestic deforestation) and donor countries (those financially supporting REDD+ country efforts to reduce deforestation). While it is argued that REDD+ was originally designed as a type of market-based conservation instrument (Fletcher et al., 2016), the supporting complementary infrastructure (e.g., a global carbon market) has not emerged (Angelsen et al., 2017). As a result, REDD+ implementation no longer reflects that original market-based hallmark (Angelsen et al., 2017). While Chapter 3 showcases REDD+'s relative prominence in the Paris Agreement, the design, development, and early implementation of REDD + was (and is) not without controversy (Dooley et al., 2011; Phelps et al., 2012; Streck, 2020). REDD+ EIPs such as UN-REDD and FCPF created processes to facilitate input and engagement from diverse nongovernmental stakeholders including Indigenous Peoples groups; non-governmental organizations; and scientific, financial, and legal experts (Forest Carbon Partnership Facility, 2013; UN-REDD Programme - UN-REDD Programme Collaborative Online Workspace, n.d.). 
Over the course of implementing REDD+ in participating tropical forested countries, it also became clear that certain commodities (e.g., palm, soy, cattle) and private sector supply chains were still driving increases in tropical deforestation (Henders et al., 2015; Meyer \& Miller, 2015). Since the REDD+ mechanism was agreed upon in the UNFCCC (and since the article Chapter 3 is based upon was published), private sector companies have made public commitments to zero-deforestation supply chains (Gardner et al., 2019; Gibbs, et al., 2015; Goal 2 | New York Declaration on Forests, 2020; Nepstad et al., 2014; Our Work | Tropical Forest Alliance, 2020) ${ }^{69}$ As REDD+ was implemented in participating countries, it became increasingly clear that achieving reductions in deforestation was a result of multiple complementary measures — not just REDD+ (Gibbs, et al., 2015; Nepstad et al., 2013, 2014). The goal of reducing deforestation and degradation expanded beyond nation-states to other market-based sectors and stakeholders. In the words of Neef and Linhares-Juvenal (2018) these commitments may represent a "new avenue towards enhanced forest governance" by offering a "vision of zero deforestation [that] provides more flexibility to respond to different national and corporate needs within sustainable development strategies (Neeff \& LinharesJuvenal, 2018, p. 6). The supporting multi-stakeholder and private sector commitments that emerged to reduce deforestation represent an evolution in the approach to addressing deforestation. What once began as building national and sub-national multi-stakeholder support for REDD+ through the UNFCCC and EIPs has evolved to include voluntary private sector commitments, often in partnership with non-governmental organizations, governments, and other stakeholders.

Such voluntary private sector efforts have included supply chain zero-deforestation commitments (ZDCs)(Gibbs, et al., 2015; Lambin et al., 2018; Nepstad et al., 2013, 2014) and multi-stakeholder commodity roundtables (Schouten \& Glasbergen, 2012). The latter is sometimes referred to as "experimentalist governance" for their efforts to employ global standards of sustainability without state or international policy intervention (Brassett et al., 2010). This concept can also apply to ZDCs in the sense that these also represent experiments in global governance whereby a standard (zero-deforestation) is committed to by private

\footnotetext{
${ }^{69}$ For a more comprehensive list of zero-deforestation commitments see: http://www.fao.org/3/i9927en/I9927EN.pdf
} 
sector companies and measured by independent civil society actors (About - NYDF Global Platform, n.d.) - all of which is supported by state actors (Our Work | Tropical Forest Alliance, 2020; What Is the New York Declaration on Forests?). Using the NSMD characteristics and phases, this next section will explore the evolution of two primary collaborative efforts to reduce deforestation: REDD+ EIPs (Chapter 3) and ZDCs (focused on the New York Declaration on Forests (NYDF)).

First, a significant part of EIPs' importance and influence in the UNFCCC REDD+ negotiations were their unique characteristics. The first characteristic of NSMD systems is they do not "derive governing authority from states nor are they accountable to them" (Bernstein \& Cashore, 2007, p.349). In the case of EIPs such as UN-REDD Programme and the Forest Carbon Partnership Facility (FCPF), they did derive authority from states and involved government representatives. As platforms, they were largely accountable to the states engaged in them (either donor countries to REDD+ or participating REDD+ countries). However, EIPs also derived authority from, and were accountable to, other (non-state) stakeholders involved. In this way, EIPs reflect a type of 'hybrid governance' (Lemos \& Agrawal, 2006) between state and non-state in terms of authority and accountability as opposed to purely non-state. Similarly, the NYDF is a "voluntary and non-binding international declaration" supported by diverse (state and non-state) stakeholders outlining collective goals and actions (What Is the New York Declaration on Forests?). Accountability to the commitments is supported by the NYDF Secretariat, the Accountability Framework Initiative, and through annual and five-year independent assessments (About-NYDF Global Platform, n.d.; About the Initiative | Accountability Framework, n.d.; NYDF Assessment Partners, 2019) .

The second characteristic of NSMD systems - that their composition includes diverse stakeholders collectively learning, developing, and working towards goals (Bernstein \& Cashore, 2007, p. 349) does reflect the REDD+ EIPs which engaged government, civil society, private sector, and Indigenous Peoples (Climate Initiatives Platform, 2018; Forest Carbon Partnership Facility, n.d.; UN-REDD Programme, n.d.). This characteristic is also reflected at national levels where implementation of REDD+ involved diverse constituencies and stakeholder groups collectively working to determine policies and practices that would 
achieve reduced deforestation and degradation ${ }^{70}$ (Forest Carbon Partnership Facility, 2013; Jagger et al., 2014; R-Package Multi-Stakeholder Self-Assessment of REDD+Readiness in Mozambique, 2017; Rantala \& Gregorio, 2014; REDD Implementation Centre, 2016).

Similarly, subsequent ZDCs also reflect collaboration among diverse stakeholders developing and working towards shared goals (Goal $2 \mid$ New York Declaration on Forests, 2020; What Is the New York Declaration on Forests?, n.d.; Neeff \& Linhares-Juvenal, 2018).

The third characteristic of NSMD systems is that they gain "authority" via their supply chain members, each which maintain sovereignty over the choice to certify products or services (Bernstein \& Cashore, 2007, pp. 349-350) requires further unpacking in relation to REDD+. REDD+ did not gain authority through private sector supply chain participants but rather national governments agreeing to phases of REDD+ under the UNFCCC (UNFCCC, 2011). ${ }^{71}$ This agreement was followed by national government agencies participating in REDD+ readiness processes such as the FCPF (Forest Carbon Partnership Facility, n.d.). The UNFCCC Cancun agreement combined with REDD+ readiness programs helped support the development of supportive national policies and activities (Danon \& Bettiati, 2011). REDD+ was agreed by country Parties under the UNFCCC and ultimately implemented by participating sovereign countries.

Achieving reduced emissions from deforestation and degradation required a degree of "authority" on several levels. First, REDD+ as a concept and mechanism needed buy-in from

\footnotetext{
${ }^{70}$ It is important to note that countries were required to consult stakeholder groups and Indigenous Peoples in order to complete their readiness self-assessments towards obtaining multilateral funding through the Forest Carbon Partnership Facility. However, there has also been significant criticism of how consultations were conducted, the perceptions of national stakeholders, and how their resulting inputs were taken into account. See, for instance, this assessment by Cadman, et al. 2016: http://www.mdpi.com/1999-4907/7/10/212

${ }^{71}$ The UNFCCC COP-16 yielded the Cancun Agreements which included the phases of REDD: “...[REDD] should be implemented in phases, beginning with the development of national strategies or action plans, policies and measures, and capacity-building, followed by the implementation of national policies and measures and national strategies of action plans that could involve further capacity-building, technology development and transfer and results-based demonstration activities, and evolving into results-based actions that should be fully measured, reported and verified"',". See paragraph 73, p. 13: https://unfccc.int/resource/docs/2010/cop16/eng/07a01.pdf
} 
donor countries and participating tropical forest countries. Second, both donor and participating tropical forest countries needed to garner domestic support for REDD + as an authoritative mechanism in order to set policies to plan for and implement REDD+ (indicative of NSMD Phase II of 'building support')(Bernstein \& Cashore, 2007)). From a technical perspective, emerging best practice standards for measuring rates of deforestation and methods for setting baselines needed to be developed and adhered to for consistent reporting across REDD+ projects and countries. Finally, participating REDD+ countries needed to work at sub-national levels with local communities to share the concept of REDD+ and foster local participation (Practitioner Observations). Related to this, the REDD+ mechanism evolved to include expectations around free, prior, and informed consent of those communities and Indigenous Peoples (Forest Carbon Partnership Facility, 2013).

Throughout this evolution of authority of the REDD+ mechanism, there was an ecosystem of early implementation platforms (EIPs) that also possessed authority to advise and assess countries' progress on REDD+. This included their readiness plans, access to funding, and performance-based payments (Forest Carbon Partnership Facility, n.d.; UN-REDD Programme, n.d.). In this way, the NSMD's third characteristic applies to the levels of authority that REDD + - as a concept and a practice - gained over time (Bernstein \& Cashore, 2007). For ZDCs such as Goal 2 of the NYDF which deals with agricultural supply chains, there is limited evidence to show corporate commitments to zero-deforestation have had much of an authoritative effect on supply chains (NYDF Assessment Partners, 2019). Reasons for this include: limited visibility into supply chains; where there is exposure to deforestation risk, exclusion or lack of transparency among small and medium producers and companies that comprise the downstream supply chain; and lack of public reporting including standardization of how information is reported (Lambin et al., 2018; NYDF Assessment Partners, 2019). The exception to this is where companies adhere to certification standards that require specific reporting across their supply chain (NYDF Assessment Partners, 2019). Although, the rate of adoption for certification systems among commodity producers remains low for a number of reasons including prohibitively high costs of changing practices and obtaining certification as compared to switching to a non-commodity crop (Van Der Ven et al., 2018). This has meant that certification has yielded little in lasting reductions of tropical deforestation (K. M. Carlson et al., 2018; Lambin et al., 2018; Van Der Ven et al., 2018). In contrast to the continuous improvement approach adopted by RSBs, it seems that the 
reporting requirements to meet certification standards would extend greater authority over supply chains - or at least the prospect of benefits from certification compels companies to get their suppliers to act in accordance with the standard (Van Der Ven et al., 2018) and to provide adequate evidence of doing so, as compared to voluntary zero-deforestation supply chain commitments (NYDF Assessment Partners, 2019).

The fourth characteristic of Bernstein and Cashore's framework is that these initiatives aim to improve sustainability of the industry, thereby "reconfiguring" the current markets $(2007, \mathrm{p}$. 350). Applying this characteristic to efforts to reduce deforestation, it is clear that the aim of REDD+ and supporting EIPs was to reduce deforestation and degradation, thereby improving sustainability. However, it was not until REDD+ got underway at national and community levels that it became apparent that more work was needed on the demand side to 'reconfigure' markets - particularly with regards to high-deforestation commodities such as palm oil, soy, cattle, and timber (Meyer \& Miller, 2015). REDD+ was not designed to be a market mechanism but rather a results-based payment or pay-for-performance mechanism between donor countries and participating tropical forest countries (United Nations Climate Change, 2014). Donor countries incented tropical forested countries to preserve their forests rather than benefit economically from converting those lands, thereby creating another demand-side influence on the preservation rather than destruction of forested lands.

Over time, voluntary deforestation-related initiatives across agricultural commodities and supply chains have emerged with the aim of reconfiguring incentives and requirements towards greater sustainability (Tropical Forest Alliance 2020, New York Declaration on Forests). While the NYDF has acknowledged that "deforestation will not be eliminated from the production of agricultural commodities by 2020 ", there have been shifts in companies implementing sector-specific efforts on "....agricultural commodities such as palm oil, soy, paper, and beef products..." (Goal $2 \mid$ New York Declaration on Forests, 2020). Yet it is clear from independent assessments of these pledges that implementation to date falls short of any significant transformation in supply chains, sectors, or the broader market (Lambin et al., 2018; NYDF Assessment Partners, 2019; Van Der Ven et al., 2018).

The last characteristic of NSMD systems is that they develop mechanisms for addressing compliance (Bernstein and Cashore 2007, 349-350). Indeed, since REDD+ was designed as a pay for performance mechanism, robust measuring, reporting and verification (MRV) 
approaches were developed to help ensure accurate and transparent reporting on reduced deforestation and degradation commitments (see FCCC/CP/2013/10/Add.1 Decision 14/CP.19, 2014). In addition, and in part via REDD+ EIPs, participating REDD+ countries, Indigenous Peoples, and civil society groups sought to devise mechanisms for transparent tracking and reporting of REDD+ payments from donor countries (Norman \& Nakhooda, 2014). Within corporate supply chains, mechanisms for compliance are primarily voluntary through certification standards and/or self-reporting mechanisms (Lambin et al., 2018). However, even with compliance measures (e.g., third-party certification) for participating entities (Supply Change, 2015), challenges such as deforestation being displaced (leakage) and lack of widespread adoption (Lambin et al., 2018; Van Der Ven et al., 2018) thwart progress on the overall goal of reducing commodity-driven deforestation (NYDF Assessment Partners, 2019). In the case of zero-deforestation commitments such as the NYDF, there is an independent third-party assessment of measured progress against those goals (NYDF Assessment Partners, 2019) and an Accountability Framework on offer (About the Initiative Accountability Framework). This additional accountability may provide the learning and standardization necessary to achieve political legitimacy (Bernstein \& Cashore, 2007; NYDF Assessment Partners, 2019). In the case of commodity-driven deforestation in Goal $2^{72}$, the assessment shows that voluntary efforts to eliminate deforestation from commodity supply chains has been unsuccessful (Goal $2 \mid$ New York Declaration on Forests, 2020).

Finally, this section will briefly explore the evolutionary phases for REDD+ EIPs and zerodeforestation commitments (ZDCs) towards the ultimate expression of "political legitimacy" (Bernstein \& Cashore, 2007). In the case of REDD+ EIPs and more broadly, the implementation of REDD+ at large, it seems that this mechanism has moved through initiation (Phase I), to building support (Phase II), to political legitimacy (Phase III). Within the forums available including multi-stakeholder EIPs, debate on REDD+ as a mechanism to reduce deforestation evolved from 'whether' to 'how'. More recently, however, there has

\footnotetext{
${ }^{72}$ NY Declaration on Forests Goal 2: "Support and help meet the private-sector goal of eliminating deforestation from the production of agricultural commodities such as palm oil, soy, paper, and beef products by no later than 2020, recognizing that many companies have even more ambitious targets" (Goal 2 | New York Declaration on Forests, 2020).
} 
been growing debate about whether REDD+ remains relevant (Angelsen et al., 2017; Fletcher et al., 2016; Redford et al., 2013)(Redford et al., 2013) considering the scarcity of lasting reductions in deforestation based upon implementation to date (Asiyanbi \& Massarella, 2020; Fletcher et al., 2016). This seems to be less of an indication that REDD+ has devolved into Phase II of building support and possibly an indication of a post-political legitimacy phase due to an inability to demonstrate significant and lasting reductions in deforestation.

For voluntary private sector efforts to reduce deforestation (including commodity roundtables and ZDCs such as the NYDF), they seem to be in Phase II of 'building support' (Bernstein \& Cashore, 2007). However, the inability to achieve widespread implementation and resulting impact may undermine a transition to Phase III of 'political legitimacy' (Bernstein \&Cashore, 2007). This may be especially true for ZDCs that originally set a timeframe by which to achieve their goals and were unable to do so. ${ }^{73}$ If this occurs, it may suggest there is a time limit to demonstrate impact within Phase II of 'building support' before evolving to Phase III of 'political legitimacy'.

The evolution from a state-centric approach (REDD+) to a portfolio approach of complementary measures is reflective of an SD diplomacy approach (Hoogeveen \& Verkooijen, 2010; Moomaw et al., 2017; D. Nepstad et al., 2014). While the NSMD framework is tailored to understanding non-state market driven governance systems, its characteristics and phases encapsulate the evolution that occurs when diverse stakeholders come together to address a particular kind of problem: one that no stakeholder group can solve alone.

\subsection{Conclusions}

\subsubsection{Roundtables for Sustainable Beef}

As RSBs evolve and as each roundtable aims to incorporate social, economic, and environmental aspects of sustainability, it is imperative to acknowledge there is currently no global benchmark against which to compare impacts over time. Considering each roundtable has a slightly different approach and set of priorities, it may be useful to develop a

\footnotetext{
${ }^{73}$ Both the New York Declaration on Forests and the Tropical Forest Alliance originally set 2020 as the target year for eliminating deforestation from supply chains.
} 
comprehensive, evidence-based framework of the sector's sustainability impacts to more readily and objectively assess improvements. This may provide an opportunity for the scientific community - social scientists, environmental scientists, livestock scientists, and economists - to play an active and collaborative role to inform and advance the work of the RSBs. The future impact pathways identified in this chapter may help to inform hypotheses that could be tested by researchers, to understand and quantify the impacts of RSBs as (and when) they make more concrete progress towards changed practices at scale.

Lack of truly global representation in the roundtables may be a limitation to achieving sustainability impact. Research to compare other commodity roundtable memberships and identifying lessons learned from more globally representative sustainability initiatives may be useful to inform the RSBs' future engagement strategy. To address some of the concerns about the efficiency of a multi-stakeholder approach, it may be useful to assess the RSB model against other governance and engagement mechanisms. There may also be an opportunity to draw insights from comparing the different governance approaches of the national RSBs.

The RSBs intend to catalyze and build momentum for sectoral sustainability. In the future, other industry commitments and activities for sustainable beef and livestock may eventually surpass the actions of the RSBs. The work of the RSBs might then transform into one that provides ongoing multi-stakeholder input and with it, continued legitimacy and credibility. For now, the RSBs are playing a role in sector-wide dialogue, adoption of better practices, and - increasingly — movement towards de facto standards. While the RSBs do not currently envision bestowing the label of sustainability on any of their members' products, as the research (and more recent actions and announcements) show, this may not prevent individual members from making such claims. Whether and how the RSBs will collectively manage this behavior — recognizing that some members see this as a problem—presents an ongoing governance discussion for RSB stakeholders which mirrors wider debates about the merits of standards vs. continuous improvement for shepherding in the transformations needed for a sustainable future.

\subsubsection{Evolution towards a portfolio approach to reducing deforestation}

Efforts to reduce deforestation have evolved from state-driven (REDD+), to private-sector approaches (commodity certification and ZDCs). To date, neither REDD+ nor voluntary 
market-driven supply chain approaches have been able to significantly and consistently curb rates of deforestation (Donofrio et al., 2017; Goal 2 | New York Declaration on Forests, 2020; Lambin et al., 2018). According to Bernstein and Cashore (2007), no NSMD system has reached the pinnacle level of 'political legitimacy' and recent studies have shown that NSMDs still suffer from lack of broad participation from the sector at hand (i.e., they remain niche and not mainstream) (NYDF Assessment Partners, 2019; Van Der Ven et al., 2018). However, where state, non-state, and multi-stakeholder approaches have been combined, their efforts to reduce deforestation have been more successful (Meyer \& Miller, 2015; Nepstad et al., 2013, 2014; Umunay et al., 2018). Linking REDD+ and voluntary private sector commitments represents a portfolio approach and evolution reflective of SD diplomacy (Hoogeveen \& Verkooijen, 2010; Moomaw et al., 2017). SD diplomacy diagnostics call for: “engaging multiple state and non-state stakeholders...identify[ing] the underlying causes of a problem or issue... and [creating] a portfolio of actions that can address the stated goals at a level of complexity that is compatible with the complexity of the problem" (Moomaw et al., 2017, pp. 76-77).

Even with support from EIPs, over time it became clear that a set of intergovernmental agreements and mechanisms to reduce deforestation did not provide an adequate solution to match the complexity and magnitude of the problem (Moomaw et al. 2017). It became increasingly clear that reducing deforestation meant engaging agricultural commodity supply chains and the private sector actors within them. This precipitated a string of multi-actor zero-deforestation commitments (Neeff \& Linhares-Juvenal, 2018). Still, these efforts arein the words of Bernstein and Cashore (2007)-

unable to make a serious dent in ameliorating global problems for two reasons. First, solving them requires widespread support. Second, because NSMD systems initially attract firms already practicing close to a system's standards, they make relatively limited impact 'on the ground' (357).

It is perhaps the case that national, market-driven, and hybrid multi-stakeholder efforts to reduce deforestation are still too limited in their participation and do not adequately respond to the complexity of the problem to bring about the required systems change.

It may be that effectively addressing the problem of deforestation is not about policy transformation in the case of REDD+ or market transformation in the case of commodity roundtables or ZDCs. For the solution to match the complexity of the problem (Moomaw et 
al. 2017), the focus must be on systems transformation. This entails a portfolio approach that encompasses state and non-state, policy and markets, incentives and disincentives. The portfolio needs to go beyond a solution that engages diverse stakeholders and creates nearterm mutual benefits for them. In addition, a portfolio approach needs to go beyond engaging stakeholders to facilitating alignment. This applies to stakeholders across the system (not solely those in the marketplace or policy arena), by emphasizing the long-term mutual benefits of realizing sustainable development. 
CHAPTER 5 | SYNTHESIS AND CONCLUSIONS 


\subsection{Introduction}

\subsubsection{Negotiation Dynamics and Evolutionary Characteristics and Phases of Multi- actor Processes in Climate, Forests, and Cattle Production}

This thesis attempts to strengthen sustainable development diplomacy theory and practice. Specifically, it set out to contribute to a better understanding of what enables multi-actor agreement and collaborative implementation in service to addressing climate change (including key drivers of climate change, deforestation and cattle production). To do this, the study examined an inter-related set of multi-actor processes on climate change, forests, and cattle production in a multi-disciplinary manner. The thesis drew upon the literatures of international relations, multi-party negotiations, and conflict resolution to analyze empirical evidence in the three aforementioned contexts. Employing two conceptual frameworks, this thesis offers snapshots into several specific multi-actor processes related to three Sustainable Development Goals (Climate SDG-13; Life on Land SDG-15; and Sustainable Consumption and Production SDG-12). While this study does not apply the conceptual frameworks to other empirical contexts such as international trade negotiations, the results from employing those models should be applicable to other multi-actor negotiation processes contributing towards other Sustainable Development Goals_-recognizing that all SDGs are 'integrated and indivisible' (United Nations General Assembly, 2015).

In the first step of analysis, this thesis examined how key negotiation dynamics relate to each other and to reaching agreement. In doing so, the study empirically grounded and evolved the descriptive Policy Dialogue Model, while offering insights into relationships between those dynamics in the context of the United Nations Framework Convention on Climate Change (UNFCCC). In the second step of the analysis, this thesis assessed how those negotiation dynamics enable or constrain agreement by taking a more focused look at the multi-actor processes on reducing emissions from deforestation and degradation (REDD+). In the third step of analysis, this thesis explored the evolutionary characteristics and phases of multistakeholder collaboration processes on cattle and deforestation that underlie their potential to contribute to sustainable development. 
This synthesis chapter is organized in the following manner. First, Section 5.1 provides answers to the three research questions outlined in Chapter 1. By answering these questions, this section synthesizes main findings of the thesis and contributes to the strengthening of sustainable development diplomacy as a theory and a practice.

Section 5.2 answers the research questions. The following section, 5.3, outlines a suggested agenda for further research, based upon the results of this study. Section 5.4 provides reflections on the thesis' research approach and conceptual frameworks including reflections on the opportunities and limitations those frameworks afforded. Next, Section 5.5 presents reflections on the methods including the choice to employ two conceptual frameworks and discusses the author's role as both a researcher and a practitioner in multi-actor sustainable development related processes. Finally, section 5.6 offers policy recommendations based upon the thesis' findings and conclusions.

\subsection{Answering the Research Questions}

\subsubsection{Research Question 1: What are the negotiation factors involved in the UNFCCC negotiations? How do those factors relate to each other and to reaching agreement?}

The findings from this thesis empirically ground a set of six factors - negotiation dynamicscentral to negotiations in the UNFCCC context, with emphasis on dynamics enabling agreement. The negotiation dynamics are: Group Process, Political Context, Negotiation Process, Power, Communication, and Data and Information. These six dynamics also reflect negotiation "factors" or "variables" outlined in the literatures of multi-party negotiations and conflict resolution. These fields have a high degree of convergence on the number and types of variables in a multi-party negotiation - these variables are reflected in the revised Integrated Negotiations Dynamic Model (INDM). The INDM improves understanding of the six dynamics and their 20 sub-factors based upon empirical evidence from the intergovernmental negotiation context of the UNFCCC. Drawing from the field of conflict resolution to explore intergovernmental UNFCCC negotiations, this research offered insights beyond the classic state-actor or negotiations-focused approach. Results based on negotiator and facilitator experiences help to enhance understanding of the dynamics and the roles they play in reaching agreement. The results are intended to be useful as a diagnostic - both retrospectively and in real-time - to identify key factors in the negotiation and to help 
diagnose challenges to parties reaching agreement. Diagnostic aspects of the results include identification of the negotiation dynamic at play, whether it is enabling or constraining, and how these dynamics (and relationships therein) have been leveraged to advance the negotiation process. This section presents the results related to answering RQ1.

First, the original five factors of the Policy Dialogue Model (Ehrmann, 1997) were revised in several key ways based upon empirical data from grounding the model in the UNFCCC context. Table 9, below, summarizes the significant revisions made based upon empirical evidence from the UNFCCC (Chapter 2) and REDD+ (Chapter 3) cases. Also see Figure 3 for the Integrated Negotiation Dynamics Model (INDM). 
Table 9. Summary of Revisions from the Policy Dialogue Model to the Integrated Negotiation Dynamics Model

\begin{tabular}{|c|c|c|}
\hline & $\begin{array}{l}\text { Policy Dialogue Model } \\
\text { (PDM) }\end{array}$ & $\begin{array}{l}\text { Integrated Negotiation Dynamics Model } \\
\text { (INDM) }\end{array}$ \\
\hline Applicability & $\begin{array}{l}\text { Applicable to informal, } \\
\text { multi-stakeholder 'policy } \\
\text { dialogue' }\end{array}$ & $\begin{array}{l}\text { Intergovernmental negotiations } \\
\text { Early Implementation Platforms } \\
\text { Informal Policy Dialogue }\end{array}$ \\
\hline $\begin{array}{l}\text { Context developed/ } \\
\text { revised }\end{array}$ & $\begin{array}{l}\text { US multi-stakeholder } \\
\text { discussions to inform } \\
\text { environmental policy }\end{array}$ & $\begin{array}{l}\text { Intergovernmental negotiations under the } \\
\text { United Nations Framework Convention on } \\
\text { Climate Change (UNFCCC) and multi- } \\
\text { stakeholder negotiation and collaboration } \\
\text { processes on REDD+ }\end{array}$ \\
\hline Uses & Descriptive & Descriptive and diagnostic \\
\hline$\Delta$ in factors & $\begin{array}{l}1 \text { factor described as } \\
\text { 'Negotiation Dynamics' }\end{array}$ & $\begin{array}{l}\text { All factors described as 'Negotiation Dynamics'; } \\
\text { original dimension renamed to 'Negotiation } \\
\text { Process' }\end{array}$ \\
\hline$\Delta$ in factors & $\begin{array}{l}\text { Data, Information and } \\
\text { Communication }\end{array}$ & $\begin{array}{l}\text { Communication separated from Data and } \\
\text { Information as distinct dynamic }\end{array}$ \\
\hline$\Delta$ in factors & N/A & $\begin{array}{l}\text { Differentiation of sub-elements within } \\
\text { negotiation dynamics (e.g., domestic vs. inter- } \\
\text { state Political Context) }\end{array}$ \\
\hline Negotiation Cycle & Linear & Cyclical in the case of UNFCCC \\
\hline $\begin{array}{l}\text { Relationships } \\
\text { between factors }\end{array}$ & $\begin{array}{l}\text { Offers descriptions of each } \\
\text { factor/dimension }\end{array}$ & $\begin{array}{l}\text { Offers empirically grounded insights into how } \\
\text { dynamics relate to each other in negotiation } \\
\text { context }\end{array}$ \\
\hline $\begin{array}{l}\text { How factors } \\
\text { enable/constrain } \\
\text { agreement }\end{array}$ & $\mathrm{N} / \mathrm{A}$ & $\begin{array}{l}\text { Offers empirically grounded insights into which } \\
\text { dynamics were more enabling or constraining to } \\
\text { reaching agreement across several contexts } \\
\text { (intergovernmental negotiations under UNFCCC } \\
\text { and REDD+; early implementation platforms and } \\
\text { informal policy dialogues on REDD+) }\end{array}$ \\
\hline
\end{tabular}

A sixth factor-Communication - was introduced separately from the Data and Information dynamic in order to make clear that Communication is linked to all negotiation dynamics. This includes interpersonal communication related to Group Process, the communication of 
domestic and global Political Contexts, the communication of interests, positions, and process from the Negotiation Process. In addition, all negotiation factors were renamed 'dynamics' to reflect the respondents' descriptions of these variables and in-line with the term's definition: "forces or processes that produce change inside a group or system" (“Dynamics”, Cambridge Dictionary). As a result, the Policy Dialogue Model's 'Negotiation Dynamics' dimension was renamed to 'Negotiation Process' which also reflects the cyclical process description respondents ascribed to this dynamic (see Chapter 2). Most multi-actor negotiation literature describes negotiation as a linear process. However, with complex topics such as climate change that involve many Parties (196 in the case of the UNFCCC)(Parties | $U N F C C C, 2018)$ the results reflected an ongoing, continuously evolving process. A process that is cyclical in nature and is informed by implementation experiences, challenges, and insights, which, in turn, shape future agenda items for further negotiation and policymaking. Second, one of the knowledge gaps in the existing literature of multi-actor negotiations and conflict resolution was a lack of understanding in how these dynamics enable (or constrain) agreement. This question was further explored in the REDD+ context (Research Question 2). In the UNFCCC context, the results showed that specific aspects of the Group Process dynamic were most enabling to reaching agreement. A particular aspect of the Group Process dynamic was found to be most enabling - the ability of individual negotiators to build relationships and trust with their counterparts from other Parties. ${ }^{74}$ Following Group Process, the results showed that the Negotiation Process dynamic was second most enabling to reaching agreement in the UNFCCC. The description of this dynamic closely followed the Policy Dialogue Model but was expanded based on the emphasis that respondents placed on the design of the negotiation. This included the importance of venue, ease of logistics and transportation, and accessibility of appropriate food and beverages - often overlooked details but significant to negotiators' ability to focus on the task at hand. The negotiation design also

\footnotetext{
74 This result reinforces diplomacy literature which emphasizes the importance of individuals in fostering agreement (Ross, 2007). However, how those individual roles relate to the negotiation dynamics and to reaching agreement contributes to the understanding of negotiation factors/variables in the fields of multi-actor negotiations and conflict resolution.
} 
included the roles that UNFCCC COP Presidencies, Chairs, Facilitators, and Secretariat play, seen as integral to supporting Parties' ability to reaching agreement.

Third, another knowledge gap in the fields of multi-actor negotiations and conflict resolution was understanding how negotiation dynamics relate to each other. In the UNFCCC context, the results uncovered a chain of relationships between Group Process, Data and Information, Negotiation Process, and Political Context dynamics that worked together to enable agreement. Specifically, individual trust and relationships among negotiators across UNFCCC Parties was linked to greater sharing of Data and Information on their respective Party's underlying interests, position, and domestic Political Context. This, in turn, fostered a more collective understanding of potential common ground upon which to build agreement. See Figure 4 for a simplified illustration of the results of the study, showing the set of relationships between negotiation dynamics that emerged most prominently from the results. While it is recognized that negotiations dynamics do not typically play out in such a clean, linear fashion as is depicted, the point of Figure 4 is to show negotiation dynamic relationships that helped enable agreement, not to show every relationship possible between them). In addition, the results and examples in the literature on the UNFCCC negotiations (Dimitrov, 2010) indicated four different types of Power, as well as intervals where those types of Power relate to other negotiation dynamics in the process. In the UNFCCC context, results showed that geopolitical Power was leveraged in the final phase of negotiation before reaching agreement, in order to sway other parties" "votes" in favor of major powers" interests. Hence, this form of Power is depicted on the right side of Figure 4.

Finally, and as illustrated in Figure 4, this research contributed to understanding of the relationship between individuals negotiating and the Parties they are representing. These results illuminate a more human-scale dimension of intergovernmental policy negotiations. This result contrasts with the emphasis that international relations (Lacy, 2012; Keohane, 2014) and multi-party negotiation scholars (Zartman, 2002; Crump, 2015; Susskind and Ali, 2015) put on parties rather than the role of individuals representing them. While not one of the main disciplines drawn upon for this thesis, it is worth acknowledging that diplomacy literature focuses on the individual roles people play in a negotiation. The emphasis of the study was on the negotiation dynamics rather than the role of negotiators/diplomats in them. It just so happened that some of the results underscored the importance of individuals 
especially in relation to leveraging certain negotiation dynamics to foster movement towards agreement. This reinforces diplomacy literature, incidentally, but is intended to contribute to the understanding across international relations, negotiation, and SD diplomacy (which, despite its name, also does not draw heavily from diplomacy literature). It is worth noting that the field of conflict resolution already reflects individual roles. The results also go beyond the traditional categories — states, non-states, individuals, diplomats - to present a more holistic understanding of the negotiation dynamics which do not necessarily adhere to the silos placed on them. Results illuminated a continuum between individual and party, across which negotiation dynamics play out. In this way, it contributes to both an integrated understanding of the negotiation dynamics and an integrated understanding of the individualParty spectrum of roles therein.

The results uncovered a more nuanced understanding of what happens when Parties negotiate a public good such as climate change: that individuals - with their own personalities, relationship- and trust-building abilities - are critical for creating pathways to finding common ground and ultimately reaching agreement. Relationships and trust were at the individual, personal level, which then set a foundation upon which they could negotiate their Party interests (and presumably defend them). While intergovernmental negotiations such as the UNFCCC and REDD+ under the Convention always have to work within the context of countries and Parties, these dynamics, especially at individual levels, also create opportunities for unexpected outcomes or areas for possible agreement. This finding underscores what has been noted in conflict resolution and diplomacy literatures but provides insight from an international relations perspective (Hoffman, 2002) that trust and trusted relationships among individuals serve to enable agreement among Parties. ${ }^{75}$ This finding also contributes to multi-party negotiation literature which acknowledges relationships and trust

\footnotetext{
${ }^{75}$ As noted in Chapter 2, diplomacy literature does include individual relationships and trust; however, the emphasis is on the individual role rather than the dynamics of the negotiation itself. The emphasis of this study was on the negotiation dynamics rather than the role of negotiators/diplomats in them. Therefore, it drew from international relations (IR), multi-party negotiation, and conflict resolution literatures. However, some of the results underscored the importance of individuals. This finding reinforces diplomacy literature, incidentally, but is a contribution to IR and multi-party negotiation literatures, in particular.
} 
can evolve and play a role (Susskind et al., 1996), mostly in the pre-negotiation stage (Zartman, 1989) but does not elaborate on how (Crump, 2015).

The resulting Integrated Negotiation Dynamics Model presented in Chapter 2 advances understanding beyond classic state-actor and negotiations-focused perspectives to interpreting the UNFCCC negotiations. By grounding the model in first-hand accounts from the negotiations, the INDM offers insights into the negotiation dynamics and how they contribute to Parties reaching agreement. The enhanced understanding gained from this study is intended to be useful both retrospectively and in real-time to identify and diagnose challenges to parties reaching agreement.

\subsubsection{Research Question 2: How did negotiation factors enable or constrain multi- actor agreements in REDD+ negotiations and supporting multi-stakeholder REDD+ processes?}

To answer this question, the analysis assessed the degree to which negotiation factors (dynamics) enabled or constrained agreement on REDD $+{ }^{76}$ in two types of multi-actor negotiations: intergovernmental negotiations under the UNFCCC and multi-stakeholder parallel complementary initiatives (PCIs). The former involving only government representatives in their official capacities as negotiators on REDD+ under the UNFCCC; the latter comprised of diverse participants - civil society, scientific experts, Indigenous Peoples representatives, funding institutions, government representatives (including individuals that negotiated REDD+ in the UNFCCC), and representatives of international organizations. First, the results of the first two steps of analysis showed that Group Process followed by Negotiation Process dynamics was most enabling to reaching agreement in the UNFCCC context. Group Process and Political Context were most enabling in the REDD+ negotiations within the UNFCCC negotiations. Political Context was most constraining in the UNFCCCC context (Chapter 2) but seen as both enabling and constraining in the REDD+ UNFCCC negotiation context. However, there was more respondent convergence that Political Context

\footnotetext{
${ }^{76}$ Reducing emissions from deforestation and forest degradation and the role of conservation, sustainable management of forests and enhancement of forest carbon stocks in developing countries. See: https://unfecc.int/topics/land-use/workstreams/reddplus
} 
was overall more constraining than enabling in the UNFCCC REDD+ negotiations. Similarly, there was more convergence that Group Process was more enabling than constraining. For all the attention given to Power in the study of international relations (Dimitrov, 2003; Keohane \& Nye, 2011; Mearsheimer, 2001; Terhalle \& Depledge, 2013) and international negotiation, the results of this study showed Power was neither the most enabling nor constraining factor for reaching agreement - a finding that contrasts with much of the emphasis on this dynamic within the literature. The results of the first two steps of analysis showed the most constraining dynamics in the UNFCCC negotiations on REDD+ were Political Context (specifically domestic-level) followed by Negotiation Processspecifically the formation of coalitions trying to control agenda-setting and conjure up asymmetries of Power in the one country, one vote context of the UN.

Second, in the context of early implementation platforms (EIPs) on REDD+, Political Context and Power dynamics were most constraining to reaching agreement. Within early implementation platforms (EIPs) - and outside of the UNFCCC context of 'one country, one vote,' which 'levels the playing field' (Zartman and Rubin, 2002: p. 22) by offering more symmetry of power than the 'real world' - the traditional geopolitical and donor-recipient aspects of Power were more prominent. Outside of institutions such as UNFCCC that foster cooperation and diplomacy (Keohane and Nye, 1989; Keohane, 2014), geopolitical factors such as Power and global Political Context grew more prominent and constraining to agreement in PCI contexts than in the UNFCCC. This finding seems to reinforce neoliberal and liberal institutionalist scholars' argument that international institutions and regimessuch as the UNFCCC - facilitate cooperation (Keohane \& Nye, 2011; Keohane \& Oppenheimer, 2016). The results of this study suggest that this is in part because the UNFCCC tempers geopolitical Power and Political Context more than parallel complementary initiatives working on the same topic. In Chapter 2, Political Context and Power were the most dominant constraining forces in the UNFCCC in part because that step of analysis only examined one context of intergovernmental negotiations in the UNFCCC. In the second step of analysis examining REDD+, three different types of contextsintergovernmental negotiation, parallel complementary initiatives, and informal policy dialogues - emerged that showed how dynamics change depending on the context of the interaction. For example, the results showed that Political Context and Power dynamics were less significant in informal policy dialogue (IPD). For IPDs, participants engage in their 
personal capacities, so their interactions are not interpreted as representative of their respective state views. In these contexts, Group Process (specifically relationship- and trustbuilding), Communication, Negotiation Process (understanding interests) played more significant roles.

Third, investigating negotiation dynamics in the REDD+ context highlighted relationships between those dynamics, including a degree of fluidity between enabling and constraining negotiation dynamics. The Policy Dialogue Model emphasized primary factors of Political Context, Negotiation Dynamics, and Group Process with cross-cutting dimensions of Power and Data and Information. Yet, the results in this thesis indicated more parity and relationships across all the negotiation dynamics than the original model would suggest, hence why the INDM is represented as a hexagon shape with cross-cutting lines to depict the relationships between the negotiation dynamics (see Figure 3). This better reflects the results which showed that all negotiation dynamics play a notable role and that all dynamics have relationships with each other. In understanding the INDM from the perspective of its diagnostic potential, the results indicated that if a negotiation dynamic was challenging and therefore constraining, drawing upon the strength of one or more enabling negotiation dynamic could overcome challenges in the constraining dynamic. Put simply, enabling dynamics can be used to overcome constraining ones. As Figure 9 shows, Power is constraining and other negotiation dynamics as less active. In the right figure, enabling negotiation dynamics are activated to counter the effects of constraining dynamics. 


\section{Figure 9. Comparison of Negotiation Dynamics' Enabling and Constraining Effects}

(within REDD + UNFCCC Negotiations and REDD + parallel complementary initiatives) Comparison of Median Scores: Constraining \& Enabling Negotiation Dynamics

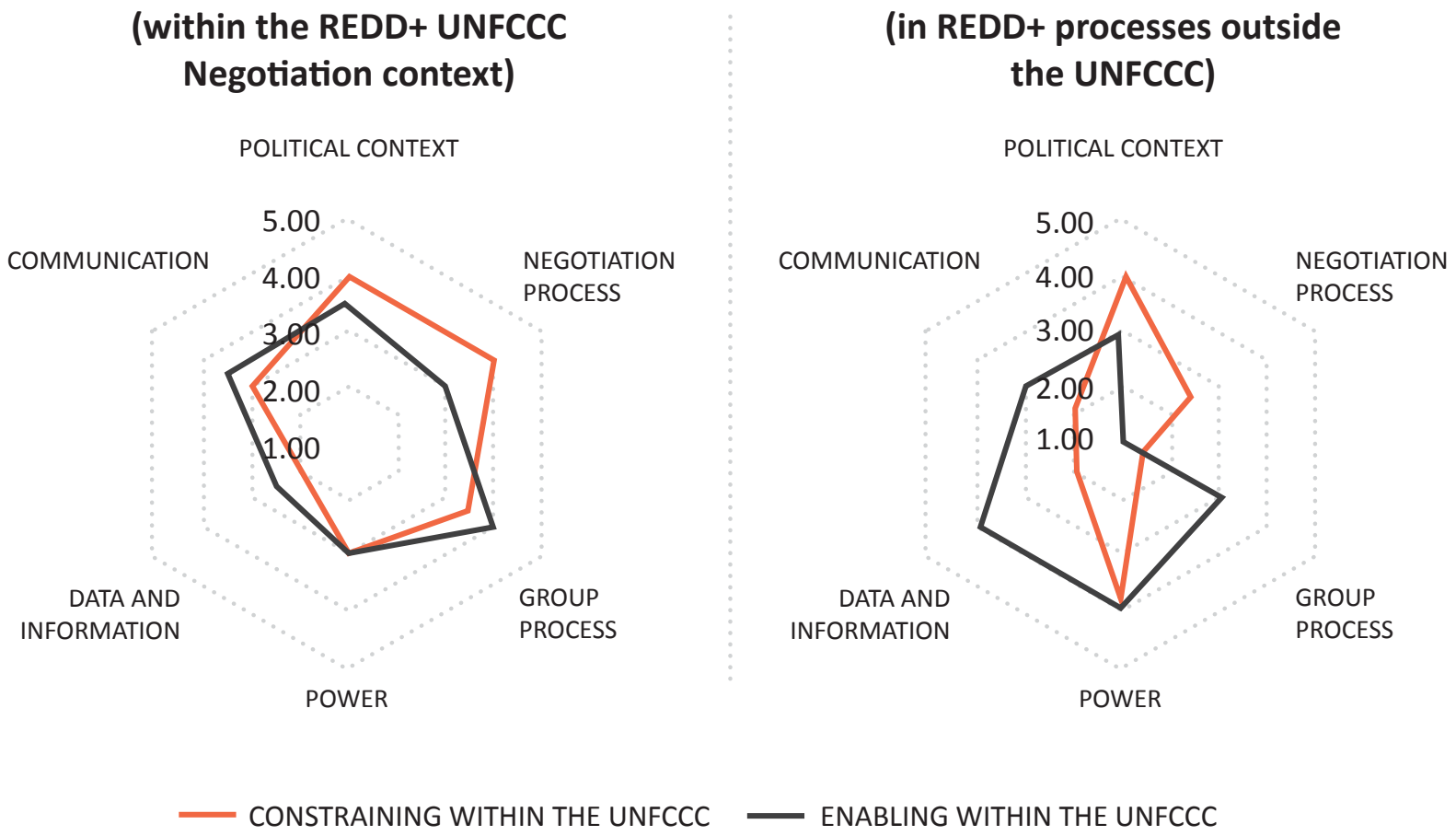

In the UNFCCC overall, individual relationships and trust were critical for overcoming constraints in the Negotiation Process dynamic. The relationships between these dynamics indicate that relationships and trust served as a foundation upon which to build agreement. As in Chapter 2, the results from Chapter 3 indicate that strong Negotiation Process design and facilitation leadership were important tools for reaching agreement on REDD + in the UNFCCC. Specifically, process design and facilitation were used to enhance the Power dynamic among chairs and facilitators. This empowered them to effectively manage the negotiations and overcome constraints from other dynamics. While the research on REDD+ emphasized the enabling or constraining nature of negotiation dynamics, the results still aligned with the theory behind the Integrated Negotiation Dynamics Model (INDM) - that all of these negotiation dynamics played significant roles in the intergovernmental negotiations on REDD+ within the UNFCCC and within multi-actor parallel complementary initiatives on REDD+. 
Finally, the second study also confirmed that REDD+ PCIs were "very or somewhat important and influential to reaching agreement on REDD+" (Results, Chapter 2) in the UNFCCC - confirming the role and influence such external multi-stakeholder processes had in shepherding an agreement on REDD+ in the UNFCCC. The results show that REDD+ emerged not from a single policy forum but rather from an ecosystem of supporting initiatives - each of which had their own negotiation dynamics but at the same time did not operate in a vacuum. Many participants engaged in one PCI also engaged in others and in REDD+ under the UNFCCC. This strengthened relationship- and trust-building aspects of the Group Process dynamic and also built a collective body of Data and Information to draw from to make informed decisions about what is in a Party's best interest.

\subsubsection{Research Question 3: What are the evolutionary characteristics and phases of multi-stakeholder collaborations on cattle and deforestation that underpin their potential for sustainability impact?}

Chapter 4 explores the multi-stakeholder collaboration processes of the roundtables for sustainable beef (RSBs) and multi-actor efforts to reduce deforestation (REDD+ EIPs and ZDCs, NYDF ${ }^{77}$, in particular). As further discussed in Section 5.4, research question 2 (RQ2) focused on negotiation dynamics and agreement whereas research question 3 (RQ3) explored implementation-oriented multi-actor processes working on sustainability of cattle production and reducing tropical deforestation. Therefore, answering RQ3 required a different conceptual framework because it examined another aspect of the policy chain: implementation post-agreement. The fourth chapter utilized the non-state market driven (NSMD) framework (Bernstein \& Cashore, 2007) to explore the evolutionary characteristics and phases of multi-stakeholder collaboration processes aimed at improving sustainability. Most of the emphasis in Chapter 4 is on the RSBs, based upon a previously published study.

\footnotetext{
77 The New York Declaration on Forests is a "voluntary and non-binding international declaration to take action to halt global deforestation. It was first endorsed at the United Nations Climate Summit in September 2014. In September 2019 the list of NYDF supporters has grown to include over 200 endorsers: national governments, sub-national governments, multi-national companies, groups representing indigenous communities, and nongovernment organizations. These endorsers have committed to doing their part to achieve the NYDF's ten goals and follow its accompanying action agenda.” See: https://forestdeclaration.org/about
} 
However, the characteristics and phases described in the NSMD framework were applicable to examine the evolution of multi-actor collaborations to reduce deforestation. The NSMD was applied with an eye towards understanding the evolutionary steps these processes move through, which underpin their potential for contributing to sustainable development. In this case, those contributions include improving sustainability of cattle production and reducing tropical deforestation. Both are critical to climate change mitigation and are embedded within the Sustainable Development Goals (SDGs). It is worth reiterating that work on reducing deforestation and sustainable cattle production began before the SDGs were negotiated and agreed (in some cases, decades beforehand). However, the SDGs provide a global framework for understanding the aims and for monitoring progress over time. Therefore, they served as a well-understood framing in this thesis.

Using the NSMD model, the results showed that RSBs and multi-actor efforts to reduce deforestation largely embody the five hallmarks of NSMDs: 1) they do not "derive governing authority from states nor are they accountable to them"; 2) their composition includes "diverse stakeholders collectively developing and working towards goals"; 3) they gain "authority" via their supply chain members, each which maintain sovereignty over the choice to certify products or services; 4) they aim to improve sustainability of the industry, thereby "reconfiguring" the current markets and "[attempting] to ameliorate global problems" 5) they develop mechanisms for addressing compliance. (Bernstein \& Cashore, 2007, pp. 349-350).

First, in all cases there is a mix of authority and accountability derived from uniting state and non-state actors in a single forum or process. RSBs, REDD+ EIPs, private sector voluntary initiatives are not uniform in nature; each has their own approach with accompanying derivations of authority and accountability. However, none of them solely derive accountability and authority from states. This suggests that there is growing recognition that a key characteristic of contributing to sustainable development requires the involvement of

\footnotetext{
${ }^{78}$ As noted in Chapter 4, Section 4.6 in applying the NSMD to multi-stakeholder efforts to reduce deforestation, these efforts did not start off with the aim of 'reconfiguring markets;' however, the private sector voluntary commitments, consumer-facing certifications, and supply chain efforts do represent market shifts, albeit not a complete reconfiguration. This is further explored and discussed in Sections 4.6 and 4.7.
} 
diverse stakeholders and sectors (reflective of SD diplomacy diagnostic) (Moomaw, et al. 2017). Results in Chapter 4 also demonstrated evolution from state-centric to multistakeholder approaches to sustainability. The emphasis on diverse participation from stakeholders in RSBs, REDD+ EIPs, and private sector voluntary initiatives also reflect the second NSMD characteristic: in all three contexts, stakeholders collectively developed goals, plans, implementation approaches, and guidance for participating members to follow towards improving their sustainability. However, the results and the literature indicate that thus far, none of these efforts has gained enough participation to be considered as evolving beyond the 'building support' phase (Bernstein \& Cashore, 2007) to becoming mainstream.

The results highlighted some challenges and potential solutions for doing so. To start, some stakeholder groups refuse to participate for fear of "legitimizing" the system before it can demonstrate significant sustainability contributions (yet to provide significant contributions requires broad support, creating a legitimacy paradox). This may indicate that early participation and support are key to evolving the system from niche to mainstream. Next, evolution to becoming mainstream requires all relevant stakeholders are engaged. For sustainable cattle production, this would entail growth beyond a handful of national roundtables and inclusion of top cattle producing countries such as India and China. It may also entail expansion beyond purely non-state stakeholders and include policymakers, as in the Mexico and Colombia roundtables. By engaging national policymakers, RSBs in Mexico and Colombia may be able to break the legitimacy paradox by fostering legitimacy through policymaker participation, prior to demonstrating significant sustainability impact. Creating this legitimacy, in turn, would hasten their ability to become mainstream, thereby bolstering RSBs' potential for sustainability contributions.

While RSBs and other non-state governance mechanisms aim to demonstrate voluntary selfregulation without government intervention, they may be undermining their potential for impact by excluding the policy sector. As such, their potential to contribute to sustainability will be limited to private sector efforts and may continue to receive criticism from civil society for not demonstrating significant sustainability contributions.

Similarly, for efforts to reduce tropical deforestation to evolve beyond the 'building support' phase may entail a 'hybrid' approach of complementary efforts (REDD+, certification, ZDCs). This requires thinking beyond state- vs. non-state to consider how to engage all 
actors that play a role in the transition towards sustainable systems. For instance, in the case of certification and ZDCs, this could include building mainstream support by exploring ways to engage beyond highly visible (mostly Western) consumer-facing multinational corporations. Besides widespread stakeholder participation, the results pointed to a need to go beyond the NSMD characteristic of diverse participation and the SD diplomacy diagnostic of engaging stakeholders at all levels. The results indicated that at times, stakeholders were working counter to each other and sometimes counter to the collective goals they strive towards. To achieve more significant and lasting sustainability contributions, these efforts also need to foster diverse stakeholder alignment.

Second, the results indicated that RSBs embody the characteristic of gaining 'authority' over supply chain members: members join, participate, and decide the degree to which they will implement RSB principles, indicators, and metrics in their own operations, thereby maintaining sovereignty over their supply chains. While a portion of national roundtables are multi-stakeholder (exclusive of governmental participation), another set of national roundtables do include national policymakers (Mexico, Colombia). While this does not represent supply chain authority, it indicates that some RSBs have evolved toward a SD diplomacy approach to engage diverse stakeholders at all levels (Moomaw, et al. 2017). As discussed in section 5.3, future research to compare the efficacy and sustainability impacts of RSBs that involve policymakers with those that do not may inform changes to RSBs composition. RSBs' proliferation of national roundtables and continued growth in member participation is reflective of the middle phase of NSMD evolution: building support (Bernstein \& Cashore, 2007). As indicated in Chapter 4, private-sector voluntary approaches to improving sustainability of commodity production remain in this phase, with low rates of adoption as compared to the entire sector (Van Der Ven et al., 2018).

In multi-stakeholder efforts to reduce tropical deforestation, gaining authority and building support is reflected in the evolution from state-driven (REDD+ under UNFCCC) to multistakeholder approaches embodied in the REDD+ EIPs and ZDCs. As efforts to reduce deforestation developed, they began to gain recognition and authority among those participating and in turn, continued to build support for their cause-reflective of the NSMD framework. However, the literature indicates that a portfolio approach that embraces all available tools (e.g., REDD+, commodity certification, ZDCs) has been most effective at 
reducing deforestation thus far (Gibbs et al., 2015; Meyer \& Miller, 2015; D. Nepstad et al., 2013, 2014; Umunay et al., 2018).

Third, RSBs and multi-actor efforts to reduce deforestation are all working to 'ameliorate global problems' (Bernstein \& Cashore, 2007) associated with cattle production, deforestation, and degradation — all of which are critically linked to addressing climate change mitigation. SD diplomacy scholars would argue that problems need to be reframed as solutions that all countries and stakeholders can benefit from achieving (Hoogeveen and Verkooijen 2011, Moomaw et al. 2017). Applying this to REDD+, SD diplomacy scholars would argue that the potential for impact is diminished due to the fact that deforestation and land degradation are still framed and tackled as expensive problems that need solving rather than as solutions that all countries and stakeholders can benefit from achieving (Hoogeveen and Verkooijen 2011, Moomaw et al. 2017). Whereas RSBs do reflect this tenet of SD diplomacy approach in that they are structured in a solutions-oriented way aimed at educating members about the benefits of improving their sustainability. In considering their efforts to solve global problems, another SD diplomacy diagnostic is applicable here. It states that the solution needs to reflect "a portfolio of actions that can address the stated goals at a level of complexity that is compatible with the complexity of the problem" (Moomaw et al. 2017, p. 77). Results in Chapter 4, for instance, indicated that RSBs do not intend to address the consumption side in their continuous improvement efforts; and that the most significant reductions in deforestation are a result of linking REDD+, commodity certification, and ZDCs. The results suggest that to reflect the complexity of the problems, the goals of RSBs and efforts to reduce deforestation need to evolve beyond a portfolio of complementary yet distinct policy-, supply chain-, and consumer- efforts to an approach that involves all aspects of the system.

Fourth, RSBs and multi-actor efforts to reduce deforestation provide ways to address compliance through monitoring, reporting, and verification (voluntary in the case of RSBs and ZDCs; required in the case of participating REDD+ countries). Even with compliance mechanisms, if the overall adoption rate remains low compared to the entirety of the sectoras it has been with RSBs, commodity certification, and ZDCs - then it is not possible for these systems to evolve beyond the 'building support' phase to the 'political legitimacy' phase, whereby the system has progressed from niche to mainstream. As such, they will not 
be able to meaningfully 'ameliorate global problems' such as unsustainable cattle production and tropical deforestation.

Finally, the aforementioned characteristics and phases of the NSMD framework provided insights into key aspects that underpin the potential for sustainability contributions on cattle production and reduced tropical deforestation. To improve the NSMD framework's applicability to understanding emergent "hybrid" approaches that are neither solely non-state or state-driven nor solely market- or policy- driven, Table 10 below offers suggestions on how to advance the NSMD framework to understand the evolving complexity of multistakeholder collaborations supporting sustainability contributions.

\section{Table 10. Characteristics of Multi-stakeholder Market Oriented (MSMO) Approaches, as compared to Non-state Market Driven (NSMD) ${ }^{79}$}

Characteristics of Non-state Market Driven

(NSMD) Initiatives

Do not "derive governing authority from states nor are they accountable to them"

Comprise diverse stakeholders collectively developing and working towards goals

Gain 'authority' via their supply chain members, each which maintain sovereignty over the choice to certify products or services

Aim to improve sustainability of the industry, thereby 're-configuring' the current markets

Develop mechanisms for addressing compliance
Characteristics of Multi-stakeholder Market Oriented (MSMO) Initiatives

Do not derive governing authority solely from states nor are they solely, or even explicitly, accountable to them (more than to other stakeholder groups)

Comprise diverse sectors and stakeholders collaborating by developing and working towards goals

Gain 'authority' via the diversity and engagement of their stakeholder groups, which maintain authority over their respective sectors

Aim to continuously improve the sustainability of sectors relevant to achieving their collective goals, thereby having the potential to 'reconfigure' markets, inform, and/or shift policy

Develop systems and tools for monitoring and assessing performance against the goals

\footnotetext{
${ }^{79}$ Summarized from Bernstein and Cashore 2007 pp. 349-350.
} 
In conclusion, multi-stakeholder market oriented (MSMO) collaborations on cattle production and efforts to reduce deforestation represent an evolution towards the "new diplomacy' called for by SD diplomacy scholars (Hoogeveen \& Verkooijen, 2010; Kjellén, 2008; Moomaw et al., 2017). The processes examined engaged diverse state and non-state stakeholders, they reflect a mutual gains approach for stakeholder involved, the RSBs in particular reframe the problem in terms of an opportunity for continuous improvement, and efforts to reduce deforestation are evolving to embrace a portfolio approach. As reflective of SD diplomacy as they may be, all of these efforts remain in the evolutionary phase of 'building support' (Bernstein \& Cashore, 2007). The literature suggests that more widespread adoption is needed to evolve these systems from niche to mainstream (Van Der Ven et al., 2018). Studies also suggest that complementary multi-actor efforts need to be combined to yield greater sustainability contributions (Meyer \& Miller, 2015; D. Nepstad et al., 2014; Umunay et al., 2018). These conclusions echo guidance embedded in SD diplomacy diagnostics, which are further explored and strengthened based upon this research.

\subsubsection{Strengthening SD Diplomacy}

Synthesizing the results from Chapters 2-4 and answers to the RQs with an eye towards strengthening SD diplomacy, this section presents some suggested changes and additions to SD diplomacy diagnostics (Moomaw et al. 2017). Chapters 2 and 3 improved understanding of the negotiation dynamics in intergovernmental negotiations within the UNFCCC, REDD+, and multi-stakeholder collaborations of REDD+. Results indicated that enabling dynamics could be identified and leveraged to overcome challenges in more constraining dynamics. In particular, results indicated that the Group Process dynamic was helpful to overcoming challenges within Negotiation Process, Political Context, and Power dynamics. Power is briefly acknowledged in the SD diplomacy diagnostics but not addressed explicitly, other than to suggest employing a mutual gains technique (Moomaw et al. 2017). Collectively, the results provided a more comprehensive perspective to identify, diagnose, understand, and leverage the negotiation dynamics to support agreement.

The results from Chapter 3 also offered insights into the roles of multi-stakeholder parallel complementary initiatives on REDD+ including their relative importance and influence in the intergovernmental REDD+ negotiations. This research advanced understanding of how parallel processes working towards the same or similar objectives (in this case, reducing 
emissions from deforestation and degradation) can be complementary and mutually reinforcing. This can serve as another contribution to SD diplomacy diagnostics, as outlined in Table 11.

Finally, results from Chapter 4 examining RSBs and multi-stakeholder efforts to reduce deforestation offered additional insights for strengthening SD diplomacy diagnostics. The results indicated that engaging diverse state and non-state stakeholders (Diagnostic 3) and developing a portfolio approach (Diagnostic 5) are important but may not go far enough to articulating the conditions necessary for making sustainability contributions. The results showed a need to go beyond stakeholder engagement to focus on alignment; to expand from a portfolio to a systems approach. Employing a systems approach also has implications for Diagnostic 4 which focuses on gathering data and information needed to understand underlying issues. Looking at the system that stakeholders are seeking to change entails examination of social data and information as well as the enabling conditions perpetuating unsustainable practices. Based upon this, suggested changes to these diagnostics are offered in Table 11 below. 
SD Diplomacy Diagnostic ${ }^{80}$

\section{New \& Strengthened SD Diplomacy Diagnostics}

[new] Identify enabling negotiation dynamics and leverage them to overcome constraining negotiation dynamics to support parties/stakeholders reaching agreement

[new] Generate shared understanding of how parallel processes working towards the same or similar sustainable development objectives can be mutually reinforcing

Engage and create alignment among diverse stakeholders including a cross-section of system actors necessary to create desired change

Assemble the relevant scientific, economic, political, and social information from across the system that stakeholders are seeking to change to identify underlying causes or enabling conditions of unsustainable practices

Create solutions that involve and address all aspects of the system stakeholders are seeking change so that resulting actions reflect the complexity of the system compatible with the complexity of the problem

\subsection{Research Agenda}

Based upon this study and existing literature, there are several areas suggested for further research. First, it may be helpful for future research to consider how multi-stakeholder processes working in parallel to intergovernmental negotiations can be more systematically analyzed. This could include examination of how parallel processes relate to and/or influence intergovernmental negotiations on the same topic. One way to do this would be to identify and interview different groups of participants - those that engage only in the intergovernmental negotiations, those that engage only in the parallel complementary initiatives, those that engage in both, and those that observe, but do not engage directly in,

\footnotetext{
${ }^{80}$ Excerpted from Moomaw et al. 2017, pp. 76-78.
} 
either. Each group could be interviewed at several intervals in the process to capture whether and how the two processes are influencing each other, especially through their respective negotiation dynamics. For instance, exploring the Political Context in a parallel complementary initiative (PCI) context vs. the intergovernmental context; whether aspects of the Political Context between the two are linked; if so, how; and how they change over the course of the study.

Second, future research could examine the process design context, a key finding in Chapter 2. Simple environmental aspects such as temperature, availability of culturally and dietarysensitive food close to the negotiation venues, more sleep and time outside the negotiations, and availability of technology are often-overlooked, but significant, variables in multi-party and intergovernmental negotiations such as those under the UNFCCC. On the last point, the results showed that where the negotiations take place may limit availability to technology (laptop, smartphones) due to concerns about host country espionage. This impinges upon negotiators' ability to effectively engage and communicate during the meetings. Further study is needed to understand the effects of negotiation venue and logistics on the negotiations they are aiming to support.

Third, the results of this thesis underscored the importance of effective chairs and facilitators for multi-actor negotiations on sustainable development. It would be useful to further understand the effectiveness of chair and facilitator training programs. This could include examination of which programs are most effective, for which negotiation contexts, and how to measure the efficacy of such training.

Fourth, since the roundtables for sustainable beef were relatively nascent at the time of this study, future research could examine the sustainability impacts roundtables are having, including exploring whether and how these impacts differ across different national roundtable contexts and why. Conducting a comparative study between the sustainability contributions from national RSBs that include policymakers vs. those that do not would further understanding about the optimal stakeholder composition for such processes. This could provide additional insight into future roundtable governance structures and implementation approaches - potentially identifying where national circumstances provide more enabling conditions for sustainability impact. 
Fifth, to understand the ways in which SD diplomacy approaches to governance and negotiations may already be reflected in existing governance models, it would be helpful to conduct a comparative analysis focused on the ability of multi-actor processes to reach agreement. This could be designed to include other sustainable development negotiation contexts beyond the UNFCCC especially considering that all SDGs are "integrated and indivisible" (UN 2030 Agenda for Sustainable Development). Comparing a diverse set of governance models might include: 1) the multi-stakeholder, government advisory model run by the Internet Corporation of Assigned Names and Numbers (ICANN); 2) the SciencePolicy Interface aspect of the UN Convention to Combat Desertification (UNCCD), which enables scientists to provide policy advice to countries; and 3) the government-centric UNFCCC approach. It would be useful to explore whether and to what extent these governance models reflect SD diplomacy approaches and if a particular governance model better fosters consensus agreement and/or implementation impact.

Finally, as imminent challenges emerge from the unsustainable path the world is on, states may begin to recognize that they no longer have the luxury of delaying difficult policy decisions in favor of competitive economic advantages over other states. In the face of collapsing biodiversity, over-taxed food systems, and significant climate change, nearly all states lose, no matter their competitive advantage. This may hasten the way towards more significant international cooperation through efforts such as coordinated sub-national policy regulation, digitally enabled citizen action networks, or more efficient intergovernmental channels such as the Group of Seven (G-7). It may be helpful to focus future research on understanding how these types of efforts can embrace aspects of SD diplomacy diagnostics to improve their chances of success. For instance: reframing environmental problems as sustainable development opportunities; considering how future cooperation efforts can, collectively, promote alignment of diverse states and stakeholders; and determining areas for complementarity to translate smaller-scale efforts into a more cohesive systems approach, ensuring that resulting actions are robust enough to respond to the "complexity of the problem" (Moomaw et al. 2017, 77).

\subsection{Reflections on the Research Approach}

The conceptual frameworks drawn upon for this research-Ehrmann's Policy Dialogue Model (Ehrmann, 1997) and Bernstein and Cashore's non-state market driven (NSMD) 
approaches to sustainability (Bernstein \& Cashore, 2007) — provided important structure to analyze the topics and processes under investigation. The Policy Dialogue Model and resulting Integrated Negotiation Dynamics Model (INDM) provided a cohesive lens for exploring the negotiation dynamics of the UNFCCC, REDD+, and supporting REDD+ multistakeholder processes. This included examination of the degree to which those dynamics were enabling or constraining of the process, as experienced firsthand by the people involved. The NSMD framework's characteristics and phases provided a way to systematically explore the evolution of early implementation processes of the roundtables for sustainable beef (RSBs) and multi-stakeholder efforts to reduce deforestation. This thesis demonstrates that these frameworks were applicable to the analysis of multi-actor (both intergovernmental and multi-stakeholder) processes working on three interrelated aspects of sustainable development: climate change, deforestation, and sustainable cattle production. Deforestation and sustainable cattle production are both inextricably linked with our changing climate. Therefore, a nested case study approach to understanding these topics was fitting.

Both frameworks selected were holistic in nature which represented limitations in terms of the breadth and complexity of the research. Some of the results can be construed as too vague and lacking in definitive answers. This is in part due to the frameworks selected but also in part due to the scope of research which explored a suite of different but related multi-actor processes related to sustainable development. With the benefit of hindsight, selecting a narrower scope with a focused, single-variable analytical model may have yielded more definitive and impactful results. For instance, it would have been interesting to focus solely on the roles that Data and Information have in enabling or constraining agreement in the UNFCCC, especially in the age of dis-information. That said, empirically grounding the Policy Dialogue Model in the UNFCCC in a holistic manner helped lay the foundation for future, focused research as described.

The process of empirically grounding the Policy Dialogue Model in the UNFCCC and REDD+ contexts evolved it into the Integrated Negotiation Dynamics Model (INDM). This evolution reflects the model's applicability to intergovernmental negotiations (UNFCCC and $\mathrm{REDD}+$ ) and to international multi-stakeholder parallel complementary initiatives (PCIs). The non-state market driven (NSMD) (Bernstein \& Cashore, 2007) framework can also expand beyond the notion of purely state vs. non-state processes to aid in understanding the 
evolution of more recent multi-stakeholder market-oriented (or performance-driven) approaches to sustainability. This includes the roundtables for sustainable beef (RSBs) and multi-stakeholder efforts to reduce deforestation, as demonstrated in this thesis. Indeed, the results showed that even so-called 'non-state' processes can be more reflective of 'hybrid governance' systems (Lemos \& Agrawal, 2006) that include both state and non-state actors. While both conceptual frameworks were appropriate for the contexts under analysis, this section includes reflections on the limitations of these models.

First, the Integrated Negotiation Dynamics Model (INDM) for analyzing international multiactor sustainable development negotiation contexts provided understanding of the negotiation dynamics prevalent at the individual and party (state) levels. Applying the INDM uncovered negotiation dynamics more likely to enable or constrain agreement in two different contexts: intergovernmental negotiations (UNFCCC and REDD+) and parallel complementary initiatives (PCIs). In addition, the results uncovered more nuanced aspects of each negotiation dynamic than the model illustrates, indicating that there are sub-factors within dynamics, each with its own definition and role to play in the negotiation. This nuance was not reflected in the model's illustration, even with the redesigned INDM which depicts greater parity across the negotiation dynamics and illustrates relationships between them.

Like any model, the INDM has limitations. For example, the INDM does not include what Zartman refers to as "strategy" or the "choices of moves or actions on the basis of payoffs or outcomes they produce when combined with other parties' choices" (Zartman, 2002, p. 8). This aspect of multi-party negotiations is partially addressed under the Negotiation Process dynamic in terms of the process itself and the way parties negotiate (in an interest-based or positional manner). However, in a real-time negotiation, 'strategy' is an important aspect for all parties to keep in mind when negotiating the best outcome for their own interests that is also compatible with all other parties' interests. The results in this thesis demonstrated that one of the most effective ways of achieving this compatibility is through the process of building relationships among negotiators. These relationships promote information sharing about parties' domestic Political Context and interests in order to more readily identify opportunities for common ground. However, this result does not adequately reflect parties' strategy and strategic decisions throughout the negotiation. 
Another limitation of the INDM is its inability to assess negotiated outcomes beyond whether or not parties reached agreement. As Zartman notes, "outcomes have long been the only recorded evidence of international negotiations, leaving the process in the shadows of history; yet, outcomes are what we are trying to explain" (Zartman, 2002, p. 10). Indeed, the INDM was employed as a lens for explaining and understanding those outcomes, but it does not have the ability to assess the outcome itself, only understanding of the chief dynamics that led to that result. A final example of the INDM's limitations is its inability to encompass a systems perspective. As demonstrated in this thesis, the INDM is applicable to different types of processes, yet how those processes interact with one another as a system was not well captured through the application of the INDM. Results in Chapter 3 demonstrated the import and influence that parallel complementary initiatives (PCIs) on REDD+ had on intergovernmental negotiations on REDD+ under the UNFCCC. The INDM was applied separately to each of these contexts and as such, it did not provide a complete view on how these processes related to and influenced one another (especially their respective negotiation dynamics). Considering the ecosystem of processes emerging to address global challenges, this type of systems analysis would be helpful for understanding the complexity of how the negotiation dynamics within parallel processes relate to each other at a meta-level (e.g., how the Power dynamic of one negotiation context relates to the Power dynamic in another context on the same topic). This would improve understanding of how parallel processes influence each other (and potentially the outcomes they are driving towards).

Second, the non-state market driven (NSMD) framework's characteristics and phases (Bernstein \& Cashore, 2007) provided a structured way to assess the evolution of multistakeholder driven approaches to sustainable development. This thesis employed the NSMD framework to examine the roundtables on sustainable beef (RSBs) and efforts to reduce deforestation. The NSMD framework offered a way of understanding how new types of sustainable development approaches are evolving, even if they are not entirely 'non-state' in nature, as was the case with both contexts investigated in the thesis. As noted in section 5.2.3, multi-stakeholder market oriented (MSMO) approaches may be a more inclusive term for future research to assess the evolution of emergent or experimentalist (Sabel and Zeitling, 
2012; Overdest and Zeitling, 2014) types of sustainable development governance. ${ }^{81}$ The diverse multi-stakeholder nature of RSBs, REDD+ EIPs, and ZDCs was not reflected in the NSMD framework which only focuses on non-state, self-regulation systems. Yet it seems the singular nature of non-state, self-governed approaches were not reflective of the more heterogenous reality encountered within those three contexts. As a result of employing the NSMD, an evolved set of characteristics - applicable to multi-stakeholder market oriented (MSMO) approaches-was presented in section 5.2.3. Ultimately, this thesis demonstrates the value of employing integrated multi-disciplinary approaches to studying multi-actor processes in sustainable development.

\subsection{Reflections on Methods and Frameworks}

As described in Chapter 1, this thesis employed a nested case study approach to investigate the negotiation dynamics and evolution of three sustainable development topics, all of which relate to climate change. The choice to study the negotiation dynamics of the UNFCCC and within that, REDD+ negotiations and parallel contexts had some positive and negative aspects. On the one hand, exploring the overall UNFCCC negotiation context helped give insight into the Convention's negotiation dynamics, but it was also important to recognize the nuance of negotiation dynamics within different negotiation tracks, such as the one on forestry and REDD+. Having a case study on both UNFCCC and REDD+ illuminated negotiation dynamics within the same general context operating at different scales and topics of emphasis. Including a case study on the RSBs and multi-stakeholder efforts to reduce deforestation using the NSMD framework provided insights into how these processes evolve to the stage where they can yield sustainability impacts - climate change mitigation being significant for cattle production and deforestation. This nested case study approach enabled study across diverse context and topics all related to climate change and overall, to sustainable development. However, this diversified approach did not foster as much in-depth analysis within any one particular context. For example, conducting several case studies across different negotiation tracks of the UNFCCC, rather than the UNFCCC negotiations overall, would have provided more in-depth understanding of the nuances and differences

\footnotetext{
${ }^{81}$ Refers to sustainable development governance broadly speaking, not limited to the Sustainable Development Goals (SDGs)
} 
within the UNFCCC negotiation context. ${ }^{82}$ However, this UNFCCC-focused comparative case study would not have yielded as much understanding of a particularly "successful" negotiating track on REDD+ because it would have omitted examination of supporting parallel complementary initiatives (PCIs). The results showed how important these PCIs were to advancing the intergovernmental negotiations on REDD+ under the UNFCCC. This understanding would have been sacrificed with a set of case studies focused exclusively on the UNFCCC context. Similarly, with the roundtables for sustainable beef, the inclusion of this case broadened the substance and context under examination. Further exploring all roundtables instead of one or two made it more difficult to conduct in-depth analysis. For instance, examining the relationship between the global roundtable for sustainable beef and a national roundtable may have yielded more detailed insights into how these processes evolve at national and global scales.

In terms of the methods of data collection, there were several areas for improvement. First, it was clear, in retrospect, that an online survey was an ineffective way of gathering data from a significant number of REDD+ respondents (considering $\mathrm{N}=12$ for the survey). Many of invited REDD+ participants play multiple roles and are extremely time constrained. This led to a low response rate. Instead, giving invited participants the option of an interview or online survey may have yielded a better response rate. Second, structuring the survey questions as more open-ended could have yielded more detailed results in terms of understanding the nuance between how negotiation dynamics worked within the context of REDD + and its parallel complementary initiatives. Asking respondents to rate them as enabling or constraining may have been too binary a choice for the complex roles these dynamics played in REDD+ contexts. Third, the response rate for interview requests was also low. Upon further reflection, asking interview respondents to help connect me with their colleagues directly — rather than asking for the names of people they would suggest interviewing would have been a more proactive way to approach the snowball method (Babbie, 2016).

\footnotetext{
${ }^{82}$ As a practitioner, I worked closely with agricultural negotiators from the UNFCCC and PCI context for several years and facilitated regular informal policy dialogues among them. However, this work was highly confidential and considered off-the-record. Therefore, I could not ethically research the negotiation dynamics therein. More about my two roles as a practitioner and researcher is discussed below.
} 
With regard to the choice of using a second conceptual framework, both the roundtables for sustainable beef and multi-stakeholder efforts to reduce deforestation (REDD+ EIPs, ZDCs) were already focused on implementation of agreed-upon negotiated outcomes. The varied 'ecosystem' of the roundtables at global and various national levels represented another set of multi-stakeholder processes working on one of the most challenging climate-related Sustainable Development Goals (SDGs): sustainable cattle production. Investigating the negotiation dynamics of the RSBs using the Integrated Negotiation Dynamics Model (INDM) would have limited the results to how those multi-stakeholder processes reach agreement or what constrains/enables agreement therein. Considering there are many national-level RSBs and the aim was to explore their evolution and resulting potential to contribute to sustainability, a different conceptual framework was chosen: the non-state market driven (NSMD) framework by Bernstein and Cashore (2007). As such, this thesis employed two conceptual frameworks - the Policy Dialogue Model (Ehrmann, 1997) and the non-state market driven (NSMD) framework (Bernstein \& Cashore, 2007)—based upon the different research aims and contexts under study. This nested case study approach using two conceptual frameworks provided breadth of understanding across multi-actor processes of sustainable development diplomacy related to climate, forests, and cattle production. However, the downside of this approach is that it did not provide as much in-depth understanding in a single process within one substantive context using one conceptual framework. For example, and as outlined in the previous section, the alternative approach of conducting several case studies within the UNFCCC using the same conceptual framework would have provided a deeper understanding of negotiation dynamics within that one intergovernmental negotiation context.

Overall, the methods utilized for collecting data could have been expanded or improved to yield greater volumes of data on a particular topic. The collective sum of data across the thesis was adequate to yield insightful results. However, had the collective sum of data been captured for a singularly focused topic rather than a diverse set of nested case studies, the results may have been better defined and carried more weight.

\subsection{Reflections on Conceptual Frameworks}

The Policy Dialogue Model—developed as a descriptive model for multi-stakeholder dialogue on environmental policymaking in the United States - was updated and revised into 
the Integrated Negotiation Dynamics Model (INDM) based upon the empirical data from interviews with UNFCCC negotiators, chairs, facilitators, and Secretariat staff.

The NSMD framework was useful to systematically investigate the evolutionary process of the roundtables for sustainable beef (RSBs) and multi-stakeholder efforts to reduce deforestation. The NSMD's characteristics and phases that these systems progress through are intended to capture the evolution towards their ultimate expression, "political legitimacy" (Bernstein \& Cashore, 2007). The purpose of that study is not to determine RSBs' political legitimacy in a static sense-especially since RSBs embrace a continuous improvement rather than a standards-based approach. Rather, the purpose of that study is to understand the evolutionary process RSBs would undergo to become mainstream, or the de facto venue for developing continuous improvement practices of sustainable beef production.

The frameworks used in this thesis also reflect my role as a 'practitioner' in the field of conflict resolution for the past 12 years and my professional experiences working within the UNFCCC and REDD+ contexts. As a mediator of multi-stakeholder processes on climate change and land use and REDD+, and a frequent observer of UNFCCC negotiations, I had practical first-hand experience which was reflected in the choice of thesis topic and frameworks of analysis. This practitioner experience came with its own benefits and challenges.

In terms of benefits, my professional experience provided access to hard-to-reach informants as interview and survey respondents. Even with efforts made to select a mix of respondents that were familiar with me as a practitioner and those that were not, the informant approach limited the pool of respondents as well as the amount of data that could be collected. As a result, some respondents also had prior knowledge and experience working with me as a practitioner within and on the margins of the UNFCCC and REDD+ (more on the challenges this presented in the next section). Exposure to academic literature supported my own professional development as a practitioner and my ability to share theoretical insights within the practitioner field. Over the course of developing this thesis while continuing to work as a practitioner, it became increasingly clear that greater connectivity between academia and practice is needed. In my experience, many professional missteps can be avoided through better understanding and application of existing empirical and theoretical material. At the 
same time, academic contributions can be strengthened through experiential understanding of the contexts under investigation.

In terms of challenges of being a practitioner researcher, it is important to acknowledge the ethical questions that arise, including: "professional integrity; relations with, and obligations to, sponsors and funders; relationships with research participants; responsibilities toward research participants; anonymity, privacy and confidentiality" (Fox et al. 2007, p. 102). As a mediator I am expected to adhere to a code of ethics to maintain professional integrity as a practitioner in the field. ${ }^{83}$ In my professional role, I was engaged with a suite of funded projects surrounding the UNFCCC context, REDD+, land use, agriculture, and food systems (including animal protein). While I had reporting obligations to funders for the research on UNFCCC and RSBs, on those projects my professional practitioner role was to serve as an independent researcher on those projects. Therefore, there was no potential conflict arising from providing a particular outcome or deliverable to the client other than analysis and reporting of the research data. I was selected to lead those research projects because of a professional reputation for objectivity.

My professional engagements translated into existing relationships with roughly half of the total respondents. Of those, the exchange of information within those relationships had been strictly confidential in relation to previous professional projects. Therefore, in the survey and interviews used for this thesis, I was careful to explain that the aggregate results would be used for research and published. The interview requests and each interview began with an explanation and distinction of my roles as practitioner and researcher. That said, it is important to recognize that respondents' previous knowledge or experience with me as a practitioner may have biased their responses. In some cases, pre-existing relationships facilitated the interview process as it was clear that respondents were already comfortable with me. However, without pre-existing relationships and knowledge, I may have asked different or more critical follow-up questions, not thinking (consciously or unconsciously) about future engagements with, or professional obligations to, the respondent.

\footnotetext{
${ }^{83}$ See Mediation Code of Ethics: https://worldmediation.org/code-of-ethics/
} 
For the RSB case study, I had no existing relationships or professional experience with any respondents in the RSB context. However, some private sector respondents seemed concerned that the research may be driven by a hidden agenda, and thus declined to participate. This limited the number of interviews possible. However, as noted in Chapter 3, by the final interviews, it was clear that data collection was reaching the saturation point, as I heard the same information from different respondents. Considering the sensitive nature of the data collected in terms of attribution to the respondent or identifying information, the data was analyzed and presented in aggregate form only. Respondent tables provide information about the type of respondent and/or sector they represented. In small circles such as REDD+ and the RSBs, any additional information or linking quotes with particular types of respondents could allow those within the community to determine the respondent's identity. This was particularly problematic with respect to the RSB paper, which was published in the journal World Development. The reviewers insisted that the article be published with respondents' names and/or more identifying details about the respondents. Since the researcher and collaborators had already committed to privacy and confidentiality with interview respondents, World Development editors' request could not be fully met.

Beyond ethical challenges, my professional understanding of multi-actor negotiation dynamics sometimes made it difficult to determine what needed to be made explicit in terms of literature and frameworks selected for analysis. I had to regularly check assumptions against multiple literatures in order to separate my normative perspective from an analytical one. Had I not been familiar with Ehrmann's Policy Dialogue Model (1997) through professional work, perhaps I would have chosen another model or topic altogether. In this way, my practitioner experience influenced the choice of what to study, and how. Years of exposure working as a facilitator in the topics of climate change, deforestation, land use, and agricultural commodities enabled precise and nuanced analysis of the empirical data collected. Yet, it is possible that without prior knowledge or practitioner experience that I would have identified slightly different patterns in the data.

\subsection{Policy Recommendations}

There were several reasons underlying the choice to explore multi-actor processes in sustainable development: 1) to strengthen theory and practice of SD diplomacy as an approach for advancing progress on the SDGs, specifically those related to climate, 
deforestation, and sustainable cattle production; 2) to understand multi-actor process negotiation dynamics, how those dynamics enabled or constrained agreement in UNFCCC and REDD+, and how those dynamics relate to one another; and 3) to explore the evolutionary aspects of implementation-focused multi-stakeholder processes that enable contributions to sustainable development. The process of negotiating and agreeing policy measures then designing processes for carrying out implementation activities is timeconsuming and complex. When it comes to sustainable development and the pace of global change, time is of the essence. Better understanding of how aspects of multi-actor sustainable development processes work will hasten progress towards a more sustainable future.

The first policy recommendation is that the Integrated Negotiation Dynamics model (INDM) can serve as a practical framework to diagnose challenges arising in intergovernmental negotiation and multi-stakeholder contexts. This model could be used in trainings of chairs, facilitators, and negotiators to help them better understand how to leverage dynamics to enable integrative negotiation and help overcome challenges that may arise. ${ }^{84}$

Second, parallel complementary initiatives (PCIs) and subsets therein — both early implementation platforms and informal policy dialogues - were shown to be important and influential for reaching agreement on REDD+ in the UNFCCC (one of the most "successful" negotiation tracks in that process). Pursuing opportunities for similar PCI-like approaches to support other intergovernmental negotiations could serve as a catalyst for supporting agreement in those negotiation contexts.

Third, the results illustrate different starting points in terms of diversity of participation in the processes of REDD+ and roundtables for sustainable beef (RSBs). In the case of REDD + , the starting point was with country negotiators engaged in intergovernmental negotiations under the UNFCCC. In the case of RSBs, the starting point was non-state, private sector and civil society representatives engaged in a multi-stakeholder initiative. If one considers these starting points to be two ends of a spectrum, both have shifted towards the midpoint, meaning, approaches to reducing deforestation and approaches to improving sustainability of

\footnotetext{
${ }^{84}$ The INDM was already utilized as the basis for a series of 'consensus-building' events with UNFCCC chairs, negotiators, facilitators, and observers through a project with the Climate and Development Knowledge Network (CDKN).
} 
cattle production have evolved to include all relevant stakeholders. The state-centric REDD+ mechanism later spurred several other multi-stakeholder and sectoral approaches to reduce deforestation, especially in supply chains (e.g., the New York Declaration on Forests, Tropical Forest Alliance 2020). In the case of RSBs, some of the national roundtables originated exclusively as non-state multi-stakeholder processes and have since evolved to include national policymakers. This hybrid public/private approach to RSBs can help inform national climate contributions and sustainability-related policies. Recognizing that sustainable development requires systemic changes, excluding some sectors or stakeholders at the outset seems contrary to our understanding of what is needed to fulfill ambitious goals. Policymakers should therefore consider how to engage relevant sectors/stakeholders from the outset of designing and implementing policy. Likewise, voluntary multi-stakeholder initiatives working on sustainability should consider engaging relevant policymakers to help inform ongoing policy development.

Fourth, while this thesis did not focus on the rich literature of legitimacy, the results uncovered a legitimacy paradox within the roundtables for sustainable beef context (which may apply more broadly within the non-state market driven (NSMD) framework) (Bernstein $\&$ Cashore, 2007). The results showed that the RSBs can be perceived as legitimate once they demonstrate sustainability impact, but according to the NSMD framework, they can only achieve significant impact once they are perceived as politically legitimate. This may indicate that for voluntary multi-stakeholder initiatives to have the desired impact, their legitimacy must be reinforced and assured at the outset. In the context of RSBs and organizations with comparable processes, involving policymakers in the process could bolster legitimacy at the outset (in which case the initiative would no longer be non-state market driven, but multistakeholder market oriented).

Finally, considering the current global trajectory on achieving the SDGs, intergovernmental efforts resulting from negotiations under the UNFCCC may lack the efficacy required to respond to imminent threats such as climate change. In the face of life-threatening sustainability challenges, it is worth considering how smaller-scale cooperation efforts can yield significant sustainability improvements. As promising smaller-scale efforts emerge, applying an SD diplomacy lens can help foster an inclusive, solutions-oriented systems approach of complementary actions that adequately respond to the complexity of these 
challenges (Hoogeveen \& Verkooijen, 2010; Moomaw et al., 2017). In the words of the former UN Secretary-General,

One of the main lessons I have learned during my five years as Secretary-General is that broad partnerships are the key to solving broad challenges. When governments, the United Nations, businesses, philanthropies and civil society work hand-in-hand, we can achieve great things. - Ban Ki-Moon 


\section{REFERENCES}

About - NYDF Global Platform. (n.d.). Retrieved January 24, 2021, from https://www.nydfglobalplatform.org/about-2/

About the initiative | Accountability Framework. (n.d.). Retrieved January 24, 2021, from https://accountability-framework.org/about/about-the-initiative/

Al-Yateem, N. (2012). The effect of interview recording on quality of data obtained: A methodological reflection. Nurse Researcher, 19(4), 31-35. https://doi.org/10.7748/nr2012.07.19.4.31.c9222

Alix-Garcia, J., Walker, S., \& Bartlett, A. (2019). Assessing the direct and spillover effects of shocks to refugee remittances. World Development, 121(March 2015), 63-74. https://doi.org/10.1016/j.worlddev.2019.04.015

Alvarez, G., Pilbeam, C., \& Wilding, R. (2010). Nestlé Nespresso AAA sustainable quality program: an investigation into the governance dynamics in a multi-stakeholder supply chain network. Supply Chain Management: An International Journal, 15(2), 165-182. https://doi.org/10.1108/13598541011028769

Angelsen, A., Brockhaus, M., Duchelle, A. E., Larson, A., Martius, C., Sunderlin, W. D., Verchot, L., Wong, G., \& Wunder, S. (2017). Learning from REDD+: a response to Fletcher et al. Conservation Biology, 31(3), 718-720. https://doi.org/10.1111/cobi.12933

Arts, B. (2000). Regimes, Non-State Actors and the State System: A "Structurational" Regime Model. European Journal of International Relations, 6(4), 513-542. https://journals-sagepubcom.ezproxy.library.wur.nl/doi/pdf/10.1177/1354066100006004003

Arts, B. (2006). Non-state Actors in Global Environmental Governance: New Arrangements Beyond the State. New Modes of Governance in the Global System, 177-200. https://doi.org/10.1057/9780230372887_8

Asem-Hiablie, S., Battagliese, T., Stackhouse-Lawson, K. R., \& Alan Rotz, C. (2019). A life cycle assessment of the environmental impacts of a beef system in the USA.

International Journal of Life Cycle Assessment, 24(3), 441-455. https://doi.org/10.1007/s11367-018-1464-6

Asiyanbi, A., \& Massarella, K. (2020). Transformation is what you expect, models are what you get: REDD+ and models in conservation and development. Journal of Political Ecology, 27(1), 476-495. https://doi.org/https://doi.org/10.2458/v27i1.23540

Babbie, E. R. (2016). The Practice of Social Research. In Contemporary Sociology (Fourteenth, Issue 2). Cengage Learning. https://doi.org/10.2307/2062956

Bäckstrand, K. (2006). Multi-stakeholder partnerships for sustainable development: rethinking legitimacy, accountability and effectiveness. European Environment, 16(5), 290-306. https://doi.org/10.1002/eet.425

Bailey, I., \& Rupp, S. (2005). The Evolving Role of Trade Associations in Negotiated Environmental Agreements: The Case of United Kingdom Climate Change Agreements. Business Strategy and the Environment, 15(1), 40-54. https://doi.org/10.1002/bse.465 
Beef, G. R. for S. (2014). Global Roundtable for Sustainable Beef Principles \& Criteria. https://grsbeef.org/Resources/Documents/GRSB Principles and Criteria for Global Sustainable Beef_091514.pdf

Bernstein, S. (2011). Legitimacy in intergovernmental and non-state global governance. Review of International Political Economy, 18(1), 17-51. https://doi.org/10.1080/09692290903173087

Bernstein, S., \& Cashore, B. (2007). Can non-state global governance be legitimate? An analytical framework. Regulation \& Governance, 1(4), 347-371. https://doi.org/10.1111/j.1748-5991.2007.00021.x

Bisht, M. (2008). Advocacy groups and multi-stakeholder negotiations: Redefining frameworks of diplomatic practice. International Studies, 45(2), 133-153. https://doi.org/10.1177/002088170804500203

Bitzer, V., Francken, M., \& Glasbergen, P. (2008). Intersectoral partnerships for a sustainable coffee chain: Really addressing sustainability or just picking (coffee) cherries? Global Environmental Change, 18(2), 271-284. https://doi.org/10.1016/j.gloenvcha.2008.01.002

Bogaerts, M., Cirhigiri, L., Robinson, I., Rodkin, M., Hajjar, R., Costa Junior, C., \& Newton, P. (2017). Climate change mitigation through intensified pasture management: Estimating greenhouse gas emissions on cattle farms in the Brazilian Amazon. Journal of Cleaner Production, 162, 1539-1550. https://doi.org/10.1016/J.JCLEPRO.2017.06.130

Brassett, J., Richardson, B., \& Smith, W. (2010). Experimentalist Governance, Deliberation and Democracy: A case study of primary commodity roundtables. In CSGR Working Papers (No. 271). http://wrap.warwick.ac.uk/42941/

Brassett, J., Richardson, B., \& Smith, W. (2012). Private Experiments in Global Governance: Primary Commodity Roundtables and the Politics of Deliberation. International Theory, 4(3), 367-399. https://doi.org/10.1017/S1752971912000188

Bryman, A. (2016). Social Research Methods (5th ed.). Oxford University Press.

Canadian Roundtable for Sustainable Beef. (n.d.). Fact Sheet. Retrieved November 3, 2016, from http://crsb.ca/wp-content/uploads/2016/09/CRSB_Factsheet_English-2.pdf

Canfax Research Services. (2016). National Beef Sustainability Assessment: Economic Assessment. https://crsb.ca/assets/Uploads/About-Us/OurWork/NBSA/a1be159b90/NBSA-EconomicAssessment-.pdf

Carlson, C. (1999). Convening. In L. Susskind, S. McKearnan, \& J. Thomas-Larmer (Eds.), The Consensus Building Handbook: A Comprehensive Guide to Reaching Agreement (pp. 169-197). SAGE Publications, Inc. https://doi.org/http://dx.doi.org/10.4135/9781452231389.n5

Carlson, K. M., Heilmayr, R., Gibbs, H. K., Noojipady, P., Burns, D. N., Morton, D. C., Walker, N. F., Paoli, G. D., \& Kremen, C. (2018). Effect of oil palm sustainability certification on deforestation and fire in Indonesia. Proceedings of the National Academy of Sciences of the United States of America, 115(1), 121-126. https://doi.org/10.1073/pnas.1704728114 
Cashore, B. (2002). Legitimacy and the Privatization of Environmental Governance: How Non-State Market-Driven (NSMD) Governance Systems Gain Rule-Making Authority. Governance, 15(4), 503-529. https://doi.org/10.1111/1468-0491.00199

Cattau, M. E., Marlier, M. E., \& DeFries, R. (2016). Effectiveness of Roundtable on Sustainable Palm Oil (RSPO) for reducing fires on oil palm concessions in Indonesia from 2012 to 2015. Environmental Research Letters, 11(10), 105007. https://doi.org/10.1088/1748-9326/11/10/105007

Chasek, P. S., \& Wagner, L. M. (2016). Breaking the mold: a new type of multilateral sustainable development negotiation. International Environmental Agreements: Politics, Law and Economics, 16(3), 397-413. https://doi.org/10.1007/s10784-016-9320-2

Chatham House. (n.d.). Chatham House Rule. https://www.chathamhouse.org/about/chatham-house-rule

Checkel, J. T. (1998). The Constructivist Turn In International Relations Theory. World Politics, 50(2), 324-348. https://doi.org/https://www.jstor.org/stable/25054040

Climate Initiatives Platform. (2018). REDD+ Partnership - Climate Initiatives Platform. http://www.climateinitiativesplatform.org/index.php/REDD\%2B_Partnership

Clinton Global Initiative. (2016). Engaging Smallholder Farmers in Value Chains: Emerging Lessons. https://www.clintonfoundation.org/sites/default/files/cgi_smallholder_report_final.pdf

Crump, L. (2003). Multiparty Negotiation and the Management of Complexity. International Negotiation, 8(2), 189-195. https://doi.org/10.1163/157180603322576103

Crump, L. (2015). Analyzing Complex Negotiations. Negotiation Journal, 31(2), 131-153. https://doi.org/10.1111/nejo.12086

Crump, L., \& Glendon, A. I. (2003). Towards a Paradigm of Multiparty Negotiation. International Negotiation, 8(2), 197-234. https://doi.org/10.1163/157180603322576112

Daniels, S., Walker, G., \& Emborg, J. (2012). Unifying Negotiation Framework: A Model of Policy Discourse. Conflict Resolution Quarterly, 30(1), 347-367. https://doi.org/10.1002/crq

Danon, S., \& Bettiati, D. (2011). Reducing Emissions from Deforestaton and Forest Degradation (REDD+) - What is Behind the Idea and What is the Role of UN-REDD and Forest Carbon Partnership Facility (FCPF)? South-East European Forestry, 2(2), 95-99. https://doi.org/10.15177/seefor.11-10

De Oliveira Silva, R., Barioni, L. G., Hall, J. A. J., Folegatti Matsuura, M., Zanett Albertini, T., Fernandes, F. A., \& Moran, D. (2016). Increasing beef production could lower greenhouse gas emissions in Brazil if decoupled from deforestation. Nature Climate Change, 6(5), 493-497. https://doi.org/10.1038/nclimate2916

de Vries, M., \& de Boer, I. J. M. (2010). Comparing environmental impacts for livestock products: A review of life cycle assessments. Livestock Science, 128(1-3), 1-11. https://doi.org/10.1016/j.livsci.2009.11.007

Dee, B., Henry, J., Lawrance, J., Swift, J., Global Ecolabelling Network, \& Ryding, S.-O. (2012). Environmental Labels and Declarations: How ISO Standards Help. https://twosidesna.org/wp- 
content/uploads/sites/16/2018/05/Environmental_Labels_and_Declarations_How_ISO_ Standards_Help.pdf

Deloitte. (2016). National Beef Sustainability Assessment: Environmental and Social Assessments. https://crsb.ca/assets/Uploads/About-Us/OurWork/NBSA/8e68cb86c3/NBSA-EnvironmentalAndSocialAssessments.pdf

Dentoni H. C., D. ;Peterso. (2011). Multi-Stakeholder Sustainability Alliances in Agri-Food Chains: A Framework for Multi-Disciplinary Research. International Food and Agribusiness Management Review, 14(5), 83-108.

Dewulf, A. (2007). An introduction to multi-actor processes. http://www.mspguide.org/sites/default/files/resource/dewulf_2007_an_introduction_to _multi-actor_processes.pdf

Dimitrov, R. S. (2003). Knowledge, Power, and Interests in Environmental Regime Formation. International Studies Quarterly, 47(1), 123-150. https://doi.org/https://www.jstor.org/stable/3096079

Dimitrov, R. S. (2010). Inside UN Climate Change Negotiations: The Copenhagen Conference. Review of Policy Research, 27(6), 795-821. https://doi.org/10.1111/j.15411338.2010.00472.x

Donnelly, J. (2000). Realism and International Relations. Cambridge University Press. https://ir101.co.uk/wp-content/uploads/2018/11/Donnelly-2000-Realism-andInternational-Relations.pdf

Donofrio, S., Rothrock, P., \& Leonard, J. (2017). Supply Change: Tracking Corporate Commitments to Deforestation-free Supply Chains, 2017. http://foresttrends.org/releases/p/supply_change_2017

Dooley, K., Griffiths, T., Martone, F., \& Ozinga, S. (2011). Smoke and mirrors. A critical assessment of the Forest Carbon Partnership Facility. https://www.forestpeoples.org/sites/fpp/files/publication/2011/03/smokeandmirrorsinter net.pdf

Druckman, D. (1997). Dimensions of International Negotiations: Structures, Processes, and Outcomes. Group Decision and Negotiation, 6(5), 395-420. https://doi.org/10.1023/A:1008649502134

Druckman, D. (2001). Turning Points in the International Negotiations. The Journal of Conflict Resolution, 45(4), 519-544. https://doi.org/10.1111/j.15719979.1991.tb00602.x

Ehrmann, J. (1997). The Policy Dialogue Model: A Descriptive Model of a New Approach to Formulating Environmental Policy [University of Michigan]. http://hdl.handle.net/2027.42/130231

Eliasch, J. (2008). Climate Change: Financing Global Forests. The Eliasch Review. Routledge.

Emerson, K., Nabatchi, T., \& Rosemary, O. (2017). Environmental Collaboration and Conflict Resolution. In R. Durant, D. Fiorino, \& R. O'Leary (Eds.), Environmental Governance Reconsiered: Challenges, Choices, and Opportunities (2nd ed., pp. 263294). The MIT Press. 
Estrada, M., Lee, D., Murray, B., O’Sullivan, R., Penman, J., \& Streck, C. (2014). Land Use in a Future Climate Agreement. https://catalogue.unccd.int/385_Land Use and ADP2 online FINAL.pdf

Fisher, R., \& Ury, W. (2011). Getting to Yes, Negotiating Agreement Without Giving In (B. Patton (Ed.); 3rd ed.). Pengiun Books.

https:/play.google.com/books/reader?id=W89fHCJZrcwC\&lr=\&printsec=frontcover\&p $\mathrm{g}=\mathrm{GBS} . \mathrm{PP} 1$

Fletcher, R., Dressler, W., Büscher, B., \& Anderson, Z. R. (2016). Questioning REDD+ and the future of market-based conservation. Conservation Biology, 30(3), 673-675. https://doi.org/10.1111/cobi.12680

Forest Carbon Partnership Facility. (n.d.). Retrieved November 30, 2020, from https://www.forestcarbonpartnership.org/

Forest Carbon Partnership Facility. (2013). Forest Carbon Partnership Facility (FCPF) Readiness Fund Readiness Package Assessment Framework. FMT Note 2013-1. https://www.forestcarbonpartnership.org/system/files/documents/FMT Note 2013-1 RPackage Assessment Framework.pdf

Fortin, E. (2013). Transnational multi-stakeholder sustainability standards and biofuels: Understanding standards processes. Journal of Peasant Studies, 40(3), 563-587. https://doi.org/10.1080/03066150.2013.796455

Fowler, A., \& Biekart, K. (2017). Multi-Stakeholder Initiatives for Sustainable Development Goals: The Importance of Interlocutors. Public Administration and Development, 37(2), 81-93. https://doi.org/10.1002/pad.1795

Fransen, L. (2011). Why Do Private Governance Organizations Not Converge? A PoliticalInstitutional Analysis of Transnational Labor Standards Regulation. Governance, 24(2), 359-387. https://doi.org/10.1111/j.1468-0491.2011.01519.x

Galletta, A. (2013). Mastering the Semi-Structured Interview and Beyond: From Research Design to Analysis and Publication. NYU Press. https://www.jstor.org/stable/j.ctt9qgh5x

Gardner, T. A., Benzie, M., Börner, J., Dawkins, E., Fick, S., Garrett, R., Godar, J., Grimard, A., Lake, S., Larsen, R. K., Mardas, N., McDermott, C. L., Meyfroidt, P., Osbeck, M., Persson, M., Sembres, T., Suavet, C., Strassburg, B., Trevisan, A., ... Wolvekamp, P. (2019). Transparency and sustainability in global commodity supply chains. World Development, 121, 163-177. https://doi.org/10.1016/j.worlddev.2018.05.025

Garnett, T. (2009). Livestock-related greenhouse gas emissions: impacts and options for policy makers. Environmental Science \& Policy, 12(4), 491-503. https://doi.org/10.1016/j.envsci.2009.01.006

Garrett, R. D., Carlson, K. M., Rueda, X., \& Noojipady, P. (2016). Assessing the potential additionality of certification by the Round table on Responsible Soybeans and the Roundtable on Sustainable Palm Oil. Environmental Research Letters, 11(4), 045003. https://doi.org/10.1088/1748-9326/11/4/045003

Gibbs, H. K., Munger, J., L'roe, J., Barreto, P., Pereira, R., Christie, M., Amaral, T., \& Walker, N. F. (2015). Did Ranchers and Slaughterhouses Respond to Zero-Deforestation 
Agreements in the Brazilian Amazon? Conservation Biology, 9(1), 32-42.

https://doi.org/https://doi.org/ 10.1111/conl.12175

Gibbs, H. K., Rausch, L., Munger, J., Schelly, I., Morton, D. C., Noojipady, P., Soares-Filho, B., Barreto, P., Micol, L., \& Walker, N. F. (2015). Brazil's Soy Moratorium: Supplychain governance is needed to avoid deforestation. In Science (Vol. 347, Issue 6220, pp. 377-378). American Association for the Advancement of Science. https://doi.org/10.1126/science.aaa0181

Giddens, A. (2009). The politics of climate change. Polity Press. https://books.google.ca/books?id=yXJKxmd2tWgC\&lpg=PR1\&ots=Te6NeQ2jmi\&dq=t he politics of climate change\&lr\&pg $=\mathrm{PR} 1 \# \mathrm{v}=$ onepage \&q$=$ the politics of climate change $\& \mathrm{f}=$ false

Gilbert, D., \& Rasche, A. (2008). Opportunities and problems of standardized ethics initiatives-a stakeholder theory perspective. Journal of Business Ethics. https://link.springer.com/article/10.1007/s10551-007-9591-1

Gilpin, R. G. (1996). No one loves a political realist. Security Studies, 5(3), 3-26. https://doi.org/10.1080/09636419608429275

Glaser, B., \& Strauss, A. (1967). The Discovery of Grounded Theory: Strategies for Qualitative Research. In Social Forces (Issue 4). Aldine. https://doi.org/10.1093/sf/46.4.555

Global Roundtable for Sustainable Beef. (2016). SUSTAINABILITY REPORT. https://grfsb.wildapricot.org/resources/Documents/Miscellaneous/GRSB_AR_2016_F_s ingleWeb.pdf

Goal 2 | New York Declaration on Forests. (2020). New York Declaration on Forests. https://forestdeclaration.org/goals\#goal-2

Gray, B. (1989). Collaborating: Finding Common Ground for Multiparty Problems. JosseyBass Publishers.

Greenpeace. (2009). Slaughtering the Amazon. https://wayback.archiveit.org/9650/20200403031101/http://p3-

raw.greenpeace.org/international/Global/international/planet-

2/report/2009/7/slaughtering-the-amazon.pdf

Grieco, J. (1990). Cooperation Among Nations: Europe, America, and Non-tariff Barriers to Trade. Cornell University Press. https://books.google.ca/books?id=bcjilfUj_o0C\&source=gbs_navlinks_s

Grieco, J. M. (1988). Realist Theory and the Problem of International Cooperation: Analysis with an Amended Prisoner's Dilemma Model. In Source: The Journal of Politics (Vol. 50, Issue 3).

Griffiths, T., \& Martone, F. (2009). Seeing'REDD'?: Forests, Climate Change Mitigation and the Rights of Indigenous Peoples and Local Communities. $\mathrm{http}: / / \mathrm{www}$.forestrynepal.org/publications/reports/4227

GRSB Sustainability Report. (2018).

https://grsbeef.org/resources/Documents/WhoWeAre/GRSB_Sustainability_Report_201 8.pdf 
Gupta, J. (2012). Negotiating challenges and climate change. Climate Policy, 12(5), 630-644. https://doi.org/10.1080/14693062.2012.693392

Gustavsson, J., Cederberg, C., Sonesson, U., van Otterdijk, R., \& Meybeck, A. (2001). Global Food Losses and Food Waste. http://www.fao.org/3/a-i2697e.pdf

Haas, E. B. (1964). Toward Controlling International Change: A Personal Plea. World Politics, 17(1), 1-12. https://www.jstor.org/stable/2009384

Haas, P. M. (2008). Forum. Global Environmental Politics, 8(3), 1-8. https://doi.org/10.1162/glep.2008.8.3.1

Hampson, F., \& Hart, M. (1995). Multilateral Negotiations: Lessons from Arms Control, Trade, and the Environment. The Johns Hopkins University Press.

https://books.google.ca/books?id=TSaHpJLNV4IC\&lpg=PA3\&dq=multilateral negotiation lessons from arms\&lr\&pg $=\mathrm{PA} 3 \# \mathrm{v}=$ onepage $\& \mathrm{q}=$ multilateral negotiation lessons from arms\&f=false

Hardin, R. (1998). Trust in Government. In V. Braithwaite \& M. Levi (Eds.), Trust and Governance (pp. 9-27). Russell Sage Foundation.

https://books.google.ca/books?id=7uWFAwAAQBAJ\&lpg=PR9\&ots=Zey0uF_sPQ\&dq $=$ trust and governance $\& 1 \mathrm{r} \& \mathrm{pg}=\mathrm{PR} \& \# \mathrm{v}=$ onepage $\& \mathrm{q}=$ trust and governance $\& \mathrm{f}=$ false

Harrison, M. E. (2011). Collecting Sensitive and Contentious Information In: Doing Development Research Collecting Sensitive and Contentious Information. Doing Development Research , 62-69. https://doi.org/10.4135/9781849208925

Held, D., \& McGrew, A. (2002). Governing globalization : power, authority and global governance. Polity Press.

https://archive.org/details/governingglobali0000unse/page/n1/mode/2up

Hemmati, M. (2002). Multi-stakeholder Processes for Governance and Sustainability: Beyond Deadlock and Conflict. Earthscan.

https://books.google.ca/books?id=bKNj41QI2RwC\&lpg=PP2\&dq=benefits of multistakeholder process\&lr\&pg $=\mathrm{PP} 2 \# \mathrm{v}=$ onepage $\& \mathrm{q}=$ benefits of multi-stakeholder process $\& \mathrm{f}=$ false

Henders, S., Persson, U. M., \& Kastner, T. (2015). Trading forests: land-use change and carbon emissions embodied in production and exports of forest-risk commodities. Environmental Research Letters, 10(12), 125012. https://doi.org/10.1088/17489326/10/12/125012

Henderson, G., Cox, F., Ganesh, S., Jonker, A., Young, W., Janssen, P. H., Abecia, L., Angarita, E., Aravena, P., Arenas, G. N., Ariza, C., Attwood, G. T., Avila, J. M., AvilaStagno, J., Bannink, A., Barahona, R., Batistotti, M., Bertelsen, M. F., Brown-Kav, A., ... Zunino, P. (2015). Rumen microbial community composition varies with diet and host, but a core microbiome is found across a wide geographical range. Scientific Reports, 5(1), 14567. https://doi.org/10.1038/srep14567

Hernández, A. M. (2014). Strategic Facilitation of Complex Decision-Making: How Process and Context Matter in Global Climate Change Negotiations. Springer. https://books.google.com/books?hl=en\&lr=\&id=XP0pBAAAQBAJ\&pgis=1

Herrero, M., Thornton, P. K., Gerber, P., \& Reid, R. S. (2009). Livestock, livelihoods and the 
environment: understanding the trade-offs. Current Opinion in Environmental Sustainability, 1(2), 111-120. https://doi.org/10.1016/J.COSUST.2009.10.003

Herrero, M., Wirsenius, S., Henderson, B., Rigolot, C., Thornton, P., Havlík, P., de Boer, I., \& Gerber, P. J. (2015). Livestock and the Environment: What Have We Learned in the Past Decade? Annual Review of Environment and Resources, 40(1), 177-202. https://doi.org/10.1146/annurev-environ-031113-093503

History of the Convention | UNFCCC. (n.d.). United Nations Climate Change. Retrieved December 4, 2020, from https://unfccc.int/process/the-convention/history-of-theconvention\#eq-1

Hoffman, A. M. (2002). A Conceptualization of Trust in International Relations. European Journal of International Relations, 8(3), 375-401.

Hoogeveen, H., \& Verkooijen, P. (2010). Transforming Sustainable Development Diplomacy: Lessons Learned From Global Forest Governance [Wageningen University]. https://edepot.wur.nl/16407

Hufty, M., \& Haakenstad, A. (2011). Reduced Emissions for Deforestation and Degradation: A Critical Review. Consilience: The Journal of Sustainable Development, 5(1), 1-24.

Ingram, V., van den Berg, J., van Oorschot, M., Arets, E., \& Judge, L. (2018). Governance Options to Enhance Ecosystem Services in Cocoa, Soy, Tropical Timber and Palm Oil Value Chains. Environmental Management, 62(1), 128-142. https://doi.org/10.1007/s00267-018-0996-7

Innes, J. E. (2004). Consensus Building: Clarifications for the Critics. Planning Theory, 3(1), 5-20. https://doi.org/10.1177/1473095204042315

IPCC. (2019). Summary for Policymakers. In: Climate Change and Land: an IPCC Special Report on climate change, desertification, land degradation, sustainable land management, food security, and greenhouse gas fluxes in terrestrial ecosystems. https://www.ipcc.ch/site/assets/uploads/sites/4/2020/02/SPM_Updated-Jan20.pdf

ISEAL Alliance. (2014). Assessing the Impacts of Social and Environmental Standards Systems ISEAL Code of Good Practice. www.isealalliance.org/our-work/definingcredibility/

Jagger, P., Brockhaus, M., Duchelle, A., Gebara, M., Lawlor, K., Resosudarmo, I., \& Sunderlin, W. (2014). Multi-Level Policy Dialogues, Processes, and Actions: Challenges and Opportunities for National REDD+ Safeguards Measurement, Reporting, and Verification (MRV). Forests, 5(9), 2136-2162.

https://doi.org/10.3390/f5092136

Jones, P. (2015). Track Two Diplomacy in Theory and Practice. Stanford University Press. https://books.google.ca/books?id=TUs_CgAAQBAJ\&lpg=PR7\&dq=track two diplomacy\&lr\&pg $=\mathrm{PR} 4 \# \mathrm{v}=$ onepage $\& \mathrm{q}=$ track two diplomacy $\& \mathrm{f}=$ false

Keohane, R. O. (1986a). Reciprocity in International Relations. International Organization, 40(1), 1-27. https://www.jstor.org/stable/2706740

Keohane, R. O. (1986b). Theory of world politics: structural realism and beyond. In Theory of World Politics (pp. 158-203). Columbia University Press.

http://ir.rochelleterman.com/sites/default/files/keohane neorealism.pdf 
Keohane, R. O. (2014). The Global Politics of Climate Change. 19-26. https://doi.org/10.1017/S1049096514001541

Keohane, R. O. (2018). Institutions for a World of Climate Injustice. Fudan Journal of the Humanities and Social Sciences, 12(2), 293-307. https://doi.org/10.1007/s40647-0180241-z

Keohane, R. O., \& Nye, J. S. (2011). Power and Interdependence (F. Zakaria (Ed.); Fourth). Longman.

Keohane, R. O., \& Oppenheimer, M. (2016). Paris: Beyond the Climate Dead End through Pledge and Review? Politics and Governance, 4(3), 142-151. https://doi.org/10.17645/pag.v4i3.634

Khan, M., Nomani, A., \& Salman, M. (2016). Impact of Beef Ban on Economy and Meat Processing Industry of India: A Complete Value Chain Analysis. Management Studies and Economic Systems, 2(4), 325-334. https://doi.org/10.12816/0035639

Kim, P. H., Pinkley, R. L., \& Fragale, A. R. (2005). Power Dynamics in Negotiation. The Academy of Management Review, 30(4), 799-822. https://www.jstor.org/stable/20159169

King, V., Pendlington, D., Walter, C., \& Smith, G. (2010). Unilever Sustainable Agriculture Code Contents. www.unilever.com/ourvalues/environment-society/publications

Kirk, E., Sherlock, K., \& Reeves, A. (2004). Non-State actors and the haphazard route to implementation of international obligations. Non-State Actors and International Law, 4(2), 87-109. https://doi.org/10.1163/1571807042341764

Kjellén, B. (2008). A New Diplomacy for Sustainable Development: The Challenge of Global Change (New York). Routledge Taylor \& Francis Group. https://doi.org/10.4324/9780203941614

Klingler, M., Richards, P. D., \& Ossner, R. (2018). Cattle vaccination records question the impact of recent zero-deforestation agreements in the Amazon. Regional Environmental Change, 18(1), 33-46. https://doi.org/10.1007/s10113-017-1234-1

Krasner, S. D. (1982). Structural Causes and Regime Consequences: Regimes as Intervening Variables. International Organization, 36(2), 185-205. http://www.jstor.com/stable/2706520

Krzywinski, M., \& Altman, N. (2014). Visualizing samples with box plots. Nature Methods, 11(2), 119-120. https://doi.org/10.1038/nmeth.2813

Kydd, A. (2005). Trust and Mistrust in International Relations. Princeton University Press. https://doi.org/https://doi.org/10.1515/9780691188515

Lacy, M. (2012). Security and Climate Change: International Relations and the Limits of Realism. Routledge. https://books.google.com/books?hl=en\&lr=\&id=hDZDrCHVpgC\&pgis $=1$

Lambin, E. F., Gibbs, H. K., Heilmayr, R., Carlson, K. M., Fleck, L. C., Garrett, R. D., Le Polain De Waroux, Y., McDermott, C. L., McLaughlin, D., Newton, P., Nolte, C., Pacheco, P., Rausch, L. L., Streck, C., Thorlakson, T., \& Walker, N. F. (2018). The role of supply-chain initiatives in reducing deforestation. Nature Climate Change, $8(2), 109$ 116. https://doi.org/10.1038/s41558-017-0061-1 
Latawiec, A. E., Strassburg, B. B. N., Valentim, J. F., Ramos, F., \& Alves-Pinto, H. N. (2014). Intensification of cattle ranching production systems: Socioeconomic and environmental synergies and risks in Brazil. Animal, 8(8), 1255-1263.

https://doi.org/10.1017/S1751731114001566

Laurance, W. F., Koh, L. P., Butler, R., Sodhi, N., Bradshaw, C. J. A., Neidel, J. D., Consunji, H., \& Mateo Vega, J. (2010). Improving the Performance of the Roundtable on Sustainable Palm Oil for Nature Conservation. Conservation Biology, 24(2), 377381. https://doi.org/https://doi.org/10.1111/j.1523-1739.2010.01448.x

Lemos, M. C., \& Agrawal, A. (2006). Environmental Governance. Annual Review of Environment and Resources, 31, 297-325.

https://doi.org/https://doi.org/10.1146/annurev.energy.31.042605.135621

Likert, R. (1932). A technique for the measurement of attitudes. Archives of Psychology, 22(140). https://psycnet.apa.org/record/1933-01885-001

Lubowski, R. N. (2008). The role of REDD in stabilising greenhouse gas concentrations Lessons from economic models. https://www.researchgate.net/publication/237343572_The_role_of_REDD_in_stabilisin g_greenhouse_gas_concentrations_Lessons_from_economic_models

Maguire-Rajpaul, V. A., Galuchi, T., Nery Alves Pinto, H., \& McDermott, C. (2016). How Brazil's sustainable cattle schemes could beef up to conserve forests and sustainable rural livelihoods (No. 148). https://hdl.handle.net/10568/78171

Maia de Souza, D., Petre, R., Jackson, F., Hadarits, M., Pogue, S., Carlyle, C., Bork, E., \& McAllister, T. (2017). A Review of Sustainability Enhancements in the Beef Value Chain: State-of-the-Art and Recommendations for Future Improvements. Animals, 7(12), 26. https://doi.org/10.3390/ani7030026

Marcus, L. J., Dorn, B. C., \& Mcnulty, E. J. (2012). The Walk in the Woods: A Step-by-Step Method for Facilitating Interest-Based Negotiation and Conflict Resolution. Negotiation Journal, 28(3), 337-349. https://doi.org/10.1111/j.1571-9979.2012.00343.x

McDonald's. (2016). MCDONALD'S SUSTAINABLE BEEF PILOT Final Report. http://www.mcdvsb.com/uploads/2/4/9/5/24957525/full_final_report_2016.07.27.pdf

McDonald's Canada. (2016). First-ever Pilot to Verify Sustainable Beef in Canada Concludes. Newswire. http://www.newswire.ca/news-releases/first-ever-pilot-to-verifysustainable-beef-in-canada-concludes-581551521.html

Mearns, R., \& Norton, A. (2010). Social Dimensions of Climate Change. https://doi.org/10.1596/978-0-8213-7887-8

Mearsheimer, J. J. (1994). The False Promise of International Institutions. International Security, 19(3), 5-49. http://www.jstor.com/stable/2539078

Mearsheimer, J. J. (2001). The Tragedy of Great Power Politics. W.W. Norton \& Company, Inc.

https://books.google.ca/books?hl=en\&lr=\&id=sQcXRDD3w_IC\&oi=fnd\&pg=PT6\&ots

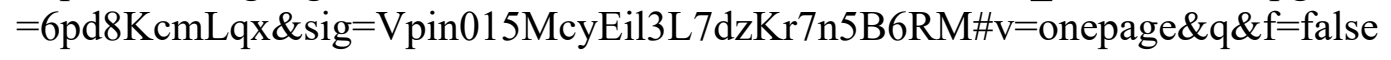

Mekonnen, M. M., \& Hoekstra, A. Y. (2012). A Global Assessment of the Water Footprint of Farm Animal Products. Ecosystems, 15(3), 401-415. https://doi.org/10.1007/s10021- 
011-9517-8

Mena, S., \& Palazzo, G. (2012). Input and Output Legitimacy of Multi-Stakeholder Initiatives. Business Ethics Quarterly, 22(3), 527-556.

https://doi.org/10.5840/beq201222333

Meyer, C., \& Miller, D. (2015). Zero Deforestation Zones: The Case for Linking Deforestation-Free Supply Chain Initiatives and Jurisdictional REDD+. Journal of Sustainable Forestry, 34(6-7), 559-580. https://doi.org/10.1080/10549811.2015.1036886

Michaelowa, K., \& Michaelowa, A. (2012). Negotiating climate change. Climate Policy, 12(5), 527-533. https://doi.org/10.1080/14693062.2012.693393

Miles, M. B., \& Huberman, M. A. (1994). Qualitative Data Analysis: An Expanded Sourcebook. SAGE. https://books.google.ca/books?hl=en\&lr=\&id=U4lU_wJ5QEC\&oi $=$ fnd\&pg=PA10\&ots=kFTB4FVT-N\&sig=p0muv-7XMOp3i$\mathrm{mqYa} 2 \mathrm{kzwGFpFc} \&$ redir_esc $=\mathrm{y} \# \mathrm{v}=$ onepage $\& \mathrm{q} \& \mathrm{f}=$ false

Moomaw, W. R., Bhandary, R. R., Kuhl, L., \& Verkooijen, P. (2017). Sustainable Development Diplomacy: Diagnostics for the Negotiation and Implementation of Sustainable Development. Global Policy, 8(1), 73-81. https://doi.org/10.1111/17585899.12350

Moomaw, W. R., \& Papa, M. (2012). Climate Policy Creating a mutual gains climate regime through universal clean energy services William Moomaw \& Mihaela Papa Creating a mutual gains climate regime through universal clean energy services. Climate Policy, 12(4), 505-520. https://doi.org/10.1080/14693062.2011.644072

Moore, C. (2014). The Mediation Process: Practical Strategies for Resolving Conflict Christopher W. Moore (Fourth Edi). Jossey-Bass.

https://books.google.ca/books?hl=en\&lr=\&id=34wfAwAAQBAJ\&oi=fnd\&pg=PR9\&dq $=$ Moore+2013+win/win+outcome+with+mutual+benefits\&ots=Dib8QGYeHj\&sig=sfqa fuGo7X05UuGorwbPe0x4zls\#v=onepage \&q \&f=false

Morse, J. M. (1991). Subjects, Respondents, Informants, and Participants? Qualitative Health Research, 1(4), 403-406. https://doi.org/10.1177/104973239100100401

Moutinho, P., Guerra, R., \& Azevedo-Ramos, C. (2016). Achieving zero deforestation in the Brazilian Amazon: What is missing? Elementa: Science of the Anthropocene, 4(0), 000125. https://doi.org/10.12952/journal.elementa.000125

Neeff, T., \& Linhares-Juvenal, T. (2018). Zero-deforestation commitments: A new avenue towards enhanced forest governance? Food and Agriculture Organization of the United Nations. http://www.fao.org/3/i9927en/I9927EN.pdf

Nepstad, D. C., McGrath, D. G., Stickler, C. M., Alencar, A., Azevedo, A. A., Swette, B., Bezerra, T., DiGiano, M., Shimada, J., Seroa da Motta, R., Armijo, E., Castello, L., Brando, P. M., Hansen, M. C., McGrath-Horn, M., Carvalho, O., Hess, L. L., Nepstad, D. C., Soares-Filho, B. S., ... Ewers, R. M. (2014). Slowing Amazon deforestation through public policy and interventions in beef and soy supply chains. Science (New York, N.Y.), 344(6188), 1118-1123. https://doi.org/10.1126/science.1248525

Nepstad, D., Irawan, S., Bezerra, T., Boyd, W., Stickler, C., Shimada, J., Carvalho, O., 
MacIntyre, K., Dohong, A., Alencar, A., Azevedo, A., Tepper, D., \& Lowery, S. (2013). More food, more forests, fewer emissions, better livelihoods: linking REDD+, sustainable supply chains and domestic policy in Brazil, Indonesia and Colombia. Carbon Management, 4(6), 639-658. https://doi.org/10.4155/cmt.13.65

Nepstad, D., Stickler, C., \& Almeida, O. T. (2006). Globalization of the Amazon Soy and Beef Industries: Opportunities for Conservation. Conservation Biology, 20(6), 15951603. https://doi.org/10.1111/j.1523-1739.2006.00510.x

Newton, P., Agrawal, A., \& Wollenberg, L. (2013). Interventions for Achieving Sustainability in Tropical Forest and Agricultural Landscapes (CAPRi Working Paper No. 110). https://doi.org/http://dx.doi.org/10.2499/CAPRiWP110

Newton, P., Alves-Pinto, H. N., \& Pinto, L. F. G. (2015). Certification, Forest Conservation, and Cattle: Theories and Evidence of Change in Brazil. Conservation Letters, 8(3), 206213. https://doi.org/10.1111/conl.12116

Nijdam, D., Rood, T., \& Westhoek, H. (2012). The price of protein: Review of land use and carbon footprints from life cycle assessments of animal food products and their substitutes. Food Policy, 37(6), 760-770. https://doi.org/10.1016/j.foodpol.2012.08.002

Norman, M., \& Nakhooda, S. (2014). The State of REDD+ Finance (No. 378). http://www.cgdev.org/publication/state-redd-finance-working-paper-378

NYDF Assessment Partners. (2019). Protecting and Restoring Forests A Story of Large Commitments yet Limited Progress Progress on the New York Declaration on Forests. New York Declaration on Forests Five-Year Assessment Report. https://forestdeclaration.org/images/uploads/resource/2019NYDFReport.pdf

Our Work | Tropical Forest Alliance. (2020). Tropical Forest Alliance. https://www.tropicalforestalliance.org/en/our-work/

Parties | UNFCCC. (2018, August 7). United Nations Climate Change. $\mathrm{https}$ ://unfccc.int/process/parties-non-party-stakeholders/parties-convention-andobserverstates?field_national_communications_target_id $\% 5 \mathrm{~B} 515 \% 5 \mathrm{D}=515 \&$ field_national_com munications_target_ $\overline{\mathrm{id}} \% 5 \mathrm{~B} 514 \% 5 \mathrm{D}=\overline{514}$

Pettenger, M. (Ed.). (2013). The Social Construction of Climate Change: Power, Knowledge, Norms, Discourses. Ashgate Publishing, Ltd. https://books.google.com/books?hl=en\&lr=\&id=qNYt4wIZ7FIC\&pgis=1

Phelps, J., Friess, D. A., \& Webb, E. L. (2012). Win-win REDD+ approaches belie carbonbiodiversity trade-offs. Biological Conservation, 154, 53-60. https://doi.org/10.1016/j.biocon.2011.12.031

Plischke, E. (1973). Treatment of "Diplomacy" in International Relations Textbooks. World Affairs, 135(4), 328-344. http://www.jstor.org/stable/20671391

Poore, J., \& Nemecek, T. (2018). Reducing food's environmental impacts through producers and consumers. Science, 360(6392), 987-992. http://science.sciencemag.org/

Potter, K. (2006). Methods for Presenting Statistical Information: The Box Plot. In H. Hagen, A. Kerren, \& P. Dannenmann (Eds.), Visualization of Large and Unstructured Data Sets. GI-Edition. Lecture Notes in Informatics. 
https://dl.gi.de/bitstream/handle/20.500.12116/4919/lni-s-4.pdf?sequence=1

Powell, R. (1991). Absolute and Relative Gains in International Relations Theory. The American Political Science Review, 84(4), 1303-1320. https://doi.org/https://doiorg.ezproxy.library.wur.nl/10.2307/1963947

Powell, R., Evans, C., Frieden, J., Gowa, J., Grieco, J., Haas, E., Katzenstein, P., Keohane, R. O., Lake, D., Morrow, J., Odell, J., \& Gross Stein, J. (1994). Anarchy in international relations theory: the neorealist-neoliberal debate. International Organization, 48(2), $313-443$.

Purdon, M. (2014). Neoclassical realism and international climate change politics: moral imperative and political constraint in international climate finance. Journal of International Relations and Development, 17(3), 301-338. https://doi.org/10.1057/jird.2013.5

R-Package Multi-stakeholder Self-Assessment of REDD+Readiness in Mozambique. (2017). https://fcp.assyst-uc.com/system/files/documents/Mozambique R-Package Submission February 21th 2017_0.pdf

Radke, A. (2016). What does McDonald's sustainability pilot mean for beef producers? | BEEF Daily. BEEF. http://beefmagazine.com/blog/what-does-mcdonald-ssustainability-pilot-mean-beef-producers

Raiffa, H. (1982). The Art and Science of Negotiation. Harvard University Press. https://books.google.ca/books?id=y-

4T88h3ntAC\&dq $=$ The + Art + and + Science + of + Negotiations + raiffa\&lr $=\&$ source $=$ gbs_na vlinks_s

Ranganathan, J., Vennard, D., Waite, R., Dumas, P., Lipinski, B., \& Searchinger, T. (2016). Shifting diets for a sustainable food future. In 2016 Global Food Policy Report (Issue April, pp. 66-79). https://doi.org/http://dx.doi.org/10.2499/9780896295827_08

Rantala, S., \& Gregorio, M. Di. (2014). Multistakeholder environmental governance in action: REDD + discourse coalitions in Tanzania. Ecology and Society, 19(2). https://doi.org/http://dx.doi.org/10.5751/ES-06536-190266

REDD Implementation Centre. (2016). REDD+Readiness Package(R-Package) and Multistakeholder Self-Assessment of REDD + Readiness in Nepal REDD Implementation Centre Ministry of Forests and Soil Conservation. https://www.forestcarbonpartnership.org/system/files/documents/Nepal R-PackageFinal- August 16 2016.pdf

Redford, K. H., Padoch, C., \& Sunderland, T. (2013). Fads, Funding, and Forgetting in Three Decades of Conservation. Biology, 27(3), 437-438. https://doi.org/10.1111/cobi

Ripple, W. J., Smith, P., Haberl, H., Montzka, S. A., McAlpine, C., \& Boucher, D. H. (2014). Ruminants, climate change and climate policy. Nature Climate Change, 4(1), 2-5. https://doi.org/10.1038/nclimate2081

Roelfsema, M., Harmsen, M., Olivier, J., \& Hof, A. (2015). Climate action outside the UNFCCC: Assessment of the impact of international cooperative initiatives on greenhouse gas emissions. https://emis.vito.be/sites/emis.vito.be/files/articles/1125/2015/pbl-2015-climate-action- 
outside-the-unfecc.pdf

Saunders, B., Sim, J., Kingstone, T., Baker, S., Waterfield, J., Bartlam, B., Burroughs, H., \& Jinks, C. (2017). Saturation in qualitative research: exploring its conceptualization and operationalization. Quality and Quantity, 52(4). https://doi.org/10.1007/s11135-0170574-8

Saunders, H. (2009). Dialogue as a Process for Transforming Relationships. In J. Bercovitch, V. Kremenyuk, \& W. Zartman (Eds.), The SAGE Handbook of Conflict Resolution (pp. 376-391). Sage Publications. http://dx.doi.org/10.4135/9780857024701

Savage, G. T., Bunn, M. D., Gray, B., Xiao, Q., Wang, S., Wilson, E. J., \& Williams, E. S. (2010). Stakeholder Collaboration: Implications for Stakeholder Theory and Practice. Journal of Business Ethics, 96, 21-26. https://doi.org/10.1007/s10551-011-0939-1

Schouten, G., \& Glasbergen, P. (2012). Private multi-stakeholder governance in the agricultural market place: An analysis of legitimization processes of the roundtables on sustainable palm oil and responsible soy. International Food and Agribusiness Management Review, 15(Special Issue B), 63-88.

Schultz, M., Hahn, T., Ituarte-Lima, C., \& Hällström, N. (2018). Deliberative multi-actor dialogues as opportunities for transformative social learning and conflict resolution in international environmental negotiations. International Environmental Agreements: Politics, Law and Economics, 18(5), 671-688. https://doi.org/10.1007/s10784-0189410-4

Sharp, P. (1999). For diplomacy: Representation and the study of international relations. International Studies Review, 1(1), 33-57. https://doi.org/10.1111/1521-9488.00140

Sprinz, D., \& Vaahtoranta, T. (1994). The Interest-Based Explanation of International Environmental Policy. International Organization, 48(1), 77-105. https://www.jstor.org/stable/2706915

Stavins, R. N. (2011). The problem of the commons: Still unsettled after 100 years. American Economic Review, 101(1), 81-108. https://doi.org/10.1257/aer.101.1.81

Stein, A. A. (2008). The Oxford Handbook on International Relations. In C. Reus-Smit \& D. Snidal (Eds.), The Oxford Handbook of International Relations (pp. 201-221). Oxford University Press. http://www.grandstrategy.net/Articles-pdf/11-Smit-Snidal-c11.pdf

Steinfield, H., Gerber, P., Wassenaar, T., Castel, V., Rosales, M., \& de Haan, C. (2006). Livestock's Long Shadow. http://www.fao.org/3/a0701e/a0701e.pdf

Stengel, F. A., \& Baumann, R. (2017). Non-State Actors and Foreign Policy. In C. Thies (Ed.), Oxford Research Encyclopedia Foreign Policy Analysis (pp. 266-286). Oxford University Press. https://doi.org/10.1093/acrefore/9780190228637.013.456

Stern, N. (2007). The Economics of Climate Change: The Stern Review. Cambridge University Press. https://doi.org/https://doi.org/10.1017/CBO9780511817434

Streck, C. (2020). Who Owns REDD+? Carbon Markets, Carbon Rights and Entitlements to REDD+ Finance. Forests, 11(9), 959. https://doi.org/10.3390/f11090959

Supply Change. (2015). Corporations, Commodities, and Commitments that Count. www.supply-change.org 
Susskind, L., \& Ali, S. H. (2014). Environmental Diplomacy: Negotiating More Effective Global Agreements. Oxford University Press.

https://books.google.com/books?hl=en\&lr=\&id=2XVMCAAAQBAJ\&pgis=1

Susskind, L., Chayes, A., \& Martinez, J. (1996). Parallel Informal Negotiation: A New Kind of International Dialogue. Negotiation Journal, 12(1), 19-29. https://doi.org/10.1111/j.1571-9979.1996.tb00076.x

Susskind, L., Fuller, B., Fairman, D., \& Ferenz, M. (2003). Multistakeholder Dialogue at the Global Scale. International Negotiation, 8(2), 235-266. https://doi.org/10.1163/157180603322576121

Tayleur, C., Balmford, A., Buchanan, G. M., Butchart, S. H. M., Ducharme, H., Green, R. E., Milder, J. C., Sanderson, F. J., Thomas, D. H. L., Vickery, J., \& Phalan, B. (2017). Global Coverage of Agricultural Sustainability Standards, and Their Role in Conserving Biodiversity. Conservation Letters, 10(5), 610-618. https://doi.org/10.1111/conl.12314

Terhalle, M., \& Depledge, J. (2013). Great-power politics, order transition, and climate governance: insights from international relations theory. Climate Policy, 13(5), 572588. https://doi.org/10.1080/14693062.2013.818849

Thoma, G., Putman, B., Matlock, M., Popp, J., \& English, L. (2017). Sustainability Assessment of U.S. Beef Production Systems.

http://www.beefissuesquarterly.org/CMDocs/BeefResearch/Sustainability Completed Project Summaries/FinalReport_ProductionSystems.pdf

Thomas, G. (2011). A typology for the case study in social science following a review of definition, discourse, and structure. Qualitative Inquiry, 17(6), 511-521. https://doi.org/10.1177/1077800411409884

Tilman, D., \& Clark, M. (2014). Global diets link environmental sustainability and human health. Nature, 515(7528), 518-522. https://doi.org/10.1038/nature13959

Tomlinson, L. (2015). Procedural justice in the United Nations framework convention on climate change: Negotiating fairness. In Procedural Justice in the United Nations Framework Convention on Climate Change: Negotiating Fairness. Springer International Publishing. https://doi.org/10.1007/978-3-319-17184-5

Turcotte, M.-F., \& Pasquero, J. (2001). The Paradox of Multistakeholder Collaborative Roundtables. The Journal of Applied Behavioral Science, 37(4), 447-464. https://doi.org/10.1177/0021886301374004

U.S. Roundtable for Sustainable Beef. (2015). 2015 U.S. Roundtable for Sustainable Beef Annual Report. https://www.usrsb.org/CMDocs/USRSB/2015 USRSB Annual Report_SinglePage_FINAL.PDF

U.S. Roundtable for Sustainable Beef. (2016). 2016 USRSB Annual Report. https://www.usrsb.org/CMDocs/USRSB/2016 USRSB Annual Report_Web-Final.pdf

Umunay, P., Lujan, B., Meyer, C., \& Cobián, J. (2018). Trifecta of Success for Reducing Commodity-Driven Deforestation: Assessing the Intersection of REDD+ Programs, Jurisdictional Approaches, and Private Sector Commitments. Forests, 9(10), 609. https://doi.org/10.3390/19100609

UN-REDD Programme. (n.d.). About REDD+. Retrieved June 13, 2018, from 
http://www.un-redd.org/aboutredd

UN-REDD Programme - UN-REDD Programme Collaborative Online Workspace. (n.d.).

Retrieved January 10, 2021, from https://www.unredd.net/about/un-reddprogramme.html

UNFCCC. (2011, March 15). The Cancun Agreements: Outcome of the work of the Ad Hoc Working Group on Long-term Cooperative Action under the Convention. FCCC/CP/2010/7/Add.1. https://unfccc.int/resource/docs/2010/cop16/eng/07a01.pdf

United Nations. (2015). United Nations, Framework Convention on Climate Change. Paris Agreement 1/CP.21, 1-25.

https://unfccc.int/files/essential_background/convention/application/pdf/english_paris_a greement.pdf

United Nations Climate Change. (2014, January 31). Report of the Conference of the Parties on its nineteenth session, held in Warsaw from 11 to 23 November 2013 Addendum Part two: Action taken by the Conference of the Parties at its nineteenth session . FCCC/CP/2013/10/Add.1. https://unfccc.int/resource/docs/2013/cop19/eng/10a01.pdf

United Nations General Assembly. (2015). Transforming Our World: The 2030 Agenda for Sustainable Development. A/RES/70/1.

https://sustainabledevelopment.un.org/content/documents/21252030 Agenda for Sustainable Development web.pdf

USDA Foreign Agricultural Service. (2017). Cattle Stocks-Selected Countries Summary. U.S. Department of Agriculture.

https://apps.fas.usda.gov/psdonline/app/index.html\#/app/downloads

USDA Foreign Agricultural Service. (2021). Livestock and Poultry: World Markets and Trade. https://public.govdelivery.com/accounts/USDAFAS/subscriber/new

Van Der Ven, H., Rothacker, C., \& Cashore, B. (2018). Do eco-labels prevent deforestation? Lessons from non-state market driven governance in the soy, palm oil, and cocoa sectors. https://doi.org/10.1016/j.gloenvcha.2018.07.002

Van Der Werf, G. R., Morton, D. C., Defries, R. S., Olivier, J. G. J., Kasibhatla, P. S., Jackson, R. B., Collatz, G. J., \& Randerson, J. T. (2009). CO2 emissions from forest loss. Nature Geoscience, 2(11), 737-738. https://doi.org/10.1038/ngeo671

van Tulder, R., Seitanidi, M. M., Crane, A., \& Brammer, S. (2016). Enhancing the Impact of Cross-Sector Partnerships: Four Impact Loops for Channeling Partnership Studies. Journal of Business Ethics, 135(1), 1-17. https://doi.org/10.1007/s10551-015-2756-4

Victor, D. G. (2006). Toward Effective International Cooperation on Climate Change: Numbers, Interests and Institutions. Global Environmental Politics, 6(3), 90-103. https://doi.org/10.1162/glep.2006.6.3.90

Vieira, L. M., Hoppe, A., \& Schneider, L. C. (2016). Multi-stakeholder initiative for sustainable beef production standards. In A Stakeholder Approach to Managing Food: Local, National, and Global Issues (pp. 3-14). Routledge.

Vogler, J. (2009). The institutionalisation of trust in the international climate regime. Energy Policy, 38, 2681-2687. https://doi.org/10.1016/j.enpol.2009.05.043

Walker, N., Patel, S., Davies, F., Milledge, S., \& Hulse, J. (2013). Demand-side interventions 
to reduce deforestation and forest degradation. In International Institute for Environment and Development (Issue October). https://doi.org/10.13140/2.1.3844.3528

Waltz, K. (1979). Theory of international relations. In Theory of international relations (pp. 111-114). Addison-Webley. http://iopscience.iop.org/article/10.1088/0029$5515 / 19 / 1 / 006 /$ meta

Weiler, F. (2012). Determinants of bargaining success in the climate change negotiations. Climate Policy, 12(5), 552-574. https://doi.org/10.1080/14693062.2012.691225

Wendt, A. E. (1992). Anarchy is what states make of it: The Social Construction of Power Politics. Source: International Organization, 46(2), 391-425. https://doi.org/10.1017/S0020818300027764

Wendt, A. E. (1994). Collective Identity Formation and the International State. The American Political Science Review, 88(2), 384-396. https://www.jstor.org/stable/2944711

What is the New York Declaration on Forests? (n.d.). New York Declaration on Forests. Retrieved November 26, 2020, from https://forestdeclaration.org/about

Wood, P. J. (2011). Climate change and game theory in "Ecological Economics Reviews." In R. Costanza, K. Limburg, \& I. Kubiszewski (Eds.), Annals of the New York Academy of Sciences (Vol. 1219, Issue 1, pp. 153-170). Blackwell Publishing Inc. https://doi.org/10.1111/j.1749-6632.2010.05891.x

Wynes, S., \& Nicholas, K. A. (2017). The climate mitigation gap: Education and government recommendations miss the most effective individual actions. Environmental Research Letters, 12(7), 74024. https://doi.org/10.1088/1748-9326/aa7541

Young, O. (2001). The Behavioral Effects of Environmental Regimes: Collective-Action vs. Social-Practice Models. International Environmental Agreements - Politics, Law and Economics, 1(1), 9-29. https://doi.org/10.1023/A:1010181007938

Zartman, I. W. (1977). Negotiation as a Joint Decision-Making Process. Journal of Conflict Resolution, 21(4), 619-638. https://doi.org/10.1177/002200277702100405

Zartman, I. W. (1988). Common Elements in the Analysis of the Negotiation Process. Negotiation Journal, 4(1), 31-43. https://doi.org/10.1007/BF01000902

Zartman, I. W. (1989). Prenegotiation: Phases and Functions. International Journal, 44(2), 237. https://doi.org/10.2307/40202597

Zartman, I. W. (1992). International environmental negotiation: Challenges for analysis and practice. Negotiation Journal, 8(2), 113-123. https://doi.org/10.1007/BF01000628

Zartman, I. W. (1994). International Multilateral Negotiation: Approaches to the Management of Complexity (W. I. Zartman (Ed.); First). Jossey-Bass Publishers.

Zartman, I. W. (2002). What I Want to Know about Negotiations. International Negotiation, 7(1), 5-15. https://doi.org/10.1163/157180602401262393

Zartman, I. W., \& Rubin, J. Z. (2002). Power and Negotiation (I. W. Zartman \& J. Z. Rubin (Eds.); First). University of Michigan Press. https://doi.org/10.3998/mpub.16897 


\section{SUMMARY}

The concept of sustainable development was defined and codified in 1987 with the World Commission on Environment and Development report. Since then, there has been a proliferation of processes, regimes, negotiations, activities, and collaborations aimed at aspects of sustainable development (or a portfolio of ambitions such as those embodied in the Sustainable Development Goals (SDGs)). Recognizing the complexity of global systems intertwined with the pursuit of sustainable development, diplomatic practitioners and scholars proposed a new approach and practice to facilitating international cooperation: sustainable development diplomacy (SD diplomacy). While SD diplomacy presents a compelling perspective and systems-like approach, the concept is still relatively nascent and lacks connectivity to related scientific fields such as international relations, multi-party negotiation, and conflict resolution. This thesis aims to strengthen SD diplomacy as a theory and a practice. It does so by qualitatively examining a cross-section of multi-actor processes in sustainable development: the intergovernmental negotiations on climate change under the United Nations Framework Convention on Climate Change (UNFCCC); inter-governmental and multi-stakeholder processes on reducing emissions from deforestation and degradation (REDD+); and multi-stakeholder roundtables on sustainable beef. In the UNFCCC and REDD+ contexts, the focus is on negotiation dynamics with an eye towards understanding how those dynamics enable and/or constrain multi-actor agreement. The beef roundtables context focuses on understanding the evolutionary characteristics and phases that underpin their potential for sustainability contributions. Finally, the thesis explores the same characteristics and phases to understand the evolution of multi-stakeholder processes to reduce deforestation. The results of the analyses inform an Integrated Negotiation Dynamics Model and consideration of multi-stakeholder market-oriented approaches to sustainability. The synthesized results are then utilized to inform and enhance the field of SD diplomacy.

Chapter 1 of this thesis introduces the theory and practice of SD diplomacy in the context of three other related disciplines: international relations, multi-party negotiations, and conflict resolution. Based upon the literature, I introduce three themes and related knowledge gaps. First, that multi-party negotiation scholars recognize the complexity inherent in the negotiation process and variably seek ways to understand it. A common thread is the desire to understand key variables or factors involved in negotiation and the roles they play. Within the realm of intergovernmental negotiations, international relations theorists debate whether and how states cooperate and the primary factors for doing so. Multi-party negotiation theorists point to multiple variables involved in how parties negotiate (state and/or non-state actors). Several conflict resolution scholars offer holistic perspectives in multi-stakeholder dialogue and collaboration processes but the contributions of this discipline can be overlooked when it comes to examining multi-actor processes at the international level. While these three disciplines provide insights into key variables involved in multi-actor negotiations, there is less understanding of the relationships between those factors. 
Second, while there is a myriad of terms used, there is general convergence within multiparty negotiation and conflict resolution frameworks around a primary set of factors involved in multi-party negotiations. Among these factors, there is little understanding about how these enable or constrain agreement (the outcomes that scholars are seeking to explain). Moreover, existing multi-party negotiation frameworks offer few insights into the optimal functioning of these key factors in order to support agreement. SD diplomacy scholars, however, do provide "diagnostics" that describe approaches to negotiation and implementation that have been effective in contributing to sustainable development outcomes. Yet, SD diplomacy literature has not been well-positioned against the broader disciplines it could contribute to.

Third, the literature emphasizes debate about the roles of non-state actor processes in sustainable development. These processes take various forms, from private sector driven, to multi-stakeholder collaborations, partnerships, and voluntary agreements. SD diplomacy diagnostics call for diverse state and non-state stakeholders to be engaged in both negotiation and implementation processes for sustainable development. The proliferation of processes involving both state and non-state actors seem to reflect an SD diplomacy approach.

However, the literature tends to deliberate on the governance, accountability, and legitimacy of non-state actor processes with little emphasis on understanding their evolution and potential for sustainability contributions.

The above-mentioned themes point to related knowledge gaps in understanding: relationships between factors in sustainable development negotiations; the roles that key factors play in enabling or constraining agreement; and the evolution and potential contributions of proliferating multi-stakeholder collaborations. Improved, inter-disciplinary understanding in these areas can, in turn, contribute to the relatively new field of SD diplomacy. Accordingly, the overarching objective of this thesis is to strengthen SD diplomacy as an approach and practice for understanding advancements related to the Sustainable Development Goals. Specifically, this thesis examined the contexts of climate change, forests, and sustainable cattle production - which relate to SDGs 13,15 , and 12, respectively. This objective is investigated through the following research questions:

1. What are the negotiation factors involved in the UNFCCC negotiations; how do those factors relate to each other and to reaching agreement?

2. How did negotiation factors enable or constrain multi-actor agreements in REDD+ negotiations and supporting multi-stakeholder REDD+ processes?

3. What are the evolutionary characteristics and phases of multi-stakeholder collaborations on cattle and deforestation that underpin their potential for sustainability impact?

Recognizing that the three research questions and corresponding areas of study span both negotiation and implementation, two conceptual frameworks were required to study these contexts and to answer the research questions. The first two research questions were examined through case studies in the UNFCCC and REDD + . Starting with an iterative, 
grounded theory approach based upon my professional experience in the UNFCCC and REDD + contexts, I observed an emerging set of common variables from those negotiation contexts. These variables were reflected in the literature and seemed to be embodied in a framework from the field of conflict resolution. The Policy Dialogue Model (PDM) served as the first conceptual framework employed in the thesis as a starting point for understanding: the key factors involved in the UNFCCC and REDD+ negotiations, their roles, relationships between them, and the degree to which they constrained or enabled agreement in those contexts.

To address research question 3 and the implementation-oriented cases under examination, a different conceptual framework was employed. The Non-State Market-Driven (NSMD) framework provided a set of characteristics and phases that reflect the hallmarks of private voluntary sustainability efforts. This framework provided a way of understanding the evolutionary steps these processes undergo to become widely recognized and adoptedunderpinnings of their potential for lasting and significant sustainability contributions.

The first chapter also includes the research methodology which outlines a nested case study approach based upon the three contexts under study: the intergovernmental negotiations of the UNFCCC; the intergovernmental and supporting parallel processes of REDD+; and the multi-stakeholder collaborations of the roundtables for sustainable beef and efforts to reduce deforestation. Each of these contexts can contribute to SDGs on climate, life on land, and sustainable production and consumption. However, they are substantively nested in the sense that cattle production is a driver of deforestation, and both cattle production and deforestation are significant contributors to the problem of climate change. These cases are also nested in terms of providing insights into and across intergovernmental negotiations, multi-stakeholder negotiations, and multi-stakeholder implementation processes. Data collection within these case studies encompassed semi-structured interviews, an online survey, and field research in the form of practitioner observations. The data collected was qualitatively analyzed and centered around thematic, targeted, and open coding based upon the interview and survey questions, as well as aspects of the conceptual frameworks employed. This allowed data to be connected back to the conceptual framework while providing an opportunity to identify new aspects that did not conform to the framework.

Chapter 2 presents the first case study exploring the intergovernmental negotiations of the UNFCCC. The study aims to understand the key factors or variables involved in those negotiations including the roles those factors play and the relationships between them. In doing so, this chapter addresses research questions 1 and 2. Starting with the first conceptual framework, the Policy Dialogue Model (PDM), this chapter applies empirical data based upon the first-hand experiences of UNFCCC negotiators, chairs, facilitators, and Secretariat staff. By applying these data to the PDM, new insights on the key factorsnegotiation dynamics - emerge and inform a resulting revised framework, the Integrated Negotiation Dynamics Model (INDM). The negotiation dynamics of the model are explained in detail, based upon grounding the model in empirical evidence from the UNFCCC context. 
Revisions include: articulation of sub-factors within each of the negotiation dynamics and the roles they play in the UNFCCC negotiations; examples of relationships between negotiation factors that play a role in reaching agreement; and visual changes to the model to reflect the results which indicated greater parity and interconnectivity across the dynamics. Chapter 2 also includes analysis of respondents' descriptions of negotiation dynamics as enabling or constraining to reaching agreement. The findings show that while the negotiation dynamics of Power and Political Context were dominant and more constraining, leveraging negotiation dynamics of Group Process, Communication, and Data and Information can help overcome those constraints. The latter three dynamics can also be leveraged to support a transition in the Negotiation Process dynamic, from distributive (win-lose) to integrative (win-win).

Chapter 3 provides the second case study which employs the empirically grounded INDM to examine the REDD+ negotiations that led to the relative prominence of REDD+ in the Paris Agreement. In doing so, it examines both the intergovernmental REDD+ negotiations under the UNFCCC and the role of supporting multi-stakeholder REDD+ processes. The aim of the study is to better understand the relationships between negotiation dynamics and the degree to which they enabled and/or constrained agreement. It also explores the role that related REDD+ multi-stakeholder processes (coined as parallel complementary initiatives) played in supporting a negotiated agreement on REDD+ in the UNFCCC. Similar to the results from Chapter 2, the findings highlight the interconnectivity between negotiation dynamics: that an obstacle emanating from one dynamic can be mitigated by harnessing the enabling aspects of another dynamic. In addition, the results indicate that parallel complementary initiatives were quite important and influential to supporting the REDD+ in the UNFCCC and provide insights on their roles. This chapter primarily addresses research question $\mathbf{2}$ and provides additional insights into the relationships between negotiation dynamics, in response to research question 1.

Chapter 4 explores the multi-stakeholder implementation processes of sustainable cattle production and efforts to reduce deforestation. The primary focus of the chapter is on the roundtables for sustainable beef, as the main global- and national- level multi-stakeholder process focused on advancing sustainable cattle production. In addition, the chapter also includes an examination of multi-stakeholder efforts to reduce deforestation, using the same Non-State Market-Driven (NSDM) conceptual framework for both contexts, cattle and forests. In doing so, this chapter addresses research question 3 by providing insights into the characteristics and phases of evolution that both the roundtables and deforestation efforts move through to realize their potential for sustainability contributions. The findings indicate that neither the roundtables nor multi-stakeholder efforts to reduce deforestation have fully evolved to becoming widely recognized and adopted (or mainstreamed). As such, their potential for lasting and significant sustainability contributions remains limited so far. Yet, the results also highlighted opportunities for these processes to yield greater contributions by inviting the participation and coordination of state- and non-state actors alike, potentially evolving towards more 'hybrid' approaches to governance. 
In Chapter 5, the collective results of chapters 2, 3, and 4 are drawn upon and synthesized in response to the three research questions. With regards to research question 1, building off of the Policy Dialogue Model, the results pointed to a set of six primary negotiation dynamics involved in the UNFCCC and REDD+ negotiation contexts. These are: Political Context, Negotiation Process, Group Process, Power, Data and Information, and Communication. Empirically grounding the conceptual framework in first-hand accounts from individuals involved in these negotiations revealed more nuanced understanding of 20 sub-factors within these main dynamics. These included, for example, differentiation between domestic and global Political Contexts; and Knowledge-based vs. Procedural Power, to name a few. With regards to how these negotiation dynamics related to each other and to reaching agreement, the results indicated that overall, negotiation dynamics are interconnected. That is to say, a challenge presented in one negotiation dynamic may be mitigated through strengthening other negotiation dynamics. In terms of more specific relationships, the results revealed that building relationships and trust among negotiators (part of Group Process) catalyzed increased sharing of Data and Information related to their respective Parties' domestic Political Context and underlying interests (part of Negotiation Process). Trusted relationships among individual negotiators led to an improvement in Parties' understanding of overlapping interests - a starting place for building agreement. The resulting Integrated Negotiation Dynamics Model (INDM) reflects the empirically grounded revisions to the Policy Dialogue Model. It depicts greater parity among the six primary negotiation dynamics and their interconnected nature and relationships.

In response to research question 2, results indicated that Group Process and Negotiation Process dynamics were most enabling to reaching agreement in the UNFCCC negotiation context; and that Group Process and Political Context were most enabling to reaching agreement on REDD+ within the UNFCCC negotiations. Among respondents, there was convergence that overall, Group Process was more enabling and Political Context was more constraining to reaching agreement. Unexpectedly, considering the emphasis on power in international relations literature in particular, the results indicate that Power was neither most constraining nor enabling. In comparing the enabling and constraining effects of negotiation dynamics within the REDD+ UNFCCC negotiations with multi-stakeholder REDD+ early implementation platforms, the results showed that Political Context and Power were more constraining in the latter. This finding was somewhat unexpected considering the higher political stakes involved in the UNFCCC and that negotiations are centered among member states. However, results indicated that the UN setting offered greater equity among Parties than they would otherwise experience in non-UN contexts such as the REDD+ early implementation platforms, thereby tempering the effects of Power and Political Context. In examining the INDM for its potential to be used diagnostically, findings from Chapters 2 and 3 indicate that first identifying which negotiation dynamics are constraining and then working to strengthen non-constraining dynamics can be used to overcome obstacles.

In response to research question 3, the results indicated that the roundtables for sustainable beef (RSBs) and multi-stakeholder efforts to reduce deforestation largely reflect the main 
hallmarks of the Non-State Market Driven (NSMD) framework employed. Although, in both contexts, there is an evolution towards including both state and non-state actors, perhaps indicating growing recognition of the need to involve diverse stakeholders, reflective of an SD diplomacy approach. Based upon the characteristics and phases of the NSMD framework, the results indicated that none of the RSBs nor multi-stakeholder efforts to reduce deforestation have evolved beyond the 'building support' phase to become mainstream. The results highlighted both obstacles and opportunities for these processes to evolve to become widely recognized and adopted. This included fostering more inclusive and diverse participation of stakeholders, sectors, and geographies. By engaging policymakers upfront, the evolution of RSBs may advance more quickly, yielding greater sustainability contributions sooner. Beyond the stakeholder engagement called for in SD diplomacy, results indicated that the prospect of more significant sustainability contributions may require stakeholder alignment. In addition, the ability of these multi-stakeholder efforts to 'ameliorate global problems' as described in the NSMD framework may require going beyond the portfolio approach called for in SD diplomacy. Instead, the results indicate that a more comprehensive systems approach inclusive of the above-mentioned sectors and stakeholders better reflects another SD diplomacy tenet, that the solution is 'compatible with the complexity of the problem'. In reflecting upon the NSMD framework based upon its application to RSBs and multi-stakeholder efforts to reduce deforestation, the thesis offers a set of suggestions for revising NSMD characteristics to broaden its future application beyond exclusively non-state market-driven approaches to sustainability.

Finally, the collective results of the thesis are synthesized and analyzed with the aim of extracting insights to strengthen SD diplomacy. Based upon the results from the thesis, Chapter 5 provides suggested changes and additions to the SD diplomacy diagnostics. Two new diagnostics are proposed: 1) identify enabling negotiation dynamics and leverage them to overcome constraining negotiation dynamics to support parties/stakeholders reaching agreement; and 2) generate shared understanding of how parallel processes working towards the same or similar sustainable development objectives can be mutually reinforcing. In addition, the thesis proposes modifications to three existing SD diagnostics to reflect the need for stakeholder alignment and implementing a systems approach to both data and information and the development of solutions. In doing so, the collective scientific contributions from this thesis strengthen the approach and practice of SD diplomacy. My hope is that SD diplomacy and these contributions to it, continue to shepherd in a "new diplomacy" that reflects the interests of future generations. 


\section{Appendix A | Interview Questions Chapter 2}

1. Are you a negotiator in the UNFCCC? If so, how many years have you served as a negotiator in the process?

2. Are you, or have you ever been a Chair/Facilitator in the UNFCCC process? If so, how many years have you served as a Chair/facilitator?

\section{Unpacking Consensus-Building}

3. In your experience, what are the key factors you have found helpful to take into account when trying to reach agreement in a multi-lateral negotiation? [Open-ended question before asking about specific dimensions in the Policy Dialogue Model]

[Questions 4-8 are directly related to exploring each dimension in the Policy Dialogue Model]

4. Do political factors/politics influence the climate negotiations happening in a room? If so, how? Are traditional geopolitics replicated in the UNFCCC process or are there different politics that are unique to the UNFCCC?

5. Does the way a Party engages affect the process? Does it matter if they are communicating their interests vs. firm policy positions? If so, how?

6. Do communications, relationship- and trust-building among Parties and negotiators play a role? If so, how?

7. What role(s) do data and information play in the UNFCCC?

8. How does power relate to the negotiation process or ability to reach agreement? For instance, is the traditional geopolitical power structure replicated or are there different power dynamics that emerge in the UNFCCC negotiations?

9. Have you found that all of the factors you identified in your responses are equally important to reach consensus? If not, which ones are most important in your experience? 


\section{Capacity of Negotiators/Facilitators to Reach Consensus}

10. How would you describe the role of the Chair and facilitators and in your experience, what skills or approaches have Chairs used that were helpful towards reaching agreement? What skills or approaches were unhelpful?

11. How do you prepare yourself for UNFCCC negotiations?

12. What kind of activities do you think would help other negotiators improve their capacity to reach agreement and develop enhanced consensus-building skills?

\section{Examining Consensus-building in the UNFCCC Process}

13. What, if anything, could be changed in the UNFCCC process that might improve or enhance Parties' ability to reach agreements?

14. Are there experiences or lessons learned from other multi-lateral negotiation processes that might be helpful to explore in relation to the UNFCCC negotiations?

15. Do you have any final questions, comments or observations? 


\section{Appendix B | Survey and Interview Questions Chapter 3}

Thank you for taking the time to complete this nine-question survey, which will take approximately 15 minutes. The results of this survey will be used to inform an academic case study aimed at understanding the negotiation dynamics that led to the prominence of forests and REDD+ in the Paris Agreement.

1. Respondent Information (optional; responses will not be attributed to you)

Name (optional)

Country (optional)

2. Please indicate your affiliation(s) over the last five years in relation to the REDD+ negotiations under the UNFCCC. You may select more than one:

REDD+ donor country

REDD+ partner country

UNFCCC REDD+ Negotiator

Non-governmental organization (NGO)

Indigenous Peoples Organization (IPO)

Scientist/researcher

UN-REDD Programme

Forest Carbon Partnership Facility (FCPF)

UNFCCC Secretariat

Private sector

Other (please specify)

The next set of questions will ask for your perspective on negotiation dynamics within the formal UNFCCC negotiations, followed by your views on factors outside of the formal negotiations that influenced the formal negotiation dynamics within the UNFCCC process. Each question provides six choices of negotiation dynamics, or variables in a negotiation, briefly described below: 
Political context: what is happening outside of the negotiation process that will influence, or needs to be taken into account as parties determine what they can and cannot agree to (e.g., domestic politics, global political economy);

Negotiating tactics: the range of skills employed during the negotiation aimed at achieving the negotiator's objectives (e.g., interest- vs. positional- bargaining)

Group process: interpersonal and group dynamics including interpersonal relations, individual personalities, trust

Power: ability to influence parties or participants whether they are aware of it or not. Includes power differentials, different types of power, and uses of power.

Data and information: access to trusted, credible data and information

Communications: the medium through which parties/participants interact, including communication style (this is linked to negotiating tactics but also to other variables such as communications related to political context or power)

3. Within the formal negotiations, what factors or negotiation dynamics presented the greatest challenge to parties' ability to reach agreement? Please rank from most to least challenging (1-5)

Other (please specify)

4. Within the formal [UNFCCC] negotiations, what negotiation dynamics most contributed to parties' ability to reach agreement on establishing a REDD+ mechanism? Please rank from most to least important (1-5)

Other (please specify)

5. Within the formal [UNFCCC] negotiations, were some dynamics leveraged to overcome challenges in others? For instance, did interpersonal relationships and trust help overcome challenges in the power or political context dynamics?

If so, please describe some of the most important relationships you observed and how they were instrumental in reaching agreement.

6. Outside of the formal [UNFCCC] negotiations (e.g., within FCPF, UN-REDD Programme, informal policy dialogues), what factors or negotiation dynamics 
presented the greatest challenge to parties' ability to reach agreement? Please rank from most (1) to least challenging (5).

Other (please specify)

7. Outside of the formal [UNFCCC] negotiations (e.g., within FCPF, UN-REDD Programme, informal policy dialogues), what factors or negotiation dynamics most contributed to parties' ability to reach agreement on establishing a REDD+ mechanism? Please rank from most (1) to least important (5).

Other (please specify)

8. Based on your experience, how important and influential was the relationship between informal REDD + processes (FCPF, UN-REDD Programme, informal policy dialogues) and parties' ability to reach agreement in the UNFCCC negotiations? [very important and influential; somewhat important and influential; important, but not influential; neither important not influential]

Other (please specify)

9. Based on your experience, what were the critical factors (e.g., decisions, turning points, contextual events, etc.) in the REDD+ negotiations that led to both forests and REDD + featuring so prominently in the Paris Agreement? 


\section{Appendix C | Interview Questions Chapter 4}

\section{Credentials, experience, and broad perspective}

1. Describe your experience and expertise in relation to the sustainability of beef supply chains including what aspects of enhancing the sustainability beef supply chains you have been most focused and/or interested in? (e.g., environmental implications of production, processing, health implications of consumption)

2. How do you and/or your organization define sustainability in the context of beef supply chains, and/or which dimension(s) of sustainability do you prioritize?

3. What geographies or scales are you focused on? (e.g., Brazil, global)

\section{Roundtables for sustainable beef}

4. What are the roles (actual and potential) of the beef roundtable(s) (global and/or country level) in enhancing sustainability?

5. What are the sustainability actions that this roundtable has taken to date?

6. What are the strengths and weaknesses of roundtable X's governance structure (including engagement, transparency, and decision-making)?

7. Recognizing the roundtables are not standards-setting bodies, in what ways does roundtable $\mathrm{X}$ conduct work on monitoring, compliance, and/or verification?

8. To what extent is roundtable X's work grounded in and informed by rigorous science?

9. What, if anything, could be done to expand upon or improve the sustainability impacts of the (global and/or country level) roundtables?

10. What, if any, challenges do you perceive or anticipate in enhancing the sustainability impact of (global and/or country level) roundtable efforts?

11. What are the limitations of roundtables? What other interventions are needed to fill any gaps that you identify?

12. Is there anything else that you would like to share that we have not asked you about?

13. Who else do you suggest we interview? 


\section{Appendix D | Visits}

1. 3- 8 April 2011 | UNFCCC Bangkok Climate Change Conference

2. 6-12 June 2011

a. UNFCCC Bonn Climate Change Conference

b. REDD+ Partnership meeting

3. 2-7 October 2011

a. UNFCCC Panama Climate Change Conference

b. REDD+ Partnership meeting

4. 30 November- 6 December 2011
a. UNFCCC COP-17 in Durban
b. Side event
c. REDD+ Partnership meeting

5. 16-21 May 2012

a. UNFCCC Bonn Climate Change Conference

b. REDD+ Partnership meeting

6. 26 November- 2 December 2012

a. UNFCCC COP-18 in Doha

b. Side event on consensus-building

7. 4 - 9 June 2013
a. UNFCC Bonn Climate Change Conference
b. Side event on consensus-building

8. 6-10 June 2014
a. UNFCCC Bonn Climate Change Conference
b. Side event on land use

\footnotetext{
* In addition to these trips, professional experience involved: attendance as an observer to UNFCCC COP-15 in Copenhagen (2009), UNFCCC COP-16 in Cancun (2010), Tianjin Climate Change Talks and REDD+ Partnership meeting (2010); facilitating the Forum on Readiness for REDD+ including South-South capacity-building and collaboration; convening a 3-year series of informal policy dialogues among UNFCCC agricultural negotiators which informed a report and policy briefing, and UNFCCC side events on agriculture and climate change; and facilitating multi-stakeholder dialogue to inform "Land Use in a Future Climate Agreement" (Estrada et al., 2014).
} 


\section{Appendix E | Sustainable Development Goals}

The following is a list of the 17 Sustainable Development Goals (SDGs) (United Nations General Assembly, 2015).

Goal 1 | No Poverty: By 2030, eradicate extreme poverty for all people everywhere.

Goal 2 | Zero Hunger: End hunger, achieve food security and improved nutrition by 2030.

Goal 3 | Good Health and Well-being: Ensure healthy lives and promote well-being for all at all ages by 2030 .

Goal 4 | Quality Education: Ensure that all girls and boys complete free, equitable and quality primary and secondary education by 2030 .

Goal 5 | Gender Equality: To achieve gender equality and empower all women and girls.

Goal 6 | Clean Water and Sanitation: Ensure availability and sustainable management of water and sanitation for all by 2030.

Goal 7 | Affordable and Clean Energy: Ensure access to affordable, reliable, sustainable and modern energy for all by 2030 .

Goal 8 | Decent Work and Economic Growth: Promote sustained, inclusive and sustainable economic growth.

Goal 9 | Industry, Innovation and Infrastructure: Build resilient infrastructure, promote inclusive and sustainable industrialization and foster innovation by 2030 .

Goal 10 | Reduced Inequality: Reduce inequality within and among countries by 2030 .

Goal 11 | Sustainable Cities and Communities: Make cities and human settlements inclusive, safe, resilient and sustainable.

Goal 12 | Responsible Consumption and Production: Ensure sustainable consumption and production patterns.

Goal 13 | Climate Action: Take urgent action to combat climate change and its impacts.

Goal 14 | Life Below Water: Conserve and sustainably use the oceans, seas and marine resources for sustainable development.

Goal 15 | Life on Land: Protect, restore and promote sustainable use of terrestrial ecosystems, combat desertification and halt biodiversity loss.

Goal 16 | Peace and Justice Strong Institutions: Promote peaceful and inclusive societies for sustainable development; provide access to justice for all.

Goal 17 | Partnerships to achieve the Goal: Strengthen the means of implementation and revitalize the global partnership for sustainable development. 
Acknowledgements of Financial Support

Portions of the research described in this thesis was financially supported by the Climate and Development Knowledge Network (CDKN) (Chapter 2); and the Global Alliance for the Future of Food (Chapter 4).

Financial support from Wageningen University for editing, designing, and printing this thesis is most appreciated and gratefully acknowledged.

Cover and graphic design by Wenceslao Almazan

Printed by Digiforce 


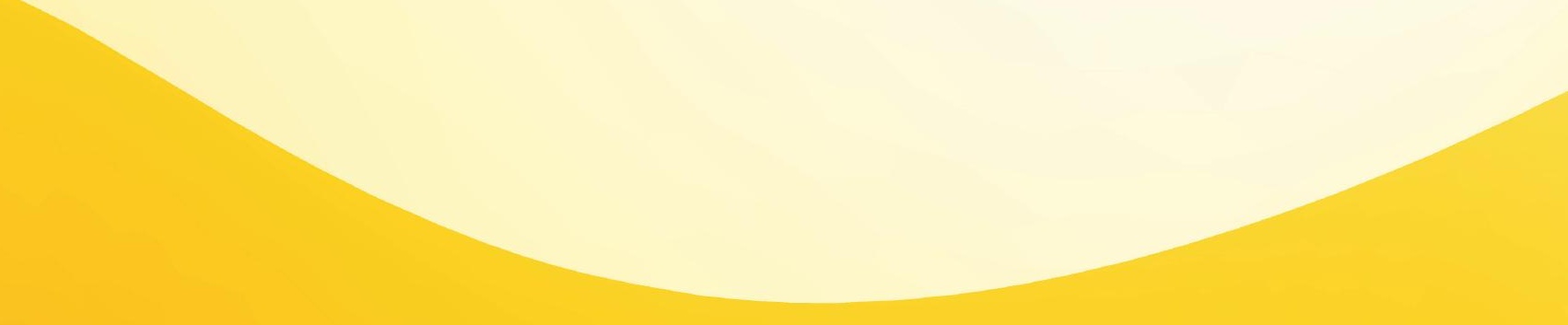

